STENIO DE SOUSA VENÂNCIO

\title{
Simulação Numérica aplicada ao Assoreamento do Reservatório Represa Velha
}

Tese apresentada à Escola de Engenharia de São Carlos da Universidade de São Paulo, como parte dos requisitos para obtenção do título de Doutor em Ciências da Engenharia Ambiental

Área de concentração: Ciências da Engenharia Ambiental

Orientador: Prof. Tit. Swami Marcondes Villela

São Carlos

2009 
AUTORIZO A REPRODUÇÃO E DIVULGAÇÃO TOTAL OU PARCIAL DESTE TRABALHO, POR QUALQUER MEIO CONVENCIONAL OU ELETRÔNICO, PARA FINS DE ESTUDO E PESQUISA, DESDE QUE CITADA A FONTE.

Ficha catalográfica preparada pela Seção de Tratamento da Informação do Serviço de Biblioteca - EESC/USP

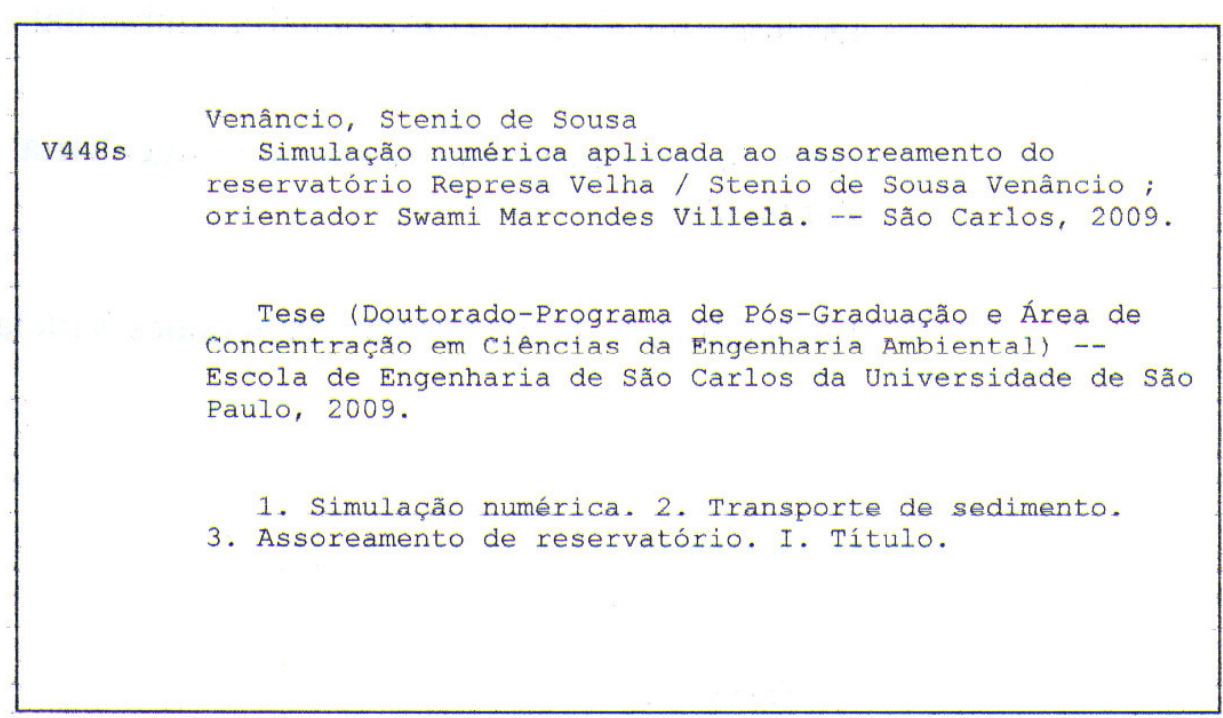


FOLHA DE JULGAMENTO

Candidato: Engenheiro STÊNIO DE SOUSA VENÂNCIO.

Tese defendida e julgada em 15/07/2009 perante a Comissão Julgadora:

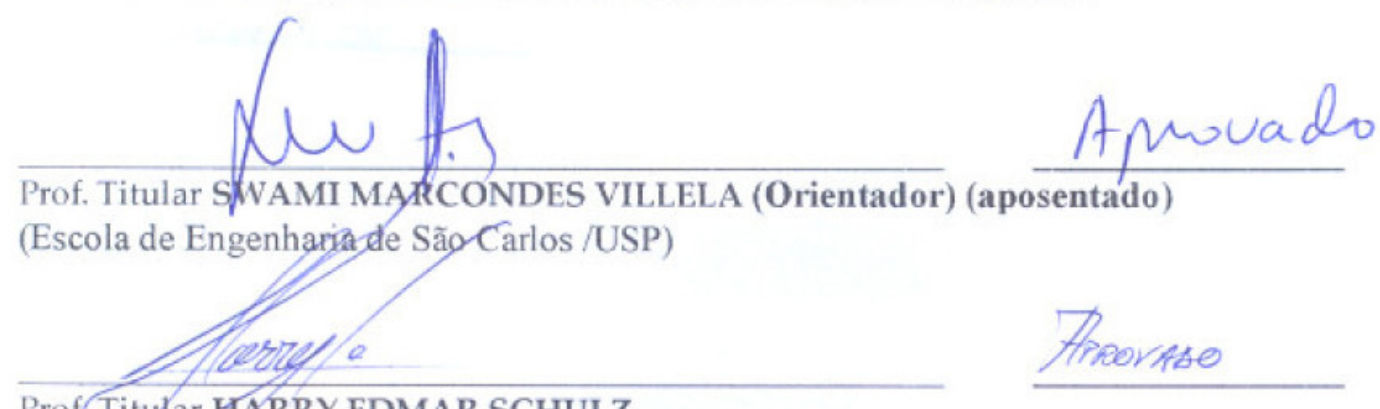

Prof. Titular HARRY EDMAR SCHULZ

(Escola de Engenharia de \$ão Carlos/USP)

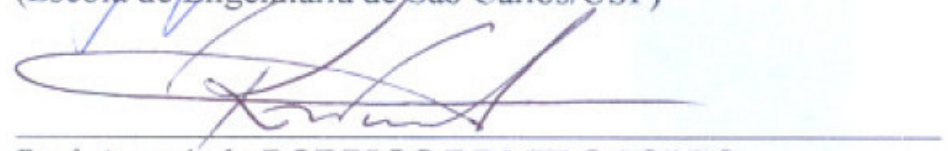

Prof. Associado RODRIGO DE MELO PORTO (Escola de Engenharia de São Carlos/USP)

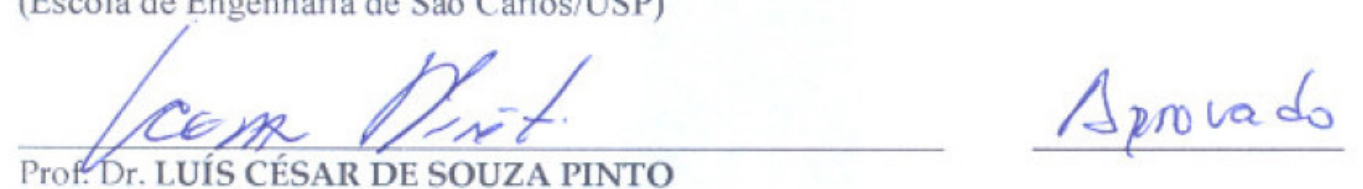

Prof?Dr. LUÍS CÉSAR DE SOUZA PINTO (Escola Politécnica/USP)

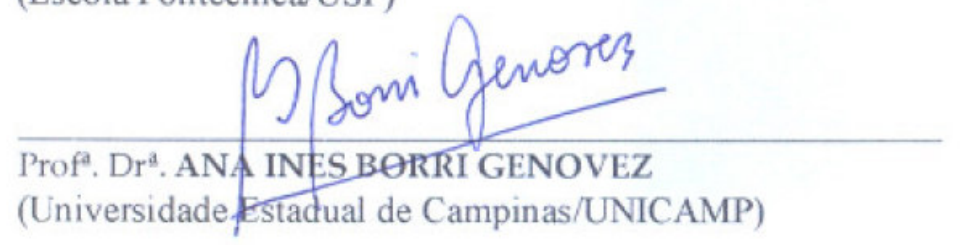

Aprovado

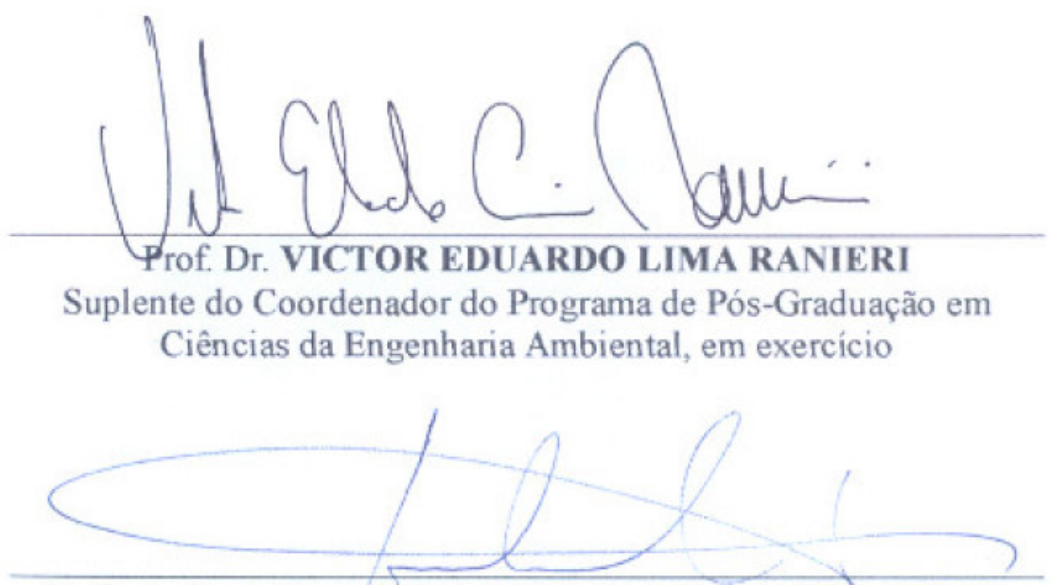

Prof. Titular GERALDO ROBERTO MARTINS DA COSTA Presidente da Comissão da Pós-Graduação da EESC 
A minha esposa, Soraia, com amor. Sua compreensão, renúncia, apoio e presença incansável, também demonstrados na elaboração deste trabalho, me deram forças para que pudesse concluí-lo.

Aos meus pais, Iêzo e Anísia. Impossível seria chegar ao objetivo se não pela base sólida do começo e pela ajuda incondicional ao longo da trajetória. 


\section{AGRADECIMENTOS}

Ao meu orientador, Professor Swami Marcondes Villela, pela confiança, diálogo, apoio e incentivo pleno nas atividades de pesquisa e extra-acadêmicas. Com seus ensinamentos, muito cresci no âmbito profissional e tão quanto como homem.

Ao Conselho Nacional de Desenvolvimento Científico e Tecnológico - CNPq, mantenedora da bolsa de estudos.

Ao CEPTA/IBAMA pela viabilização das visitas ao reservatório Represa Velha, em especial ao engenheiro José Henrique de Souza, pelo acompanhamento das mesmas, informações sobre o reservatório, liberação e discussão de dados extra bibliotecários.

Ao professor Dr. André Gustavo Mazzini Bufon pela disponibilidade em discutir dados do seu trabalho e ceder os não publicados, todos importantes e necessários para esta pesquisa.

A empresa DHI Water and Environment, em especial aos engenheiros $\mathrm{PhD}$ Bo Brahtz Christensen pelo suporte técnico ao trabalho de simulação; e Msc. Alejandro Lasarte pela assistência na substituição dos periféricos do MIKE 21C e orientação para o envio dos dados.

Ao professor Dr. Leonardo Barra Santana de Souza, pelo incentivo, apoio e colaboração com críticas e sugestões em cada etapa deste trabalho, além da ajuda no trabalho de simulação.

Ao professores Dr. Harry Edmar Schulz e Dr. Rodrigo de Melo Porto, pela inspiração e minha formação, desde o mestrado, e pela grande contribuição quando da participação na banca.

Ao professor Dr. Frederico Fábio Mauad pela contribuição ao trabalho quando da participação na qualificação.

Aos professores Dra. Ana Inés Borri Genovez e Dr. Luís César de Souza Pinto, pela contribuição ao trabalho quando da participação na banca.

A Pós-doutoranda Liliane Lazzari Albertin, pelas informações prestadas sobre os equipamentos de medição de velocidade em rios.

A Coordenação, aos professores, funcionários e colegas do Programa de Pós Graduação em Ciências da Engenharia Ambiental da EESC, pelos ensinamentos, apoio, incentivo e principalmente pela amizade.

Aos meus sogros, Sebastião e Onedes, pelo apoio e orações, fortalecendo minha caminhada.

A toda minha família e aos amigos que estiveram juntos, torceram, colaboraram e motivaramme nesta empreitada. De forma mais estreita, Sabrina (irmã), Rodrigo, Natália, José Francisco, Sílvia, Eudes, Maurício e Luiz Márcio.

A Rhana. Das coisas importantes na vida, como alegria, simplicidade e amor incondicional, muitas vezes não praticadas pelo homem, encontramos nos animais.

A Deus, pelo dom da vida. Sem a Sua graça, nada disso seria possível. 



\section{RESUMO}

\section{VENÂNCIO, S. S. Simulação Numérica aplicada ao assoreamento do reservatório Represa}

Velha. 2009. 168 p + Anexos. Tese (Doutorado) - Escola de Engenharia de São Carlos, Universidade de São Paulo, São Carlos.

Todos os cursos de água carream sedimentos com maior ou menor intensidade, sendo responsáveis pela redução da calha de rios e volume de reservatórios. O assoreamento dos reservatórios reduz sua vida útil, comprometendo os sistemas de geração de energia, de navegação, de irrigação, gerando problemas de ordem ambiental. Neste contexto, subsídios ao processo de gerenciamento dos reservatórios pela predição do assoreamento, tornam-se necessários. O Reservatório Represa Velha, situado na Bacia Hidrográfica do Mogi Guaçu, foi escolhido para estudo de caso pela disponibilidade de dados batimétricos, de vazão e de sedimentos. Com os recursos da dinâmica dos fluidos computacional (DFC), é utilizado o programa MIKE 21C. A solução das equações hidrodinâmicas (Saint-Venant 2D) integradas na vertical, tiveram como condição de contorno a vazão constante em cada período da medição, na entrada do reservatório, e a altura de água constante, para cada dado de vazão, no canal de saída. A calibração do modelo numérico foi feita para os dados temporais de vazão, concentração de sedimentos e batimetrias do reservatório. Com dados da primeira batimetria e campanhas batimétricas sucessivas, foi realizada a comparação entre os resultados obtidos pela simulação numérica e aqueles medidos em campo. As dificuldades e limitações encontradas neste processo são comentadas.

Palavras-chave: simulação numérica; transporte de sedimento; assoreamento de reservatório. 


\begin{abstract}
VENÂNCIO, S. S. Simulação Numérica aplicada ao assoreamento do reservatório

Represa Velha. 2009. 168 p + Anexos. Tese (Doutorado) - Escola de Engenharia de São Carlos, Universidade de São Paulo, São Carlos.
\end{abstract}

All rivers transport sediments with bigger or smaller intensity, being responsible for the reduction of their channel and volume of reservoirs. The sedimentation of reservoirs reduces their useful life, compromising energy generation systems, navigation, irrigation, and generating problems of environmental order. In this context, subsidies to the process of reservoirs management for the prediction of sedimentation become necessary. The Reservoir Represa Velha, located in the Mogi Guaçu's watershed, was chosen as a case study because of its available data of bathymetry, flow and sediment discharge. With the resources of computational fluids dynamics (CFD), the program MIKE 21C was used. In the solution of the problem are used the hydrodynamic equations (Saint-Venant 2D) integrated in the vertical. The boundary conditions are the constant flow, in each period of the measurement, at the entrance of the reservoir, and the constant water level, for each flow measured, at the exit channel. The calibration of the numeric model was developed with data from previews work, of flow, sediment concentration and reservoir bathymetry. The numerical data were compared with the measured sedimentation. The difficulties and limitations found in this process are commented on.

Key-words: numerical simulation, sediment transport, reservoir sedimentation. 


\section{LISTA DE SÍMBOLOS}

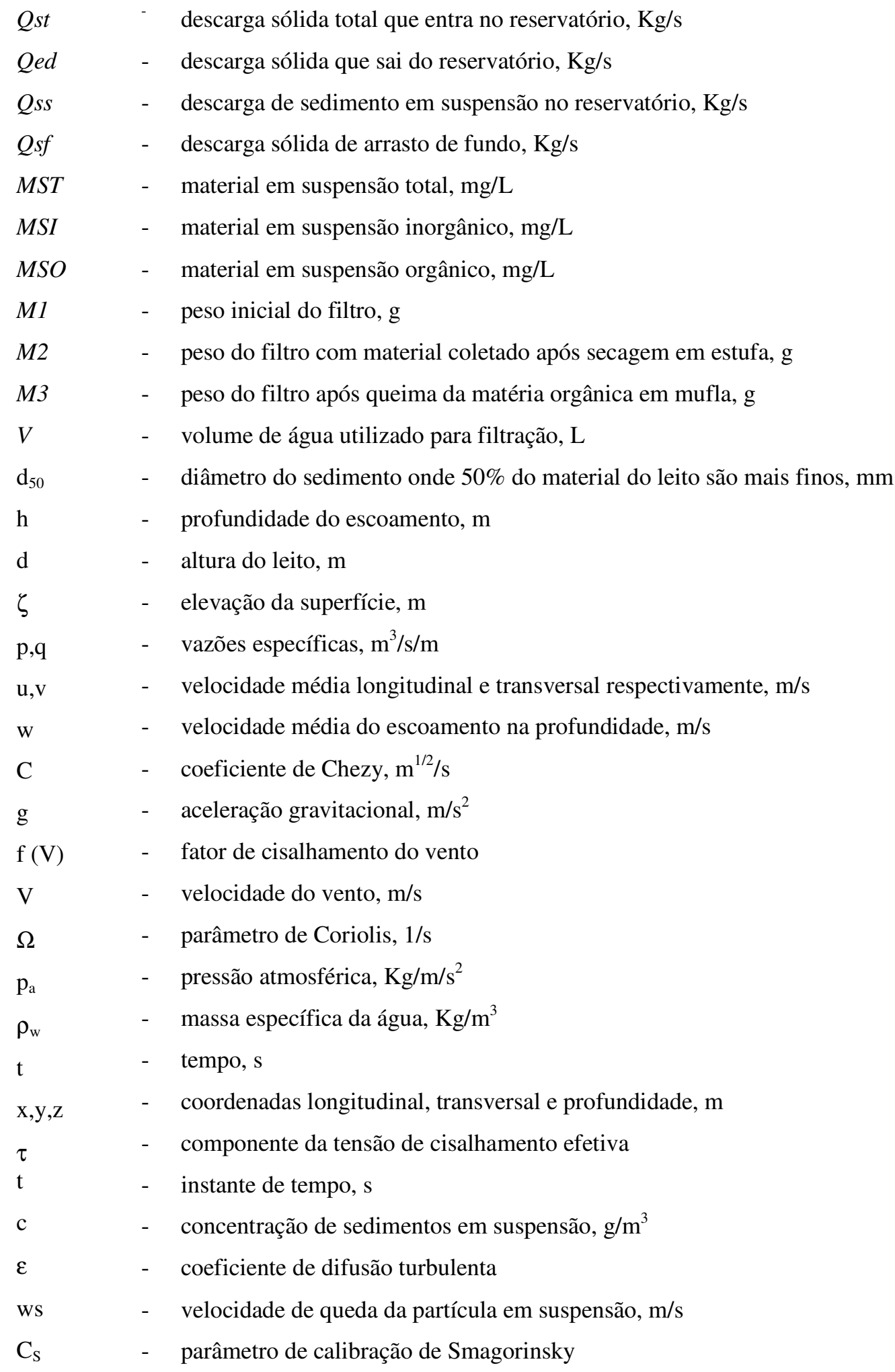





\section{SUMÁRIO}

RESUMO

ABSTRAT

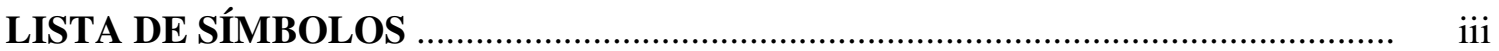

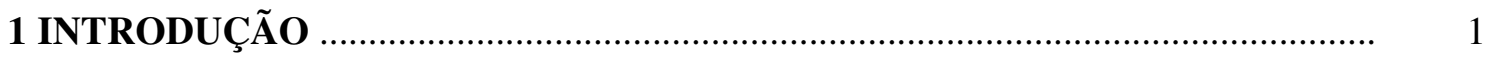

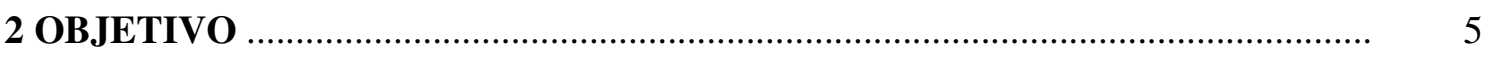

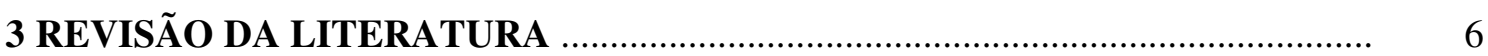

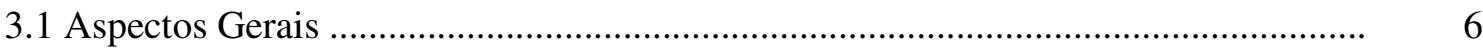

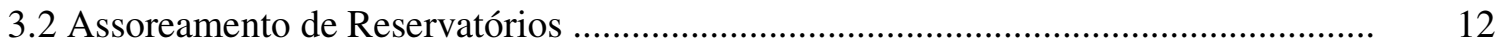

3.2.1 Descarga e Volume de Sedimento Depositado nos Reservatórios ........................... 16

3.2.1.1 Perda de solo na Bacia Hidrográfica ..................................................................... 17

3.2.1.2 Curva Chave de Sedimentos ......................................................................... 19

3.2.1.3 Generalidades sobre os Modelos Matemáticos Clássicos de Transporte de

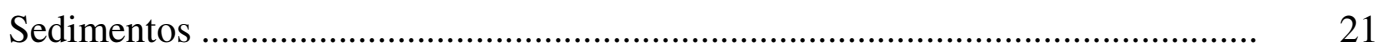

3.2.2 Sedimentos e a Relação com a Vida Útil do Reservatório ..................................... 23

3.2.2.1 Eficiência de Retenção de Sedimento do Reservatório ....................................... 26

3.3 Dinâmica de Fluidos Computacional (DFC) e Transporte de Sedimentos ................. 28

3.3.1 Trabalhos de Modelagem Numérica aplicada ao Estudo do Transporte de Sedimentos em Rios e Reservatórios Reais ........................................................ 29

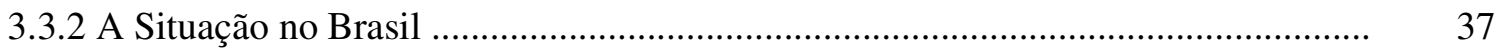

3.4 Breve Histórico de um Ciclo de Pesquisas em Transporte de Sedimentos ............... 41

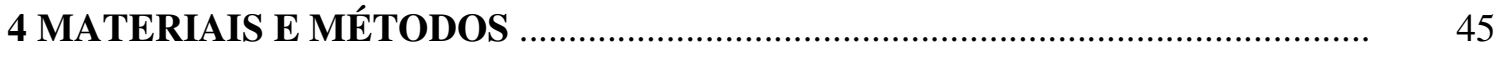

4.1 Descrição da Área de Estudo .............................................................................. 45

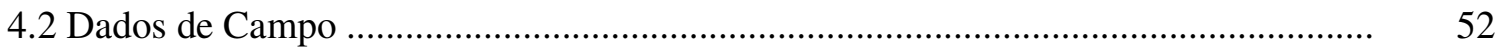

4.2.1 Campanhas de Batimetria ….......................................................................... 52

4.2.2 Vazões Características ........................................................................................ 58

4.2.3 Concentração de Sedimentos Suspensos ................................................................... 59

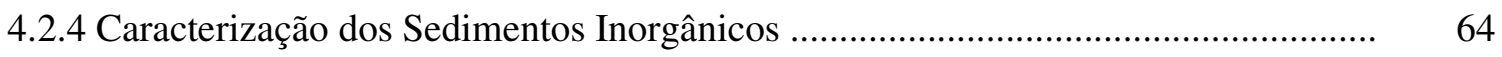

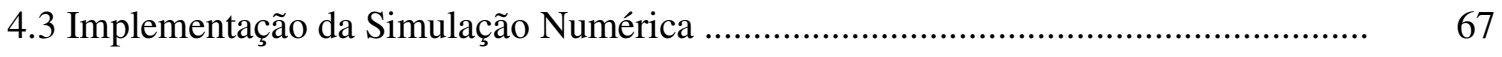

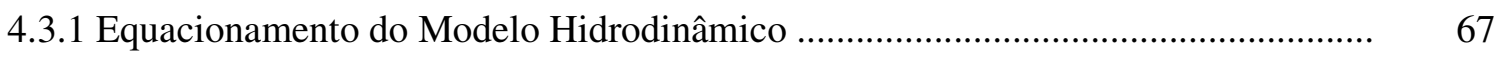

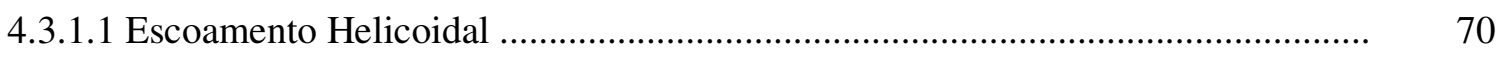

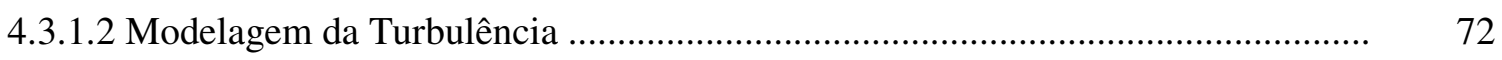

4.3.2 Modelo de Transporte de Sedimentos ................................................................ 72 


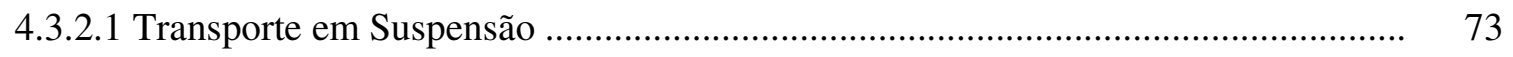

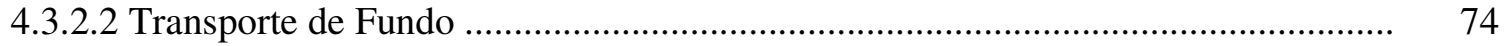

4.3.2.3 Equações de Transporte de Sedimentos ................................................................. 75

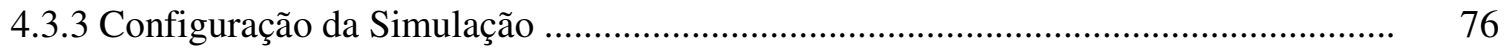

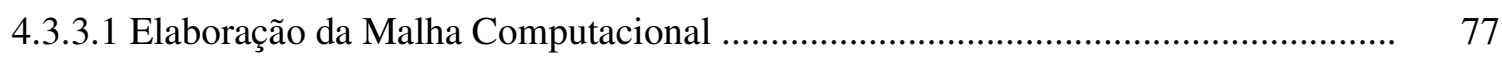

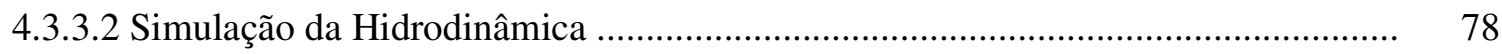

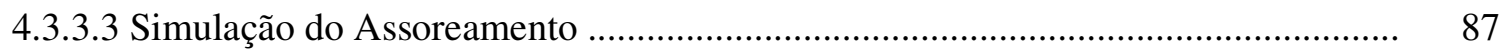

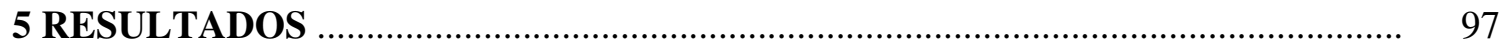

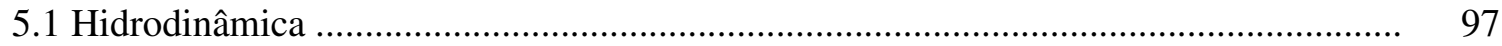

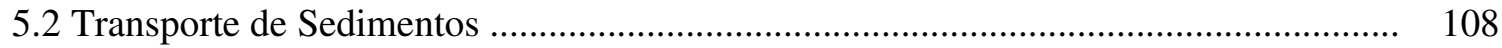

5.3 Modificação Morfológica ..................................................................................... 114

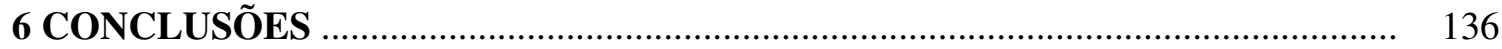

7 SUGESTÕES PARA TRABALHOS FUTUROS ….............................................. 141

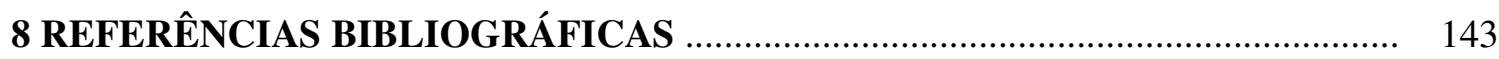

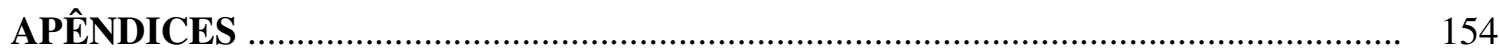

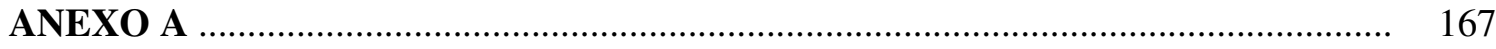

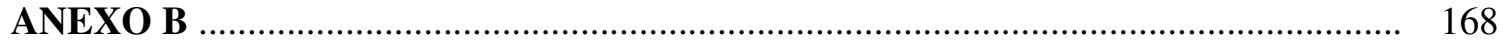




\section{INTRODUÇÃO}

Desde a antiguidade barragens são construídas no leito dos rios para armazenamento de água, viabilizando os consumos. $\mathrm{O}$ armazenamento de água em reservatórios formados por barragens tem uma história própria e milenar, com registros apontando, por exemplo, a barragem de Sadd-el-Kaffara, construída no Egito por volta de 2600 a.C., com 14m de altura e 113m de comprimento na crista, como a mais antiga de seu porte (SMITH, 1971; SCHNITTER, 1994). Atualmente, a construção de barragens associada à má utilização do solo da bacia hidrográfica tem intensificado o acúmulo de sedimentos nos reservatórios formados pelas mesmas, acarretando uma série de problemas operacionais. Em termos regionais, tanto no estado de São Paulo como em suas divisas existem reservatórios importantes considerados "jovens", pois têm menos de 50 anos. Contudo, a vida útil dos mesmos pode variar desde alguns poucos anos até centenas de anos. No processo de assoreamento, os sedimentos ocupam parte do volume útil destas estruturas de reservação, causando diversos problemas, por vezes irreparáveis, dentre os quais cita-se:

- impacto na vida aquática, com aterramento dos locais de desova e abrigo dos peixes;

- poluição e contaminação da água, impedindo ou onerando o tratamento para consumo;

- obstrução de tomadas de água para geração de energia elétrica;

- danificação de rotores de turbinas e outras estruturas, por abrasão;

- formação de bancos de areia que alteram e dificultam as rotas de navegação;

- diminuição do volume útil do reservatório, com conseqüente diminuição da vazão regularizada;

- redução da eficiência dos reservatórios de detenção de cheias urbanas; 
Como caso extremo de assoreamento, cita-se Lake Powell no rio Colorado, que de acordo com Morris e Fan $^{1}$ (1997 apud NICKLOW;MAYS, 2000), necessitaria de U\$83 bilhões para recuperação de seu volume inicial de $33 \mathrm{~km}^{3}$, completamente tomado por sedimentos.

No Brasil, a importância dos reservatórios se dá pela riqueza dos recursos hídricos de superfície, assumindo um caráter de multiplicidade (navegação, irrigação, abastecimento público, detenção de cheias, geração de energia). Para se ter uma idéia desta importância, se tomarmos, como exemplo, somente o setor de energia, temos que atualmente é gerado um total de $102.435 .257 \mathrm{Kw}$, onde 75,58\% estão relacionados às usinas hidrelétricas. Somente no estado de São Paulo, maior produtor de energia elétrica do país $(21,47 \%)$, mais de $81 \%$ corresponde às hidrelétricas, isto já considerando os ditos pequenos reservatórios que constituem as PCH's (ANEEL, 2008²). Para um gerenciamento eficiente desses reservatórios, por exemplo, é importante frisar que a curva cota-área-volume determinada na fase de projeto serve apenas como ponto de partida para o plano de gestão dos seus recursos hídricos; além do que nem sempre ela é baseada em levantamentos topográficos em escala adequada, disponíveis na época de sua construção. Adicionalmente, a fixação da chamada vazão regularizada de um reservatório depende de sua política de operação, que tem como dado inicial o volume útil disponível do mesmo. No Brasil, onde praticamente todos os reservatórios têm menos de um século, tem-se feito as políticas de operação utilizando-se o volume útil original do reservatório. É simples verificar que estas políticas podem usar dados incorretos, pois os reservatórios perdem volume continuamente pela deposição de sedimentos. Um monitoramento é evidentemente necessário. Um levantamento batimétrico atual dos diferentes reservatórios fornece a situação atual do assoreamento e pode re-orientar o plano de

\footnotetext{
${ }^{1}$ MORRIS,G.L; FAN,J. (1997). Reservoir sedimentation handbook. McGraw-Hill, New York.

${ }^{2}$ ANEEL (2008). Site: www.aneel.gov.br - Agência Nacional de Energia Elétrica - 19/12/2008 às 19:42hs
} 
gestão. Entretanto, este procedimento pouco adiciona ao conhecimento da vida útil do reservatório, que requer análise continuada da evolução do fundo do mesmo.

O estudo para estimativa do assoreamento em reservatórios pode ser feito através de medições diretas de vazão do rio e concentração de sedimentos, realizadas simultaneamente em locais próximos às entradas dos mesmos. Os dados obtidos produzem a chamada curva-chave de sedimentos, relacionando a vazão de água à descarga de sedimentos. De posse de uma série de vazões e da curva chave de sedimentos para cada rio que abastece um reservatório, faz-se a previsão do assoreamento ao longo do tempo, devido a descarga de sedimentos do rio em questão. Com o reservatório já construído e em operação, batimetrias podem ser realizadas periodicamente para acompanhamento do assoreamento.

A partir dessas técnicas de avaliação da deposição de material nos reservatórios, existem medidas preventivas e corretivas que podem ser tomadas no combate ao assoreamento dos mesmos e são importantes para o prolongamento de sua vida útil. Das medidas preventivas, cita-se o controle de erosão na bacia e a proteção das margens do reservatório. Como medidas corretivas tem-se as dragagens (operações de retirada de sedimentos dos reservatórios) e as lavagens (do inglês flushing), que compreendem a liberação de sedimentos através de comportas de fundo na barragem (descarregadores de fundo), usuais para pequenos reservatórios. Como exemplo deste último, cita-se o reservatório "Represa Velha" do Centro de Pesquisa e Gestão de Recursos Pesqueiros Continentais CEPTA/IBAMA, situado no município de Pirassununga-SP, com 5 ha de área alagada e volume útil de $57.000 \mathrm{~m}^{3}$ aproximadamente, tendo sido esvaziado para limpeza 7 (sete) vezes (BUFON, 2006).

Caso houvesse uma estimativa espaço-temporal do assoreamento para os reservatórios brasileiros, as medidas citadas acima poderiam ser preditas. Assim, como exemplo, descarregadores de fundo seriam propostos com melhor localização e dimensionamento, para 
que lavagens do reservatório fossem programadas e executadas com eficiência (em caso de pequenos reservatórios); e as dragagens realizadas em períodos e locais pré-estabelecidos (para os grandes reservatórios principalmente).

Modelos computacionais baseados na dinâmica dos fluidos são desenvolvidos, mas não são comumente utilizados no Brasil, principalmente devido à falta de dados necessários para a sua aplicação. Assim, as batimetrias dos reservatórios e a calibração de modelos matemáticos de simulação do assoreamento podem representar um ganho na eficiência de gerenciamento, uma vez que a variação do fundo dos reservatórios é conhecida para cenários distintos no tempo. Portanto, com o conhecimento da quantidade de sedimento depositado em um reservatório, onde ele fica e qual sua densidade (portanto seu volume), facilita imensamente a tarefa do planejamento dos usos múltiplos destas estruturas bem como a verificação das consequiências ambientais do seu assoreamento, como por exemplo, a qualidade da água. Como vantagem adicional, pode-se dizer que um modelo calibrado para um reservatório pode ser utilizado como início de planejamento de outros reservatórios com características semelhantes. 


\section{OBJETIVO DO TRABALHO}

Este trabalho tem como objetivo a aplicação e avaliação do uso da simulação numérica na determinação da variação de fundo do reservatório Represa Velha, pertencente ao CEPTAIBAMA em Pirassunuga SP. É utilizado, para tanto, o programa MIKE 21C, calibrado para os dados do reservatório. O histórico de vazões e concentração de sedimentos medidos em períodos seco e chuvoso, a granulometria dos sedimentos, assim como as campanhas batimétricas realizadas, atuam como parâmetros para calibragem e verificação da acuracidade do modelo. A batimetria simulada pelo MIKE 21C, é comparada com a batimetria levantada em campo. A aproximação obtida entre batimetrias medida e simulada, viabiliza a discussão das dificuldades e limitações encontradas neste processo, norteando a aplicação do modelo numérico em outros estudos acadêmicos, atingindo o maior objetivo desta linha de pesquisa: o uso confiável de simulações numéricas para estudo e estimativa do assoreamento de reservatórios de água formados por barragens. 


\section{REVISÃO DA LITERATURA}

\subsection{Aspectos Gerais.}

A otimização do gerenciamento de reservatórios é elemento importante e decisivo nas práticas operacionais destas estruturas, como parte integrante do meio ambiente. Desse modo, com a tecnologia gerencial, envolvendo variáveis ambientais, é possível obter melhores resultados em relação às vazões regularizadas, à produção de energia elétrica, à qualidade da água, ao aporte e deposição de sedimentos, dentre outros (RIGHETTO, 1998).

Considerando o aporte e deposição de sedimentos, pesquisas têm sido realizadas com o propósito de quantificar os sedimentos de fundo e em suspensão veiculados por cursos de água, com estudos experimentais em laboratório e medições diretas em reservatórios reais. Contudo, o estudo da evolução do assoreamento nos reservatórios formados por barragens, associando medições e simulações computacionais que possam quantificar e localizar os sedimentos nos mesmos, ainda não é aplicado no Brasil, onde a exploração múltipla dos recursos hídricos, por meio dessas estruturas, é expressiva.

Esta utilização múltipla dos recursos hídricos mereceu destaque após o período da segunda guerra mundial. $\mathrm{O}$ crescimento industrial motivado pelo governo, principalmente nas regiões sul-sudeste, desencadeou um processo migratório campo-cidade e também de outras regiões do país. O crescimento populacional acelerado (FIGURA 1) provocou intervenções (TUCCI; HESPANHOL; NETTO, 2001) nas áreas de energia, abastecimento público, irrigação, transporte fluvial, dentre outras. Se observada a densidade populacional atual (FIGURA 2), fica evidente a maior concentração da população nas regiões onde se encontra a maior parte dos aproveitamentos hídricos brasileiros (FIGURA 3), com destaque para as hidrelétricas, responsáveis por 75,58\% da energia gerada no país (ANEEL, 2008³).

\footnotetext{
${ }^{3}$ ANEEL (2008). Site: www.aneel.gov.br - Agência Nacional de Energia Elétrica - 19/12/2008 às 19:42hs
} 


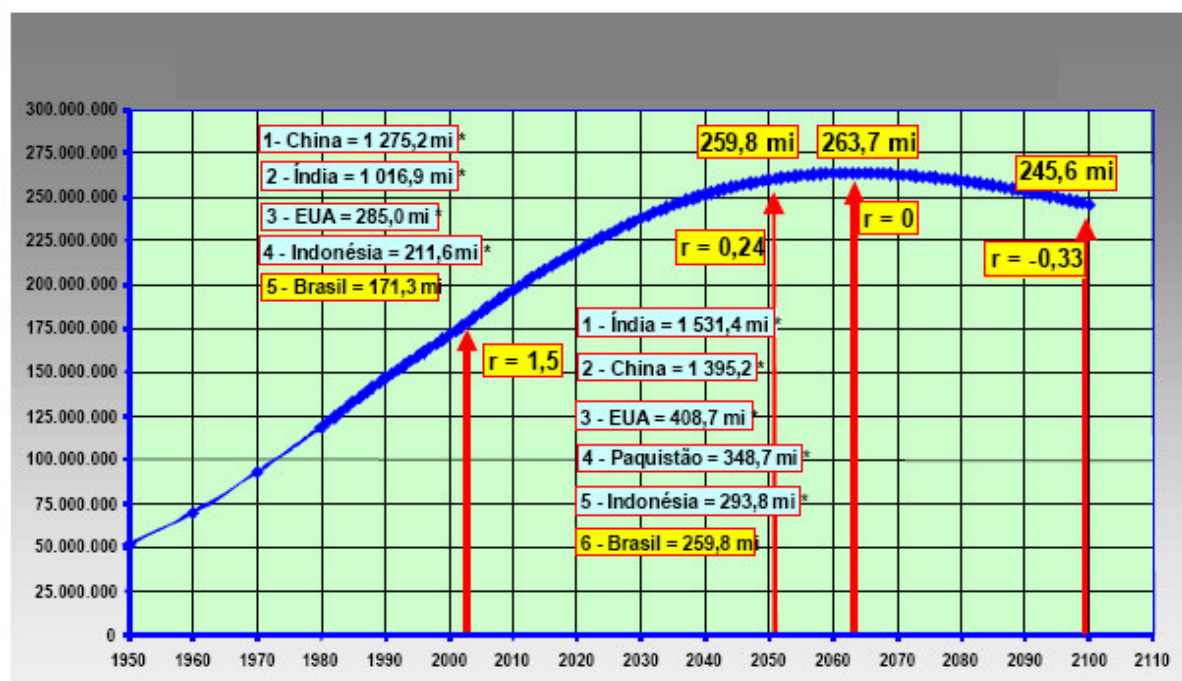

FIGURA 01 - Projeção Populacional do Brasil 1950/2100 (IBGE-Rev./2004 ${ }^{4}$ )

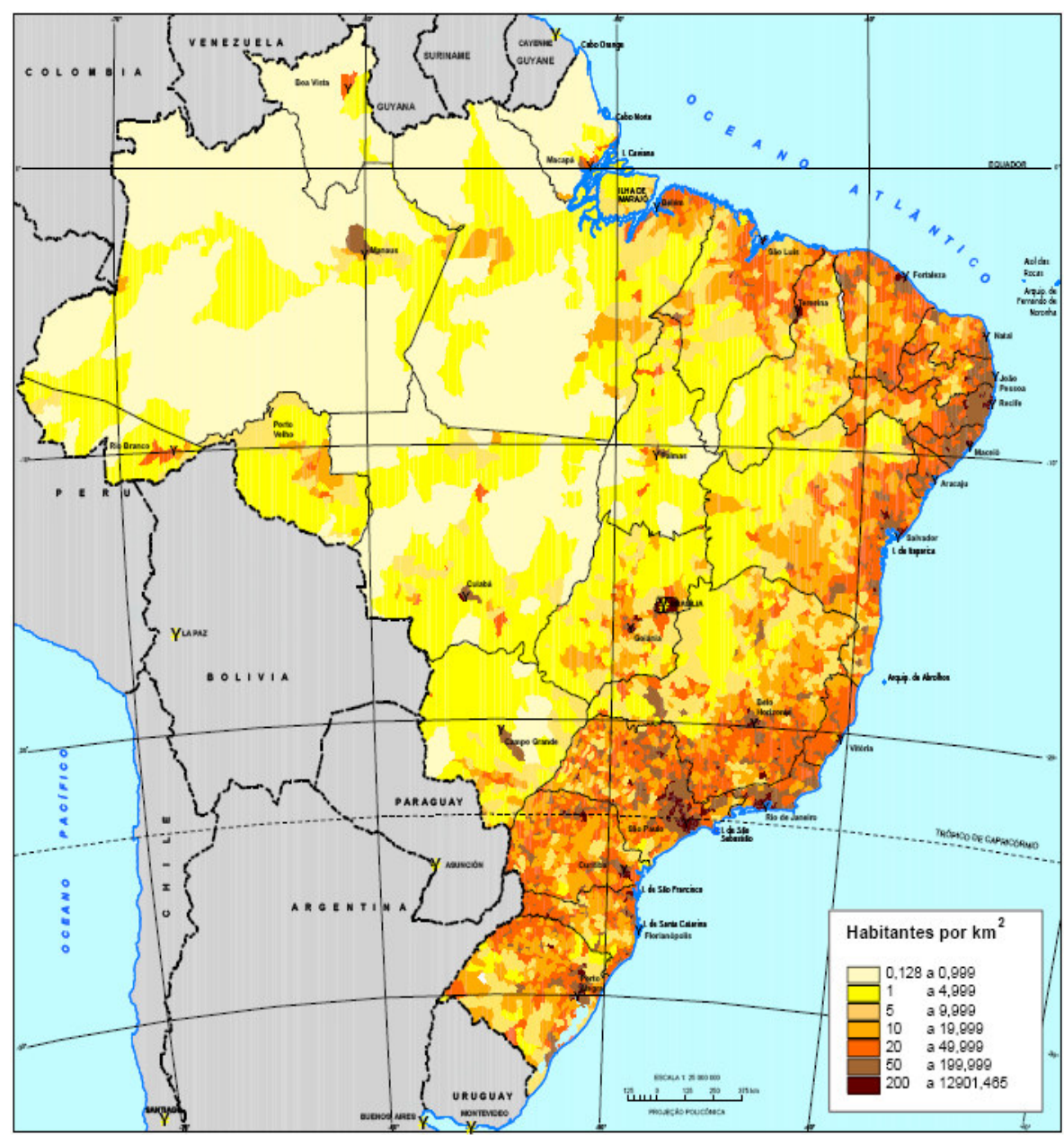

FIGURA 02 - Densidade Demográfica Brasileira (IBGE-Rev./2004 ${ }^{4}$ )

${ }^{4}$ IBGE (2004). Site: www.ibge.gov.br - Instituto Brasileiro de Geografia e Estatística - 20/12/2008 às 11:50hs 


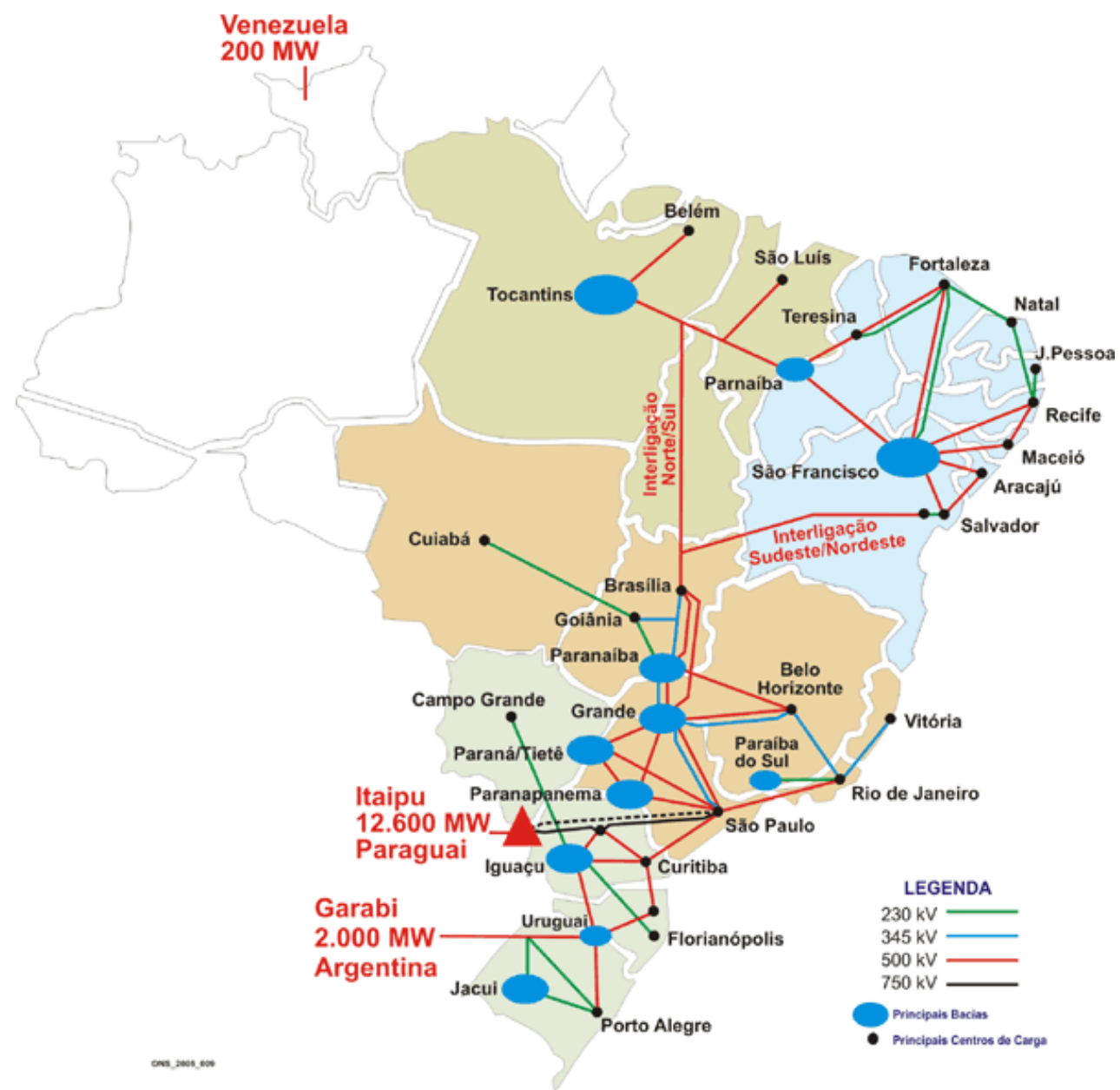

\section{FIGURA 03 - Principais Bacias e Integração Eletroenergética (ONS/20085)}

O cenário apresentado, associado à ausência de uma preocupação no sentido de preservação e conservação dos recursos naturais, especificamente os recursos hídricos, fizeram com que ocorresse uma degradação ambiental. Este fato, só atualmente mereceu destaque em termos de legislação e políticas públicas, inserindo ao projeto de crescimento econômico dos países o conceito de desenvolvimento sustentável (TUCCI; HESPANHOL; NETTO, 2001).

Muito tem-se avançado no Brasil neste início de século em termos de uso sustentável dos recursos hídricos. No entanto, monitoramentos e estudos aplicados ainda precisam ser

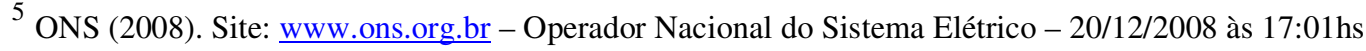


elaborados, como forma de garantia dos usos múltiplos com quantidade e qualidade necessárias.

Do ponto de vista de usos não consuntivos (consumo indireto com manutenção da vazão), o setor de energia elétrica desperta grande motivação para a implementação de estudos aplicados. O Brasil possui um total de 1.989 empreendimentos em operação gerando, aproximadamente, 104.914 MW de potência sendo 77.258,25 MW proveniente das grandes hidrelétricas (UHE) e pequenas centrais $(\mathrm{PCH})$. Está prevista para os próximos anos uma adição de 37.043,36 MW na capacidade de geração do país, através de 155 empreendimentos atualmente em construção $(69,32 \%$ destes correspondentes às UHE $+\mathrm{PCH})$ e mais 435 empreendimentos outorgados $(46,28 \%$ de UHE + PCH) (ANEEL, 2008 $)$.

Com a riqueza dos recursos hídricos brasileiros, além dos aproveitamentos hidrelétricos, criou-se uma perspectiva favorável quanto ao transporte hidroviário (FIGURA 04). Este transporte, hoje com aproximadamente $10.000 \mathrm{Km}$ de trechos navegavelmente explorados, apesar de ainda pouco utilizado em relação aos países desenvolvidos, se apresenta como um dos meios de transporte mais baratos, com menor valor unitário (R $\$$ Ton) $\left(\mathrm{MT}, 2008^{7}\right.$ ). Em países com extensão territorial expressiva e com grande riqueza fluvial como o Brasil, este tipo de transporte se justifica pelo baixo custo de implantação e manutenção. Os desníveis característicos da hidrografia são vencidos pelas eclusas executadas junto das barragens.

Outro setor que muito tem se utilizado de reservatórios formados por barragem é o da macrodrenagem urbana. A grande ocupação e a impermeabilização das bacias hidrográficas urbanas, associadas ao aumento da freqüência das chuvas máximas intensas, fizeram com que grande parte das cidades brasileiras recorressem aos reservatórios de contenção de cheias, popularmente conhecidos como "piscinões". Em São Paulo, por exemplo, a cada ano,

\footnotetext{
${ }^{6}$ ANEEL (2008). Site: www.aneel.gov.br - Agência Nacional de Energia Elétrica - 19/12/2008 às 19:42hs

${ }^{7}$ MT (2008). Site: www.transportes.gov.br - Ministério dos Transportes - 23/12/2008 às 00:29hs
} 
segundo dados da Secretaria de Infra Estrutura municipal, o volume de sedimentos depositado pelas cheias nos reservatórios alinhados com os rios, atinge $10 \%$ do seu volume (GIROLDO, 2003).

Com relação aos usos consuntivos (consumo direto com redução da vazão), merece destaque o crescimento da irrigação no país (FIGURA 5), associada ao grande potencial agrícola brasileiro. Do total de água disponibilizado para o consumo (TUCCI; HESPANHOL; NETTO, 2001), 64,7\% é destinado à irrigação. Com esta prática, regiões com baixo índice pluviométrico ou mesmo semi-áridas tornaram-se agricultáveis (caso da fruticultura no Nordeste brasileiro), gerando emprego, renda e desenvolvimento. Contudo, vale lembrar que além da questão de consumo hídrico, a prática agrícola intensa e sem critérios de manejo, tem um papel expressivo dentro do processo de assoreamento, que reflete diretamente na vida útil do reservatório.

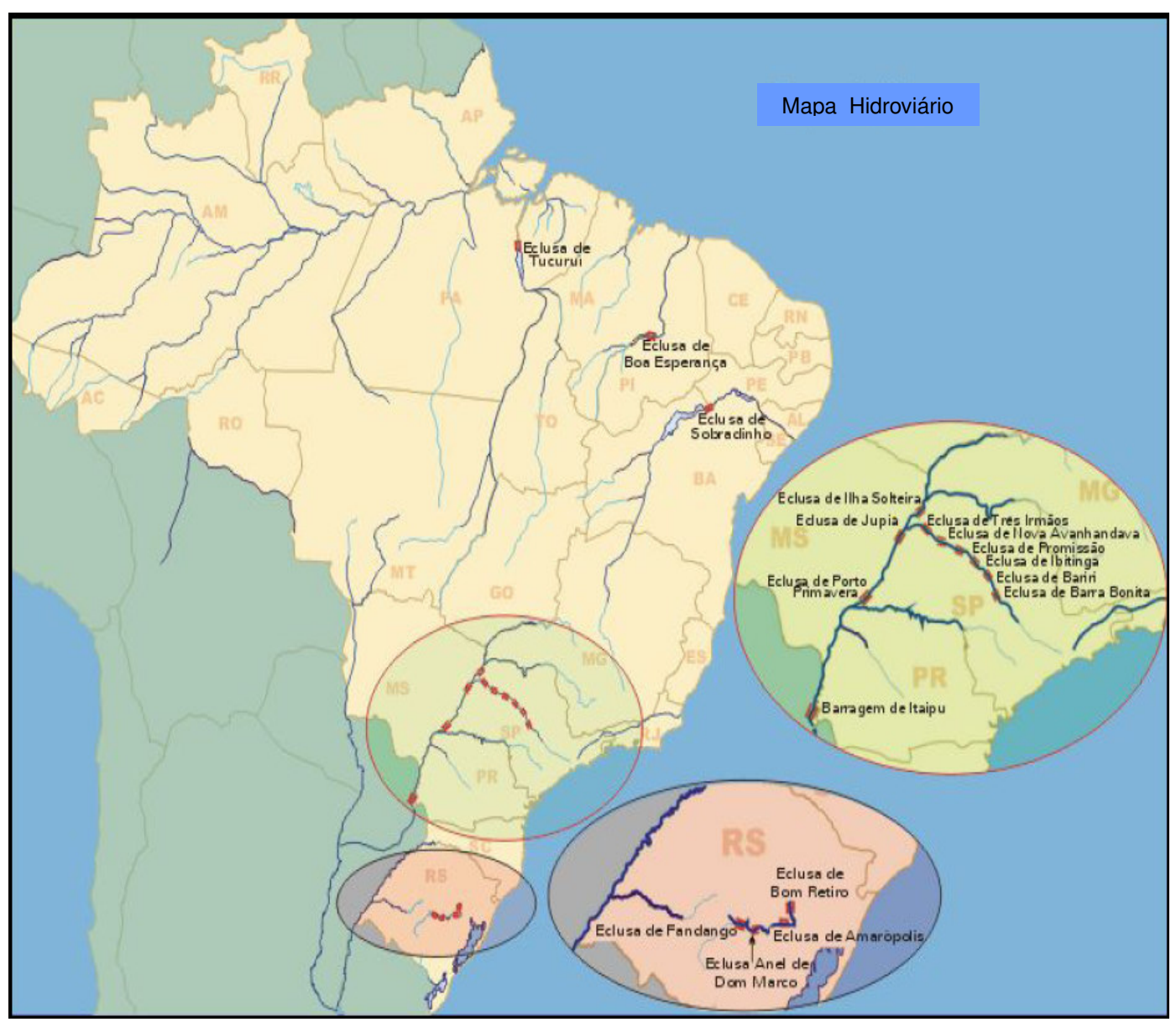

FIGURA 04 - Hidrovias e Eclusas brasileiras (MT/2008 $\left.{ }^{7}\right)$ 


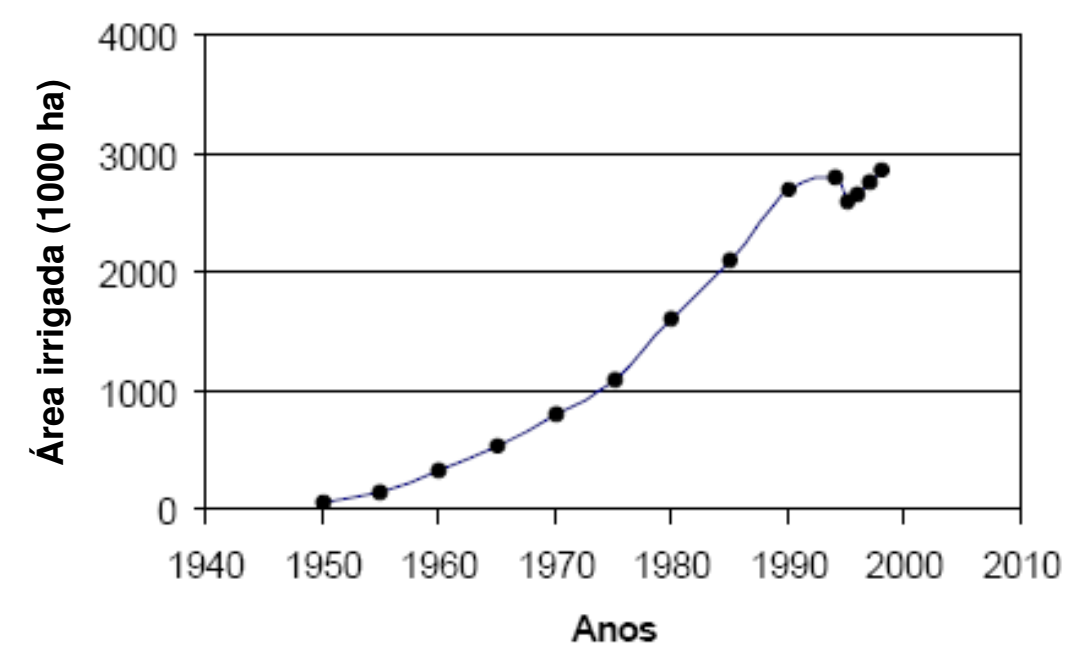

FIGURA 05 - Evolução da Área Irrigada (LIMA et al., 1999)

Os consumos humano e industrial, com $16,4 \%$ e $13,9 \%$ respectivamente do total consuntivo, além da dessedentação de animais, com 4,9\%, se isoladamente não representam valores tão expressivos de consumo, juntos totalizam mais de $35 \%$ do total consuntivo, além de corresponderem a uma necessidade fundamental (TUCCI; HESPANHOL; NETTO, 2001).

A regra para gerenciamento de reservatórios formados por barragem na liberação de suas vazões, portanto, passa a ser não somente, por exemplo, a demanda dos consumidores de energia, mas sim o estabelecimento dos níveis mínimos necessários para a navegação, dos usos consuntivos na bacia hidrográfica, além da preservação e conservação ambiental.

Atualmente, o problema do assoreamento de reservatórios é tratado, na maioria das vezes, através de ações corretivas. Ações preventivas requerem estudos que possam prognosticar o fenômeno, ou seja, sua evolução espaço-temporal, o que ainda não é vislumbrado. É claro que o barramento de um rio, por funcionar como uma "armadilha" de sedimentos, melhora a qualidade da água. Contudo, pode trazer consequiências indesejáveis para a operação do reservatório, promovendo impactos ambientais negativos e podendo chegar à inutilização completa do sistema. 


\subsection{Assoreamento de Reservatórios.}

Os fundamentos da hidrossedimentologia, sua aplicação, retratando a importância de estudos para um melhor entendimento, acompanhamento e controle do assoreamento de reservatórios no Brasil são destacados em Carvalho (1994). Na Tabela 1 abaixo, está relacionada uma série de reservatórios que já foram afetados pelo fenômeno do assoreamento.

TABELA 01 - Alguns reservatórios no Brasil parcial ou totalmente assoreados (CARVALHO, 1994).

\begin{tabular}{|c|c|c|c|}
\hline RESERVATÓRIO & CURSO DEÁGUA & PROPRIETÁRIO & FINALIDADE \\
\hline Bacia do São Francisco & & & \\
\hline Rio das Pedras & Velhas & CEMIG & UHE - $10 \mathrm{MW}$ \\
\hline Paraúna & Paraúna & CEMIG & UHE - $30 \mathrm{MW}$ \\
\hline Pandeiros & Pandeiros & CEMIG & UHE - 4,2 MW \\
\hline Acabamundo & Acabamundo & DNOS & Controle de cheias \\
\hline Arrudas & Arrudas & DNOS & Controle de cheias \\
\hline Pampulha & Pampulha & DNOS & Controle de cheias \\
\hline \multicolumn{4}{|l|}{ Bacia Atlântico/Leste } \\
\hline Funil & Contas & CHESF & UHE - $30 \mathrm{MW}$ \\
\hline Pedras & Contas & CHESF & UHE - $23 \mathrm{MW}$ \\
\hline Peti & Santa Bárbara & CEMIG & UHE - 9,4 MW \\
\hline Brecha & Piranga & - & UHE - $10,5 \mathrm{MW}$ \\
\hline Piracicaba & Piracicaba & Belgo - Mineira & UHE - - \\
\hline Sá Carvalho & Piracicaba & Acesita & UHE - $50 \mathrm{MW}$ \\
\hline Dona Rita & Tanque & - & UHE - 2,41 MW \\
\hline Salto Grande & Santo Antônio & CEMIG & UHE - 104 MW \\
\hline Tronqueiras & Tronqueiras & - & UHE - 7,87 MW \\
\hline Bretas & Suaçuí Pequeno & - & - \\
\hline Mascarenhas & Rio Doce & ESCELSA & UHE - $120 \mathrm{MW}$ \\
\hline Paraitinga & Paraitinga & CESP & UHE - 85 MW \\
\hline Jaguari & Jaguari & CESP & UHE - 27,6 MW \\
\hline Una & Una & PM Taubaté & Abastecimento de água \\
\hline \multicolumn{4}{|l|}{ Bacia do Paraná } \\
\hline Caconde & Pardo & CESP & UHE - 80,4 MW \\
\hline Euclides da Cunha & Pardo & CESP & UHE - 108,8 MW \\
\hline Americana & Atibaia & CPFL & UHE - 34 MW \\
\hline Jurumirim & Paranapanema & CESP & UHE - 22 MW \\
\hline Piraju & Paranapanema & CPFL & UHE - $120 \mathrm{MW}$ \\
\hline Presidente Vargas & Tibaji & Klabin & UHE - 22,5 MW \\
\hline Poxoréu & Poxoréu & CEMAT & UHE - - \\
\hline São Gabriel & Coxim & ENERSUL & UHE - 7,5 MW \\
\hline Ribeirão das Pedras & Descoberto & CAESB & Abastecimento de água \\
\hline São João & São João & ENRSUL & UHE - 3,2 MW \\
\hline \multicolumn{4}{|l|}{ Bacia do Uruguai } \\
\hline Caveiras & Caveiras & CELESC & UHE - 4,3 MW \\
\hline Silveira & Santa Cruz & CELESC & UHE - - \\
\hline Celso Ramos & Chapecozinho & CELESC & UHE - 5,76 MW \\
\hline Furnas do Segredo & Jaguari & CEEE & UHE - - \\
\hline Bacia Atlântico/Sudeste & Tacanica & & \\
\hline Santa Cruz & Piraí & CCPRB & UHE - 1,4 MW \\
\hline Piraí & Jacuí & CELESC & UHE - 1,37 MW \\
\hline Ernestina & Jacuí & CEEE & UHE - 1,0 MW \\
\hline Passo Real & & CEEE & UHE - $125 \mathrm{MW}$ \\
\hline
\end{tabular}


O acúmulo de sedimento no reservatório tem conseqüências graves não só a montante da barragem, mas também a jusante. Segundo Coiado (2001), a jusante da barragem, tem-se como conseqüência principal, o aumento da erosão devido ao desequilíbrio provocado pela retirada da carga natural de sedimentos do escoamento. O estudo de Lloret Ramos (2002) discute as implicações ambientais de sedimentos efluentes do Reservatório Billings, em São Paulo, mostrando a característica do material de transpasse, constituído na sua totalidade por sedimentos finos coesivos potencialmente contaminados. Conclui que a influência destes sedimentos à jusante da barragem, na região estuarina, pode ser um fator relevante em problemas de natureza ambiental ou mesmo um fator limitante a processos de dragagens sistemáticas de manutenção.

No processo de assoreamento, sedimentos em suspensão, resultantes da lavagem da bacia hidrográfica (wash load) e sedimentos que compõem o fundo (bed load), são depositados no reservatório. De acordo com Dendy (1968), o tamanho e a forma do reservatório; as razões entre a sua capacidade e o tamanho da bacia hidrográfica e deflúvio afluente; a topografia da bacia, cobertura vegetal e uso da terra; declividade e densidade da rede de canais, assim como as características físicas e químicas do sedimento afluente, têm influência importante na taxa de sedimentação do reservatório.

Bufon (2006) apresenta o caso do reservatório Represa Velha, pertencente ao CEPTA/IBAMA (Centro de Pesquisa e Gestão de Recursos Pesqueiros Continentais do Instituto Brasileiro de Meio Ambiente), no qual o carreamento de solo arenoso da bacia para o afluente (FIGURA 6), devido ao uso de práticas inadequadas de conservação, contribuiu para o seu assoreamento. Um dos esvaziamentos para remoção dos sedimentos ocorreu em 1994 (FIGURA 7), sendo identificado um acúmulo de material carreado na entrada do reservatório, formando um delta. 


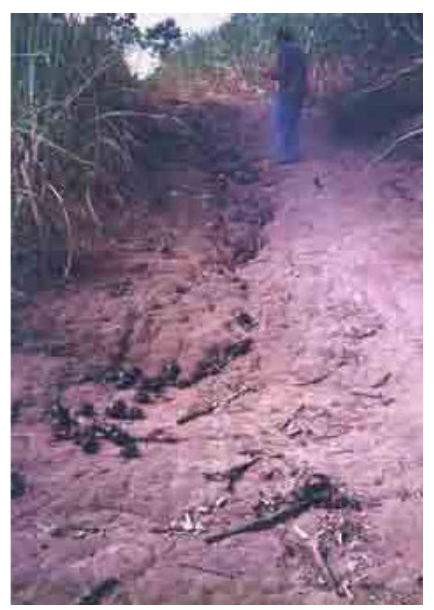

FIGURA 06 - Carreamento de Material Arenoso (BUFON, 2006)

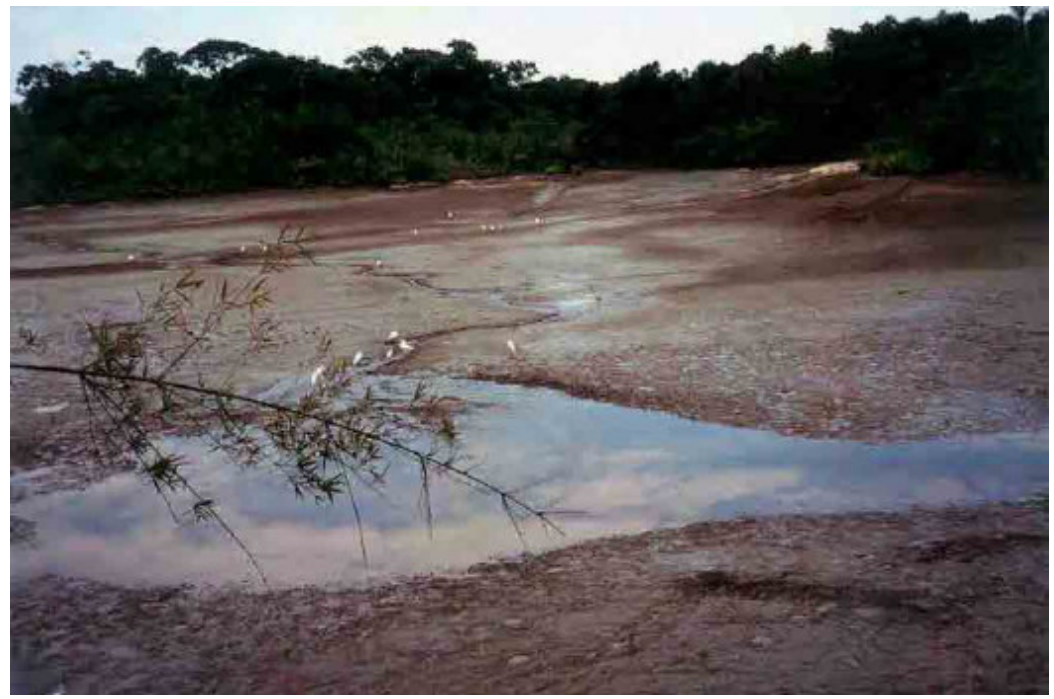

FIGURA 07 - Esvaziamento da Represa Velha (BUFON, 2006)

Em Coiado (2001) é apresentado o caso do reservatório de Cariobinha, operado pela CPFL (Companhia Paulista de Força e Luz do Estado de São Paulo). Este reservatório foi esvaziado em 1986 e 1992 para a desobstrução da tomada d’água, com 2/3 de sua altura obstruída no esvaziamento de 1992. Na Figura 8 tem-se a vista parcial (próxima a barragem) do reservatório, após o esvaziamento. Na Figura 9 são mostradas as grades da tomada d'água (direita) e da comporta de fundo (esquerda), durante os trabalhos de desobstrução. 


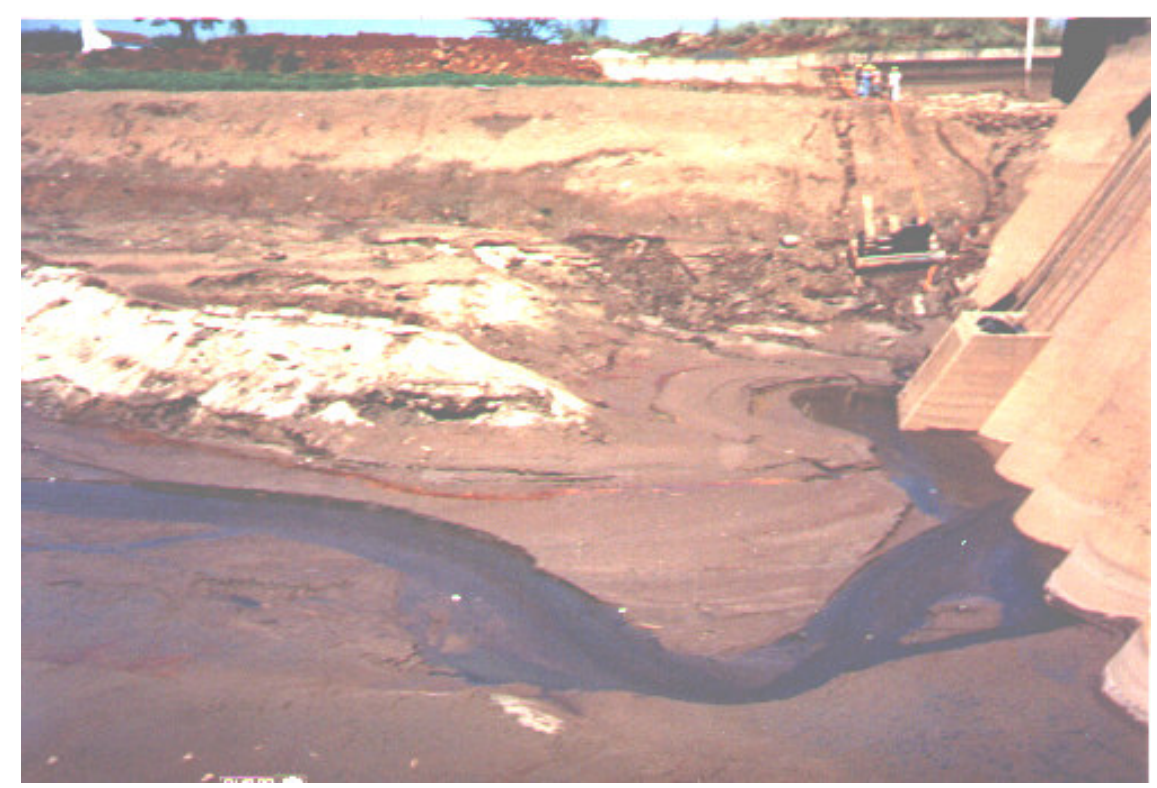

FIGURA 08 - Vista Parcial do Reservatório de Cariobinha (Convênio CPFL/UNICAMP Coiado, 2001)

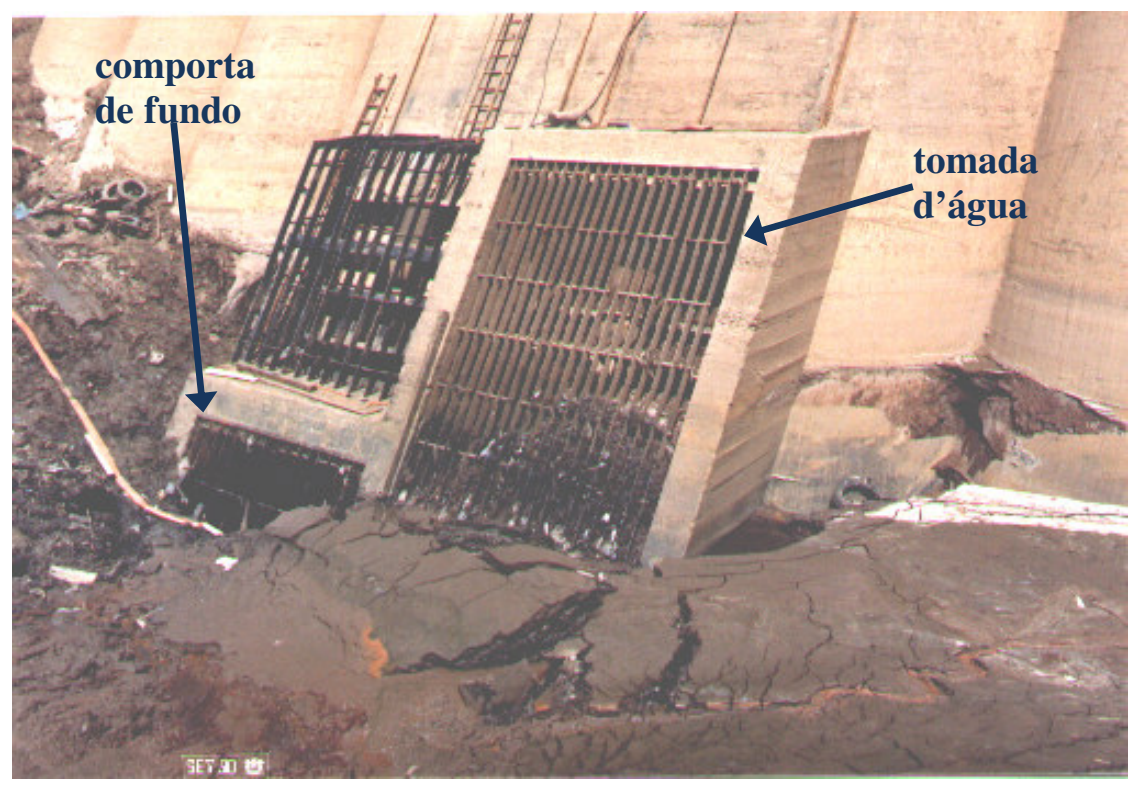

FIGURA 09 - Vista das Grades de Tomada d'água e da Comporta de Fundo do Reservatório de Cariobinha (Convênio CPFL/UNICAMP Coiado, 2001)

As partículas mais finas se depositam no interior do reservatório e próximas da barragem (CARVALHO, 1994), como pode ser visualizado na Figura 9. O aumento do volume assoreado interferere na hidrodiâmica podendo, como conseqüência, alterar a característica deposicional. 


\subsubsection{Descarga e Volume de Sedimento Depositado nos Reservatórios.}

O volume de sedimentos depositado nos reservatórios, ou volume assoreado, tem como principal causa o aumento da seção transversal da corrente do rio, devido à construção da barragem, fazendo com que haja uma diminuição na velocidade do escoamento. Com a diminuição desta velocidade o material em suspensão, que está sendo carreado pelo rio, tende a se depositar no reservatório (ALAMY FILHO et al, 2002).

Tendo em vista que os sedimentos desprendidos na bacia hidrográfica atingem e são transportados pelos afluentes do reservatório, estimativas e medições são realizadas para a determinação da descarga sólida total nos cursos d'água. A descarga sólida total (Qst) ou "total load" é definida como a soma da descarga sólida transportada por arrasto de fundo (Qsf) ou "bed load" com a descarga sólida em suspensão (Qss) (De PAIVA, 2001b). Esta última é composta por sedimentos resuspensos do fundo ("suspended load") e daqueles provenientes da bacia hidrográfica ("wash load"). A granulometria do "wash load" é bem fina, e atinge o reservatório através da vazão afluente ou por contribuição direta do escoamento superficial. Os "bed load" são transportados mediante saltos das partículas ou deslizamentos entre elas, constituídos inclusive por sedimentos originados pelo processo de erosão das rochas e solos de embasamento dos rios (SIMÔES; COIADO, 2001).

Para um reservatório onde haja $100 \%$ de deposição, o volume sedimentado corresponde à quantidade total de partículas de solo resultantes de processos erosivos na bacia hidrográfica contribuinte, menos a quantidade de partículas depositadas entre a mesma e o reservatório (DUNNE; DIETRICH, 1982). Como os sedimentos que atingem o reservatório não sedimentam na sua totalidade, Coiado (2001) apresenta a Equação 1, indicada para o cálculo da quantidade de sedimento que será depositada no reservatório $(Q t d)$, durante um dado período de tempo. 


$$
Q t d=Q s t-(Q e d+Q s s)
$$

onde:

Qst: descarga sólida total que entra no reservatório;

Qed: quantidade de sedimentos que sai pelas estruturas de descarga no período considerado;

Qss: quantidade de sedimento mantida em suspensão não retida pelo reservatório no espaço de tempo considerado.

A produção de sedimentos ou descarga sólida total pode ser estimada por métodos simples e que se baseiam nas características regionais, i.e. Equação Universal da Perda de Solo (USLE) ou modificada (MUSLE), e na medição sedimentométrica para a determinação da curva chave de sedimentos (SOUZA et al., 2006). Quando não se tem dados medidos e com representatividade temporal, são empregadas equações ou modelos matemáticos para o cálculo da carga total de sedimento afluente ao reservatório (MAIA, 2006).

\subsubsection{Perda de solo na Bacia Hidrográfica.}

A perda de solo na bacia hidrográfica representa a principal fonte dos sedimentos que irão se depositar no reservatório. Este fenômeno ocorre devido a elementos de ordem natural, desencadeando uma erosão hídrica que pode ser acelerada devido ao fator antrópico.

Dentre as muitas equações (WISCHMEIER; SMITH ${ }^{8}, 1978$ apud SILVA; SCHULZ; CAMARGO, 2003, p. 65) que buscam exprimir a ação dos principais fatores que sabidamente influenciam as perdas de solo por erosão hídrica, a que trata o assunto de modo mais dinâmico, por superar parcialmente restrições climáticas e geográficas e ter aplicação

\footnotetext{
${ }^{8}$ Wischmeier, W. H.; Smith, D. D. Predicting rainfall erosion losses. A guide to conservation planning. Supersedes Agriculture Handbook, n. 282. Science and Education Administration United States Department of Agriculture, 1978.
} 
generalizada, é a chamada "Equação Universal de Perda de Solo" - EUPS (Universal Soil Loss Equation - USLE). A variante mais empregada da USLE é a "Equação Modificada da Perda de Solo" (Universal Soil Loss Equation Modified - MUSLE) que se presta a avaliações de chuvas isoladas, em detrimento às estimativas médias de períodos longos (meses ou anos) realizadas pela USLE (SOUZA et al., 2006).

A USLE (WISCHMEIER e SMITH ${ }^{8}, 1978$ apud De PAIVA, 2001a) é um modelo conceitual destinado a calcular a perda de solo média proveniente da erosão laminar e por sulcos, não prevendo deposição nem computando produção de sedimento por ravina e erosão das margens e fundo do canal. Sua aplicação é recomendada em pequenas bacias hidrográfica, uma vez que a área, densidade de drenagem e erodibilidade, interferem significativamente na estimativa do sedimento transportado até o curso d'água (VANONI, 1975). Segundo o mesmo autor, do total de sedimento erodido na bacia hidrográfica e transportado de um ponto até o leito do rio num determinado período, a aplicação da USLE pode conduzir a uma variação de $10 \%$ a $70 \%$ deste total. A entrega do sedimento erodido na "bacia" ao canal afluente pode ser calculada por meio de equações que estimam a taxa de entrega - SDR (Sediment Delivery Ratio), como a sugerida por Vanoni (1975) e Willians e Berndt (1972).

Souza et al. (2006), aplicaram a USLE para um estudo comparativo de estimativas de produção de sedimentos na bacia do Rio Potiribu (área de $610,1 \mathrm{Km}^{2}$ ), contribuinte da margem esquerda do Rio Ijuí, afluente do Rio Uruguai. Aplicando as equações de Vanoni (1975) e Willians e Berndt (1972) para o cálculo de SDR, chegaram aos valores de 740 ton $/ \mathrm{Km}^{2}$.ano e $220 \mathrm{ton} / \mathrm{Km}^{2}$.ano respectivamente. O resultado obtido pela curva chave de sedimentos, em medições realizadas no mesmo período, foi de 17,91 ton/ $/ \mathrm{Km}^{2}$.ano.

As maiores dificuldades na aplicação da USLE estão em inter-relacionar os fenômenos inerentes ao processo de erosão e o transporte de sedimentos na bacia hidrográfica, de obter dados consistentes e determinar com confiança a taxa de entrega. Por este motivo é que a 
espacialização do potencial de erosão do solo, obtido pela USLE, associada a um sistema de informações geográficas (SIG), tem maior importância para ações preventivas que visem à minimização da produção de sedimentos na bacia hidrográfica, do que quantificar o volume de sedimento afluente ao curso d'água.

\subsubsection{Curva Chave de Sedimentos.}

Dentre os modelos empíricos utilizados para a estimativa de produção de sedimentos mais comumente empregados, encontram-se métodos associados à determinação da curva-chave de sedimentos, incluindo a utilização de dados de vazão média líquida, e o método da curva de permanência (CARVALHO et al., 2000).

Com a vazão média líquida (SOUZA et al., 2006), medida na entrada do reservatório, e amostragens de concentração de sedimentos, coletadas em pontos onde se mede a vazão líquida, pode-se calcular a descarga sólida em suspensão (Qss) que o curso d'água entrega ao reservatório. A relação entre a descarga sólida em suspensão e a vazão média líquida na seção de entrada do reservatório, referente a cada medida de concentração (FIGURA 10), é chamada de curva-chave de sedimento (MAIA, 2006).

O volume afluente de sedimentos em suspensão, portanto, é calculado a partir da equação representativa da curva (FIGURA 10), com dados de uma série de vazões históricas, ou sintéticas. Para cada dado da série de vazões, é estabelecido um valor correspondente de descarga sólida em suspensão, o que torna possível a obtenção da série de dados de sedimento em suspensão afluente ao reservatório (CARVALHO et at., 2000).

A obtenção da curva-chave, ora descrita, é aplicada também com a utilização do método da curva de permanência, cujo objetivo é o mesmo. A descrição deste método, que utiliza o conceito de freqüência de vazões em períodos distintos, pode ser encontrada em 
Carvalho (1994). Os valores obtidos de descarga afluente, por ambos os métodos, tem se mostrado equivalentes. No estudo de Souza et al. (2006), por exemplo, envolvendo o Rio Potiribu, a diferença entre a descarga de sedimentos total pelas duas metodologias, apresentou um erro relativo de $0,22 \%$.

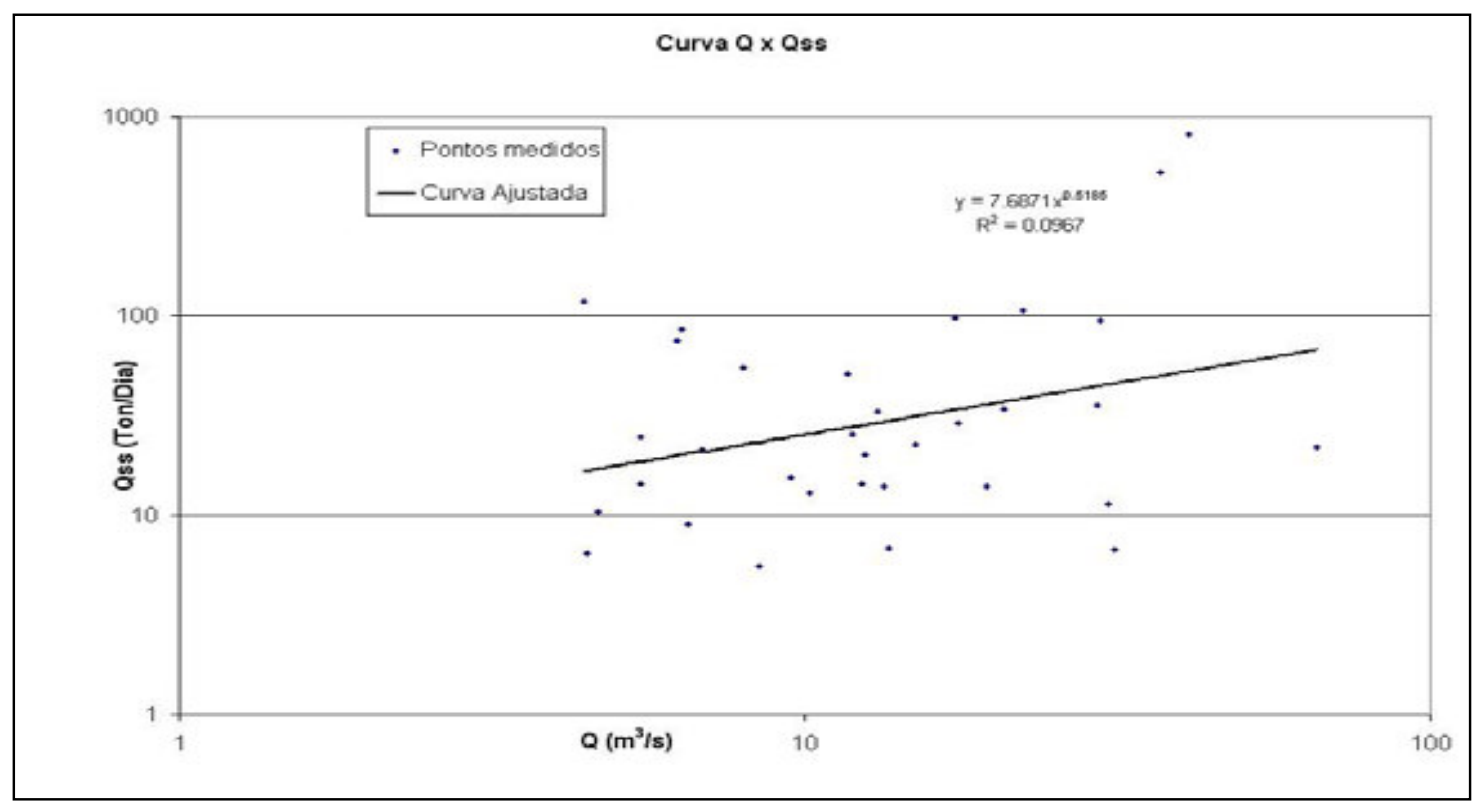

Figura 10. Curva-chave de sedimento do Rio Potiribu (SOUZA et al., 2006)

As metodologias comentadas dependem da qualidade das medições sedimentométricas realizadas. Como toda metodologia apresenta limitações, a limitação principal decorre da subestimação do valor de descarga sólida, sendo o grau de subestimação relacionado ao grau de dispersão dos pares de dados na curva chave (PHILLIPS et al., 1999). O estudo de Asselman (2000) mostrou que estimativas de fluxo de sedimentos de longo prazo, baseados em curva chave obtida pela transformação logarítmica de dados e regressão através dos mínimos quadrados, subestimaram a taxa de transporte sólida em valores que variam entre 10 e 50\%. Além do exposto, no Brasil são comuns somente medições de concentração de sólidos suspensos, o que possibilita apenas o cálculo da descarga de sedimentos em suspensão (Qss), multiplicando a concentração pela vazão líquida. Para a obtenção da descarga de arrasto de 
fundo $(Q s f)$, ou se utiliza de dados da literatura para reservatórios específicos, ou se aplica modelos matemáticos.

\subsubsection{Generalidades sobre os Modelos Matemáticos Clássicos de Transporte de}

\section{Sedimentos.}

Considerando que, em geral, medições diretas para a quantificação da descarga de sedimento total ( $Q s t)$ e principalmente da descarga de arrasto de fundo $(Q s f)$, não são comuns, medidas indiretas são realizadas para a estimativa da descarga sólida via equações ou modelos matemáticos de transporte de sedimentos. Os equipamentos e metodologia utilizados em medições diretas e indiretas para a estimativa da carga sólida transportada são apresentados em Carvalho (1994) e Carvalho et al. (2000).

Os modelos ditos clássicos surgiram a partir de meados do século vinte e incorporam observações experimentais intensas, informações relacionadas basicamente ao escoamento médio e considerável trabalho estocástico (ALAMY FILHO, 2006). Assim, estes modelos (CARVALHO, 1994) devem ser escolhidos com critério, tanto baseado nas condições locais do curso d'água quanto no desenvolvimento teórico ou facilidade de aplicação.

Diante do grande número de equações e métodos concebidos para calcular a descarga de sedimentos nos rios, merece destaque o estudo feito por Einsten, baseado em considerações estatísticas de forças de sustentação, resultando nas equações de Einsten (1942, 1952). Até então, eram utilizadas equações do tipo Du-Boys (1879). Nessas últimas, a descarga de fundo de arrasto (Qsf) só existia quando os valores das tensões de cisalhamento do escoamento ultrapassassem os valores das tensões críticas de início de movimento, estabelecidas primeiramente por Shields (1936) (COIADO; PAIVA, 2008). 
Um estudo comparativo analítico de algumas equações, para avaliar o transporte de fundo de arrasto (VILLELA, $2001^{9}$ ), considerando canal com seção retangular, largura de $50 \mathrm{~m}$ e declividade de $0,002 \mathrm{~m} / \mathrm{m}, \mathrm{d}_{50}$ para os diâmetros representativos de $0,5,1,0$ e 2,0 mm e vazão de $2 \mathrm{~m}^{3} / \mathrm{s} . \mathrm{m}$, é apresentado na Tabela 2 abaixo.

TABELA 02 - Valores de descarga de fundo para algumas equações (VILLELA, 2001').

\begin{tabular}{lc}
\hline & Descarga de Fundo (Kg/s) \\
\hline $\left.\mathbf{1}^{\circ}\right)$ DuBoys (1879) & 781,75 \\
$\mathbf{2}^{\text {o) }}$ Peter-Meyer (1934) & 388,80 \\
$\left.\mathbf{3}^{\circ}\right)$ Kalinske (1947) & 132,50 \\
$\left.\mathbf{4}^{\circ}\right)$ Einsten (1942) & 388,25 \\
$\left.\mathbf{5}^{\circ}\right)$ Einsten (1950) & 390,15 \\
\hline
\end{tabular}

Coiado e Paiva (2008) analisaram catorze das principais equações utilizadas no cálculo de transporte de sedimentos na camada do leito, confrontando alguns dos parâmetros medidos numa seção do Rio Atibaia/SP, durante o período de março de 1993 a abril de 2000. Considerando nas análises, as tensões médias de cisalhamento do escoamento e as tensões de cisalhamento críticas referentes ao diâmetro representativo de cada equação, verificaram que todas apresentam algum tipo de restrição. No trabalho de Scapin (2005), comparando dados medidos e os estimados por oitos equações de transporte de sedimentos, num pequeno rio urbano em Santa Maria, RS, durante treze eventos chuvosos, foram verificadas também as limitações de cada modelo.

Dentre os modelos mais notáveis, além do de Einsten $(1942,1950)$ aplicado para descargas sólidas de fundo e suspensas, destacam-se o de Van Rijn (1984) para sedimentos suspensos e o modificado de Einsten, por Colby e Hembree (1955). A descrição destes métodos pode ser vista em Carvalho (1994), Coiado (2001), Scapin (2005) e Coiado e Paiva (2008). Atualmente, os modelos clássicos de transporte de sedimentos vêm perdendo espaço no tocante a aplicação geral, à medida que os avanços no entendimento das estruturas

\footnotetext{
${ }^{9}$ VILLELA, Swami Marcondes (2001). Hidráulica Fluvial. / Curso ministrado na EESC/USP - São Carlos, no período de agosto-novembro/2001
} 
turbulentas contribuem para uma melhor caracterização e descrição do fenômeno (ALAMY FILHO, 2006). Em trabalhos de simulação numérica, os modelos clássicos são acoplados a modelagem matemática hidrodinâmica, considerando ainda o efeito da viscosidade turbulenta. As equações hidrodinâmicas e o conceito de viscosidade turbulenta são descritos com detalhes em Schulz $(2003,2001)$ respectivamente. Nestas simulações, os modelos de transporte de Engelund e Hansen (1967) e Engelund e Fredsoe (1976), para descargas de arrasto de fundo e suspensão, têm sido utilizados com resultados satisfatórios (DHI, 2005).

\subsubsection{Sedimentos e a Relação com a Vida Útil do Reservatório.}

Na medida em que os sedimentos adentram o reservatório e se depositam no fundo, conseqüentemente ocorre uma redução no volume do mesmo. A intensidade de ocorrência deste fenômeno é que determina o tempo que o reservatório poderá ser explorado, assegurados os aspectos ambientais de quantidade e qualidade da água, fixados pelos comitês de bacias hidrográficas, apoiados na legislação ambiental e nas resoluções do Conselho Nacional de Meio Ambiente (CONAMA).

O fenômeno da deposição de sedimentos no reservatório, em escala temporal, impacta negativamente na vida útil dessa estrutura hidráulica. Entre os vários fatores contribuintes, o grau deste impacto depende basicamente, além da descarga sólida total afluente, da característica do sedimento e a sua distribuição espacial, associados à eficiência do reservatório em reter estes sedimentos (CARVALHO, 1994).

Um dos parâmetros que caracteriza e classifica os sedimentos é a granulometria. É através dela que se estabelece o nível de adensamento dos solos, sob determinadas condições 
(YOSHIZANE ${ }^{10}$, 2005). O sedimento depositado no reservatório sofre uma ação de adensamento, reduzindo o volume das partículas com o tempo (VILLELA; MATTOS, 1975). Este processo de compactação dos sedimentos depende das regras de operação, a textura e o tamanho das partículas de sedimento, a taxa de compactação, a idade do depósito, o acúmulo de matéria orgânica e ainda outros fatores de menor importância (STRAND, 1974). Destaque é dado à forma com que o reservatório é operado, pois determina o grau de exposição do sedimento e, por conseguinte, o seu grau de compactação. Quanto maior a profundidade em que o sedimento é depositado maior será o valor do seu peso específico, devido à carga de compactação sofrida pelo material (MAIA, 2006). O diâmetro dos grãos de sedimento é outro fator importante. Pesquisas mostram que para os sedimentos finos, caso das argilas, o peso específico diminui proporcionalmente com o aumento do percentual presente (HEINEMANN, 1962), ao contrário das areias com diâmetros acima de 0,05 mm (LANE; KOELZER ${ }^{11}, 1943$ apud ROCHA; FERREIRA, 1980).

Em termos de projeto do reservatório, a forma mais utilizada para "resolver" a questão do assoreamento é a destinação de um volume, denominado de volume "morto", que nada mais é do que uma percentagem do volume total do reservatório, para receber sedimentos. Este procedimento (PONCE, 1986) na verdade, não soluciona o problema, podendo retardálo. Isto porque os sedimentos que depositam em um reservatório não se limitam ao espaço alocado para o volume morto ou a sua região inferior (VILELLA, 20019 ${ }^{9}$. As partículas mais pesadas, que geralmente são transportadas por arrasto, são depositadas na entrada do reservatório, enquanto que as menores avançam mais para o interior (FIGURA 11), podendo ou não se depositar (COIADO, 2001). Os níveis operacionais do reservatório, que influenciam

\footnotetext{
${ }^{10}$ Yoshizane, H. P. (2005). Mecânica dos Solos. Notas de aula do curso ministrado na UNICAMP - ST 409 e 624

${ }^{11}$ LANE, E. W. ;KOELZER, V. A. (1943). Density of Sedimentations Deposited in Reservoirs. Report nº9. A study of methods used in measurements and analysis of sediment loads in streams. Hydraulic Lab. Univ. of Iowa, Iowa City, Iowa, November.
} 
o adensamento do sedimento, também são responsáveis por sua distribuição, sendo que a forma do reservatório representa o principal elemento da caracterização espacial do sedimento depositado. Para a estimativa da distribuição espacial, normalmente é utilizado o chamado

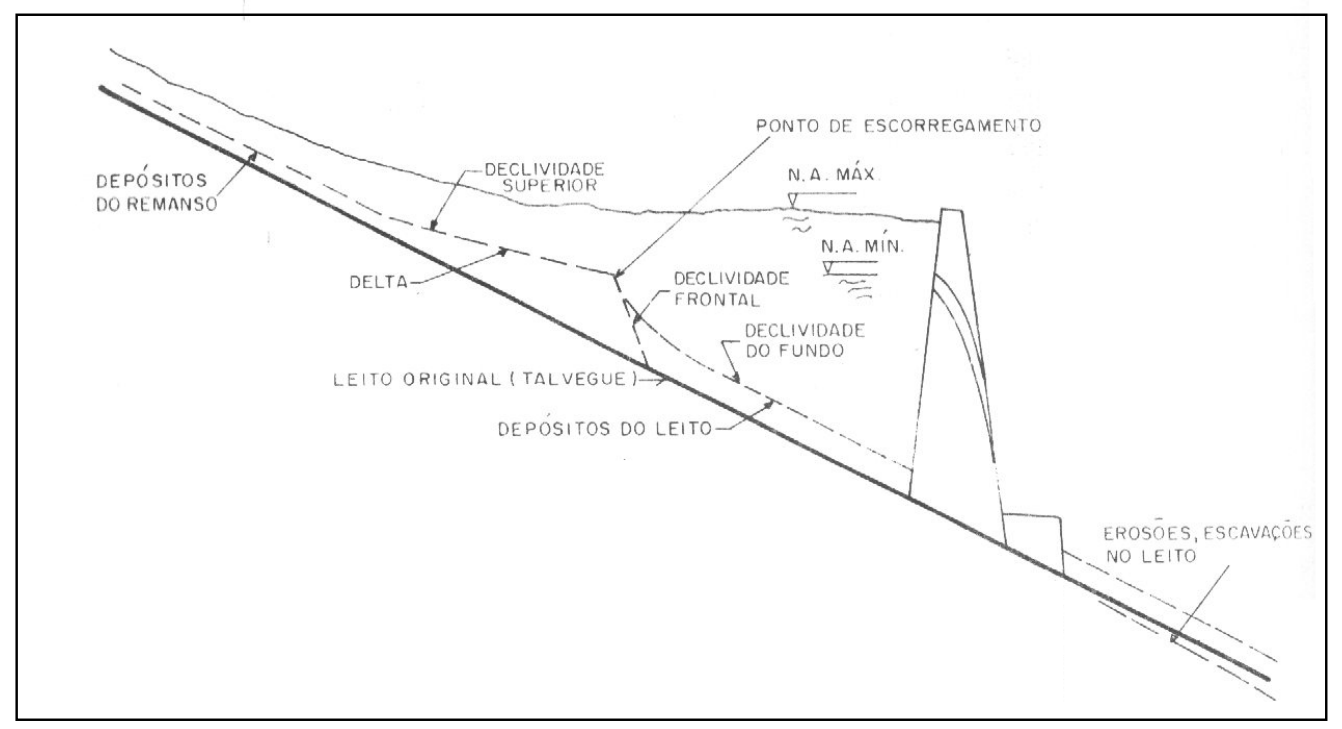

Figura 11. Distribuição típica dos sedimentos no reservatório (CARVALHO, 1994)

“Método Empírico de Redução de Área” (LARA ${ }^{12}, 1962$ apud VANONI, 1975), que consiste na revisão do método de Borland e Miller, 1958. O método se baseia no levantamento de 30 reservatórios dos EUA, onde foi observada a existência de uma relação entre forma do reservatório e percentual de sedimentos depositados em várias profundidades. Este método (CARVALHO, 1994) requer comprovação de aplicabilidade para o Brasil, em função dos fatores ambientais típicos como clima, regime de chuvas, recobrimento vegetal, solos, dentre outros.

Em nível operacional, ferramentas como sensoriamento remoto e geoestatística (BORGES; FILHO; JUNIOR, 2005) aplicados à estimativa da batimetria, além das próprias campanhas batimétricas, obtêm a distribuição espacial do sedimento, além de permitir o

\footnotetext{
${ }^{12}$ Lara, J. M. Revision of Procedures to Compute Sediment Distribution in Large Reservoirs. United States Bureau of Reclamation, Denver, Colorado, may. 1962.
} 
traçado das novas curvas cotas-áreas-volumes, para a estimativa da vida útil. Porém, o grande gargalo das batimetrias está relacionado ao custo. Com o desenvolvimento da dinâmica dos fluidos computacional (DFC) é possível modelar a evolução sedimentológica no reservatório, a partir da calibragem de modelos numéricos, como o proposto por esta pesquisa.

\subsubsection{Eficiência de Retenção de Sedimento do Reservatório.}

A eficiência de retenção de sedimentos no reservatório é definida pela relação entre a quantidade de sedimento depositado e a descarga sólida total (Qst) afluente. Esta eficiência depende, principalmente, das características do reservatório (volume, operação, forma e idade), da vazão líquida afluente, além das características do sedimento. Em termos práticos, a eficiência pode ser obtida a partir de medições sistemáticas das descargas sólidas afluentes e a jusante da barragem. Já na fase de projeto, métodos empíricos são aplicados.

Em projeto de pequenos reservatórios (CARVALHO et al., 2000), a análise da eficiência é feita com a utilização das curvas de Churchill (1948), que representam o percentual de sedimento efluente do reservatório, em função do índice de sedimentação (FIGURA 12). O índice de sedimentação é a razão entre o volume de reservação e o produto da vazão média afluente diária e o comprimento do reservatório. É um método empírico, baseado em dados experimentais dos reservatórios da Tennessee Valley Authority.

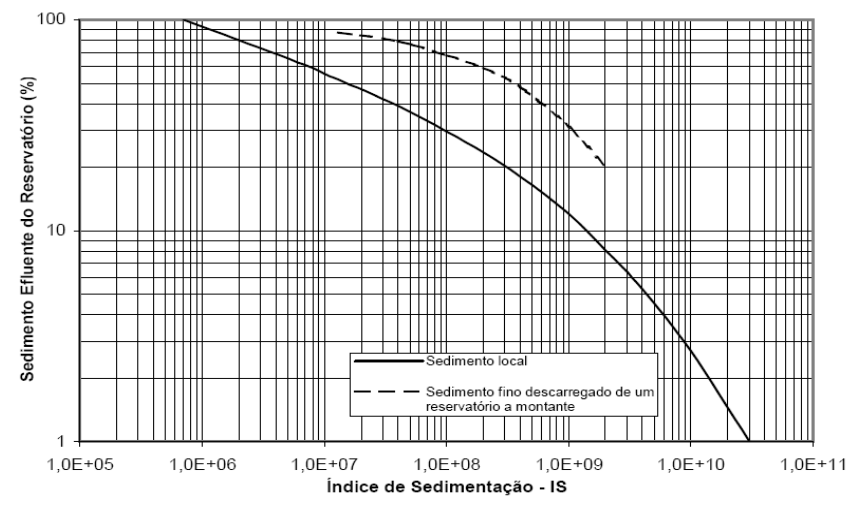

Figura 12. Curvas de Churchill (ANNANDALE, 1987) 
Já para os médios e grandes reservatórios (CARVALHO et al., 2000), é utilizado o método empírico de Brune (1953). É baseado na análise de um grande número de reservatórios americanos, para a determinação da percentagem de sedimentos retidos, em função da capacidade de afluência (FIGURA 13). A capacidade de afluência, no eixo das abscissas, é dada pela razão entre a capacidade do reservatório e o volume afluente anual. Roberts $^{13}$ (1982 apud ANNANDALE, 1987) constatou que o uso do gráfico é mais indicado quando o volume do reservatório é substituído pelo volume de operação do reservatório.

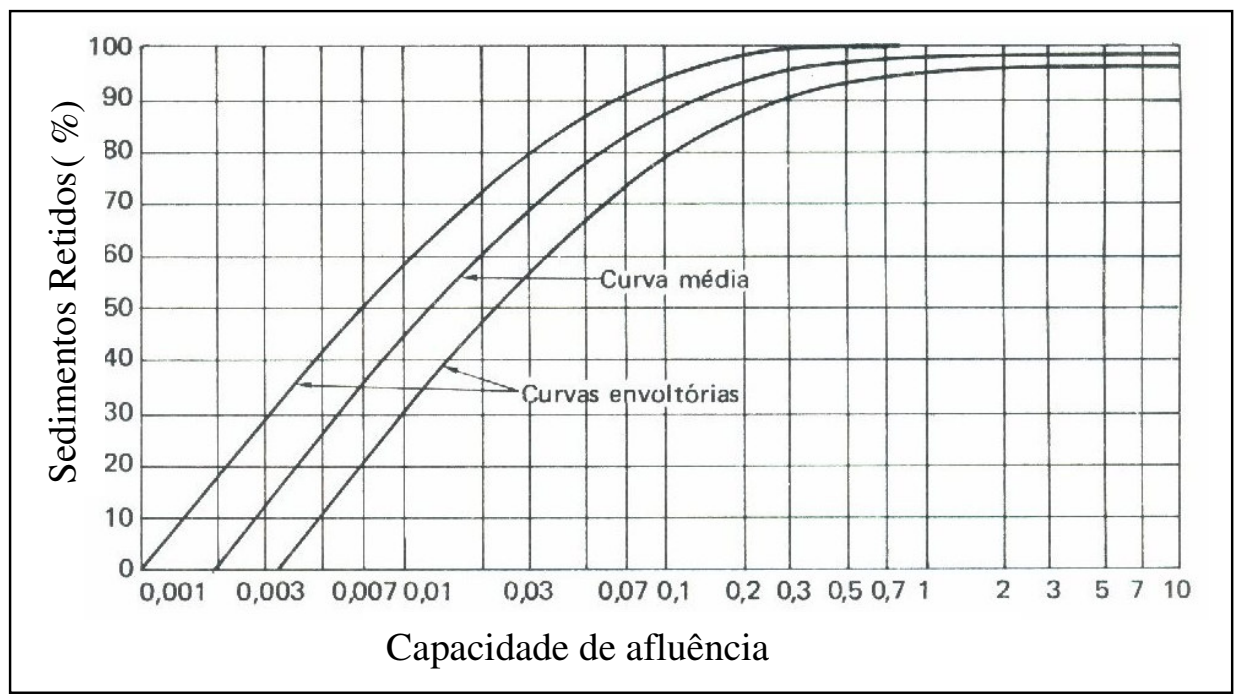

Figura 13. Curvas de Brune (VILLELA; MATTOS, 1975)

A curva superior é aplicada aos sedimentos de diâmetros maiores e também aos sedimentos finos com floculação elevada. No caso dos sedimentos finos e coloidais dispersos utiliza-se a curvatura inferior. Sedimentos mistos são analisados através da curva média. A utilização dos métodos ora apresentados é descrita com detalhes, incluindo suas limitações, em Strand (1974), Vilela e Mattos (1975), Vanoni (1975), Carvalho (1994) e Morris e Fan (1997).

\footnotetext{
${ }^{13}$ Roberts C.P.R. (1982). Flow profile calculations. HYDRO 82. Pretoria, University of Pretoria.
} 


\subsection{Dinâmica de Fluidos Computacional (DFC) e Transporte de Sedimentos.}

O cálculo de escoamento e transporte de sedimentos, tanto em rios quanto em reservatórios, é tarefa importante na hidráulica fluvial. Considerando o exposto no item 3.2, fica evidente que o estudo aplicado ao assoreamento de reservatórios tem uma fundamentação empírica, cujos modelos tradicionais não podem assumir um caráter universal por não incorporarem conhecimentos a respeito da turbulência. Neste apecto, é válido ressaltar o importante trabalho desenvolvido por Alamy Filho (2006) sob orientação do Professor Harry Edmar Schulz (SHS-EESC-USP), que consiste de um modelo tridimensional de transporte de sedimentos, com Simulação de Grandes Escalas de turbulência (SGE) e Método de Fronteira Imersa (MFI) para simulação do escoamento sobre a superfície irregular do leito. Como alternativa, os trabalhos de campo de medição direta, pouco comuns no Brasil, só permitem prognosticar o assoreamento para um grande conjunto de medições temporais, num mesmo cenário, além de representar custos consideráveis. O desenvolvimento da dinâmica de fluidos computacional viabiliza a associação da modelagem matemática hidrodinâmica ao transporte de sedimentos, apresentando-se como uma boa alternativa quando se deseja estudar a evolução do fenômeno no espaço e no tempo.

Apesar do número crescente de estudos aplicados ao transporte de sedimentos, o uso da simulação numérica na predição do assoreamento em reservatórios reais com confiabilidade, é incipiente. Isto se justifica primeiramente pela ausência de dados medidos (vazão, concentração, temperatura, ventos, chuvas, etc), e segundo, devido às limitações dos modelos numéricos existentes quanto à representação física do fenômeno. Atendendo ao objetivo deste trabalho, destacam-se neste capítulo os estudos aplicados ao transporte de sedimentos em rios e reservatórios reais, com o uso de simulação numérica. Parte dos estudos aqui citados consta em Souza (2006), que também apresenta algumas pesquisas no âmbito de 
laboratório, utilizando modelos reduzidos, as quais são de grande importância para avaliar a eficiência do sistema em fase de projeto, bem como para validar o modelo numérico. Os programas computacionais utilizados são desenvolvidos por agências de governo, empresas particulares e universidades, havendo em alguns casos, parceria entre estas instituições.

\subsubsection{Trabalhos de Modelagem Numérica aplicada ao Estudo do Transporte de Sedimentos em Rios e Reservatórios Reais.}

Ziegler e Nisbet (1995) fizeram uma simulação de 30 anos (de 1961 a 1991) de transporte de sedimentos finos, coesivos, no reservatório de Watts Bar, localizado no Tennessee, e que faz parte do sistema de reservatórios Tennessee Valley Authority. Demonstrou-se que o modelo SEDZL reproduziu bem deposição e erosão neste grande reservatório. O modelo foi calibrado com dados de batimetrias realizadas em 1946, 1951, 1956, 1961 e 1991. Uma comparação quantitativa entre as batimetrias real e simulada, com relação à variação do nível do fundo, acusou um erro relativo médio de $46 \%$ e foi considerada satisfatória pelos autores. O modelo predisse que $76 \%$ do sedimento que entra no reservatório em 30 anos é mantido no reservatório, contra 72\% ( $\pm 6 \%$ ) observado. As batimetrias foram realizadas em 64 seções transversais no reservatório (as mesmas em todas as medições). A batimetria de 1991 usou equipamento Acoustic Depth Finder (precisão de \pm 0,03 metros) com Global Positioning System (GPS). O trabalho preocupou-se com o tempo de permanência de sedimentos finos e coesivos no reservatório, muitas vezes carregados de compostos químicos e metais pesados, prejudiciais ao meio ambiente. A pequena profundidade do reservatório em questão, associada aos pequenos efeitos de estratificação térmica, indicou que a coluna de água pôde ser assumida misturada verticalmente, isto é, as velocidades da água e concentrações de sedimentos, na horizontal, são aproximadamente uniformes na direção 
vertical. Essas condições permitiram que o processo físico fosse aproximado por uma modelagem bidimensional, com equações integradas na vertical. A malha computacional continha 157 elementos. Os resultados mostraram-se coerentes com a realidade, com sedimentos de maior diâmetro, não coesivos, depositados na entrada do reservatório; e sedimentos finos e coesivos (silte e argila) em maior quantidade na medida em que se aproxima da barragem. O SEDZL também foi usado em simulações de transporte de sedimentos finos em outros sistemas aquáticos, como Fox River, em Wisconsin (GAILANI; ZIEGLER; LICK, 1991); Pawtuxet River, em Rhode Island (ZIEGLER; NISBET, 1994) e Lake Irie (LICK W.; LICK J.; ZIEGLER, 1994).

Chang et al. (1996) discutiram a acumulação de sedimentos em reservatórios ao longo do rio North Feather, fenômeno que afetará num futuro próximo a geração de energia elétrica. Para controle do assoreamento, descargas de fundo têm sido consideradas, para que os sedimentos atravessem os reservatórios. O objetivo é manter o balanço de sedimentos sem erosão ou assoreamento resultante nos reservatórios, em um extenso ciclo de operação. A velocidade do escoamento para que os sedimentos sejam transportados e passem por cada reservatório seria atingida com o rebaixamento do nível de água, usando descargas de fundo durante períodos de cheia. Um estudo com modelagem numérica, usando o programa FLUVIAL-12, foi realizado para se avaliar a viabilidade e eficiência dessa operação. O FLUVIAL-12, segundo Chang (1988), tem sido formulado e desenvolvido desde 1972 para modelagem de escoamento e transporte de sedimentos fluviais. Apesar de não ter sido focado por este estudo, a liberação de sedimentos através de descarregadores de fundo sem um estudo criterioso, atua decisivamente na geração de impacto ambiental à jusante da barragem e mesmo às turbinas, que passarão a receber água com maior concentração de sedimentos. Os autores citam que o modelo foi previamente validado e calibrado com dados medidos e 
operacionais do reservatório. Nos resultados são apresentados dados de saída da simulação numérica.

Em Gessler et al. (1999), descreve-se o modelo tridimensional (3D) de escoamento e transporte de sedimentos CH3D-SED; e sua aplicação no Projeto Deep Draft Navigation, no baixo Mississipi. A capacidade do programa em simular transporte de sedimentos (apenas areia) em canais de fundo móvel foi desenvolvida em conjunto pelo Laboratório de Hidráulica do U.S. Army Corps of Engineers e a Waterways Experiment Station, no Iowa Institute of Hydraulic Research. O trabalho não contempla uma comparação em termos de distribuição do sedimento observado e simulado. Do ponto de vista volumétrico, segundo os autores, o erro é da ordem de $25 \%$ entre o assoreamento observado e aquele obtido pelo modelo numérico.

Em Molino, Greco e Rowan (2001), aplicou-se um modelo bidimensional (2D) ao estudo de caso do reservatório Abbeystead, no Reino Unido. Os resultados simulados foram comparados e mostraram boa concordância com os dados de 7 batimetrias realizadas entre 1851 e 1991, representando satisfatoriamente o crescimento do delta no reservatório. No interior do reservatório e próximo à barragem, foram verificadas distorções consideráveis entre o assoreamento medido e o simulado. Raramente são encontrados reservatórios com essa quantidade de levantamentos batimétricos.

O trabalho de Nicklow e Mays (2000) diferencia-se dos demais citados por apresentar uma metodologia de otimização junto à simulação de transporte de sedimentos, para minimizar a erosão e o assoreamento em sistemas de múltiplos reservatórios, englobando tomadas de decisões no gerenciamento do sistema. A otimização é trabalhada com o programa HEC-6, modelo de simulação de transporte de sedimentos, do U.S. Army Corps of Engineers, aplicado a um hipotético sistema de três reservatórios, bem como a um sistema real de reservatórios do rio Mississipi. Os resultados apresentados no trabalho, envolvendo 
deposição e erosão no reservatório, mostram a eficiência do sistema na liberação de suas vazões, para algumas equações empíricas de transporte de sedimentos.

Dargahi (2004) aplicou simulação numérica tridimensional, que utiliza o modelo de turbulência RNG (Renormalização de Grupo) $k$ - $\varepsilon$, para estudar o Rio Klaralven na região sudoeste da Suécia. Os objetivos foram analisar a natureza do escoamento na bifurcação do rio e investigar os padrões de transporte de sedimento (erosão-deposição) em período de curto prazo. Dados de velocidade para a caracterização do escoamento real e validação do modelo numérico foram obtidos através de medições de campo através do equipamento Acoustic Doppler Current Profiler (ADCP), em onze seções transversais do rio. O transporte de sedimento foi calculado pelo modelo 3D com a resolução da equação da continuidade de sedimentos. Campanhas batiméricas foram realizadas em maio de 1997 e março de 2003 ao longo de 70 seções transversais. Para a simulação numérica da hidrodinâmica e transporte de sedimento, utilizou-se o programa FLUENT. Os resultados de erosão e deposição apresentados pela simulação mostraram uma boa concordância com os dados de campo, segundo o autor, apesar de não serem considerados conclusivos devido à pequena taxa de assoreamento observada no período de análise. O modelo numérico sugeriu ainda a formação de um grande banco de areia à montante da bifurcação. Relata o autor que, apesar deste banco ser verificado na batimetria de 2003, sua dimensão é divergente do resultado apresentado pela simulação numérica. Atribui como fonte de erros principais do modelo o emprego de equações semi-empíricas de transporte de sedimentos e utilização do diâmetro médios dos grãos e profundidade média. A substituição do modelo de transporte de sedimento semiempírico (Ackers-White, 1973 por Rijn, 1990) apresentou resultados variando na ordem de 15\%. Dentre as várias conclusões do trabalho, afirma que a resposta do transporte de sedimento de curto prazo de um rio, para altas vazões, pode ser estudado pela resolução da equação da continuidade de transporte de sedimento bidimensional em combinação com um 
modelo de escoamento; e que o padrão do transporte de sedimentos nas bifurcações de rios é caracterizado por crescimento de bancos de areia.

Jin e Ji (2004) calibraram o modelo LOEM 3D, com medições de campo em período seco e chuvoso, para modelarem o transporte de sedimentos e o impacto de ondas de vento no Lago Okeechobee, localizado no sul da Flórida. A concentração de sedimentos suspensos medida e simulada foi comparada em seis estações distribuídas no interior do lago. Os autores comentam que as discrepâncias verificadas entre os dados observados e simulados de concentração (erro relativo médio de até 40,12\%) têm, entre outras causas, a variação da profundidade do lago $(3,6 \mathrm{~m} \leq \mathrm{h} \leq 5 \mathrm{~m})$ que sofre influência de correntes de vento no transporte de sedimentos e no processo de ressuspensão para profundidades mínimas, e da estratificação térmica para profundidades máximas. O LOEM é um software de domínio público e também foi aplicado em estudos do Blackstone River, Massachusetts (Ji et al., 2002) e Morro Bay, California (Ji ET al., 2000, 2001).

O trabalho de Carroll et al. (2004) teve como objetivo modelar processos de erosãodeposição de sedimentos durante eventos extremos de cheia no Rio Carson, no oeste central de Nevada. Este rio, segundo a United States Environmental Protection Agency (US EPA), é um dos sistemas fluviais na América do Norte mais contaminado por mercúrio. O modelo aplicado na simulação hidrodinâmica foi o RIVMOD unidimensional (US EPA), que resolve as equações diferenciais de continuidade e momento pela rotina de Newton-Raphson gerando, como dados de saída, altura d'água e velocidade. O programa WASP5 (US EPA), empregado para simular o transporte de sedimentos, considerou sedimentos resultantes do washload $(\mathrm{d}<$ 0,063 mm), os suspensos no curso do rio e ainda os bedload. A calibração do modelo ocorreu para medidas de concentração de sedimentos. Segundo os autores, existe uma boa concordância entre a erosão medida e predita. No processo de deposição, para os sedimentos com d > 0,063 mm a aproximação é razoável, sendo que o mesmo não é verificado para 
partículas menores, onde a considerável divergência ocorreu em 95\% dos intervalos medidos no rio.

Stoschek e Zimmermann (2006) modelaram o transporte de sedimentos no estuário do Rio Weser, no noroeste da Alemanha, considerando o efeito da maré e a salinidade no processo deposicional no estuário e no porto de Bremerhaven. O assoreamento na região portuária demanda manutenções contínuas por dragagens para garantia da navegação, tendo uma taxa de elevação do fundo de $5 \mathrm{~m}$ por ano em média. A simulação numérica utilizou dados de campo de topogafria e batimetria (sonar), vazão e velocidade (ADCP), além de medições de maré e salinidade, os quais atuaram na calibração e verificação da acuracidade do modelo. Para simular a hidrodinâmica no estuário, incluindo o efeito da maré, variações de densidade e transporte de sedimentos, foi utilizado o sistema de programas denominado MIKE3 do Danish Hydraulic Institute (DHI). Este programa usa algorítimos de diferenças finitas para a resolução das equações de Navier-Stokes em três dimensões. A boa concordância obtida entre os resultados medidos e simulados permitiram aos autores analisar cenários de vazão, gradiente de salinidade, maré no estuário e geometria portuária, destacando o grau de influência destes parâmetros no assoreamento.

Kwnow, Maa e Lee (2007), de forma semelhante ao trabalho anteriormente citado, aplicaram simulação numérica para o cálculo da Máxima Turbidez no Estuário (ETM) do Rio York, Virgínia - USA. O trecho modelado tem uma extensão de $120 \mathrm{Km}$ que foram divididos em 25 estações para medidas de salinidade e sólidos totais suspensos, além da maré à jusante, servindo para calibração e comparação com os resultados da simulação numérica. A taxa de erosão na simulação foi considerada constante e existente somente nas fases de maré alta. É comentado no trabalho que uma das maiores dificuldades na simulação de transporte de sedimentos coesivos e, como consequência, na formação da ETM, é ter um simples e seguro processo de erosão. Foi utilizado para a simulação o programa HEM-3D. Os resultados, 
apesar de distorções verificadas em alguns trechos monitorados, foram considerados satisfatórios pelos autores.

No trabalho de Ganju e Schoellhamer (2009), utilizando o modelo ROMS-3D para calibração do transporte de sedimento no estuário da Baía Suisun, Califórnia, os autores comentam que uma boa calibração dos modelos tipicamente utilizados para dados de nível de água, concentração de sedimentos em suspensão e vazão, não garantem uma boa concordância com dados reais de evolução geomorfológica. Os erros apresentados podem não ser tão óbvios devido à complexidade do problema. O modelo ROMS também é utilizado no trabalho de Kim e Lim (2009) para simular a deposição e dispersão de sedimentos devido às atividades de mineração na Baía Kyunggi, Korea.

Hu et al. (2009) modelaram a hidrodinâmica e transporte de sedimentos do Estuário Yangtze, China, utilizando o Delft3D-Flow. A simulação considerou inclusive ventos e ondas devido a tufões, cujos resultados foram comparados aos registrados por duas estações locais. Os autores comentam a dificuldade de se ter dados medidos de onda de vento, assim como de bedload, os quais, dentre outros parâmetros, interferem significativamente nos resultados da simulação. Observam também a necessidade de se considerar a estratificação de sedimentos para se ter maior acurácia do modelo numérico. Nos últimos anos, têm-se observado um maior enfoque na modelagem da dinâmica de sedimentos em estuários.

O trabalho de Kiat et al. (2008) teve como objetivo estudar mudanças na seção transversal e do nível de água do Rio Kulim, Malásia, provocada pelo intenso carreamento de sedimentos da bacia hidrográfica. O modelo numérico FLUVIAL-12 foi utilizado para a simulação hidrodinâmica e de transporte de sedimentos. O trabalho testou sete equações semiempíricas de sedimento, com a equação de Engelund-Hansen mostrando a melhor concordância. Medidas de campo, para calibração e validação do modelo numérico (vazão, carga de sedimentos em suspensão e de fundo, nível da água, elevação do fundo) foram 
obtidas durante outubro de 2004 a janeiro de 2007 ao longo de 120 seções transversais selecionadas, cobrindo uma extensão aproximada de $14,5 \mathrm{Km}$. Segundo os autores, boas concordâncias foram obtidas para nível de água e perfil de fundo do rio, entre os dados medidos e predictos pela simulação, o que permitiu a análise futura do problema. O Rio Kulim é caracterizado por altas vazões e sedimentos com diâmetro médio vaiando entre $0,75 \mathrm{~mm}$ e $1,5 \mathrm{~mm}$.

Chao et al. (2008) aplicaram simulação numérica 3D para o transporte de sedimentos coesivos no Lago Deep Hollow, Mississipi. Este lago possui extensão aproximada de $1 \mathrm{Km}$ por $100 \mathrm{~m}$ de largura, com profundidades entre $0,5 \mathrm{~m}$ e 2,6 m, situado em uma bacia hidrográfica predominantemente agrícola com área de $2 \mathrm{Km}^{2}$. O CCHE3D, modelo numérico utilizado, pode ser empregado para simular escoamentos turbulentos transientes com contornos irregulares e superfície livre, envolvendo equação tridimensional de transporte de massa para a simulação do sedimento, considerando ainda o efeito do vento. Os dados de campo foram obtidos para a calibração do modelo entre outubro e dezembro de 1999 e os dados de validação foram levantados entre agosto e outubro de 2000. Os autores relatam que apesar de não ter havido descarga no interior do lago no período da calibração, a concentração de sedimentos variou de $20 \mathrm{mg} / \mathrm{L}$ para $90 \mathrm{mg} / \mathrm{L}$ sendo a variação atribuída às ondas de vento. A validação do modelo foi conseguida através da comparação entre medições de concentração de sedimentos em três estações de monitoramento e valores obtidos pelo modelo numérico. Os maiores erros foram verificados para a desconsideração das ondas de vento na simulação $(\mathrm{Er}=38 \%)$.

Apesar do grande avanço nas últimas décadas da dinâmica dos fluidos computacional aplicada ao estudo do transporte de sedimentos em rios e reservatórios, com várias simulações em caráter tridimensional, muitas são as dificuldades ainda encontradas para modelar numericamente o fenômeno físico real. A indisponibilidade de dados de campo para 
calibragem e validação, os extensivos tempos computacionais para ajuste e análise de sensibilidade destes dados e ainda as limitações dos modelos para contemplar determinados tipos de dados, ou ainda considerá-los de forma adequada, tornam o processo de simulação numérica árduo para resultados que nem sempre representam acuracidade. No que tange aos modelos numéricos, a revisão de suas capacidades e performance tem sido discutidas por National Research Council (1983); American Society of Civil Engineers Task Committee on Hydraulics, Bank Mechanics, and Modeling of River Width Adjustment (ASCE, 1998); e Federal Interagency Stream Restoration Working Group (FISRWG, 2001). Além disso, aplicações são descritas em Ghani et al. (2003) e Chang (2006a). A seleção do modelo certo, para um determinado problema, requer conhecimento das capacidades e características dos modelos disponíveis (Kiat et al., 2008).

\subsubsection{A Situação no Brasil.}

Quando comparado a outros países, cujos recursos hídricos não têm uma dimensão tão expressiva como a nossa, o Brasil tem uma realidade caracterizada por raras pesquisas envolvendo aplicação de simulação numérica à hidráulica fluvial. Se restringirmos a análise ao estudo de morfologia de reservatórios, no qual leva-se em conta a dinâmica do processo de transporte de sedimentos, o número de trabalhos nacionais é ainda menor (Souza, 2006). Em se tratando de simulações numéricas que tem como base a solução das equações hidrodinâmicas e de transporte de sedimentos em caráter 2D (bidimensional) e 3D (tridimensional), seja para rios ou reservatórios, apenas um trabalho foi encontrado na literatura específica pesquisada. Os trabalhos de modelagem numérica aplicada ao transporte de sedimentos e assoreamento de rios e reservatórios brasileiros (2D e 3D) encontram-se em estágio inicial, com predomínio de pesquisas que propõem a calibração e validação de 
modelos concebidos em outros países, como subsídio para um gerenciamento fiel da realidade do sistema.

Em 1987, no Departamento de Hidráulica e Saneamento da Escola de Engenharia de São Carlos - Universidade de São Paulo (SHS-EESC-USP), Alvim (1987) apresentou um modelo matemático para estudo do processo de assoreamento de reservatórios, utilizando equacionamento unidimensional para o transporte do fluido.

Cogollo e Villela (1988) aplicaram o modelo matemático de escoamento unidimensional para multi-canais, desenvolvido por Lopes (1978), na estimativa do assoreamento do Reservatório de Urra II no Rio Sinu, Colômbia. Os resultados mostraram uma deposição na entrada do reservatório, representando o delta, e foram considerados satisfatórios.

Collischonn e Merten (2000) apresentaram o modelo computacional HIDROSED e sua aplicação na análise do transporte de sedimentos no rio Taquari, no Pantanal Matogrossense. O módulo hidrodinâmico do modelo é unidimensional e semelhante àquele encontrado nos programas DAMBRK (FREAD, 1991) e FLDWAV (FREAD, 1993). O módulo de transporte de sedimentos foi adaptado do programa FLUVIAL-12 (CHANG, 1993).

Alamy Filho et al. (2002) estudaram o caso do reservatório Salto Grande, localizado no rio Atibaia, em Americana-SP, através de um programa computacional 1D que utiliza código Visual Basic aplicado aos objetos do EXCEL, desenvolvido no SHS-EESC por Maia et al. (2002). A estimativa do volume assoreado pelo modelo depende basicamente das vazões mensais e descargas sólidas afluentes (série medida ou curva chave de sedimentos), eficiência de retenção (curvas de Brune) e peso específico aparente sólido. Os resultados da simulação foram comparados com o trabalho de Coelho (1993) que realizou amostragem direta da coluna de depósito pontualmente em 15 setores distintos do reservatório, onde o volume 
assoreado é representado pela espessura média de depósito multiplicada pela área do setor. Os autores recomendam o modelo para a aplicação em estudos preliminares para se ter uma idéia da ordem de grandeza do fenômeno.

Terabe et al. (2006) modelaram numericamente a hidrodinâmica e o processo de transporte e deposição de sedimentos no reservatório Fiú, parte integrante do aproveitamento hidrelétrico de Apucaraninha, no município de Londrina-PR. O reservatório tem área inundada de $2 \mathrm{Km}^{2}$, volume total de $15 \times 10^{6} \mathrm{~m}^{3}$ e vazão média de longo período de 12,1 $\mathrm{m}^{3} /$ mês. O conjunto de programas utilizados foi o RMA10/RMA11 (Resource Modelling Associates), desenvolvido por King (2003) com patrocínio do U.S. Army Corps of Engineers, utilizando aproximação bidimensional em planta. O transporte de sedimentos é obtido pela resolução da equação advecção-difusão, considerando sedimentos coesivos, não coesivos e processos de erosão e deposição do leito, sendo a variação da batimetria desacoplada do modelo hidrodinâmico. O período de análise do assoreamento consistiu do início da operação do reservatório (1949), com dados da topografia do mesmo, e o ano de 2003, onde foram levantados dados (ADCP com GPS topográfico) de batimetria, características do sedimento, concentração espacial de sólidos suspensos (utilizada na calibração do assoreamento), vazão afluente e velocidade em 11 seções transversais. A estimativa do assoreamento foi feita com base na freqüência de ocorrência de vazões dentro de um registro de 16,5 anos de dados (jun/87 a out/03). A calibração hidrodinâmica, com valores modelados não próximos dos medidos, é justificada e atribuída pelos autores às baixas velocidades no reservatório (erro significativo do ADCP), incerteza na posição de medição de campo (erro do GPS) e ainda a influência da atuação variável do vento. Para o cálculo da evolução morfológica (1949 a 2003), a somatória dos depósitos de sedimentos foi assumida como sendo independente da sequência temporal em que vazões e níveis de água ocorreram. Os autores concluíram, através de uma análise qualitativa dos dados de campo (1949 e 2003), que o modelo é capaz de 
simular o assoreamento. Contudo, uma análise quantitativa do assoreamento, devido à divergência de material depositado entre a planta batimétrica e simulação numérica para o ano de 2003, não foi discutida pelos autores.

Maia (2006), a partir de dados de assoreamento obtidos do reservatório de Promissão, através de levantamento topobatimétrico, analisou a resposta da simulação feita pelo programa RESSASS, desenvolvido pela Overseas Development Unit da HR Wallingford. Este programa analisa o volume útil do reservatório (dados de topografia e batimetria) seção por seção em períodos distintos, a previsão de perda desse volume (taxa de sedimento afluente constante) baseado nas curvas de Brune, bem como os depósitos futuros de sedimentos com a aplicação da dinâmica dos fluidos computacional. A hidrodinâmica consiste da resolução de Saint Venant 1D, considerando regime permanente. O transporte de sedimentos utiliza a equação de Ackers \& White (1973) para areia $(\mathrm{d} \geq 0,063 \mathrm{~mm})$ e o método de Westrich e Jurashek $^{14}$, adaptado por Atkinson (1992), para sedimentos mais finos. O período da simulação numérica foi de 1975 (início da operação) a 2005 (campanha batimétrica). Os principais problemas do modelo que afetaram os resultados calculados são apresentados pela autora como sendo: divisão do reservatório para simulação em função do número limitado de seções de análise (300 seções); não envolve na simulação afluentes de $2^{\mathrm{a}}$ ordem; e por fim, necessidade de um modelo de otimização para a calibração dos dados referentes à localização dos sedimentos. Segundo a autora, a não utilização dos dados referentes à localização do sedimento no reservatório para a calibração do modelo, levou a resultados inesperados, como o aumento do volume útil do ano de 2005 para o ano de 2055.

Chaves et al. (2008) aplicaram o modelo HEC-RAS 4.0, desenvolvido por US Army corps of Engineers, na simulação hidrossedimentológica de trecho de jusante do rio Macaé, localizado no estado do Rio de Janeiro. A calibração do modelo hidráulico, considerando

\footnotetext{
${ }^{14}$ Westrich, B. ; Jurashek, M. (1985). Flow transport capacity for suspended sediment. Apresentado ao $21^{\text {st }}$ Congress IAHR, Melbourne, Australia, 1985.
} 
regime permanente, ocorreu para dados de níveis de água levantados durante a topobatimetria das seções transversais escolhidas (15 seções) e também para os níveis registrados em uma estação fluviométrica. O modelo sedimentológico foi calibrado para dados de descargas líquidas e sólidas levantados entre outubro de 2000 e janeiro de 2006. O sedimento preponderante na classificação granulomérica apresentou diâmetro superior a 0,25 mm (areia média a grossa), cujo diâmetro foi adotado para todas as seções. As condições de contorno foram vazões (montante) e altura de água (jusante), constantes em cada período, e uma curva chave de sedimentos linear (montante). Os resultados apresentam a variação do fundo médio longitudinal, obtido pelos valores interpolados entre as seções. Os autores comentam que os resultados numéricos obtidos da evolução morfológica expõem que o processo erosãodeposição deve ser analisado com base em aspectos teóricos, conhecimento sobre o sistema modelado e experiência obtida em outros sistemas de comportamentos similares.

Guennec, Belaud e Baume (2008) fizeram a modelagem unidimensional dos sedimentos finos em suspensão nos rios Solimões, Madeira e Amazonas, utilizando o modelo de transporte de sedimentos SEDI (Belaud, 2000) acoplado ao modelo hidrodinâmico SIC (Baume et al., 2005). A principal simplificação da simulação de transporte decorre da consideração de concentração de sedimentos suspensos constante, de um ano a outro, nos períodos hidrológicos equivalentes. Os resultados apresentados mostram uma aproximação satisfatória, segundo os autores.

\subsection{Breve Histórico de um Ciclo de Pesquisas em Transporte de Sedimentos.}

Na Escola de Engenharia de São Carlos (EESC-USP), pesquisas importantes têm sido implementadas para o estudo do transporte de sedimentos. Poderíamos relatar, por exemplo, parte dos muitos trabalhos do grupo de pesquisas do professor Frederico Fábio Mauad, que 
tem um papel importante principalmente nos trabalhos de levantamento e análise de dados de campo, com propostas de gerenciamento e otimização de sistemas, visando o uso múltiplo da água nos reservatórios; as nobres e necessárias pesquisas do grupo do professor Harry Edmar Schulz, principalmente para o entendimento das estruturas turbulentas no processo de transporte de sedimentos e comportamento dos padrões hidrodinâmicos, abrindo um importante caminho para a implementação de modelos que possam assumir um caráter universal; ou ainda do grupo de pesquisas do professor Rodrigo de Melo Porto no estudo dos fenômenos hidráulicos aplicados, com desenvolvimento e avaliação de modelos numéricos. Neste momento, porém, a revisão desse trabalho, último do ciclo de um grupo, se remete à origem das pesquisas em transporte de sedimentos na EESC-USP, mais especificamente ao marco inicial do grupo de pesquisas do professor Swami Marcondes Villela, para retratar uma síntese desta trajetória.

Após o início das atividades como professor na Escola de Engenharia de São Carlos (EESC-USP) em 1960, os anos de 1970/1971 representaram o começo das pesquisas que se realizariam pelo professor Swami em transporte de sedimentos, através do curso em morfologia de rios na Universidade de Iowa (EUA) ministrado pelo professor Kennedy. Até este período, para se ter uma idéia, publicações no assunto no país foram raríssimas, existindo mais trabalhos no campo da sedimentometria (CARVALHO, 1994). Destaca-se o trabalho publicado pelo professor Bandini em 1958 na EESC-USP, intitulado Hidráulica Fluvial, contendo fundamentos de morfologia dos cursos d'água, de transporte sólido e regularização dos álveos.

Villela e Mattos (1975), com a publicação do livro Hidrologia Aplicada, introduziram em um dos capítulos, os conceitos de hidráulica de canais erodíveis, transporte e sedimentação de sólidos. Também juntamente com Mattos, em 1985, publicou o trabalho $A$ Critical Analysis of Sediment Transport Measurement Method Used for a Brasilian River 
(Pakistan Binational Symposium on Mechanics of Alluvial Channels, Lahore Paquistão); Proceedings of the Symposium. Em sequência, podem ainda ser citados, entre outros:

- Villela e Ponce (1988), Mathematical Model for Reservoir Silting, Proceedings of the Porto Alegre Symposium of the International Association of Hydraulic Research;

- Villela e Teixeira (1988), Some Factors Affecting Erosion of Bed Channels Protected with Riprap, Proceedings of the Porto Alegre Symposium of the International Association of Hydraulic Research;

- PAIVA, J. B. D. ; VILLELA, S. M. (1989) . Avaliação dos Métodos de Cálculo da Descarga Sólida em Rios, Revista Brasileira de Engenharia, v. 7, n. 2-1;

- Paiva, J. B. D.; Paiva, E. M. C. D.; Villela, S. M. (1996). Balanço Sedimentométrico do Canal e Vida Útil dos Reservatórios do Sistema Adutor Principal do Projeto de Transposição das Águas do Rio São Francisco, Anais do II Encontro Nacional de Engenharia de Sedimentos -ABRH;

Já mais recentemente encontram-se os trabalhos de mestrado de Menescal (2003), consistindo da aplicação de um modelo matemático para avaliação da erosão a jusante do reservatório do Castanhão CE., e de Bramorski (2004), que estudou a qualidade de sedimentos dos compartimentos de entrada do reservatório de Barra Bonita SP.

No campo de simulações numéricas aplicada ao transporte de sedimentos e assoreamento de reservatórios, duas pesquisas de doutorado importantes do grupo, já citadas por este trabalho; a de Maia (2006), consistindo da simulação 1D da perda de volume do reservatório de Promissão SP, e o trabalho de Souza (2006), que simulou numericamente o assoreamento em uma "armadilha" de sedimentos em laboratório, com cálculo de volume e distribuição.

Esta pesquisa, ora apresentada, consiste da última deste ciclo, permeando entre os dois últimos trabalhos anteriormente citados. O estudo de caso do reservatório Represa Velha, 
Pirassununga SP, emprega o modelo escolhido e utilizado no trabalho de Souza (2006). Apesar de fechar o ciclo de pesquisas em transporte de sedimentos do professor Swami, acredita-se ser longo ainda o caminho das pesquisas nesta área, de forma a propor com segurança e confiabilidade, modelos que possam subsidiar o gerenciamento de rios e reservatórios. 


\section{MATERIAIS E MÉTODOS}

\subsection{Descrição da Área de Estudo.}

A área de estudo se localiza geograficamente em $21^{\circ} 55^{\prime} 35^{\prime}$ ' S e $47^{\circ} 22^{\prime} 00^{\prime}$ ' W, e $21^{\circ}$ 57' 30' S e 47 24' 00' ' W, a aproximadamente $575 \mathrm{~m}$ acima do nível do mar, no município de Pirassununga, estado de São Paulo, Brasil (FIGURA 14). Tem uma extensão aproximada de $4 \mathrm{Km}$ e área estimada em 862 há, sendo aproximadamente $40 \%$ desta de propriedade da União desde 1938 (SILVA et al., 1994).

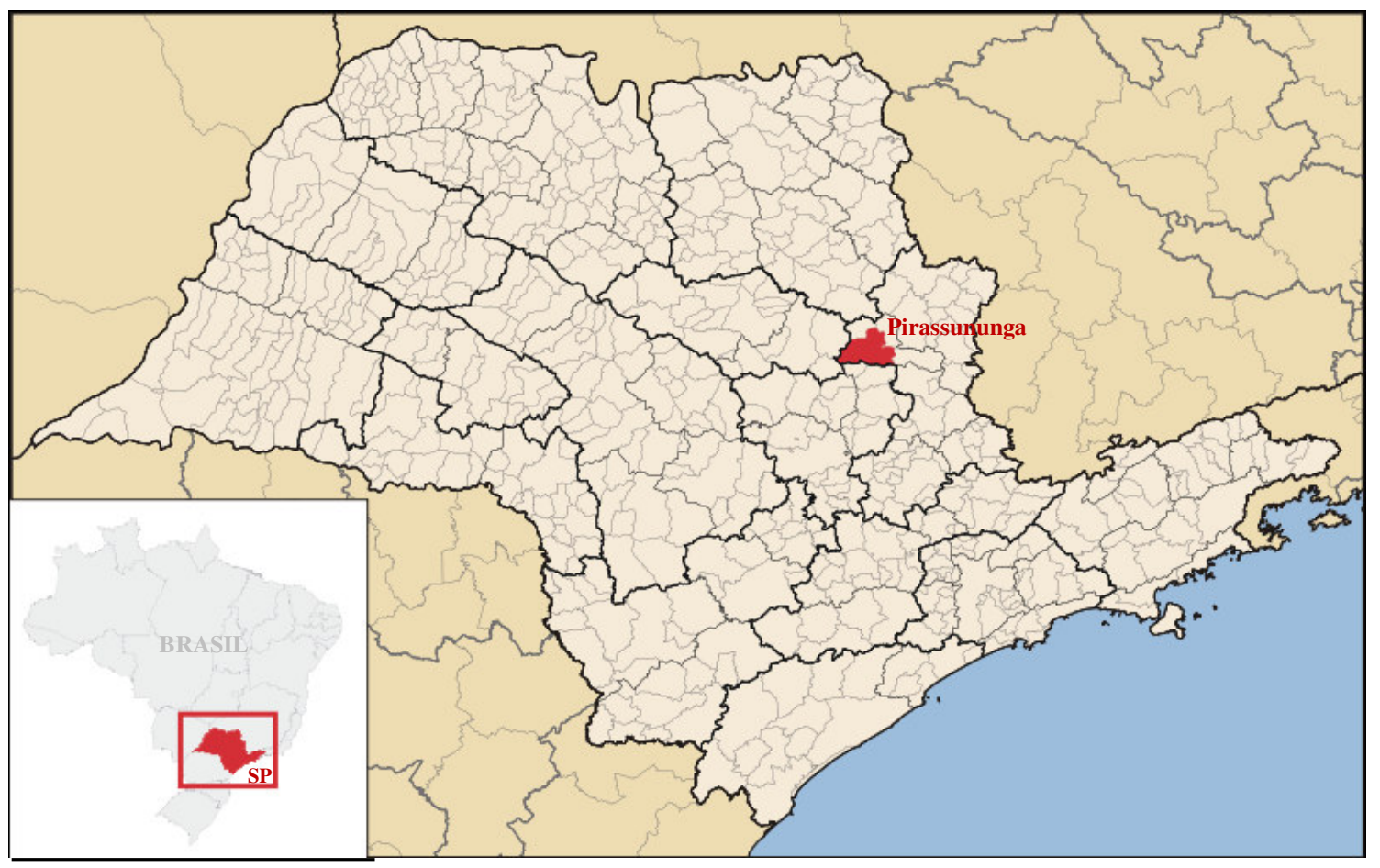

Figura 14. Localização Regional da área de estudo (WIKIPEDIA, 2009 ${ }^{15}$ )

Em termos de bacias hidrográficas, a área faz parte da microbacia do córrego da Barrinha, pertencente à Unidade de Gerenciamento de Recursos Hídricos (UGRH) do estado de São Paulo, do Mogi Guaçu (FIGURA 15), parte integrante da região hidrográfica mais

\footnotetext{
${ }^{15}$ WIKIPEDIA (2009). Site: pt.wikipedia.org/wiki/Pirassununga - Enciclopédia Livre - 18/02/2009 às 16:40hs
} 
desenvolvida do país que é a do rio Paraná. O córrego da Barrinha é afluente do rio Mogi Guaçu e também alimenta o Reservatório Represa Velha.

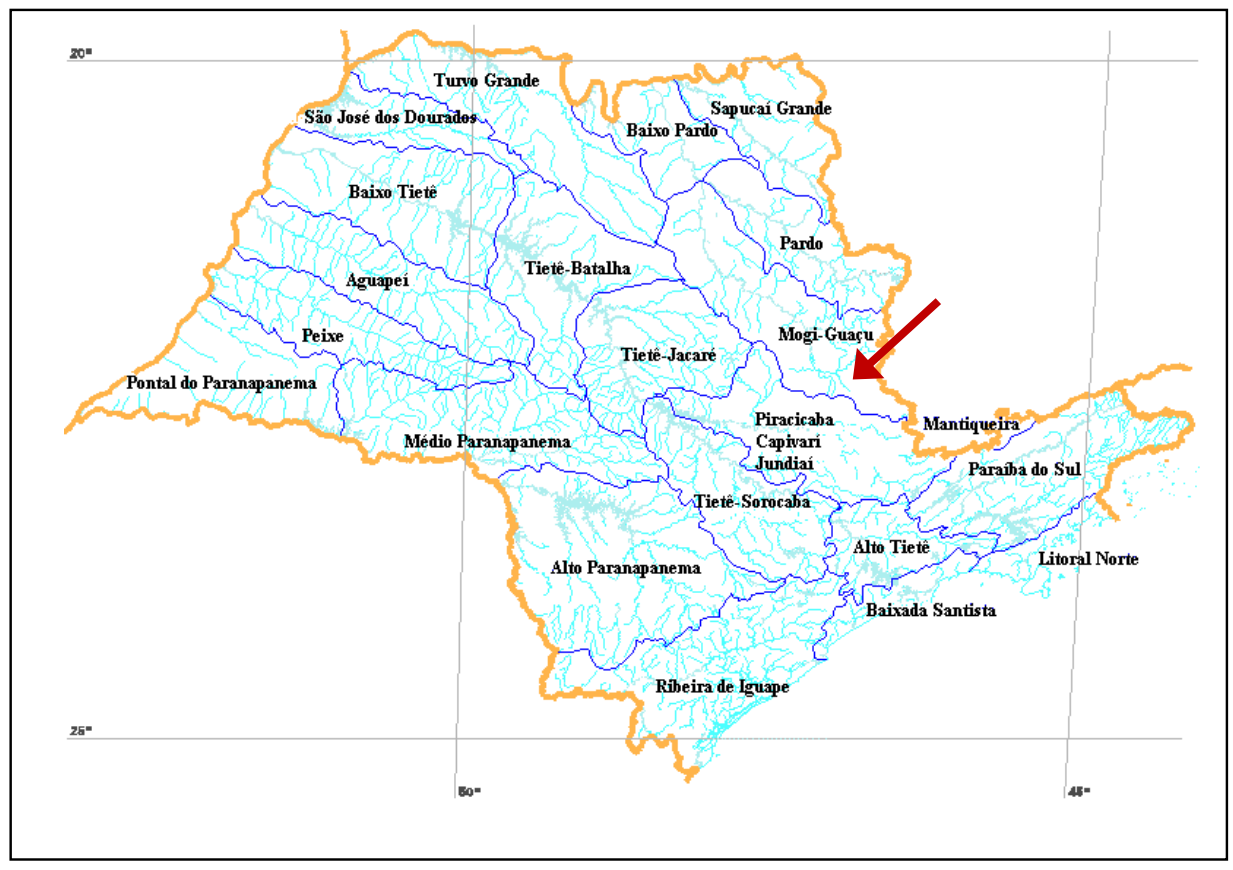

Figura 15. UGRH do Estado de São Paulo (BIOTA, 2004)

A microbacia tem um coeficiente de escoamento superficial médio ("runoff") igual a 0,40, obtido em função do tipo de solo, cobertura vegetal e declividade (BUFON, 2006). A intensidade média máxima de chuva é da ordem de $72 \mathrm{~mm} / \mathrm{h}$ (KLEEREKOPER, 1944). Uma característica marcante da área diz respeito à economia, com perfil predominantemente rural. A área se divide em pequenas propriedades rurais que desenvolvem diversas atividades agropecuárias, destacando a plantação de cítricos, cana-de-açúcar, forrageiras de inverno, criação de bovinos, atividades de mineração (extração de areia), entre outras.

Com relação às características climáticas da região de Pirassununga, tem-se uma definição de clima subtropical de altitude com inverno seco e chuvas no verão. A temperatura dos meses mais quentes (janeiro e fevereiro) é superior a $22^{\circ} \mathrm{C}$ e a do mês mais frio (julho), inferior a $18^{\circ} \mathrm{C}$ (BUFON, 2006). O total médio de chuva do mês mais seco não ultrapassa 30 mm (LOMBARDI NETO; CAMARGO, 1992). A pluviosidade anual é de 1.410,99 mm, 
média calculada para os últimos dez anos (FIGURA 16), segundo dados fornecidos pelo $\operatorname{DMET}\left(2005^{16}\right)$.

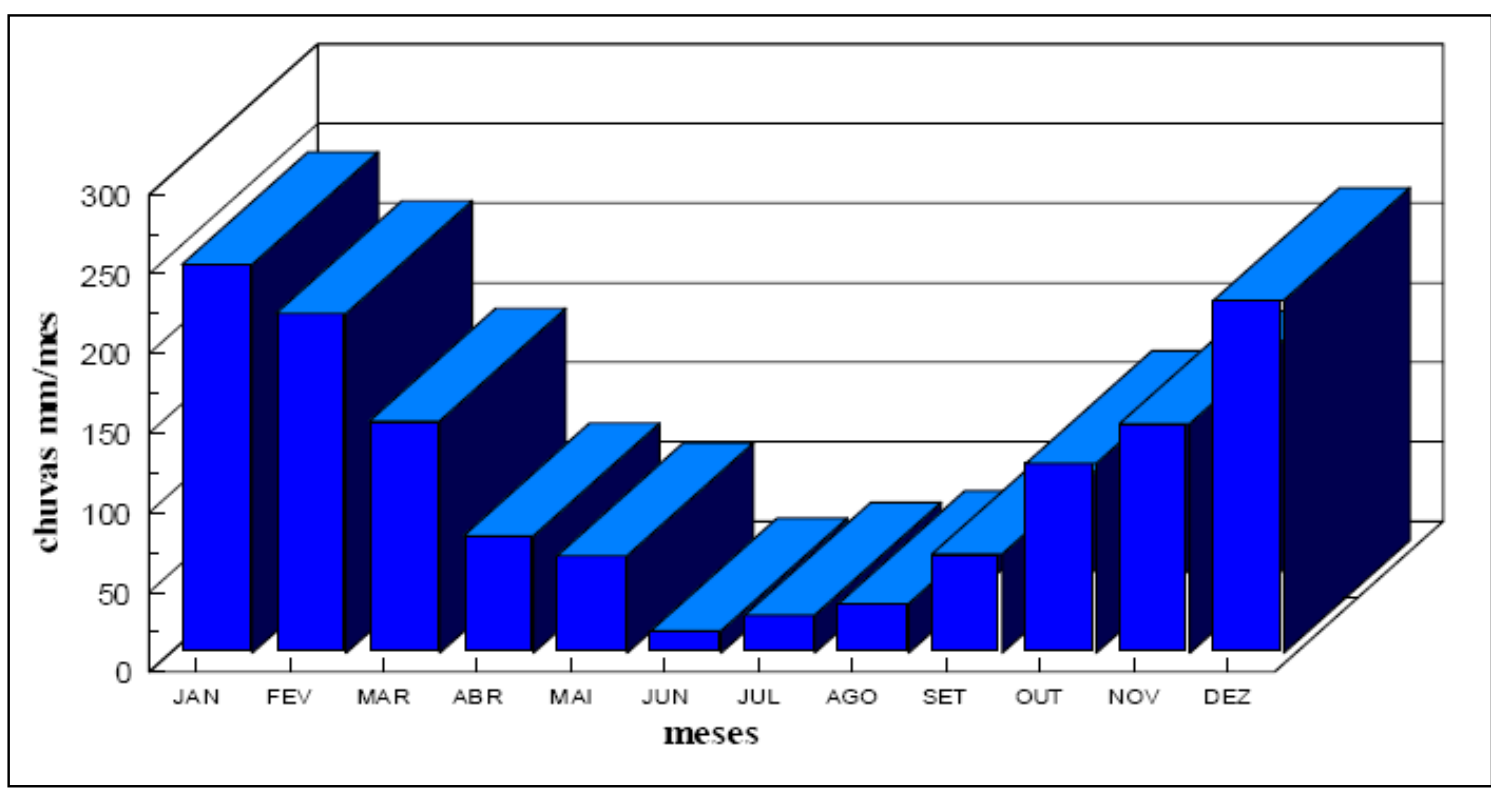

Figura 16. Média anual pluviométrica, relativo a 10 anos de série de dados (DMET, 2005 ${ }^{16}$ )

No que diz respeito à ocupação e utilização do solo, a atividade antrópica que tem maior influência sobre a mata ciliar do córrego da Barrinha diz respeito às culturas temporárias (18\%), onde ocorrem rotações de cultura como soja, milho e algodão. Quando somadas as culturas de laranja e cana-de-açúcar, tem-se um valor de 46,5\% do total da área da microbacia. Apesar de a mineração ter um valor representativo menor que $1 \%$, o poder de degradação provocado pela extração de areia na área é muito grande (SILVA et al., 1994). Estes fatores têm acentuado o transporte de sedimentos e poluentes para o leito do córrego, assoreando-o e também o reservatório Represa Velha conforme relata Bufon (1999). Na Figura 17 é apresentada a distribuição ocupacional e característica de exploração do solo da microbacia do córrego da Barrinha. Nota-se um percentual expressivo das culturas na área de estudo.

\footnotetext{
${ }^{16}$ DMET (2005). Dados obtidos pessoalmente por BUFON - Divisão de Meteorologia Aeronáutica da Academia da Força Aérea (AFA) - Pirassunuga/SP
} 


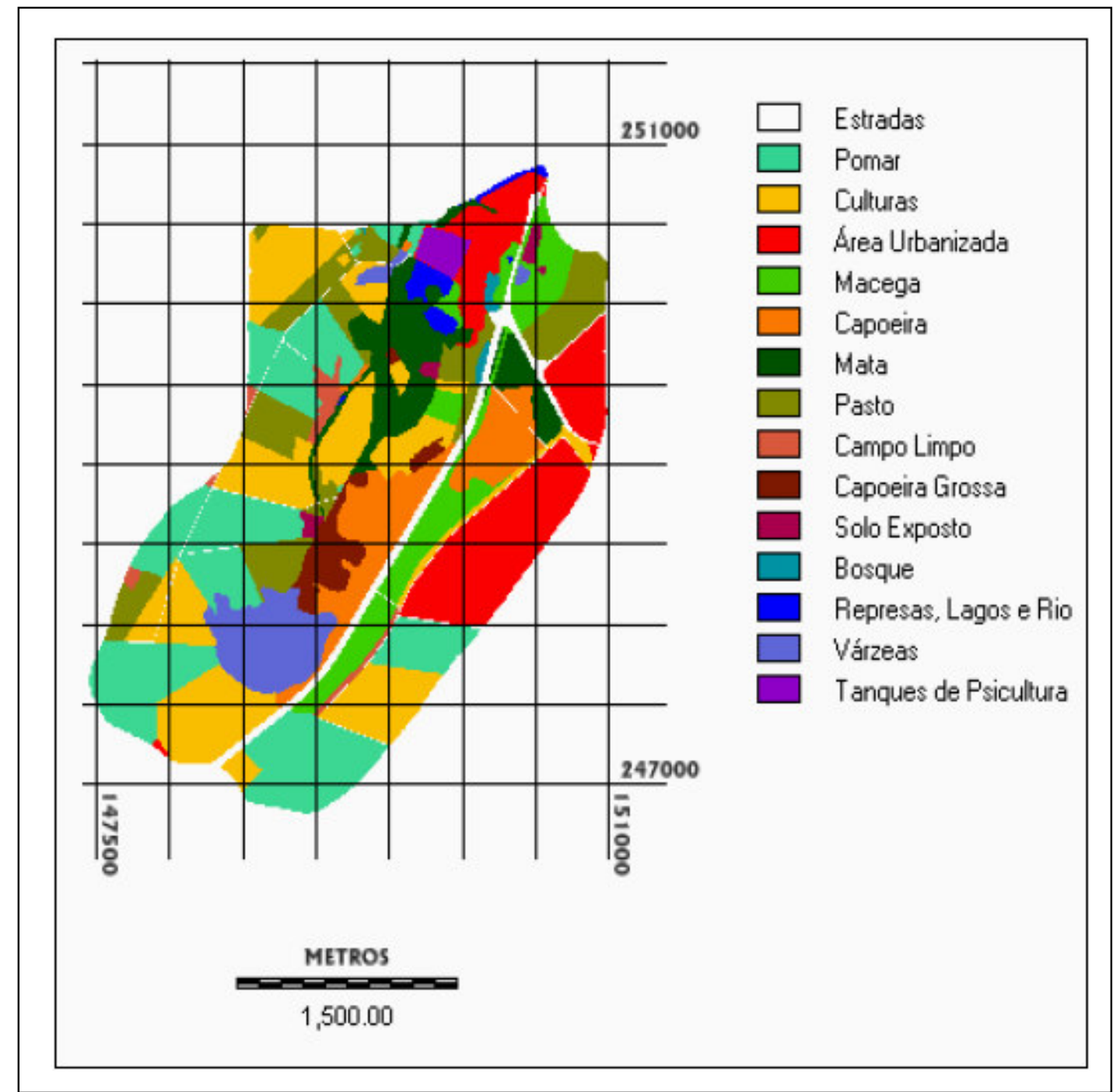

Figura 17. Mapa de uso e ocupação do solo da microbacia do córrego Barrinha (BUFON, 2006)

A localização da área lhe confere uma morfologia caracterizada principalmente por relevo suave com baixa amplitude altimétrica, registrando-se cotas não superiores a $850 \mathrm{~m} \mathrm{e}$ não inferiores a $500 \mathrm{~m}$. No município de Pirassununga, o assoalho geológico é representado por sedimentos mal consolidados de idade cenozóica, por litotipos do grupo São Bento (BUFON, 2006). Na área da microbacia, ocorre predomínio de terra roxa estruturada na extensão leste (FIGURA 18) e, interposta a este domínio, constata-se a ocorrência de latossolos oriundos do intemperismo sobre sedimentos predominantemente arenosos a areno 
argilosos da formação Pirassununga (FIGURA 19), de idade Cenozóica, abrangendo cerca de 80\% da área (GALIANO, 2001).

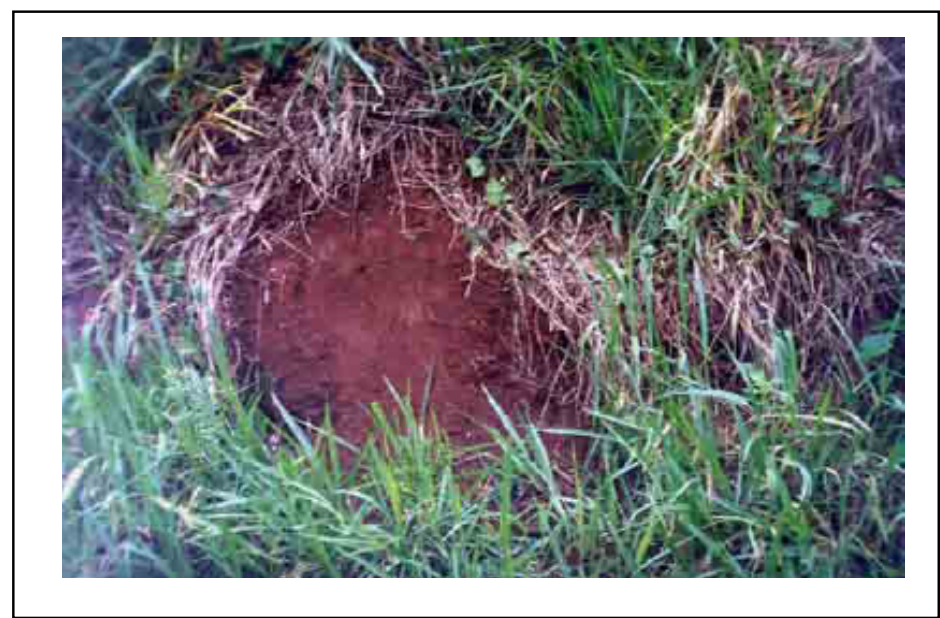

Figura 18. Terra roxa estruturada (BUFON, 2006)

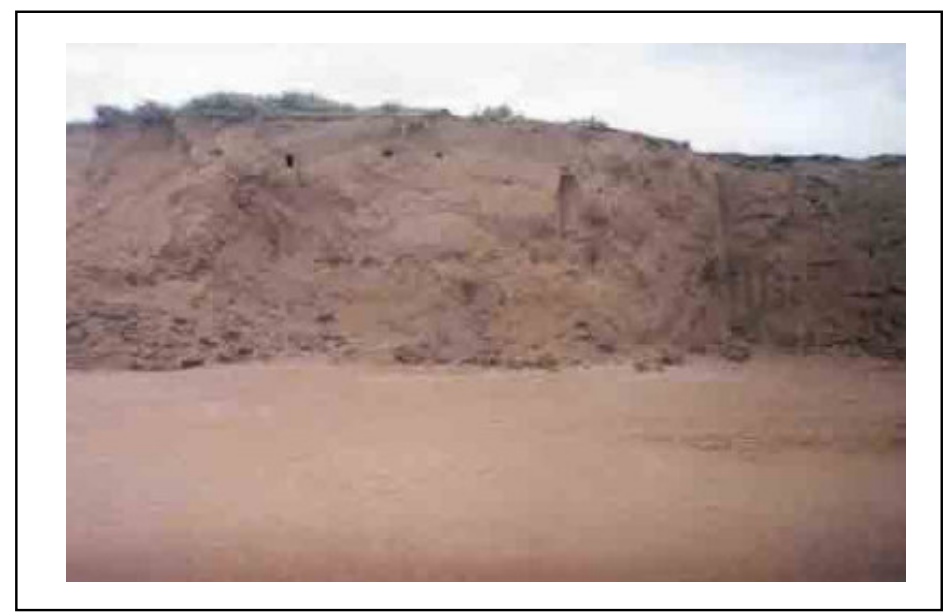

Figura 19. Solo arenoso - área de mineração (BUFON, 2006)

A morfologia de superfície, que em toda a extensão da microbacia registra classes de declives nunca superiores a $20 \%$, quando associada ao manejo do solo, ainda que prevaleçam as culturas temporárias, respondem pelo predomínio da erosão laminar nas propriedades, e de sulcos, ravinas e voçorocas (FIGURA 20) junto ao terraço fluvial (BUFON, 2006). A perda de solo na microbacia, causada principalmente pelo manejo mal orientado, como carreadores sem curvas de nível e práticas agrícolas (FIGURA 21) em área de preservação permanente (APP), além de impactar negativamente na fertilidade, tem intensificado o assoreamento nos 
canais e no reservatório. Atualmente é verificado, no entorno do reservatório, que a propriedade de contenção erosiva da mata ciliar é rompida somente em pequenos trechos.

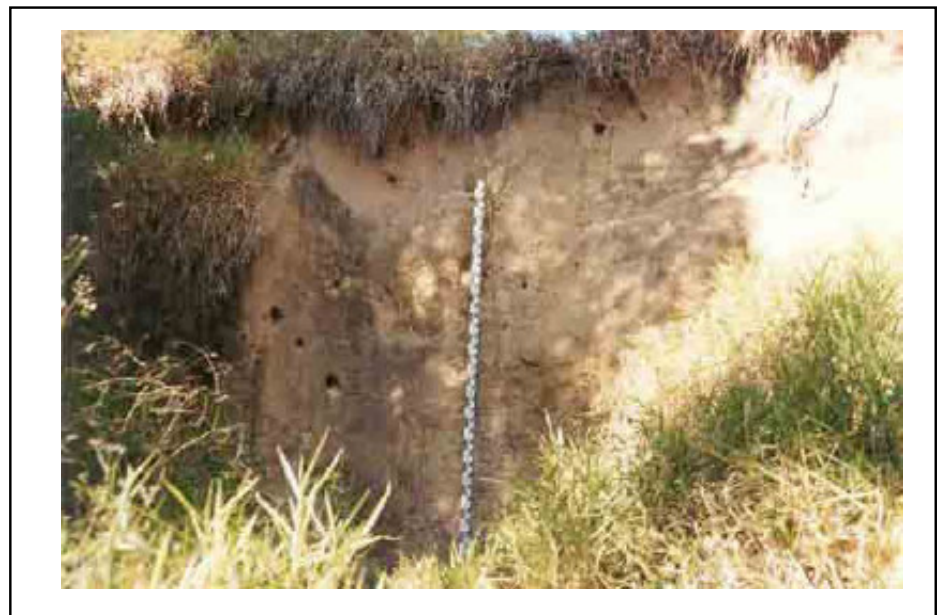

Figura 20. Vossoroca a montante do reservatório Represa Velha (BUFON, 2006)

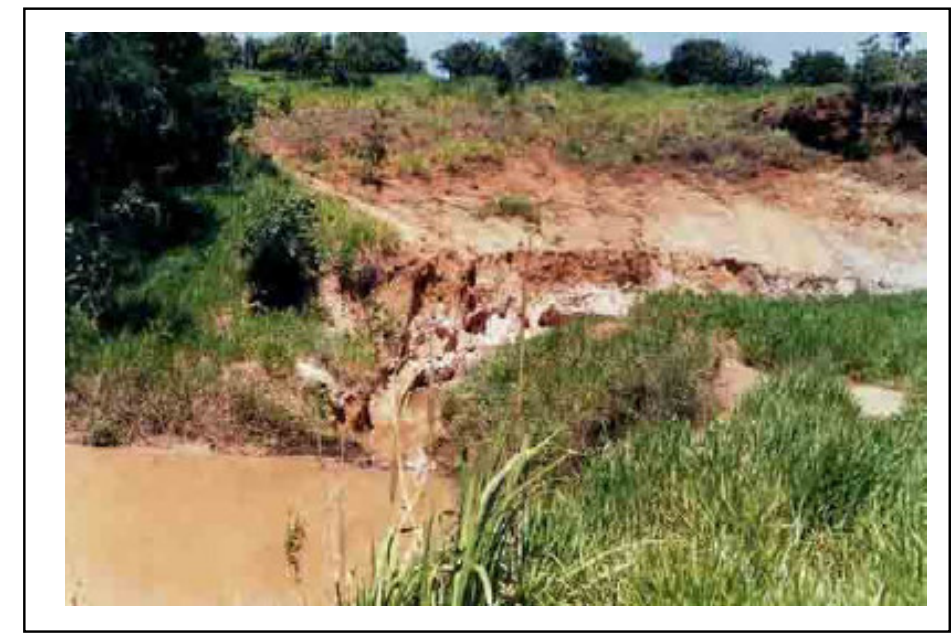

Figura 21. Plantio de cana e cítricos em APP, próximo ao reservatório (BUFON, 2006)

Inserido na abrangência da microbacia ora descrita encontra-se o principal objetivo desta pesquisa. O reservatório Represa Velha, pertence ao Centro de Pesquisa e Gestão de Recursos Pesqueiros Continentais - CEPTA/IBAMA. A área do CEPTA é de 273 ha e representa a antiga Estação Experimental de Biologia e Psicultura - EEBP. Está área corresponde ao repasse da União, feito no ano de 1979 (BUFON, 2006). 
O abastecimento principal do reservatório se dá através do córrego da Barrinha, que sofreu retificação e derivações para fins agrícolas. A extensão do córrego é de $3.217 \mathrm{~m}$, da nascente até desembocar no reservatório Represa Velha (BUFON, 2006). Este reservatório (KLEEREKOPER, 1944) foi construído no final do ano de 1939, através de uma barragem de terra de $300 \mathrm{~m}$ de comprimento por aproximadamente $5,5 \mathrm{~m}$ de altura, cuja operação foi iniciada em fevereiro de 1940. As profundidades variam entre 0,02 m e 4,79 m. Com uma superfície de aproximadamente 5 ha e um sistema de comporta de fundo que permite seu esvaziamento total, o reservatório Represa Velha (FIGURA 22) é atualmente o responsável pela garantia do suprimento de água dos tanques, viveiros e laboratórios do CEPTA, que a utilizam para manutenção da vida aquática local e em experimentos e pesquisas em piscicultura. O efluente gerado é lançado no rio Mogi Guaçu.

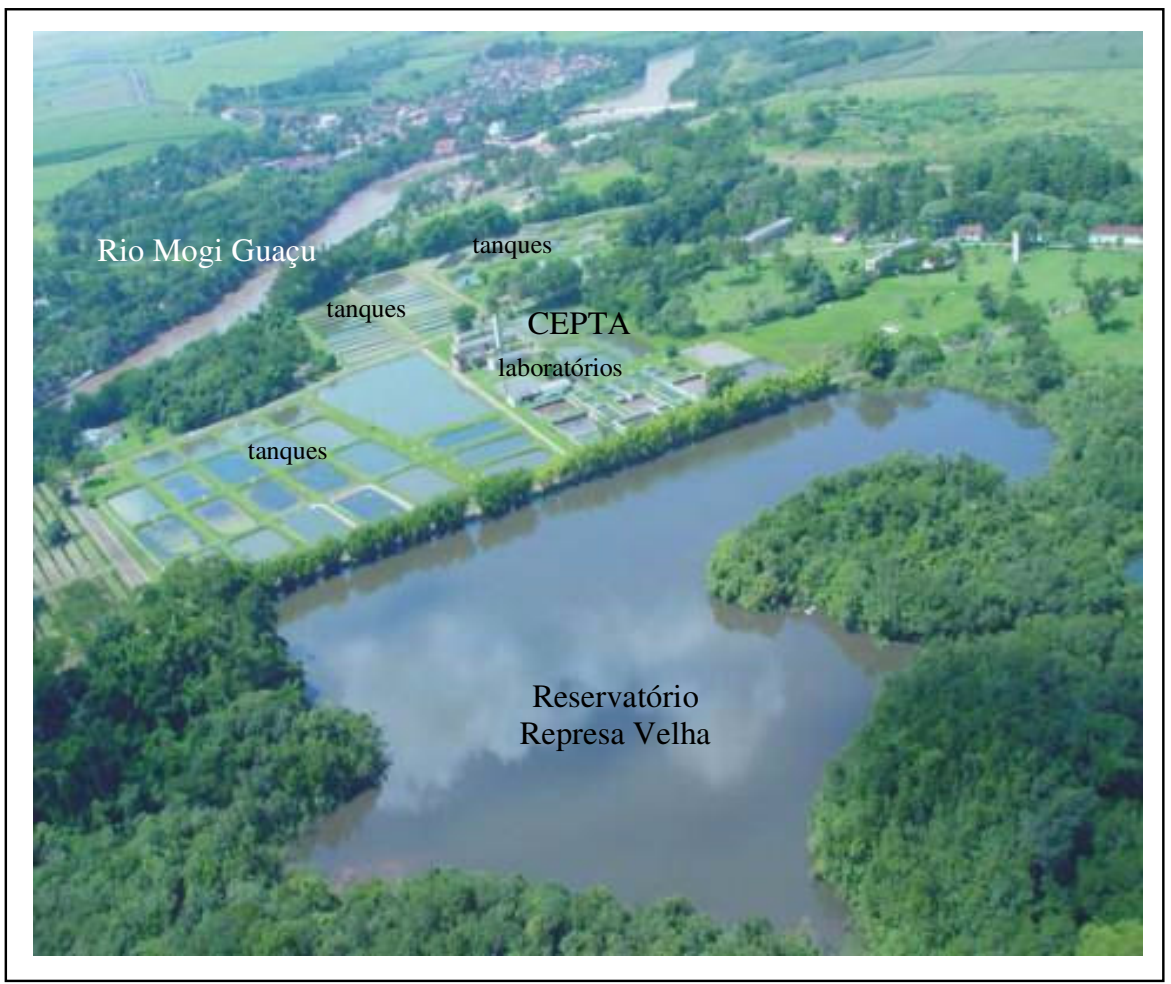

Figura 22. Vista aérea atual do Reservatório, do CEPTA e Rio Mogi Guaçu (CEPTA, 2009 ${ }^{17}$ )

\footnotetext{
${ }^{17}$ CEPTA (2009). Site: www.icmbio.gov.br/cepta - Ministério do Meio Ambiente - 18/02/2009 às 17:49hs
} 


\subsection{Dados de Campo.}

Os dados de campo utilizados nesta pesquisa foram obtidos através:

- do estudo realizado na dissertação de Bufon (2002), que implicou nas análises limnológicas e campanhas batimétricas no reservatório Represa Velha;

- da análise do assoreamento e sua relação com a vida útil do referido reservatório, com medições de vazão, ensaio para caracterização dos sedimentos e medições de sedimentos suspensos, extraídos da tese de Bufon (2006).

\subsubsection{Campanhas de batimetria.}

Para o acompanhamento espaço-temporal do processo de sedimentação no reservatório Represa Velha, foram realizadas 4 batimetrias (BUFON, 2002). A batimetria inicial em 22/08/1998 constitui o fundo original da represa para este estudo, sendo sua evolução acompanhada pelas batimetrias de 21/08/1999, 29/08/2000 e 17/08/2001. O levantamento topográfico, por método trigonométrico, a partir de uma referência de nível (RN) na área do CEPTA, forneceu as coordenadas que auxiliaram na determinação e amarração dos pontos batimétricos por irradiação. Tendo como base este procedimento e através de guincho hidrométrico em embarcação (CARVALHO, 1994 pg.104), procedeu-se a medição pontual de profundidade (389 pontos). Na Figura 23 é mostrada a locação dos pontos batimétricos na área do reservatório. A parte inferior da Figura constitui a barragem de terra. O espaçamento entre os pontos da malha é de $10 \mathrm{~m}$. 


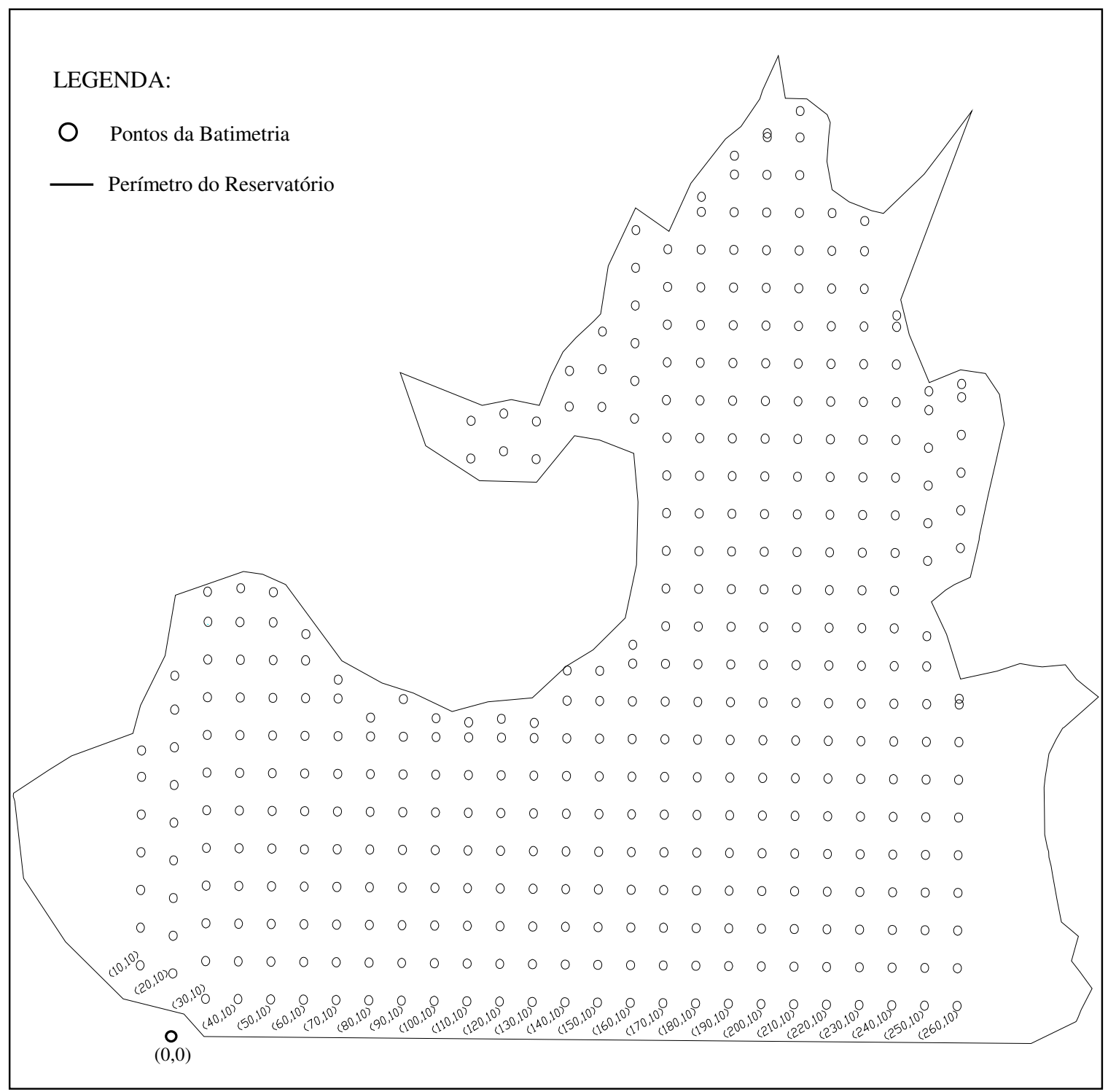

Figura 23. Locação dos pontos batimétricos no Reservatório (BUFON, 2002)

Este levantamento, mostrando as cotas do fundo $\mathrm{z}(\mathrm{m})$ e as correspondentes coordenadas de posição, é apresentado na Tabela 3. O nível de água (NA) no reservatório está na cota $10 \mathrm{~m}$. A referência de nível $(\mathrm{RN}=0,0 \mathrm{~m})$ para lançamento do fundo do reservatório, em cada batimetria, corresponde a uma plano horizontal passando abaixo deste fundo. Portanto, a determinação da profundidade h (m), para cada ponto batimétrico, consiste da diferença entre NA e z (m). Os pontos foram levantados da barragem para montante. 
TABELA 03 - Dados anuais das campanhas batimétricas em metros (BUFON, 2002).

\begin{tabular}{|c|c|c|c|c|c|c|c|c|c|c|c|}
\hline \multicolumn{2}{|c|}{ Coordenadas } & \multicolumn{4}{|c|}{$\begin{array}{l}\text { Cotas de Fundo }(\mathrm{m}) \\
\text { Período }\end{array}$} & \multicolumn{2}{|c|}{$\begin{array}{l}\text { Coordenadas } \\
\text { Levantadas }\end{array}$} & \multicolumn{4}{|c|}{$\begin{array}{r}\mathrm{RN}= \\
\mathrm{NA}= \\
\text { Cotas de Fundo }(\mathrm{m}) \\
\text { Período }\end{array}$} \\
\hline $\mathrm{X}$ & Y & 1998 & 1999 & 2000 & 2001 & $\mathrm{X}$ & $\mathrm{Y}$ & 1998 & 1999 & 2000 & 2001 \\
\hline 10,00 & 10,00 & 9,53 & 9,69 & 9,42 & 9,68 & 50,00 & 110,00 & 9,69 & 9,79 & 9,81 & 9,69 \\
\hline 10,00 & 20,00 & 9,51 & 9,57 & 9,42 & 9,30 & 50,00 & 118,00 & 10,00 & 10,00 & 10,00 & 10,00 \\
\hline 10,00 & 30,00 & 9,59 & 9,58 & 9,48 & 9,49 & 60,00 & 10,00 & 8,58 & 8,80 & 8,94 & 8,96 \\
\hline 10,00 & 40,00 & 9,28 & 9,47 & 9,41 & 9,55 & 60,00 & 20,00 & 8,87 & 9,01 & 8,80 & 8,86 \\
\hline 10,00 & 50,00 & 9,37 & 9,49 & 9,11 & 9,56 & 60,00 & 30,00 & 8,95 & 9,05 & 9,16 & 9,29 \\
\hline 10,00 & 60,00 & 9,34 & 9,46 & 9,58 & 9,66 & 60,00 & 40,00 & 8,93 & 9,03 & 9,02 & 9,12 \\
\hline 10,00 & 67,00 & 10,00 & 10,00 & 10,00 & 10,00 & 60,00 & 50,00 & 8,71 & 8,79 & 8,70 & 8,90 \\
\hline 20,00 & 10,00 & 9,52 & 9,61 & 9,62 & 9,85 & 60,00 & 60,00 & 8,69 & 8,68 & 8,40 & 8,83 \\
\hline 20,00 & 20,00 & 9,41 & 9,46 & 9,65 & 9,62 & 60,00 & 70,00 & 8,68 & 8,79 & 8,25 & 8,84 \\
\hline 20,00 & 30,00 & 9,49 & 9,39 & 9,35 & 9,31 & 60,00 & 80,00 & 8,68 & 8,67 & 8,74 & 9,16 \\
\hline 20,00 & 40,00 & 9,41 & 9,35 & 9,37 & 9,34 & 60,00 & 90,00 & 8,77 & 8,95 & 9,01 & 9,31 \\
\hline 20,00 & 50,00 & 9,37 & 9,43 & 9,33 & 9,41 & 60,00 & 100,00 & 9,49 & 9,58 & 9,67 & 9,86 \\
\hline 20,00 & 60,00 & 9,49 & 9,43 & 9,29 & 9,39 & 60,00 & 107,00 & 10,00 & 10,00 & 10,00 & 10,00 \\
\hline 20,00 & 70,00 & 9,21 & 9,61 & 9,34 & 9,49 & 70,00 & 10,00 & 8,25 & 8,37 & 8,76 & 8,71 \\
\hline 20,00 & 80,00 & 9,29 & 9,60 & 9,48 & 9,63 & 70,00 & 20,00 & 8,53 & 8,61 & 9,01 & 8,74 \\
\hline 20,00 & 89,00 & 10,00 & 10,00 & 10,00 & 10,00 & 70,00 & 30,00 & 8,58 & 8,63 & 8,96 & 9,00 \\
\hline 30,00 & 10,00 & 9,43 & 9,51 & 9,26 & 9,53 & 70,00 & 40,00 & 8,53 & 8,59 & 8,77 & 8,92 \\
\hline 30,00 & 20,00 & 9,33 & 9,44 & 9,45 & 9,52 & 70,00 & 50,00 & 8,20 & 8,21 & 8,26 & 8,61 \\
\hline 30,00 & 30,00 & 9,39 & 9,43 & 9,34 & 9,39 & 70,00 & 60,00 & 8,05 & 8,17 & 7,99 & 8,39 \\
\hline 30,00 & 40,00 & 9,33 & 9,36 & 9,31 & 9,33 & 70,00 & 70,00 & 8,13 & 8,18 & 8,51 & 8,49 \\
\hline 30,00 & 50,00 & 9,21 & 9,29 & 9,15 & 9,30 & 70,00 & 80,00 & 8,65 & 8,76 & 9,07 & 9,12 \\
\hline 30,00 & 60,00 & 9,21 & 9,27 & 9,08 & 9,35 & 70,00 & 90,00 & 9,10 & 9,26 & 9,76 & 9,76 \\
\hline 30,00 & 70,00 & 9,23 & 9,37 & 9,08 & 9,36 & 70,00 & 95,00 & 10,00 & 10,00 & 10,00 & 10,00 \\
\hline 30,00 & 80,00 & 9,23 & 9,29 & 9,08 & 9,32 & 80,00 & 10,00 & 8,08 & 8,13 & 8,57 & 8,52 \\
\hline 30,00 & 90,00 & 9,25 & 9,36 & 9,41 & 9,46 & 80,00 & 20,00 & 8,09 & 7,67 & 8,65 & 8,73 \\
\hline 30,00 & 100,00 & 9,65 & 9,68 & 9,82 & 9,84 & 80,00 & 30,00 & 8,03 & 7,41 & 8,62 & 8,70 \\
\hline 30,00 & 108,00 & 10,00 & 10,00 & 10,00 & 10,00 & 80,00 & 40,00 & 8,03 & 7,47 & 8,39 & 8,56 \\
\hline 40,00 & 10,00 & 9,03 & 9,18 & 9,56 & 9,39 & 80,00 & 50,00 & 8,01 & 7,51 & 7,84 & 8,01 \\
\hline 40,00 & 20,00 & 9,18 & 9,19 & 9,26 & 9,35 & 80,00 & 60,00 & 7,79 & 7,64 & 7,83 & 7,77 \\
\hline 40,00 & 30,00 & 9,21 & 9,19 & 9,21 & 9,32 & 80,00 & 70,00 & 8,67 & 8,81 & 8,78 & 8,16 \\
\hline 40,00 & 40,00 & 9,27 & 9,28 & 9,24 & 9,28 & 80,00 & 80,00 & 9,41 & 9,46 & 9,40 & 9,46 \\
\hline 40,00 & 50,00 & 9,14 & 9,11 & 8,99 & 9,15 & 80,00 & 85,00 & 10,00 & 10,00 & 10,00 & 10,00 \\
\hline 40,00 & 60,00 & 8,99 & 9,07 & 8,94 & 9,20 & 90,00 & 10,00 & 7,71 & 7,76 & 8,22 & 8,27 \\
\hline 40,00 & 70,00 & 9,03 & 9,18 & 8,93 & 9,21 & 90,00 & 20,00 & 7,37 & 7,36 & 8,13 & 8,33 \\
\hline 40,00 & 80,00 & 9,03 & 9,11 & 8,44 & 9,08 & 90,00 & 30,00 & 7,11 & 7,06 & 7,68 & 8,15 \\
\hline 40,00 & 90,00 & 9,17 & 9,17 & 8,95 & 9,15 & 90,00 & 40,00 & 7,11 & 7,09 & 7,44 & 7,96 \\
\hline 40,00 & 100,00 & 9,25 & 9,06 & 9,19 & 9,35 & 90,00 & 50,00 & 7,36 & 7,26 & 7,51 & 7,56 \\
\hline 40,00 & 110,00 & 9,71 & 9,57 & 9,89 & 9,56 & 90,00 & 60,00 & 7,58 & 8,39 & 7,89 & 7,62 \\
\hline 40,00 & 119,00 & 10,00 & 10,00 & 10,00 & 10,00 & 90,00 & 70,00 & 8,33 & 9,33 & 8,98 & 8,34 \\
\hline 50,00 & 10,00 & 8,79 & 8,87 & 9,27 & 9,39 & 90,00 & 80,00 & 9,17 & 9,84 & 9,77 & 9,24 \\
\hline 50,00 & 20,00 & 8,73 & 8,81 & 9,24 & 9,20 & 90,00 & 90,00 & 10,00 & 10,00 & 10,00 & 10,00 \\
\hline 50,00 & 30,00 & 9,25 & 9,31 & 9,26 & 9,22 & 100,00 & 10,00 & 7,58 & 7,54 & 8,11 & 8,00 \\
\hline 50,00 & 40,00 & 9,14 & 9,23 & 9,09 & 9,22 & 100,00 & 20,00 & 7,09 & 7,11 & 7,51 & 7,52 \\
\hline 50,00 & 50,00 & 8,93 & 9,11 & 8,85 & 9,04 & 100,00 & 30,00 & 6,76 & 6,76 & 7,19 & 7,26 \\
\hline 50,00 & 60,00 & 8,87 & 9,01 & 8,64 & 8,99 & 100,00 & 40,00 & 6,95 & 7,14 & 7,29 & 7,14 \\
\hline 50,00 & 70,00 & 8,95 & 9,07 & 8,67 & 8,93 & 100,00 & 50,00 & 7,09 & 7,51 & 8,13 & 7,38 \\
\hline 50,00 & 80,00 & 8,83 & 8,99 & 8,69 & 8,91 & 100,00 & 60,00 & 8,29 & 8,65 & 9,08 & 7,81 \\
\hline 50,00 & 90,00 & 8,51 & 9,11 & 8,91 & 8,89 & 100,00 & 70,00 & 9,08 & 9,30 & 9,49 & 8,87 \\
\hline 50,00 & 100,00 & 9,26 & 9,26 & 9,23 & 9,38 & 100,00 & 80,00 & 9,56 & 9,88 & 9,91 & 9,50 \\
\hline
\end{tabular}


continuação

\begin{tabular}{|c|c|c|c|c|c|c|c|c|c|c|c|}
\hline \multicolumn{2}{|c|}{$\begin{array}{l}\text { Coordenadas } \\
\text { Levantadas }\end{array}$} & \multicolumn{4}{|c|}{$\begin{array}{c}\text { Cotas de Fundo }(\mathrm{m}) \\
\text { Período }\end{array}$} & \multicolumn{2}{|c|}{$\begin{array}{l}\text { Coordenadas } \\
\text { Levantadas }\end{array}$} & \multicolumn{4}{|c|}{$\begin{array}{r}\mathrm{RN}= \\
\mathrm{NA}= \\
\text { Cotas de Fundo }(\mathrm{m}) \\
\text { Período }\end{array}$} \\
\hline$X$ & $\mathrm{Y}$ & 1998 & 1999 & 2000 & 2001 & $x$ & $\mathrm{Y}$ & 1998 & 1999 & 2000 & 2001 \\
\hline 100,00 & 85,00 & 10,00 & 10,00 & 10,00 & 10,00 & 150,00 & 40,00 & 6,65 & 6,94 & 6,67 & 6,70 \\
\hline 110,00 & 10,00 & 7,13 & 7,11 & 7,70 & 7,64 & 150,00 & 50,00 & 7,46 & 7,84 & 7,31 & 7,59 \\
\hline 110,00 & 20,00 & 7,09 & 7,08 & 6,99 & 7,16 & 150,00 & 60,00 & 7,89 & 8,23 & 8,01 & 8,06 \\
\hline 110,00 & 30,00 & 6,68 & 6,66 & 6,84 & 6,66 & 150,00 & 70,00 & 8,54 & 8,51 & 8,59 & 8,91 \\
\hline 110,00 & 40,00 & 7,08 & 6,73 & 7,13 & 6,82 & 150,00 & 80,00 & 8,95 & 9,06 & 9,13 & 9,32 \\
\hline 110,00 & 50,00 & 7,21 & 7,88 & 8,22 & 7,11 & 150,00 & 90,00 & 9,46 & 9,43 & 9,75 & 9,64 \\
\hline 110,00 & 60,00 & 8,08 & 8,55 & 8,87 & 8,26 & 150,00 & 98,00 & 10,00 & 10,00 & 10,00 & 10,00 \\
\hline 110,00 & 70,00 & 9,13 & 9,17 & 9,42 & 9,10 & 150,00 & 168,00 & 7,88 & 8,35 & 8,41 & 8,19 \\
\hline 110,00 & 80,00 & 9,54 & 9,76 & 9,88 & 9,51 & 150,00 & 178,00 & 9,54 & 9,05 & 9,79 & 9,49 \\
\hline 110,00 & 84,00 & 10,00 & 10,00 & 10,00 & 10,00 & 150,00 & 188,00 & 10,00 & 10,00 & 10,00 & 10,00 \\
\hline 110,00 & 154,00 & 9,33 & 9,64 & 9,01 & 9,16 & 160,00 & 10,00 & 5,78 & 5,68 & 5,96 & 6,01 \\
\hline 110,00 & 164,00 & 10,00 & 10,00 & 10,00 & 10,00 & 160,00 & 20,00 & 5,89 & 5,91 & 5,92 & 6,30 \\
\hline 120,00 & 10,00 & 6,96 & 7,06 & 7,42 & 7,35 & 160,00 & 30,00 & 6,08 & 6,36 & 7,06 & 7,04 \\
\hline 120,00 & 20,00 & 6,92 & 6,91 & 7,16 & 7,03 & 160,00 & 40,00 & 6,89 & 7,16 & 7,74 & 8,01 \\
\hline 120,00 & 30,00 & 6,82 & 6,56 & 6,73 & 6,63 & 160,00 & 50,00 & 7,67 & 7,89 & 8,56 & 8,38 \\
\hline 120,00 & 40,00 & 6,68 & 6,87 & 6,80 & 7,02 & 160,00 & 60,00 & 8,18 & 8,56 & 8,73 & 8,69 \\
\hline 120,00 & 50,00 & 7,69 & 7,42 & 8,09 & 7,63 & 160,00 & 70,00 & 8,37 & 8,69 & 8,81 & 8,83 \\
\hline 120,00 & 60,00 & 8,33 & 8,25 & 8,74 & 8,39 & 160,00 & 80,00 & 8,98 & 9,03 & 9,13 & 8,61 \\
\hline 120,00 & 70,00 & 9,03 & 8,96 & 9,19 & 8,96 & 160,00 & 90,00 & 9,29 & 9,15 & 9,45 & 8,60 \\
\hline 120,00 & 80,00 & 8,43 & 9,51 & 9,77 & 9,47 & 160,00 & 100,00 & 9,58 & 9,46 & 9,80 & 9,79 \\
\hline 120,00 & 85,00 & 10,00 & 10,00 & 10,00 & 10,00 & 160,00 & 105,00 & 10,00 & 10,00 & 10,00 & 10,00 \\
\hline 120,00 & 156,00 & 9,06 & 9,35 & 8,96 & 8,86 & 160,00 & 165,00 & 9,50 & 9,65 & 9,89 & 9,87 \\
\hline 120,00 & 166,00 & 10,00 & 10,00 & 10,00 & 10,00 & 160,00 & 175,00 & 9,31 & 9,16 & 9,55 & 9,36 \\
\hline 130,00 & 10,00 & 6,86 & 6,96 & 7,07 & 7,05 & 160,00 & 185,00 & 8,09 & 8,61 & 9,01 & 9,29 \\
\hline 130,00 & 20,00 & 6,75 & 6,75 & 7,02 & 7,03 & 160,00 & 195,00 & 8,18 & 7,69 & 7,78 & 8,53 \\
\hline 130,00 & 30,00 & 6,33 & 6,80 & 6,84 & 6,61 & 160,00 & 205,00 & 9,73 & 9,39 & 9,16 & 9,76 \\
\hline 130,00 & 40,00 & 6,85 & 6,57 & 6,77 & 6,60 & 160,00 & 215,00 & 10,00 & 10,00 & 10,00 & 10,00 \\
\hline 130,00 & 50,00 & 7,16 & 7,27 & 8,60 & 7,56 & 170,00 & 10,00 & 5,62 & 5,66 & 5,86 & 5,67 \\
\hline 130,00 & 60,00 & 7,84 & 8,65 & 9,19 & 8,28 & 170,00 & 20,00 & 5,31 & 5,31 & 5,85 & 5,12 \\
\hline 130,00 & 70,00 & 8,79 & 9,27 & 9,51 & 8,91 & 170,00 & 30,00 & 5,89 & 6,43 & 6,36 & 6,38 \\
\hline 130,00 & 80,00 & 9,31 & 9,80 & 9,94 & 9,34 & 170,00 & 40,00 & 6,20 & 6,47 & 6,97 & 6,45 \\
\hline 130,00 & 84,00 & 10,00 & 10,00 & 10,00 & 10,00 & 170,00 & 50,00 & 6,23 & 6,61 & 7,57 & 6,65 \\
\hline 130,00 & 154,00 & 8,29 & 8,77 & 8,79 & 8,42 & 170,00 & 60,00 & 6,38 & 6,89 & 7,96 & 6,92 \\
\hline 130,00 & 164,00 & 10,00 & 10,00 & 10,00 & 10,00 & 170,00 & 70,00 & 6,36 & 6,88 & 8,26 & 6,88 \\
\hline 140,00 & 10,00 & 6,55 & 6,54 & 7,04 & 6,64 & 170,00 & 80,00 & 6,17 & 7,11 & 8,37 & 7,00 \\
\hline 140,00 & 20,00 & 6,37 & 5,98 & 6,90 & 6,09 & 170,00 & 90,00 & 6,83 & 7,11 & 8,48 & 7,16 \\
\hline 140,00 & 30,00 & 6,32 & 6,41 & 6,22 & 6,24 & 170,00 & 100,00 & 6,13 & 6,48 & 7,89 & 7,16 \\
\hline 140,00 & 40,00 & 6,59 & 6,77 & 6,91 & 6,58 & 170,00 & 110,00 & 6,28 & 6,56 & 6,63 & 6,82 \\
\hline 140,00 & 50,00 & 7,21 & 7,45 & 7,25 & 7,33 & 170,00 & 120,00 & 6,54 & 6,59 & 6,71 & 6,49 \\
\hline 140,00 & 60,00 & 7,87 & 8,08 & 7,83 & 7,86 & 170,00 & 130,00 & 6,96 & 7,23 & 7,35 & 6,31 \\
\hline 140,00 & 70,00 & 8,41 & 8,69 & 8,57 & 8,59 & 170,00 & 140,00 & 7,43 & 7,34 & 7,34 & 7,11 \\
\hline 140,00 & 80,00 & 9,10 & 9,13 & 9,04 & 8,95 & 170,00 & 150,00 & 7,46 & 7,46 & 7,71 & 7,19 \\
\hline 140,00 & 90,00 & 9,52 & 9,53 & 9,64 & 9,48 & 170,00 & 160,00 & 7,53 & 7,69 & 7,92 & 7,30 \\
\hline 140,00 & 98,00 & 10,00 & 10,00 & 10,00 & 10,00 & 170,00 & 170,00 & 7,77 & 8,23 & 8,60 & 7,71 \\
\hline 140,00 & 168,00 & 8,43 & 8,88 & 8,95 & 8,06 & 170,00 & 180,00 & 8,33 & 8,59 & 8,73 & 8,15 \\
\hline 140,00 & 177,50 & 10,00 & 10,00 & 10,00 & 10,00 & 170,00 & 190,00 & 8,43 & 8,96 & 9,45 & 8,83 \\
\hline 150,00 & 10,00 & 6,05 & 6,09 & 6,84 & 6,02 & 170,00 & 200,00 & 9,32 & 9,74 & 9,76 & 9,10 \\
\hline 150,00 & 20,00 & 6,16 & 6,08 & 6,68 & 6,02 & 170,00 & 210,00 & 10,00 & 10,00 & 10,00 & 10,00 \\
\hline 150,00 & 30,00 & 6,13 & 6,13 & 6,37 & 6,04 & 180,00 & 10,00 & 5,49 & 5,53 & 5,81 & 5,43 \\
\hline
\end{tabular}


continuação

\begin{tabular}{|c|c|c|c|c|c|c|c|c|c|c|c|}
\hline \multicolumn{2}{|c|}{$\begin{array}{l}\text { Coordenadas } \\
\text { Levantadas }\end{array}$} & \multicolumn{4}{|c|}{$\begin{array}{l}\text { Cotas de Fundo (m) } \\
\text { Período }\end{array}$} & \multicolumn{2}{|c|}{$\begin{array}{l}\text { Coordenadas } \\
\text { Levantadas }\end{array}$} & \multicolumn{4}{|c|}{$\begin{array}{l}\text { Cotas de Fundo }(\mathrm{m}) \\
\text { Período }\end{array}$} \\
\hline$x$ & Y & 1998 & 1999 & 2000 & 2001 & $x$ & $\mathrm{Y}$ & 1998 & 1999 & 2000 & 2001 \\
\hline 180,00 & 20,00 & 5,37 & 5,47 & 6,26 & 5,37 & 200,00 & 40,00 & 5,39 & 5,44 & 5,46 & 5,39 \\
\hline 180,00 & 30,00 & 5,60 & 5,70 & 6,58 & 5,70 & 200,00 & 50,00 & 5,41 & 5,54 & 5,48 & 5,46 \\
\hline 180,00 & 40,00 & 6,08 & 6,18 & 6,91 & 6,15 & 200,00 & 60,00 & 5,58 & 5,68 & 5,60 & 5,61 \\
\hline 180,00 & 50,00 & 6,11 & 6,17 & 7,10 & 6,16 & 200,00 & 70,00 & 5,70 & 5,79 & 5,66 & 5,79 \\
\hline 180,00 & 60,00 & 5,98 & 6,03 & 7,46 & 6,14 & 200,00 & 80,00 & 5,93 & 6,01 & 5,80 & 5,93 \\
\hline 180,00 & 70,00 & 5,73 & 5,97 & 7,84 & 6,14 & 200,00 & 90,00 & 5,82 & 5,98 & 6,08 & 5,95 \\
\hline 180,00 & 80,00 & 5,91 & 6,08 & 7,68 & 6,05 & 200,00 & 100,00 & 6,08 & 6,14 & 6,45 & 6,42 \\
\hline 180,00 & 90,00 & 6,08 & 6,66 & 7,61 & 6,56 & 200,00 & 110,00 & 6,54 & 6,59 & 6,74 & 6,50 \\
\hline 180,00 & 100,00 & 6,10 & 6,26 & 7,46 & 6,20 & 200,00 & 120,00 & 6,65 & 6,64 & 7,05 & 6,31 \\
\hline 180,00 & 110,00 & 6,30 & 6,26 & 7,11 & 6,20 & 200,00 & 130,00 & 6,39 & 6,91 & 7,02 & 7,11 \\
\hline 180,00 & 120,00 & 6,41 & 6,47 & 6,59 & 6,16 & 200,00 & 140,00 & 7,19 & 7,34 & 7,07 & 7,29 \\
\hline 180,00 & 130,00 & 6,68 & 6,78 & 6,53 & 6,33 & 200,00 & 150,00 & 7,50 & 7,61 & 7,40 & 7,62 \\
\hline 180,00 & 140,00 & 6,97 & 7,23 & 7,10 & 6,94 & 200,00 & 160,00 & 7,69 & 7,75 & 7,65 & 7,69 \\
\hline 180,00 & 150,00 & 7,46 & 7,71 & 7,38 & 7,33 & 200,00 & 170,00 & 7,77 & 7,78 & 7,90 & 7,74 \\
\hline 180,00 & 160,00 & 7,75 & 7,86 & 7,37 & 7,31 & 200,00 & 180,00 & 7,95 & 7,95 & 8,24 & 7,92 \\
\hline 180,00 & 170,00 & 7,77 & 7,81 & 7,61 & 7,46 & 200,00 & 190,00 & 8,10 & 8,15 & 8,50 & 8,13 \\
\hline 180,00 & 180,00 & 7,61 & 7,70 & 7,68 & 7,62 & 200,00 & 200,00 & 8,37 & 8,34 & 8,68 & 8,29 \\
\hline 180,00 & 190,00 & 7,69 & 7,79 & 7,81 & 8,25 & 200,00 & 210,00 & 8,56 & 8,78 & 8,92 & 8,65 \\
\hline 180,00 & 200,00 & 7,91 & 8,26 & 8,01 & 8,46 & 200,00 & 220,00 & 8,43 & 8,69 & 9,19 & 8,66 \\
\hline 180,00 & 210,00 & 8,53 & 8,91 & 8,73 & 8,99 & 200,00 & 230,00 & 8,94 & 8,63 & 9,36 & 8,62 \\
\hline 180,00 & 220,00 & 9,41 & 9,81 & 9,83 & 9,42 & 200,00 & 240,00 & 9,51 & 9,49 & 9,68 & 9,46 \\
\hline 180,00 & 224,00 & 10,00 & 10,00 & 10,00 & 10,00 & 200,00 & 241,00 & 10,00 & 10,00 & 10,00 & 10,00 \\
\hline 190,00 & 10,00 & 5,41 & 5,45 & 5,51 & 5,39 & 210,00 & 10,00 & 5,38 & 5,38 & 5,41 & 5,39 \\
\hline 190,00 & 20,00 & 5,39 & 5,39 & 5,32 & 5,29 & 210,00 & 20,00 & 5,30 & 5,38 & 5,37 & 5,37 \\
\hline 190,00 & 30,00 & 5,41 & 5,36 & 5,31 & 5,28 & 210,00 & 30,00 & 5,21 & 5,25 & 5,34 & 5,37 \\
\hline 190,00 & 40,00 & 5,41 & 5,47 & 5,38 & 5,39 & 210,00 & 40,00 & 5,38 & 5,44 & 5,37 & 5,48 \\
\hline 190,00 & 50,00 & 5,63 & 5,64 & 5,54 & 5,54 & 210,00 & 50,00 & 5,50 & 5,51 & 5,47 & 5,59 \\
\hline 190,00 & 60,00 & 5,55 & 5,59 & 5,61 & 5,54 & 210,00 & 60,00 & 5,58 & 5,59 & 5,60 & 5,70 \\
\hline 190,00 & 70,00 & 5,63 & 5,76 & 5,74 & 5,67 & 210,00 & 70,00 & 5,62 & 5,65 & 5,71 & 5,70 \\
\hline 190,00 & 80,00 & 5,76 & 6,01 & 5,86 & 5,88 & 210,00 & 80,00 & 5,73 & 5,79 & 5,83 & 5,82 \\
\hline 190,00 & 90,00 & 5,95 & 6,06 & 6,27 & 6,12 & 210,00 & 90,00 & 5,94 & 5,99 & 5,97 & 5,88 \\
\hline 190,00 & 100,00 & 6,35 & 6,51 & 6,65 & 6,55 & 210,00 & 100,00 & 6,24 & 6,34 & 6,28 & 6,21 \\
\hline 190,00 & 110,00 & 6,20 & 6,36 & 7,06 & 6,35 & 210,00 & 110,00 & 6,51 & 6,56 & 6,53 & 6,48 \\
\hline 190,00 & 120,00 & 6,33 & 6,70 & 7,36 & 6,52 & 210,00 & 120,00 & 6,71 & 6,77 & 6,85 & 6,85 \\
\hline 190,00 & 130,00 & 6,83 & 7,12 & 7,23 & 6,86 & 210,00 & 130,00 & 6,81 & 6,83 & 6,92 & 6,90 \\
\hline 190,00 & 140,00 & 7,22 & 7,41 & 7,13 & 7,28 & 210,00 & 140,00 & 6,61 & 6,69 & 6,98 & 6,49 \\
\hline 190,00 & 150,00 & 6,52 & 7,65 & 7,60 & 7,61 & 210,00 & 150,00 & 6,87 & 6,91 & 7,27 & 7,01 \\
\hline 190,00 & 160,00 & 7,64 & 7,74 & 7,83 & 7,72 & 210,00 & 160,00 & 7,03 & 7,08 & 7,47 & 7,04 \\
\hline 190,00 & 170,00 & 7,83 & 7,89 & 8,05 & 7,88 & 210,00 & 170,00 & 7,30 & 7,21 & 7,73 & 7,10 \\
\hline 190,00 & 180,00 & 7,88 & 7,98 & 8,32 & 7,91 & 210,00 & 180,00 & 7,33 & 7,36 & 8,10 & 7,38 \\
\hline 190,00 & 190,00 & 7,96 & 8,17 & 8,62 & 8,01 & 210,00 & 190,00 & 7,62 & 7,40 & 8,38 & 7,71 \\
\hline 190,00 & 200,00 & 7,83 & 7,95 & 8,90 & 7,72 & 210,00 & 200,00 & 7,74 & 7,69 & 8,53 & 7,95 \\
\hline 190,00 & 210,00 & 8,00 & 8,01 & 9,14 & 7,93 & 210,00 & 210,00 & 8,25 & 8,23 & 8,68 & 8,10 \\
\hline 190,00 & 220,00 & 8,13 & 8,12 & 9,44 & 8,05 & 210,00 & 220,00 & 8,23 & 8,13 & 8,76 & 8,57 \\
\hline 190,00 & 230,00 & 9,58 & 9,86 & 9,81 & 9,16 & 210,00 & 230,00 & 8,69 & 8,63 & 9,01 & 8,85 \\
\hline 190,00 & 235,00 & 10,00 & 10,00 & 10,00 & 10,00 & 210,00 & 240,00 & 9,48 & 9,26 & 9,75 & 9,56 \\
\hline 200,00 & 10,00 & 5,28 & 5,21 & 5,27 & 5,25 & 210,00 & 247,00 & 10,00 & 10,00 & 10,00 & 10,00 \\
\hline 200,00 & 20,00 & 5,31 & 5,29 & 5,29 & 5,31 & 220,00 & 10,00 & 5,73 & 5,85 & 5,90 & 5,76 \\
\hline 200,00 & 30,00 & 5,33 & 5,32 & 5,36 & 5,34 & 220,00 & 20,00 & 5,44 & 5,56 & 5,55 & 5,48 \\
\hline
\end{tabular}


continuação

\begin{tabular}{|c|c|c|c|c|c|c|c|c|c|c|c|}
\hline \multicolumn{2}{|c|}{$\begin{array}{l}\text { Coordenadas } \\
\text { Levantadas }\end{array}$} & \multicolumn{4}{|c|}{$\begin{array}{l}\text { Cotas de Fundo }(\mathrm{m}) \\
\text { Período }\end{array}$} & \multicolumn{2}{|c|}{$\begin{array}{l}\text { Coordenadas } \\
\text { Levantadas }\end{array}$} & \multicolumn{4}{|c|}{$\begin{array}{r}\mathrm{RN}= \\
\mathrm{NA}= \\
\text { Cotas de Fundo }(\mathrm{m}) \\
\text { Período }\end{array}$} \\
\hline$X$ & $Y$ & 1998 & 1999 & 2000 & 2001 & $X$ & $Y$ & 1998 & 1999 & 2000 & 2001 \\
\hline 220,00 & 30,00 & 5,22 & 5,28 & 5,31 & 5,24 & 240,00 & 80,00 & 6,58 & 6,62 & 6,97 & 6,52 \\
\hline 220,00 & 40,00 & 5,28 & 5,41 & 5,35 & 5,36 & 240,00 & 90,00 & 7,25 & 7,24 & 7,85 & 8,20 \\
\hline 220,00 & 50,00 & 5,58 & 5,55 & 5,46 & 5,53 & 240,00 & 100,00 & 8,17 & 8,16 & 9,09 & 8,28 \\
\hline 220,00 & 60,00 & 5,68 & 5,74 & 5,81 & 5,66 & 240,00 & 110,00 & 8,17 & 8,39 & 9,71 & 8,22 \\
\hline 220,00 & 70,00 & 5,66 & 5,86 & 6,11 & 5,76 & 240,00 & 120,00 & 8,26 & 8,25 & 9,21 & 7,72 \\
\hline 220,00 & 80,00 & 5,81 & 5,94 & 6,19 & 5,91 & 240,00 & 130,00 & 7,95 & 8,13 & 9,45 & 8,03 \\
\hline 220,00 & 90,00 & 6,07 & 6,20 & 6,62 & 6,09 & 240,00 & 140,00 & 8,06 & 8,29 & 8,76 & 8,24 \\
\hline 220,00 & 100,00 & 6,56 & 6,63 & 6,86 & 6,52 & 240,00 & 150,00 & 8,26 & 8,51 & 8,43 & 8,48 \\
\hline 220,00 & 110,00 & 6,78 & 6,87 & 7,43 & 6,69 & 240,00 & 160,00 & 8,48 & 8,67 & 8,57 & 8,61 \\
\hline 220,00 & 120,00 & 7,03 & 7,14 & 7,88 & 6,96 & 240,00 & 170,00 & 8,68 & 8,90 & 9,58 & 8,92 \\
\hline 220,00 & 130,00 & 6,86 & 7,06 & 7,58 & 7,27 & 240,00 & 180,00 & 8,93 & 9,27 & 9,37 & 9,26 \\
\hline 220,00 & 140,00 & 7,03 & 7,03 & 7,38 & 7,35 & 240,00 & 190,00 & 9,33 & 9,65 & 9,36 & 9,37 \\
\hline 220,00 & 150,00 & 7,26 & 7,28 & 7,68 & 7,60 & 240,00 & 193,00 & 10,00 & 10,00 & 10,00 & 10,00 \\
\hline 220,00 & 160,00 & 7,51 & 7,49 & 8,11 & 7,72 & 250,00 & 10,00 & 7,08 & 7,11 & 7,10 & 7,13 \\
\hline 220,00 & 170,00 & 7,70 & 7,74 & 8,35 & 8,10 & 250,00 & 20,00 & 7,28 & 7,30 & 7,32 & 7,39 \\
\hline 220,00 & 180,00 & 8,00 & 8,26 & 8,58 & 8,80 & 250,00 & 30,00 & 7,13 & 7,13 & 7,43 & 7,29 \\
\hline 220,00 & 190,00 & 8,23 & 8,39 & 8,79 & 8,41 & 250,00 & 40,00 & 6,39 & 6,49 & 7,86 & 7,04 \\
\hline 220,00 & 200,00 & 8,43 & 8,48 & 9,12 & 8,46 & 250,00 & 50,00 & 6,00 & 6,09 & 6,59 & 6,51 \\
\hline 220,00 & 210,00 & 8,43 & 8,52 & 9,26 & 9,27 & 250,00 & 60,00 & 6,23 & 6,25 & 6,88 & 6,89 \\
\hline 220,00 & 220,00 & 10,00 & 10,00 & 10,00 & 10,00 & 250,00 & 70,00 & 6,90 & 6,87 & 7,28 & 7,08 \\
\hline 230,00 & 10,00 & 6,10 & 6,18 & 6,25 & 6,38 & 250,00 & 80,00 & 7,05 & 7,05 & 7,33 & 7,82 \\
\hline 230,00 & 20,00 & 5,53 & 5,48 & 5,60 & 5,74 & 250,00 & 90,00 & 7,81 & 7,81 & 8,04 & 8,29 \\
\hline 230,00 & 30,00 & 5,25 & 5,25 & 5,32 & 5,45 & 250,00 & 100,00 & 9,08 & 9,08 & 9,14 & 9,09 \\
\hline 230,00 & 40,00 & 5,38 & 5,34 & 5,40 & 5,60 & 250,00 & 108,00 & 10,00 & 10,00 & 10,00 & 10,00 \\
\hline 230,00 & 50,00 & 5,42 & 5,51 & 5,46 & 5,77 & 250,00 & 128,00 & 9,21 & 9,33 & 8,98 & 9,04 \\
\hline 230,00 & 60,00 & 5,73 & 5,79 & 5,81 & 6,12 & 250,00 & 138,00 & 8,72 & 8,74 & 8,91 & 8,83 \\
\hline 230,00 & 70,00 & 6,03 & 6,05 & 6,36 & 6,29 & 250,00 & 148,00 & 8,39 & 8,35 & 9,92 & 9,26 \\
\hline 230,00 & 80,00 & 6,03 & 6,07 & 6,69 & 6,38 & 250,00 & 158,00 & 9,39 & 9,31 & 9,91 & 9,81 \\
\hline 230,00 & 90,00 & 6,39 & 6,39 & 7,50 & 7,64 & 250,00 & 168,00 & 9,25 & 9,20 & 9,70 & 9,52 \\
\hline 230,00 & 100,00 & 6,63 & 6,69 & 8,67 & 7,48 & 250,00 & 173,00 & 10,00 & 10,00 & 10,00 & 10,00 \\
\hline 230,00 & 110,00 & 7,11 & 7,17 & 9,02 & 7,21 & 260,00 & 10,00 & 7,47 & 7,56 & 7,57 & 7,46 \\
\hline 230,00 & 120,00 & 7,53 & 7,54 & 8,68 & 7,56 & 260,00 & 20,00 & 7,50 & 7,61 & 7,59 & 7,50 \\
\hline 230,00 & 130,00 & 7,19 & 7,25 & 8,68 & 7,82 & 260,00 & 30,00 & 7,64 & 7,78 & 7,81 & 7,69 \\
\hline 230,00 & 140,00 & 7,03 & 7,10 & 7,92 & 8,06 & 260,00 & 40,00 & 7,99 & 8,18 & 8,53 & 7,98 \\
\hline 230,00 & 150,00 & 7,50 & 7,51 & 7,66 & 8,32 & 260,00 & 50,00 & 8,54 & 8,77 & 9,39 & 8,57 \\
\hline 230,00 & 160,00 & 7,72 & 7,73 & 7,97 & 8,50 & 260,00 & 60,00 & 8,59 & 8,81 & 9,76 & 8,50 \\
\hline 230,00 & 170,00 & 7,95 & 7,94 & 8,48 & 8,75 & 260,00 & 70,00 & 7,31 & 7,56 & 9,39 & 7,42 \\
\hline 230,00 & 180,00 & 8,25 & 8,26 & 8,77 & 8,82 & 260,00 & 80,00 & 7,34 & 7,31 & 8,51 & 7,42 \\
\hline 230,00 & 190,00 & 8,49 & 8,45 & 8,79 & 8,94 & 260,00 & 90,00 & 8,00 & 7,99 & 8,88 & 8,81 \\
\hline 230,00 & 200,00 & 8,67 & 8,77 & 9,11 & 9,25 & 260,00 & 91,50 & 10,00 & 10,00 & 10,00 & 10,00 \\
\hline 230,00 & 210,00 & 8,77 & 9,29 & 9,20 & 9,59 & 260,00 & 131,50 & 9,20 & 9,11 & 9,37 & 9,21 \\
\hline 230,00 & 218,00 & 10,00 & 10,00 & 10,00 & 10,00 & 260,00 & 141,50 & 8,90 & 8,86 & 9,40 & 9,09 \\
\hline 240,00 & 10,00 & 6,63 & 6,59 & 6,70 & 6,54 & 260,00 & 151,50 & 9,44 & 9,41 & 9,27 & 9,50 \\
\hline 240,00 & 20,00 & 6,18 & 6,24 & 6,36 & 6,21 & 260,00 & 161,50 & 9,61 & 9,60 & 9,45 & 9,57 \\
\hline 240,00 & 30,00 & 5,37 & 5,44 & 5,64 & 5,60 & 260,00 & 171,50 & 9,75 & 9,55 & 9,81 & 9,26 \\
\hline 240,00 & 40,00 & 5,35 & 5,46 & 5,57 & 5,45 & 260,00 & 175,00 & 10,00 & 10,00 & 10,00 & 10,00 \\
\hline 240,00 & 50,00 & 5,54 & 5,53 & 5,65 & 5,68 & - & - & - & - & - & - \\
\hline 240,00 & 60,00 & 5,77 & 5,81 & 6,01 & 5,76 & - & - & - & - & - & - \\
\hline 240,00 & 70,00 & 6,23 & 6,30 & 6,60 & 6,29 & - & - & - & - & - & - \\
\hline
\end{tabular}




\subsubsection{Vazões Características.}

A vazão foi obtida pelo método de integração de área e medições de velocidade com molinete convencional. Os pontos amostrados situam-se no córrego da Barrinha (a montante e também a jusante do reservatório), bem como nos pontos de entrada e saída da represa. A Figura 24 mostra a localização dos pontos amostrados na entrada e saída do reservatório.

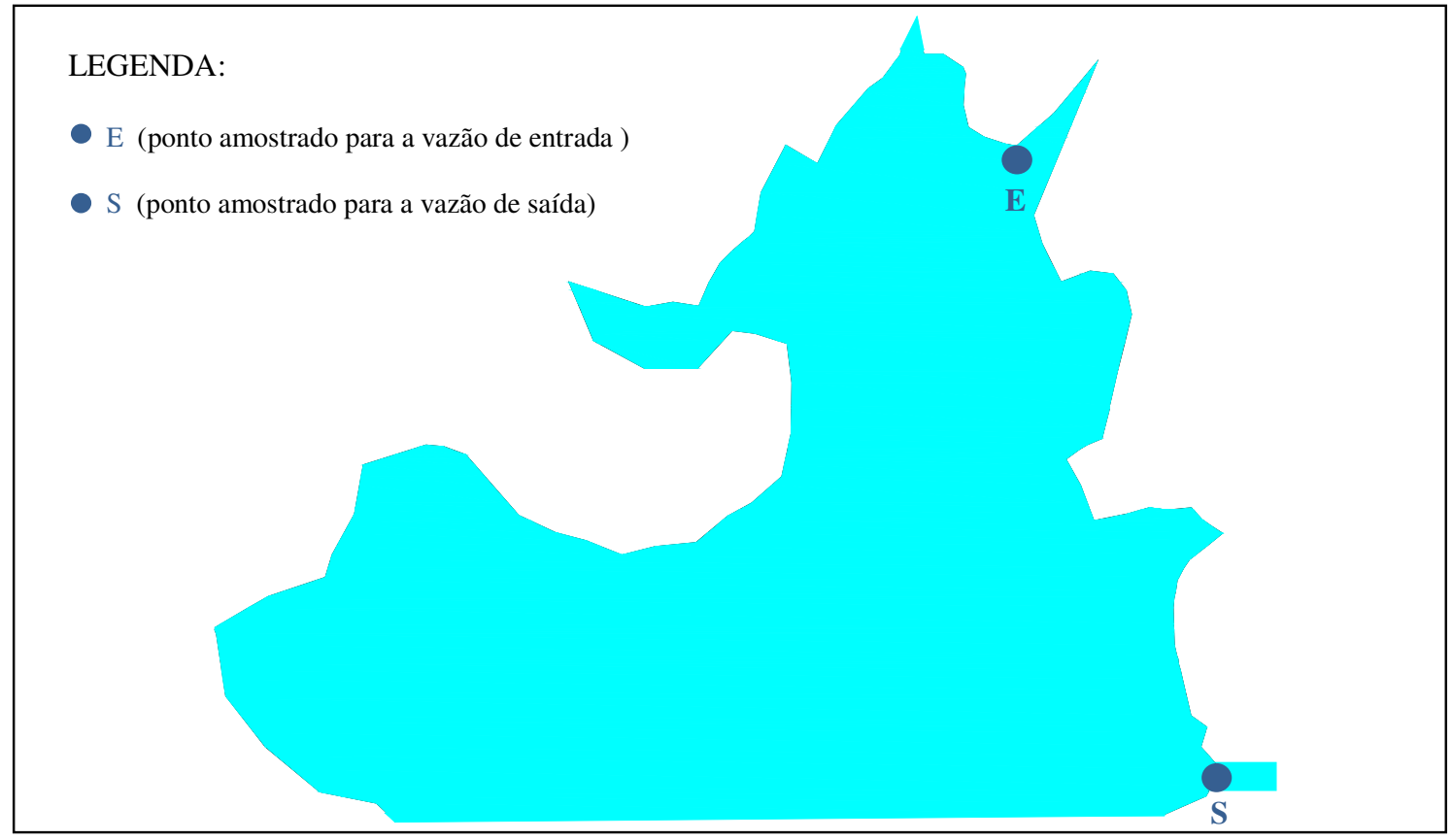

Figura 24. Localização dos pontos amostrados de vazão - entrada e saída (BUFON, 2006)

Na Tabela 4 estão relacionados os valores calculados para a vazão de entrada e saída de 1998 a 2001, para períodos secos e chuvosos. Nota-se que os valores de vazão de saída são bem superiores aos valores da entrada, com exceção daqueles obtidos em janeiro e fevereiro de 2001. De acordo com Bufon (2006), este fato se deve a presença de minas de água no interior do reservatório. Valores máximos e mínimos de vazão, obtidos na entrada e saída, são destacados em vermelho. As vazões na entrada, sobretudo nos períodos secos, ocorrem como jatos de superfície. 
TABELA 04 - Valores de vazão obtidos na entrada (E) e saída (S) do reservatório (BUFON, 2006).

\begin{tabular}{ccc}
\hline Datas & \multicolumn{2}{c}{ Vazão-Q $\left(\mathrm{m}^{3} / \mathbf{s}\right)$} \\
& $\mathrm{E}$ & $\mathbf{S}$ \\
\hline 14-jul-98 & 0,006 & 0,125 \\
22-ago-98 & 0,004 & 0,129 \\
16-dez-98 & 0,010 & 0,089 \\
30-jan-99 & 0,021 & 0,099 \\
27-fev-99 & 0,048 & 0,198 \\
1-mai-99 & 0,024 & 0,087 \\
26-jun-99 & 0,016 & 0,114 \\
24-jul-99 & 0,019 & 0,082 \\
21-ago-99 & 0,011 & 0,050 \\
23-out-99 & 0,014 & 0,072 \\
31-dez-99 & 0,009 & 0,099 \\
28-jan-00 & 0,024 & 0,017 \\
26-fev-00 & 0,042 & 0,203 \\
28-jun-00 & 0,011 & 0,114 \\
24-jul-00 & 0,009 & 0,084 \\
29-ago-00 & 0,014 & 0,072 \\
27-out-00 & 0,002 & 0,076 \\
21-dez-00 & 0,006 & 0,135 \\
31-jan-01 & 0,390 & 0,097 \\
21-fev-01 & 0,110 & 0,100 \\
25-abr-01 & 0,034 & 0,014 \\
\hline
\end{tabular}

\subsubsection{Concentração de Sedimentos Suspensos.}

A coleta do material em suspensão foi feita a partir de amostragens espaciais no reservatório num total de 6 pontos discretos (FIGURA 25). A metodologia utilizada é descrita por Maricato (1994) e Leite (1998) e consiste da instalação de câmaras de sedimentação (FIGURA 26), confeccionadas em tubos de PVC de $10 \mathrm{~cm}$ de diâmetro por $30 \mathrm{~cm}$ de comprimento, dispostas verticalmente na coluna de água. O tempo de exposição da câmara para recolhimento das amostras é de $24 \mathrm{~h}$. As tomadas de leituras concordaram com os períodos de obtenção da vazão, de 1998 a 2001. No período seco as amostras foram coletadas nos meses de junho, julho, agosto e outubro e, no período chuvoso, nos meses de dezembro, janeiro, fevereiro e abril (BUFON, 2006). 


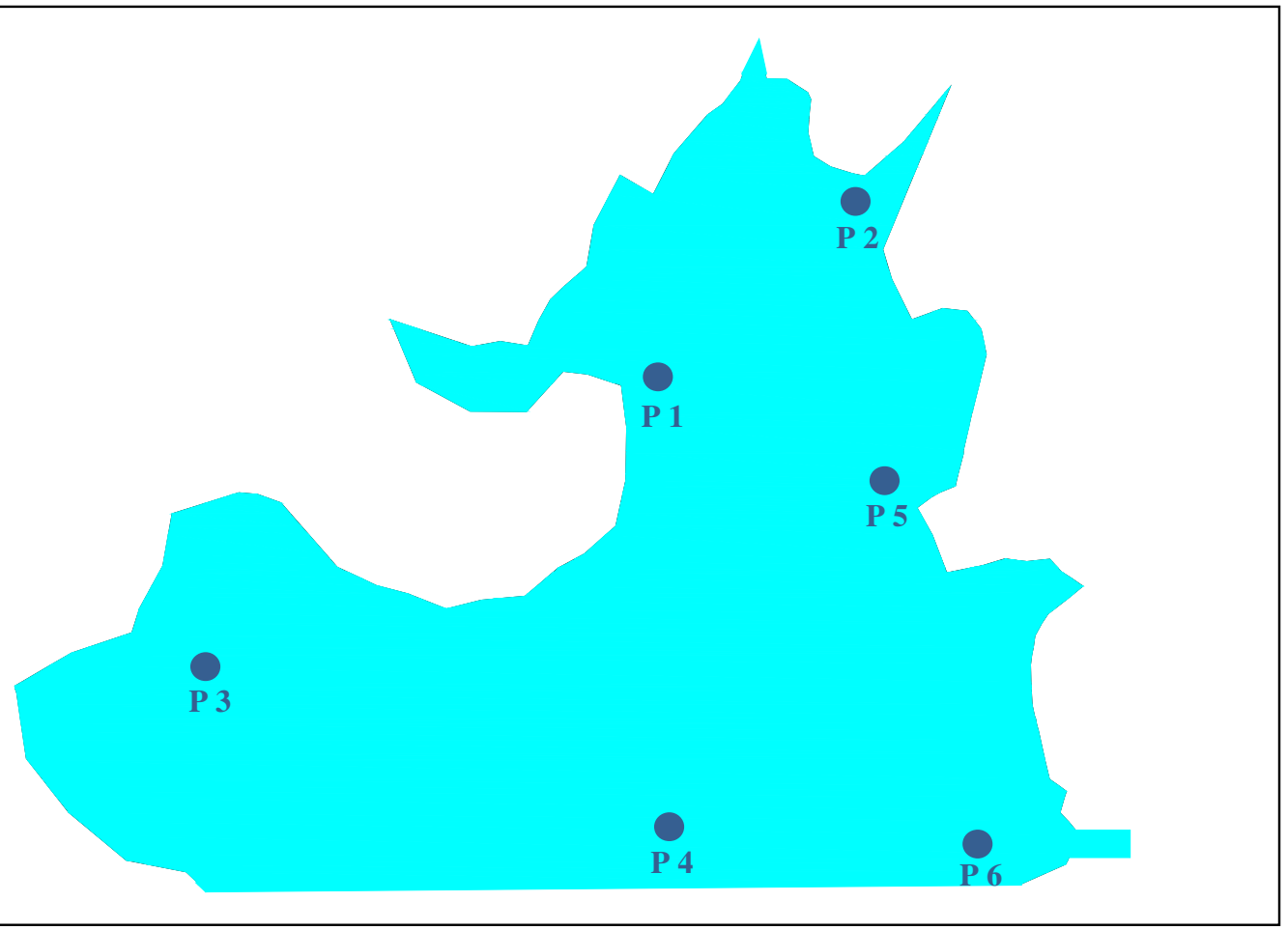

Figura 25. Localização dos pontos amostrados de sedimentos (BUFON, 2006)

LEGENDA:

01-Abertura da câmara; 02-Fundo da câmara; 03-Suporte das câmaras; 04-Rosca de trava; 05-Trava das câmaras; 06-Parafuso da trava; 07-Alça da amarração.

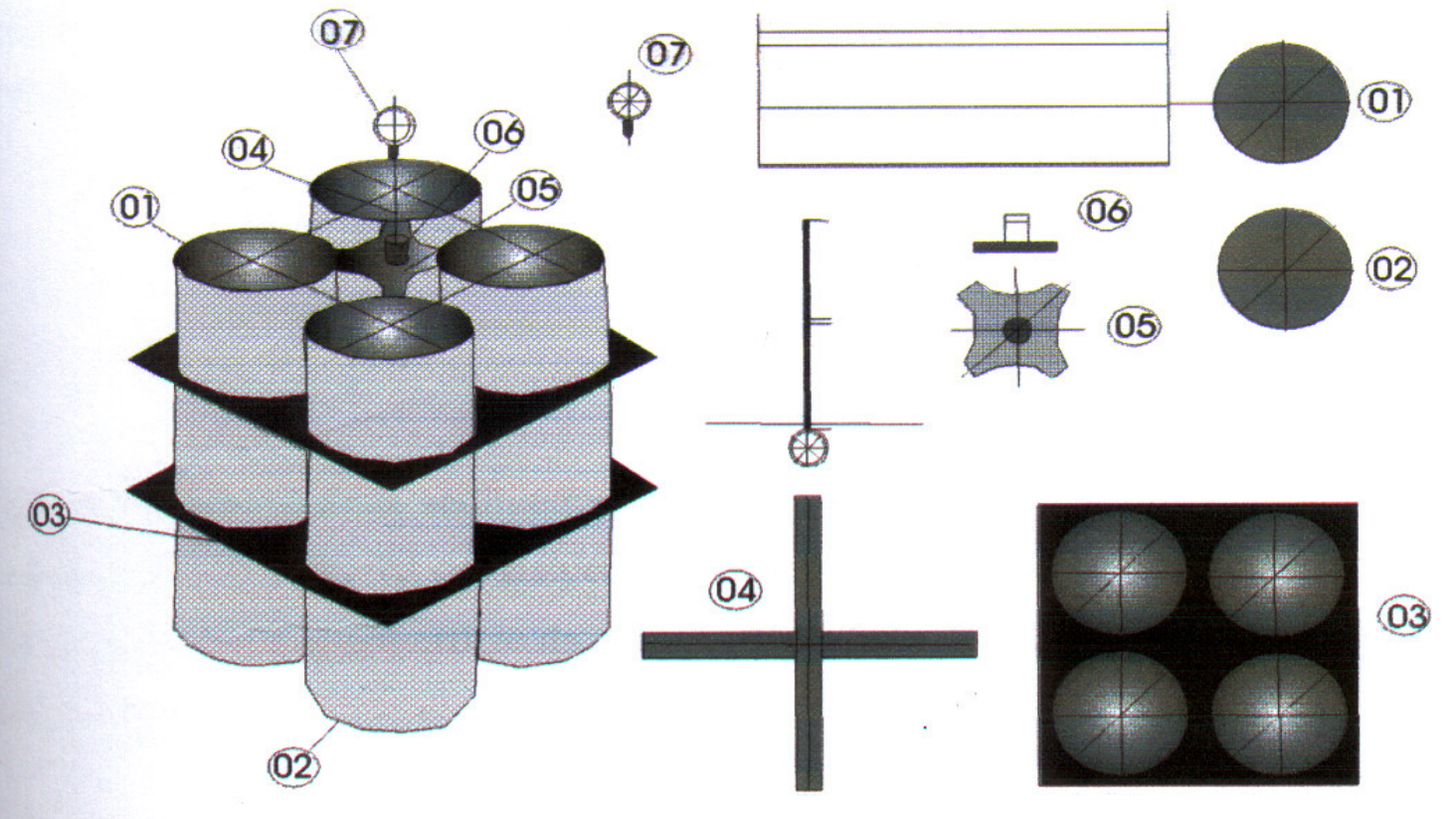

Figura 26. Esquema das câmaras de sedimentação (BUFON, 2006) 
Para a determinação da concentração de sedimentos suspensos inorgânicos, orgânicos e totais (BUFON, 2006) utilizou-se de amostras brutas e fracionadas (malhas de 68 e $20 \mu \mathrm{m}$ ), retidas em filtros de fibra de vidro, previamente calcinados e de massa conhecida (M1), por técnica gravimétrica (WETZEL; LIKENS, 1991). Os filtros foram secos em estufa a $60^{\circ} \mathrm{C}$ durante um período de $24 \mathrm{~h}$, resfriados e pesados (M2). Após este procedimento, foram calcinados em mufla a $480^{\circ} \mathrm{C}$, por 60 min, resfriados e pesados (M3). O cálculo foi feito segundo as equações utilizadas por Leite (1998), sendo:

- Material em Suspensão Total:

$$
M S T=\frac{(M 2-M 1)}{V * 1000}
$$

onde:

MST: material em suspensão total $\left(\mathrm{mg} . \mathrm{L}^{-1}\right)$;

M1: peso inicial do filtro $(\mathrm{g})$;

M2: peso do filtro com material coletado após secagem em estufa (g);

$V$ : volume de água utilizado para a filtração (L);

1000: conversão para miligramas.

- Material em Suspensão Inorgânico:

$$
M S I=\frac{(M 3-M 1)}{V^{*} 1000}
$$

onde:

MSI: material em suspensão inorgânico $\left(\mathrm{mg} . \mathrm{L}^{-1}\right)$;

M3: peso do filtro após queima da matéria orgânica em mufla (g). 
- Material em Suspensão Orgânico:

$$
M S O=M S T-M S I
$$

onde:

MSO: material em suspensão orgânico (mg.L $\left.\mathrm{L}^{-1}\right)$.

As Tabelas 5, 6 e 7, apresentadas a seguir, mostram os valores temporais obtidos para a concentração de sólidos suspensos totais, inorgânicos e orgânicos respectivamente, nos 6 pontos de amostragem no reservatório.

TABELA 05 - Material em suspensão total - mg/L (BUFON, 2006).

\begin{tabular}{ccccccc}
\hline \multirow{2}{*}{ Datas } & \multicolumn{7}{c}{ Pontos de Amostragem } \\
\cline { 2 - 7 } P1 & P2 & P3 & P4 & P5 & P6 \\
\hline 14-jul-98 & 159,70 & 19,60 & 85,70 & 61,90 & 42,90 & 45,40 \\
22-ago-98 & 157,00 & 211,00 & 341,70 & 39,20 & 61,60 & 56,00 \\
16-dez-98 & 42,50 & 161,10 & 269,30 & 73,50 & 52,50 & 65,40 \\
30-jan-99 & 26,90 & 114,60 & 73,10 & 45,40 & 56,90 & 35,90 \\
27-fev-99 & 52,90 & 47,60 & 151,30 & 118,00 & 86,80 & 93,80 \\
01-mai-99 & 83,20 & 44,50 & 94,70 & 58,90 & 60,60 & 57,30 \\
26-jun-99 & 119,50 & 38,70 & 68,20 & 28,90 & 32,70 & 32,20 \\
24-jul-99 & 51,80 & 34,50 & 104,60 & 45,30 & 53,70 & 33,60 \\
21-ago-99 & 51,70 & 45,80 & 251,20 & 50,40 & 81,20 & 59,80 \\
23-out-99 & 285,20 & 103,10 & 483,80 & 35,00 & 40,70 & 49,70 \\
31-dez-99 & 133,10 & 123,20 & 112,00 & 191,20 & 247,20 & 271,00 \\
28-jan-00 & 81,90 & 112,70 & 149,90 & 70,70 & 194,00 & 67,20 \\
26-fev-00 & 152,00 & 225,50 & 213,60 & 89,60 & 79,10 & 63,70 \\
28-jun-00 & 264,00 & 102,90 & 145,00 & 59,50 & 49,00 & 47,60 \\
24-jul-00 & 62,30 & 51,80 & 186,30 & 38,50 & 32,20 & 34,30 \\
29-ago-00 & 102,90 & 87,50 & 95,20 & 35,00 & 30,80 & 31,50 \\
27-out-00 & 131,00 & 161,80 & 163,90 & 58,10 & 42,00 & 38,50 \\
21-dez-00 & 65,60 & 131,10 & 585,10 & 65,60 & 44,60 & 50,30 \\
31-jan-01 & 76,40 & 446,90 & 585,70 & 72,60 & 59,20 & 71,90 \\
21-fev-01 & 116,20 & 226,20 & 145,70 & 88,90 & 86,10 & 56,70 \\
25-abr-01 & 53,20 & 618,30 & 122,50 & 39,20 & 38,50 & 42,70 \\
\hline
\end{tabular}

Observando-se a Tabela 5, verifica-se que o menor valor encontrado de material em suspensão total (19,6 mg/L) e o maior (618,3 mg/L), ocorreram nos períodos seco e chuvoso 
respectivamente, para o mesmo ponto de amostragem P2 (entrada do córrego Barrinha no reservatório). Nos lagos de clima tropical, onde suas águas invadem o solo adjacente, o aporte de sedimentos orgânicos e inorgânicos para o seu interior é intensificado (BUFON, 2006).

TABELA 06 - Material em suspensão inorgânico - mg/L (BUFON, 2006).

\begin{tabular}{|c|c|c|c|c|c|c|}
\hline \multirow{2}{*}{ Datas } & \multicolumn{6}{|c|}{ Pontos de Amostragem } \\
\hline & $\mathrm{P} 1$ & $\mathrm{P} 2$ & P3 & $\mathrm{P} 4$ & P5 & P6 \\
\hline 14-jul-98 & 119,90 & 8,70 & 50,40 & 47,60 & 36,40 & 33,60 \\
\hline 22-ago-98 & 95,30 & 157,00 & 238,70 & 22,40 & 33,60 & 28,00 \\
\hline 16-dez-98 & 9,80 & 91,90 & 176,80 & 31,50 & 19,60 & 21,90 \\
\hline 30-jan-99 & 12,30 & 33,30 & 44,30 & 21,80 & 28,30 & 16,20 \\
\hline 27-fev-99 & 34,00 & 29,40 & 101,50 & 77,70 & 56,40 & 63,40 \\
\hline 01-mai-99 & 53,10 & 25,10 & 60,10 & 34,60 & 35,00 & 34,60 \\
\hline 26-jun-99 & 78,00 & 20,10 & 41,10 & 12,60 & 15,90 & 14,50 \\
\hline 24-jul-99 & 27,50 & 13,50 & 67,20 & 23,80 & 29,90 & 15,90 \\
\hline 21-ago-99 & 27,10 & 16,80 & 173,20 & 26,10 & 48,60 & 31,70 \\
\hline 23-out-99 & 196,10 & 63,00 & 340,60 & 12,10 & 17,20 & 23,60 \\
\hline 31-dez-99 & 98,00 & 84,00 & 70,00 & 135,20 & 184,20 & 215,20 \\
\hline 28-jan-00 & 56,70 & 81,90 & 104,30 & 41,30 & 120,40 & 39,20 \\
\hline $26-f e v-00$ & 102,20 & 177,20 & 147,80 & 58,10 & 50,40 & 39,20 \\
\hline 28-jun-00 & 181,40 & 68,60 & 94,50 & 30,80 & 23,10 & 20,30 \\
\hline 24-jul-00 & 39,90 & 30,10 & 130,30 & 19,60 & 14,70 & 18,20 \\
\hline 29-ago-00 & 65,10 & 46,90 & 60,90 & 14,70 & 10,50 & 11,20 \\
\hline 27-out-00 & 87,50 & 107,10 & 109,20 & 33,60 & 20,30 & 18,90 \\
\hline 21-dez-00 & 36,30 & 87,20 & 415,70 & 33,70 & 21,00 & 24,80 \\
\hline 31-jan-01 & 44,60 & 330,40 & 412,50 & 40,10 & 35,70 & 45,80 \\
\hline 21-fev-01 & 74,20 & 162,50 & 99,40 & 51,10 & 53,20 & 29,40 \\
\hline $25-a b r-01$ & 26,60 & 425,80 & 71,40 & 16,10 & 21,70 & 18,20 \\
\hline
\end{tabular}

Com relação aos resultados de material em suspensão inorgânicos, o menor e maior valor encontrados também se refere ao ponto de coleta P2, em julho de 1998 (8,70 mg/L) e abril de 2001 (425,80 mg/L). Apesar dos maiores valores de concentração terem sido registrados na entrada, em parte do período analisado pode ser observada uma taxa crescente de sedimentos suspensos, no sentido da entrada para o interior do reservatório Represa Velha. 
TABELA 07 - Material em suspensão orgânico - mg/L (BUFON, 2006).

\begin{tabular}{|c|c|c|c|c|c|c|}
\hline \multirow{2}{*}{ Datas } & \multicolumn{6}{|c|}{ Pontos de Amostragem } \\
\hline & $\mathrm{P} 1$ & $\mathrm{P} 2$ & P3 & $\mathrm{P} 4$ & P5 & P6 \\
\hline 14-jul-98 & 39,80 & 10,90 & 35,30 & 14,30 & 6,50 & 11,80 \\
\hline 22-ago-98 & 61,70 & 54,00 & 103,00 & 16,80 & 28,00 & 28,00 \\
\hline 16-dez-98 & 32,70 & 69,20 & 92,50 & 42,00 & 32,90 & 43,50 \\
\hline 30-jan-99 & 14,60 & 81,30 & 28,80 & 23,60 & 28,60 & 19,70 \\
\hline 27-fev-99 & 18,90 & 18,20 & 49,80 & 40,30 & 30,40 & 30,40 \\
\hline 01-mai-99 & 30,10 & 19,40 & 34,60 & 24,30 & 25,60 & 22,70 \\
\hline 26-jun-99 & 41,50 & 18,60 & 27,10 & 16,30 & 16,80 & 17,70 \\
\hline 24-jul-99 & 24,30 & 21,00 & 37,40 & 21,50 & 23,80 & 17,70 \\
\hline 21-ago-99 & 24,60 & 29,00 & 78,00 & 24,30 & 32,60 & 28,10 \\
\hline 23 -out-99 & 89,10 & 40,10 & 143,20 & 22,90 & 23,50 & 26,10 \\
\hline 31-dez-99 & 35,10 & 39,20 & 42,00 & 56,00 & 63,00 & 55,80 \\
\hline 28-jan-00 & 25,20 & 30,80 & 45,60 & 29,40 & 73,60 & 28,00 \\
\hline $26-f e v-00$ & 49,80 & 48,30 & 65,80 & 31,50 & 28,70 & 24,50 \\
\hline 28-jun-00 & 82,60 & 34,30 & 50,50 & 28,70 & 25,90 & 27,30 \\
\hline 24-jul-00 & 22,40 & 21,70 & 56,00 & 18,90 & 17,50 & 16,10 \\
\hline 29-ago-00 & 37,80 & 40,60 & 34,30 & 20,30 & 20,30 & 20,30 \\
\hline 27 -out- 00 & 43,50 & 54,70 & 54,70 & 24,50 & 21,70 & 19,60 \\
\hline 21-dez-00 & 29,30 & 43,90 & 169,40 & 31,90 & 23,60 & 25,50 \\
\hline 31-jan-01 & 31,80 & 116,50 & 173,20 & 32,50 & 23,50 & 26,10 \\
\hline 21-fev-01 & 42,00 & 63,70 & 46,30 & 37,80 & 32,90 & 27,30 \\
\hline 25 -abr-01 & 26,60 & 192,50 & 51,10 & 23,10 & 16,80 & 24,50 \\
\hline
\end{tabular}

A matéria orgânica particulada (em lagos e oceanos) pode ser originada de fontes alóctones (adubação orgânica e rações) ou autóctones (matéria orgânica natural, sendo vegetal e animal). Isto inclui os organismos vivos e não-vivos, livres e flutuantes na água, que participam do sistema trófico. O reservatório Represa Velha sofre influência de ambas as fontes com intensidade expressiva. O maior e menor valor de sedimentos suspensos orgânicos foi de $192,50 \mathrm{mg} / \mathrm{L}$ (entrada) e $6,50 \mathrm{mg} / \mathrm{L}$ (área central) respectivamente.

\subsubsection{Caracterização dos Sedimentos Inorgânicos.}

Das amostras de sedimentos retidas nas câmaras de sedimentação, parte foi destinada à caracterização dos mesmos. Esta caracterização se deu através de um único ensaio realizado 
em 22 de outubro de 1998. Este ensaio, apesar de não ter sido utilizado na tese de Bufon (2006), foi por ele disponibilizado para esta pesquisa. Os procedimentos de preparação das amostras seguiram a NBR 6457 (Preparação de Amostras de Solo para ensaios de Compactação e Caracterização), com secagem natural (em ausência de sol), destorroamento e homogeneização por quarteamento. O ensaio de granulometria por sedimentação foi aplicado, com o intuito de classificar os solos finos $(d<0,074 \mathrm{~mm})$, tendo como base a Lei de Stokes, que relaciona a velocidade de queda das partículas, num meio líquido em repouso, com o diâmetro das mesmas. $\mathrm{O}$ ensaio de granulometria por peneiramento foi aplicado para a caracterização dos solos de diâmetros superiores ao anteriormente citado. Os ensaios granulométricos foram realizados segundo instruções da NBR 7181 (Análise Granulométrica de Solos). Os resultados são apresentados na Tabela 8, que constitui a base para o traçado da curva granulométrica (FIGURA 27).

TABELA 08 - Resultado do ensaio granulométrico (BUFON, 2006 ${ }^{18}$ )

\begin{tabular}{|c|c|c|c|c|c|}
\hline \multicolumn{6}{|c|}{ Perfil Granulométrico } \\
\hline \multicolumn{2}{|c|}{ Tipo Ensaio } & \multirow{2}{*}{$\frac{\text { Grãos (mm) }}{4,75}$} & \multirow{2}{*}{$\frac{\% \text { Retida }}{0,0}$} & \multirow{2}{*}{$\frac{\% \text { que passa }}{100,00}$} & \multirow{2}{*}{$\frac{\text { Tempo }}{-}$} \\
\hline \multirow{7}{*}{$\begin{array}{l}\text { Peneiras } \\
\text { (U.S.B.S.) }\end{array}$} & 4 & & & & \\
\hline & 10 & 2,00 & 1,6 & 98,40 & - \\
\hline & 16 & 1,19 & 1,7 & 98,30 & - \\
\hline & 40 & 0,42 & 3,5 & 96,50 & - \\
\hline & 60 & 0,24 & 5,4 & 94,60 & - \\
\hline & 100 & 0,149 & 14,7 & 85,30 & - \\
\hline & 200 & 0,074 & 35,1 & 64,90 & - \\
\hline \multirow{12}{*}{ 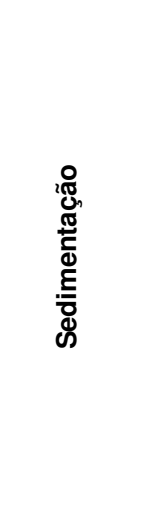 } & - & 0,058 & - & 48,15 & $30 \mathrm{~s}$ \\
\hline & - & 0,043 & - & 44,37 & $1 \mathrm{~min}$ \\
\hline & - & 0,031 & - & 43,88 & $2 \min$ \\
\hline & - & 0,021 & - & 43,88 & $4 \min$ \\
\hline & - & 0,015 & - & 43,01 & $8 \mathrm{~min}$ \\
\hline & - & 0,011 & - & 42,29 & $15 \mathrm{~min}$ \\
\hline & - & 0,008 & - & 41,41 & $30 \mathrm{~min}$ \\
\hline & - & 0,0056 & - & 41,12 & $60 \mathrm{~min}$ \\
\hline & - & 0,0040 & - & 39,23 & 2 horas \\
\hline & - & 0,0028 & - & 39,23 & 4 horas \\
\hline & - & 0,0021 & - & 38,94 & 8 horas \\
\hline & - & 0,0012 & - & 36,62 & 25 horas \\
\hline
\end{tabular}

\footnotetext{
${ }^{18}$ BUFON (2006). Dados obtidos por BUFON - Laboratório de Mecânica dos Solos -UFSC - São Carlos/SP.
} 


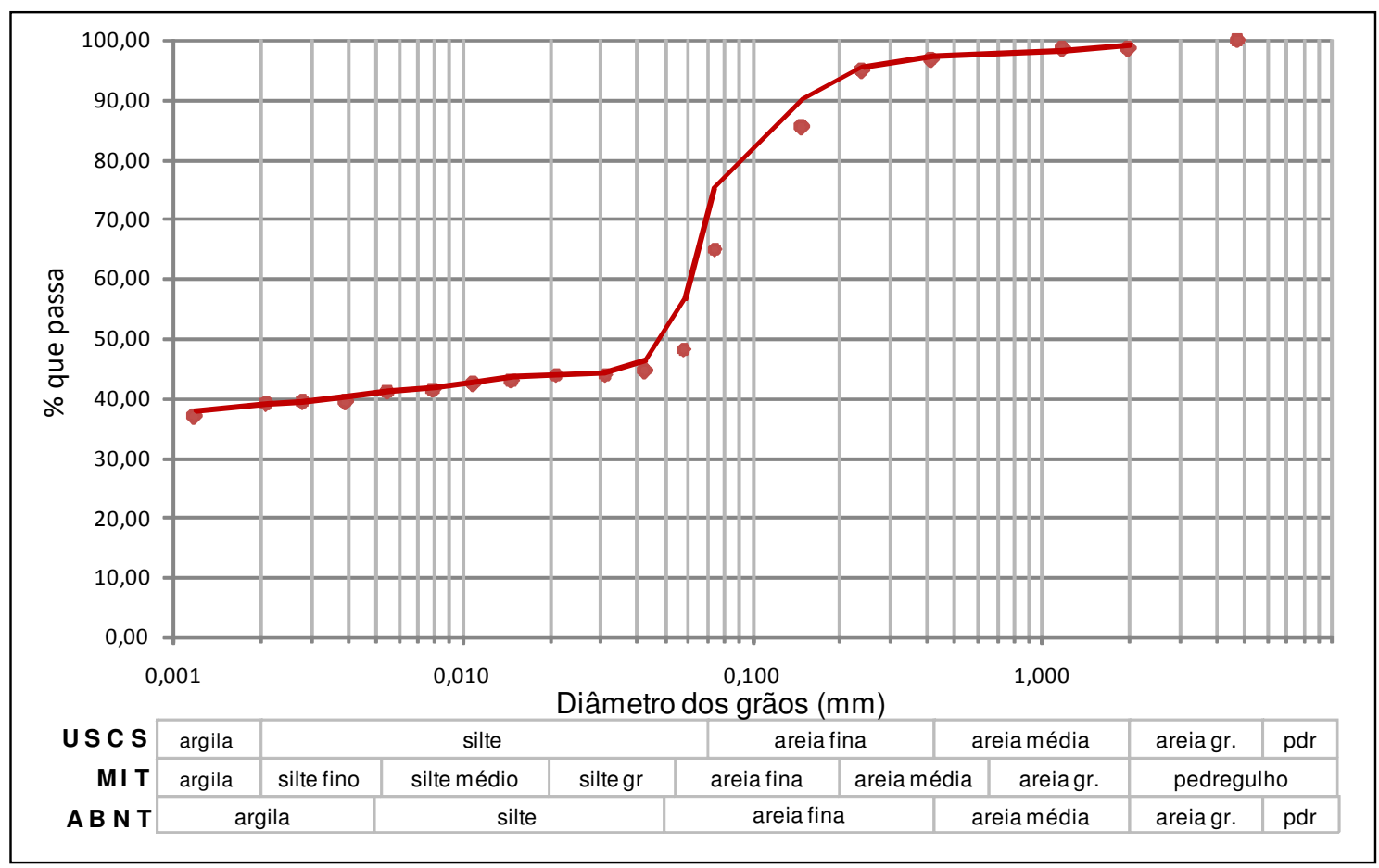

Figura 27. Curva Granulométrica (BUFON, 2006 ${ }^{18}$ )

No perfil dos sedimentos apresentado pela curva granulométrica, são mostradas algumas das principais escalas utilizadas para a classificação dos solos sendo: $A B N T$ (Associação Brasileira de Normas Técnicas), com classificação regida pela NBR 6502/95; MIT (Institute Massachusetts of Tecnology); e um dos mais utilizados por se tratar de sistema unificado internacional USCS (Unified Soil Classification System). Por este último método de classificação, as frações de solos obtidas correspondem a 38\% de argila, $12 \%$ de silte e 50\% de areia. Os diâmetros de cada fração $\left(\mathrm{d}_{50}\right)$ são $0,0013 \mathrm{~mm}, 0,022 \mathrm{~mm}$ e $0,10 \mathrm{~mm}$ para argila, silte e areia respectivamente. O diâmetro médio geral da curva granulométrica é de 0,049 mm. Carvalho (1994) ainda recomenda a utilização do método do American Geophysical Union devido ao seu cunho internacional. Numa análise comparativa entre as metodologias citadas, verificou-se uma modificação percentual muito pequena das frações de sedimentos, mantendo-se assim a distribuição obtida pelo método USCS. A densidade da amostra homogênea obtida (segundo NBR 6508 - Massa específica real dos grãos) foi de $2,73 \mathrm{~g} / \mathrm{cm}^{3}$. 


\subsection{Implementação da Simulação Numérica.}

Para a simulação numérica do assoreamento do reservatório Represa Velha, foi utilizado o programa computacional MIKE 21C, da empresa dinamarquesa DHI Water and Environment (DHI vem do antigo nome da empresa, Danish Hydraulic Institute). O MIKE 21C é um módulo do MIKE 21 (C vem de malha curvilínea), aplicável a problemas de hidráulica marítima e costeira e a hidromorfologia de rios. Este programa foi escolhido, adquirido e utilizado por Souza (2006) para modelagem do escoamento e do assoreamento em uma armadilha de sedimentos no laboratório de hidráulica ambiental da EESC-USP. Muitos são os trabalhos de validação e aplicação do MIKE 21C em sistemas reais, que consistem basicamente na prestação de serviços da DHI para empresas privadas. Trabalhos de validação do modelo numérico também foram desenvolvidos na Delft University of Technology, como Olesen (1987) e Talmon (1982). Algumas aplicações são apresentadas de forma sintética em DHI Water and Environment (2005).

A descrição da ficha técnica do MIKE 21C é feita resumidamente nos subitens 4.3.1 e 4.3.2, tendo como base o seu manual e o texto de Souza (2006). A configuração das simulações desse trabalho é apresentada no subitem 4.3.3. Informações técnicas detalhadas, as ferramentas e equacionamentos, podem ser encontrados em DHI (2004) e DHI (2005), também disponíveis em DHI Water and Environment (2005).

\subsubsection{Equacionamento do Modelo Hidrodinâmico.}

A hidrodinâmica de escoamentos com fundo móvel é caracterizada por padrões tridimensionais complexos. Isso tem que ser levado em consideração quando se estuda morfologia de rios e assoreamento de reservatórios. Por outro lado, a aplicação de um modelo hidrodinâmico tridimensional a simulações de grande escala de tempo (décadas, no caso de 
assoreamento de reservatórios) requer um grande trabalho computacional, muitas vezes inviável. Por isso, nesse programa, as equações de Navier-Stokes (conservação de massa e quantidade de movimento) são reduzidas a equações bidimensionais, no plano horizontal e integradas na vertical. Efeitos tridimensionais, chamados de escoamentos secundários, são mantidos através de um modelo de escoamento helicoidal. O equacionamento também adota hipóteses de distribuição hidrostática de pressão na vertical e ausência da condição de nãoescorregamento (velocidade zero) junto às paredes, fazendo com que o modelo seja aplicável a escoamentos de águas rasas (pequena profundidade com relação à largura do canal) e gradualmente variados.

A geração de malha pelo programa pode seguir uma configuração ortogonal e curvilínea ou por coordenadas cartesianas. A primeira opção é indicada como sendo ideal para escoamentos em rios e reservatórios (FIGURA 28). Considerando a geometria e dimensões do reservatório estudado nesta pesquisa (permitindo uma malha refinada), associados à simplicidade de geração da malha por coordenadas cartesianas devido aos dados de campo disponíveis, foi utilizada a segunda opção.

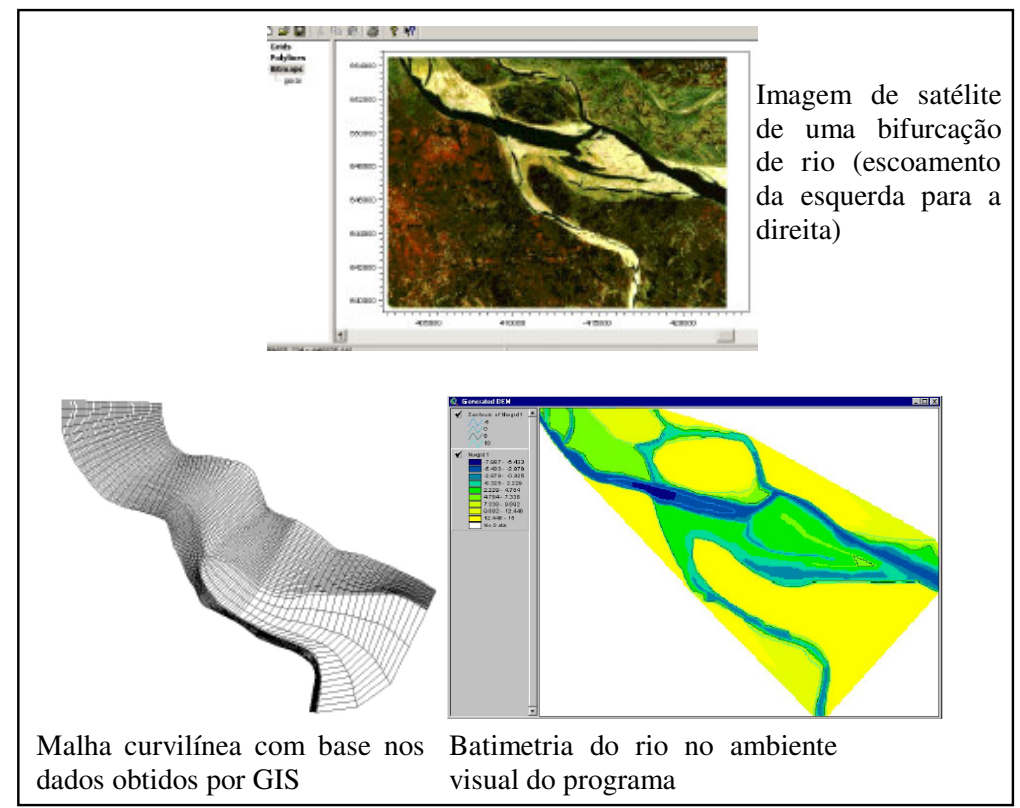

Figura 28. Processo de geração de malha curvilínea (DHI, 2005) 
As equações governantes do modelo, de conservação de massa e quantidade de movimento, descrevem o comportamento do escoamento em resposta às diferentes forças atuantes, referentes, por exemplo, às diferenças de nível da superfície da água e às condições de contorno do problema. Essas equações, para malhas cartesianas, são resolvidas através de um método de diferenças finitas, Alternating Direction Implicit Technique. Com as hipóteses adotadas, são também conhecidas como equações de Saint-Venant em duas direções, na forma como se segue:

- Conservação da massa:

$$
\frac{\partial \zeta}{\partial t}+\frac{\partial p}{\partial x}+\frac{\partial q}{\partial y}=\frac{\partial d}{\partial t}
$$

- Quantidade de movimento na direção x:

$$
\begin{aligned}
& \frac{\partial p}{\partial t}+\frac{\partial}{\partial x}\left(\frac{p^{2}}{h}\right)+\frac{\partial}{\partial y}\left(\frac{p q}{h}\right)+g h \frac{\partial \zeta}{\partial x}+\frac{g p \sqrt{p^{2}+q^{2}}}{C^{2} h^{2}}- \\
& \frac{1}{\rho_{w}}\left[\frac{\partial}{\partial x}\left(h \tau_{x x}\right)+\frac{\partial}{\partial y}\left(h \tau_{x y}\right)\right]-\Omega q-\mathrm{fVV}_{x}+\frac{h}{\rho_{w}} \frac{\partial}{\partial x}\left(p_{a}\right)=0
\end{aligned}
$$

- Quantidade de movimento na direção y:

$$
\begin{aligned}
& \frac{\partial \mathrm{q}}{\partial \mathrm{t}}+\frac{\partial}{\partial \mathrm{y}}\left(\frac{\mathrm{q}^{2}}{\mathrm{~h}}\right)+\frac{\partial}{\partial \mathrm{x}}\left(\frac{\mathrm{pq}}{\mathrm{h}}\right)+\mathrm{gh} \frac{\partial \zeta}{\partial y}+\frac{\mathrm{gq} \sqrt{\mathrm{p}^{2}+\mathrm{q}^{2}}}{\mathrm{C}^{2} \mathrm{~h}^{2}}- \\
& \frac{1}{\rho_{\mathrm{w}}}\left[\frac{\partial}{\partial \mathrm{y}}\left(\mathrm{h} \tau_{\mathrm{yy}}\right)+\frac{\partial}{\partial \mathrm{x}}\left(\mathrm{h} \tau_{\mathrm{xy}}\right)\right]-\Omega \mathrm{p}-\mathrm{fVV}_{\mathrm{y}}+\frac{\mathrm{h}}{\rho_{\mathrm{w}}} \frac{\partial}{\partial \mathrm{y}}\left(\mathrm{p}_{\mathrm{a}}\right)=0
\end{aligned}
$$

onde:

$\mathrm{h}(\mathrm{x}, \mathrm{y}, \mathrm{t}) \quad$ profundidade do escoamento $=\zeta$-d $(\mathrm{m})$

$\mathrm{d}(\mathrm{x}, \mathrm{y}, \mathrm{t}) \quad$ altura do leito variando no tempo $(\mathrm{m})$;

$\zeta(\mathrm{x}, \mathrm{y}, \mathrm{t}) \quad$ elevação da superfície $(\mathrm{m})$

$\mathrm{p}, \mathrm{q}(\mathrm{x}, \mathrm{y}, \mathrm{t}) \quad$ vazão específica nas direções $\mathrm{x}$ e $\mathrm{y}=\mathrm{uh}, \mathrm{vh}\left(\mathrm{m}^{3} / \mathrm{s} / \mathrm{m}\right)$;

$\mathrm{u}, \mathrm{v}(\mathrm{x}, \mathrm{y}, \mathrm{t}) \quad$ velocidades médias na profundidade, nas direções $\mathrm{x}$ e y $(\mathrm{m} / \mathrm{s})$; 


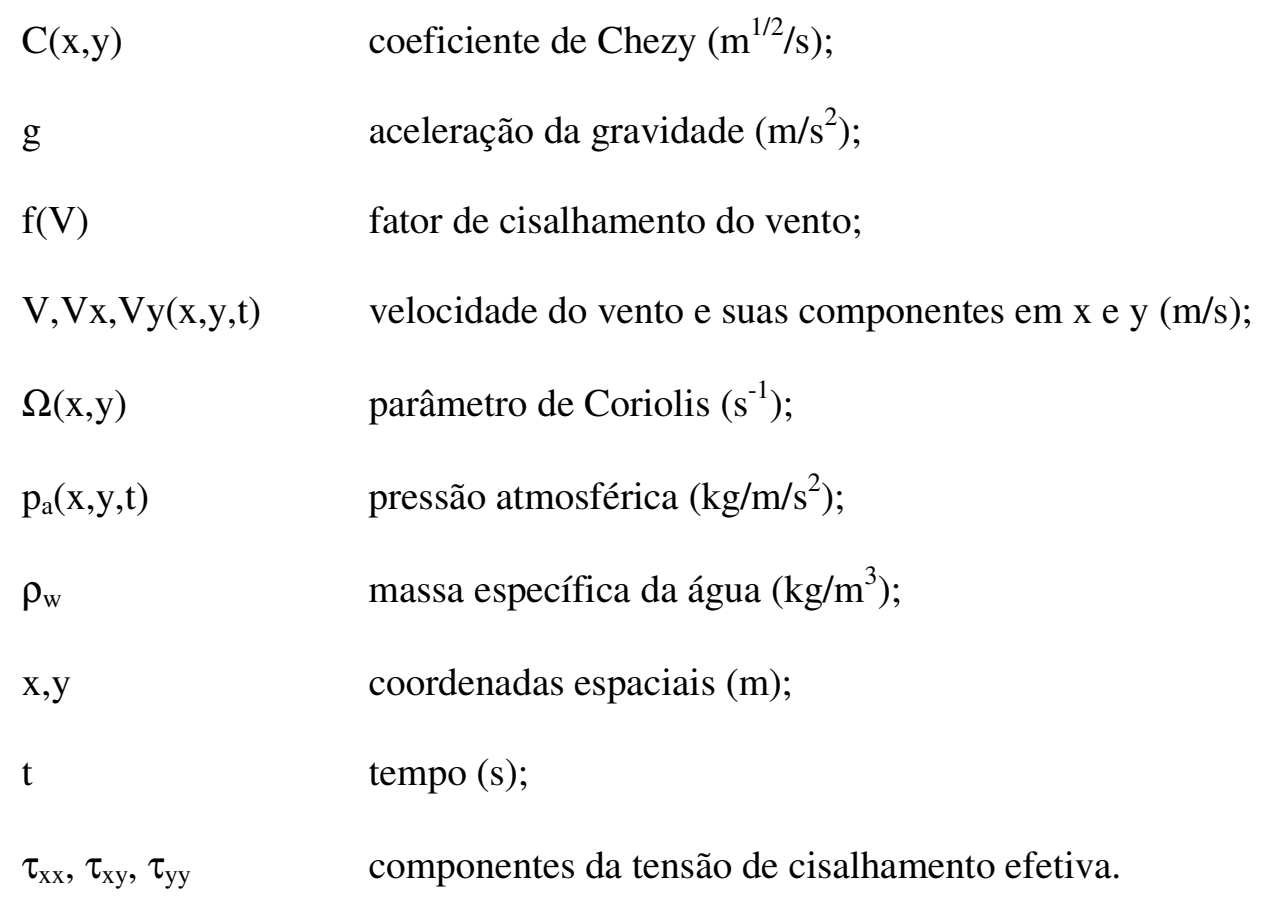

\subsubsection{Escoamento Helicoidal.}

Quando o escoamento livre muda de direção, um desbalanço de força centrípeta gera um movimento para fora da curva junto à superfície e para dentro da curva junto ao fundo. A razão disso é que, de acordo com a distribuição de velocidade vertical para escoamentos livres, a parte superior do escoamento tem maior velocidade. Em consequiência, partículas na parte superior seguem um caminho com maior raio de curvatura para manter aproximadamente constante a força centrípeta ao longo da profundidade (a aceleração centrípeta é igual à razão entre o quadrado da velocidade e o raio de curvatura). A forma do escoamento pode ser considerada como a soma da componente longitudinal do escoamento com o movimento helicoidal, como mostrado na Figura 29. 


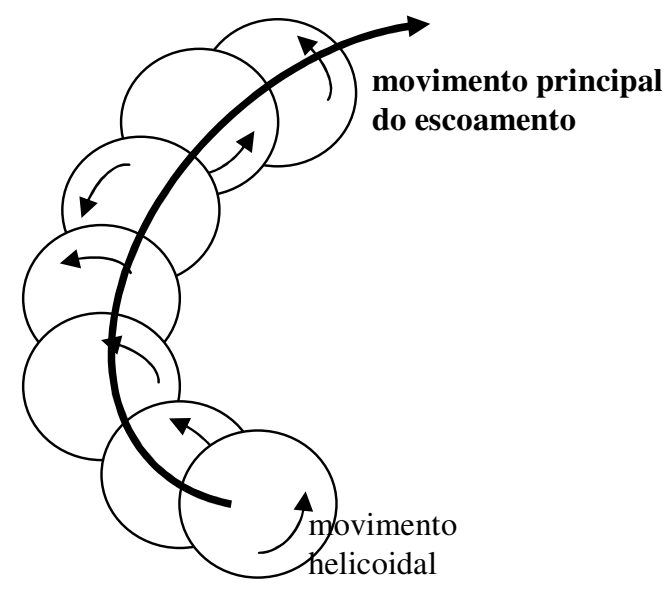

Figura 29. Efeitos de movimento considerados em uma curva (figura adaptada de DHI, 2004)

O movimento helicoidal causa uma pequena variação na direção do escoamento principal junto ao fundo. Em conseqüência, ocorrem também mudanças na direção da tensão de cisalhamento, no transporte de sedimentos em suspensão e na topografia do fundo móvel. A modelagem proposta por Rozovskii (1957) para a nova direção da tensão de cisalhamento junto ao fundo é incluída no programa. As novas direções do escoamento junto à superfície, junto ao fundo e da tensão de cisalhamento, são ilustradas simplificadamente e sem apresentação do extenso equacionamento, na Figura 30.

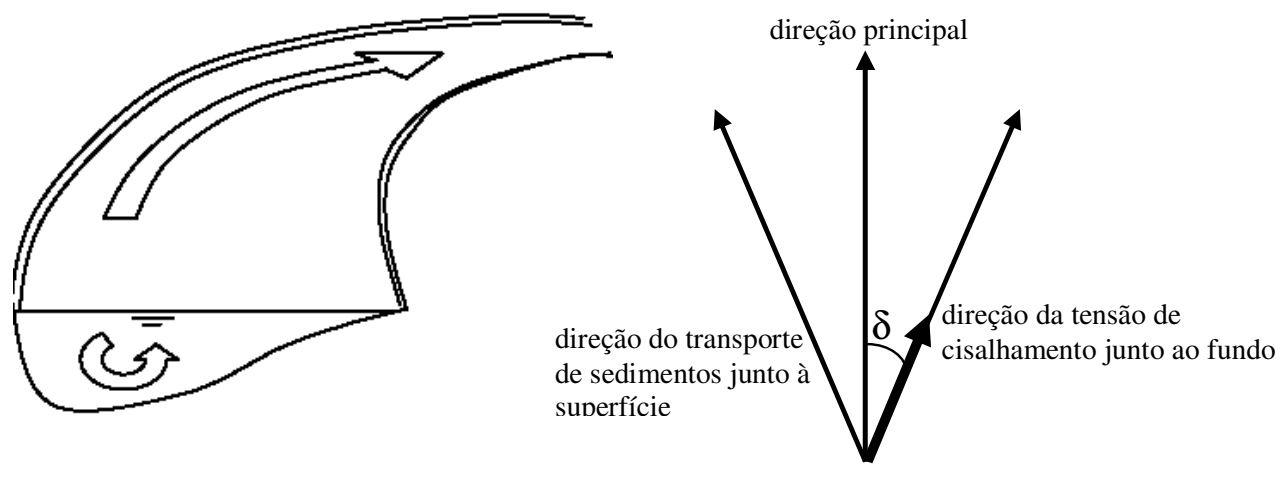

Figura 30. Direções do escoamento, do transporte de sedimento e da tensão de cisalhamento (figura adaptada de DHI, 2004) 
Embora o movimento helicoidal não modifique consideravelmente o padrão de escoamento de águas rasas, sua influência no transporte de sedimentos e na morfologia pode ser significativa.

\subsubsection{Modelagem da Turbulência.}

A viscosidade turbulenta pode ser introduzida ou não nos escoamentos simulados, sobre a quantidade de movimento, de diferentes formas:

- Escoamento invíscido: a viscosidade é desprezada.

- Viscosidade constante: um valor constante pode ser aplicado para todo o domínio ou diferentes valores podem ser especificados para as células da malha computacional.

- Formulação de Smagorisnky: modelo dinâmico com uma equação de fechamento para turbulência. Esse equacionamento é baseado no conceito de Smagorinsky (1963), para cálculo do coeficiente de viscosidade turbulenta.

Detalhes do equacionamento podem ser obtidos em Lilly (1966), Leonard (1974), Aupoix (1984) e Horiuti (1987).

\subsubsection{Modelo de Transporte de Sedimentos.}

Como descrito na revisão bibliográfica deste trabalho, o transporte fluvial de sedimentos é classificado tradicionalmente em transportes de fundo (bed load transport) e de suspensão (suspended load). A primeira classe constitui o material que forma o leito, transportado mediante deslizamentos, rolamentos ou saltos e, a segunda, por sedimentos ressuspensos do fundo (com permanência temporária) e originados pelo wash load (com 
permanência "constante"). Este mecanismo de classificação tradicional pode ser encontrado em Jansen et al. (1979), cujo esquema é apresentado na Figura 31.

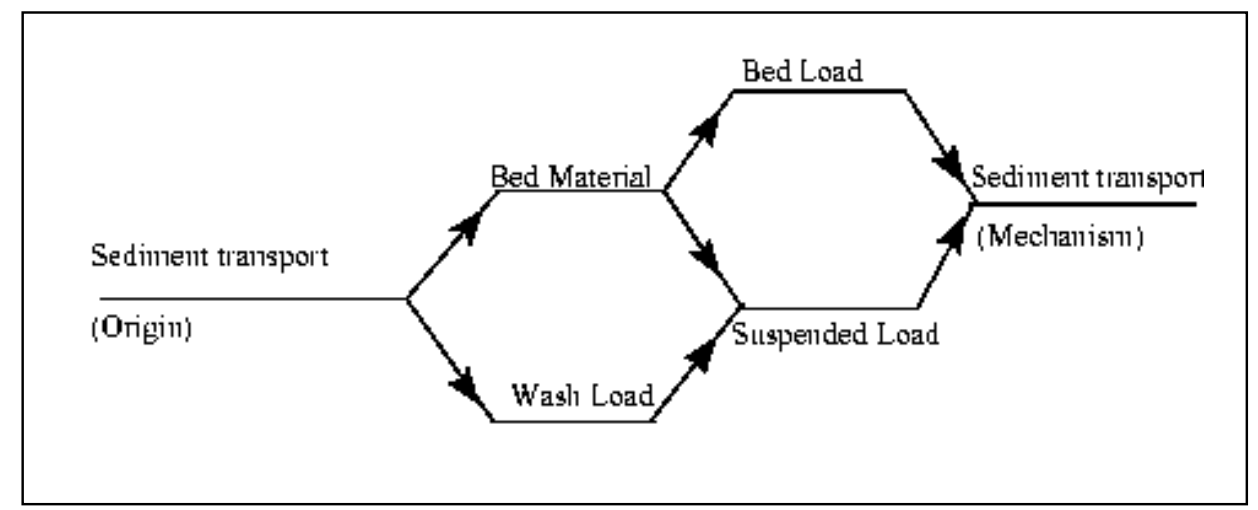

Figura 31. Classificação do transporte de sedimentos (JANSEN et al., 1979)

No presente trabalho, onde é estudado o desenvolvimento do assoreamento, com interação entre batimetria e hidrodinâmica, considerando as características reais do sistema, o material do leito é o fator importante. Assim, o transporte de fundo e parte do transporte em suspensão, no reservatório, é considerado pelo modelo. Os sedimentos envolvidos na modelagem deste trabalho são aqueles que se depositaram nas câmaras de sedimentação fixada a $50 \mathrm{~cm}$ do sedimento de fundo.

A seguir, os dois tipos de transporte são tratados separadamente, de forma simplificada. Posteriormente, equacionamentos clássicos da literatura para quantificação desses transportes e implementados no modelo (do programa MIKE 21C) são citados.

\subsubsection{Transporte em Suspensão.}

O modelo para transporte em suspensão é baseado na teoria descrita por Galappatti (1983). O transporte é representado por uma equação de advecção-dispersão, dada por:

$$
\frac{\partial c}{\partial t}+u \frac{\partial c}{\partial x}+v \frac{\partial c}{\partial y}+w \frac{\partial c}{\partial z}=w_{s} \frac{\partial c}{\partial z}+\frac{\partial}{\partial x}\left(\varepsilon \frac{\partial c}{\partial x}\right)+\frac{\partial}{\partial y}\left(\varepsilon \frac{\partial c}{\partial y}\right)+\frac{\partial}{\partial z}\left(\varepsilon \frac{\partial c}{\partial z}\right)
$$


onde:

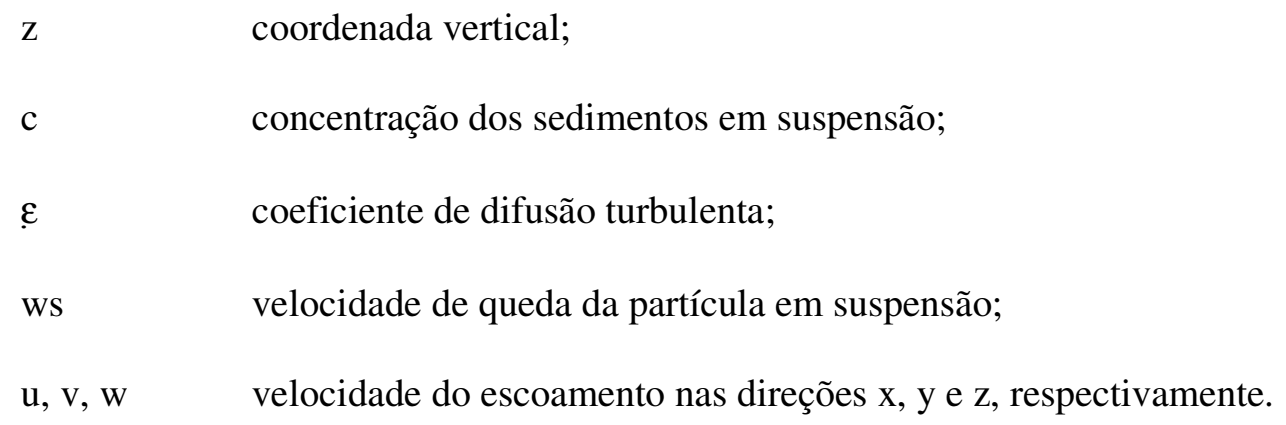

As condições de contorno especificam fluxo zero na superfície e certa concentração para uma altura logo acima do leito, que divide as regiões de transportes de fundo e em suspensão. Nessa teoria, esta altura é igual $2 \%$ da profundidade do escoamento.

Apesar de o modelo hidrodinâmico ser baseado na integração vertical da velocidade, informação a respeito da distribuição vertical dessa propriedade (velocidade) é necessária para determinação da tensão de cisalhamento junto ao fundo e para cálculo do transporte de sedimentos em suspensão. Por esse motivo, perfis de concentração de sedimentos e de distribuição vertical de velocidade são incorporados no equacionamento.

\subsubsection{Transporte de Fundo.}

Em contraste com o transporte em suspensão, assume-se na modelagem que o transporte de fundo responde imediatamente às mudanças hidrodinâmicas locais. Assim, não há necessidade de uma equação de advecção-dispersão. Porém, leva-se em consideração a mudança de direção da tensão de cisalhamento junto ao leito, devido ao movimento helicoidal, e a alteração no transporte em conseqüência da declividade do leito. Estudos relacionando declividade do leito e transporte de fundo podem ser encontrados em Lane (1953), Koch (1980), Ikeda (1980) e Olesen (1987). 


\subsubsection{Equações de Transporte de Sedimentos.}

As equações semi-empíricas disponibilizadas pelo MIKE 21C para o cálculo do transporte de sedimentos são:

- Van-Rijn (1984) - para transporte de fundo e em suspensão com diâmetros representativos entre 200 e 2000 microns;

- Meyer-Peter e Müller (1948) - para transporte de fundo por arraste com diâmetro médio aritmético entre 0,4 e 4,22 $\mathrm{mm}$;

- Smart and Jaeggi (1983) - para transporte de fundo por arraste com diâmetro médio superior a $0,4 \mathrm{~mm}$ e $\mathrm{d}_{90} / \mathrm{d}_{30}$ menor do que 8,5 (inclui a não-uniformidade das partículas e o efeito da declividade no método anteriormente citado);

- Yang (1983) - para transporte total em rios com sedimentos arenosos não coesivos;

- Yang (1984) - para transporte de fundo em rios com sedimentos pedregulhosos;

- Engelund-Hansen (1967) - para transporte total em rios com leito de areia e escoamento subcrítico;

- Engelund-Fredsøe (1976) - para transporte de fundo e em suspensão de sedimentos arenosos não coesivos.

A escolha do equacionamento deve-se às limitações teóricas que validam a aplicação e a experiência adquirida em outros estudos. No modelo desenvolvido por Engelund-Hansen (1967), para a estimativa do transporte total (de fundo + em suspensão), dois fatores, $\mathbf{k}_{\mathbf{b}}$ e $\mathbf{k}_{\mathbf{s}}$, são inseridos na modelagem. A partir de calibração, como parâmetros de entrada, cada um multiplica o transporte total, para determinação das frações representativas de cada tipo de transporte. Por exemplo, caso se especifique $\mathbf{k}_{\mathbf{b}}=0,9$ e $\mathbf{k}_{\mathbf{s}}=0,1,90 \%$ do transporte será considerado de fundo e 10\% em suspensão. Já a equação de Engelund-Fredsøe (1976), por 
exemplo, apresenta separadamente cálculos para transporte de fundo e em suspensão, a exemplo de Van-Rijn (1984). Com relação ao modelo de Yang (1983), apesar de ser um dos métodos que apresenta maior acuracidade nas condições de aplicação, pode não representar a melhor escolha para o MIKE 21C que usa uma descrição de não equilíbrio para o transporte de sedimentos suspensos (DHI, 2005). A razão para isto é que a relação de transporte do método não dá nenhuma informação de como o transporte total deveria ser dividido em carga de fundo e carga suspensa. Observadas as características dos sedimentos, as limitações dos modelos clássicos de transporte, e as aplicações feitas pelo MIKE 21C, foram utilizadas neste trabalho as equações de Engelund-Hansen (1967) e de Engelund-Fredsøe (1976). Esta última foi empregada por Souza (2006) para $d_{50}=0,12 \mathrm{~mm}$, e traz o transporte de fundo como $\mathbf{q}_{\mathbf{b}}$ e o transporte em suspensão como $\mathbf{q}_{\mathbf{s}}$. A primeira tem sido utilizada em trabalhos da DHI e testada em outros trabalhos com êxito para diâmetros finos. A aplicação desta equação, com restrições, para diâmetros maiores que $0,15 \mathrm{~mm}$, têm gerado resultados satisfatórios. A síntese de ambos os métodos é apresentado no ANEXO A p.167. O ANEXO B p.168 traz o trabalho, na ítegra, de Engelund-Fredsøe (1976), para o qual foram obtidos os melhores resultados deste trabalho.

\subsubsection{Configuração da Simulação.}

Para a apresentação da configuração da simulação numérica, três etapas distintas são seguidas: elaboração da malha computacional, simulação hidrodinâmica e simulação do assoreamento. Apesar de ser uma sequência lógica, a necessidade de calibração dos parâmetros faz com que as etapas sejam interativas dentro de um processo dinâmico para a obtenção de uma configuração ideal em cada caso. 


\subsubsection{Elaboração da Malha Computacional.}

O processo em si de elaboração da malha computacional por coordenadas cartesianas é relativamente simples. Contudo, dependendo do número de células da grade, o tempo de confecção torna-se exaustivo devido à inserção (célula por célula) das cotas de fundo levantadas pela batimetria. No presente estudo, a malha final foi obtida após um período de 6 meses. Isto se deve principalmente às instabilidades numéricas ocorridas na simulação hidrodinâmica e também de sedimentos. A malha é composta por 45.569 células com $1 \mathrm{~m}$ de lado (FIGURA 32).

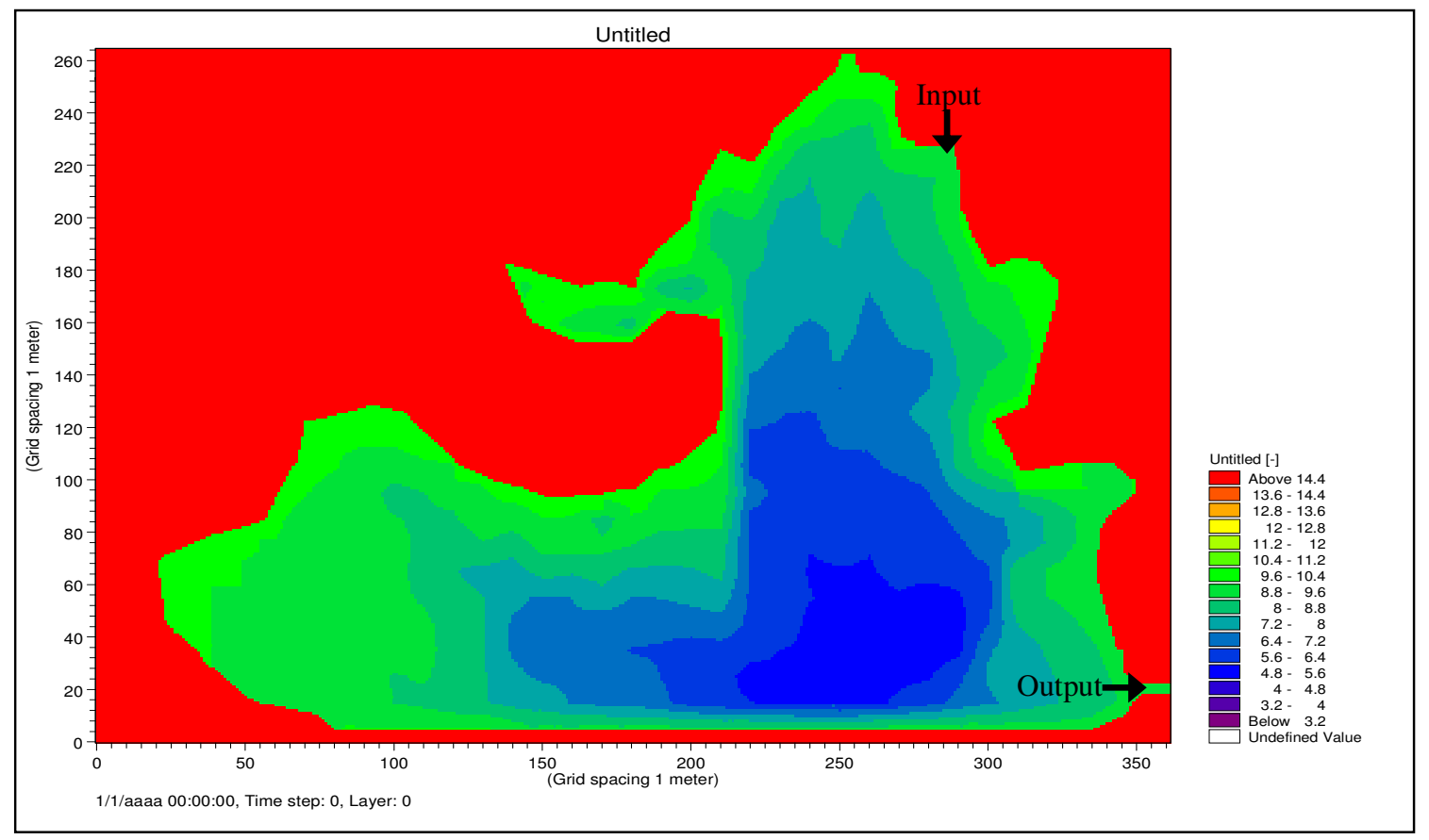

Figura 32. Malha computacional do reservatório Represa Velha

A variação topográfica apresentada na Figura acima (cores verde e azul) corresponde à batimetria de 1998. Para a consideração das cotas de fundo em cada célula, foi realizada interpolação linear, tendo em vista que os pontos levantados pela batimetria são espaçados em $10 \mathrm{~m}$. Na entrada, a cota de fundo corresponde a $9 \mathrm{~m} \mathrm{e}$, na interface do reservatório com o 
canal de saída é de $8,96 \mathrm{~m}$. Este canal natural tem extensão de $10 \mathrm{~m}$ por $5 \mathrm{~m}$ de largura, e declividade de $0,0001 \mathrm{~cm} / \mathrm{m}$, tendo sido aproximado por uma geometria retangular por questão de estabilidade numérica. Foi suprimido propositadamente o trecho do córrego da Barrinha, afluente ao reservatório, uma vez que o ponto de amostragem para a estimativa da vazão e concentração de sedimentos, na entrada, está localizado já dentro da represa.

\subsubsection{Simulação da Hidrodinâmica.}

Apesar de não estar desacoplada da modelagem do transporte de sedimento, no MIKE 21C a simulação hidrodinâmica é realizada, primeiramente, para se estabelecer uma condição de regime. Nesta fase, a ocorrência de instabilidades numéricas provocadas pela deficiência da malha e adoção do número de Courant (fora da faixa de estabilidade), podem ser identificadas. A seguir, são apresentados os parâmetros considerados e a abordagem feita nesta etapa, dentro da interface visual ou "janelas" do programa.

Defini-se inicialmente o tipo de simulação desejada que, no momento, é apenas para a hidrodinâmica do escoamento (FIGURA 33).

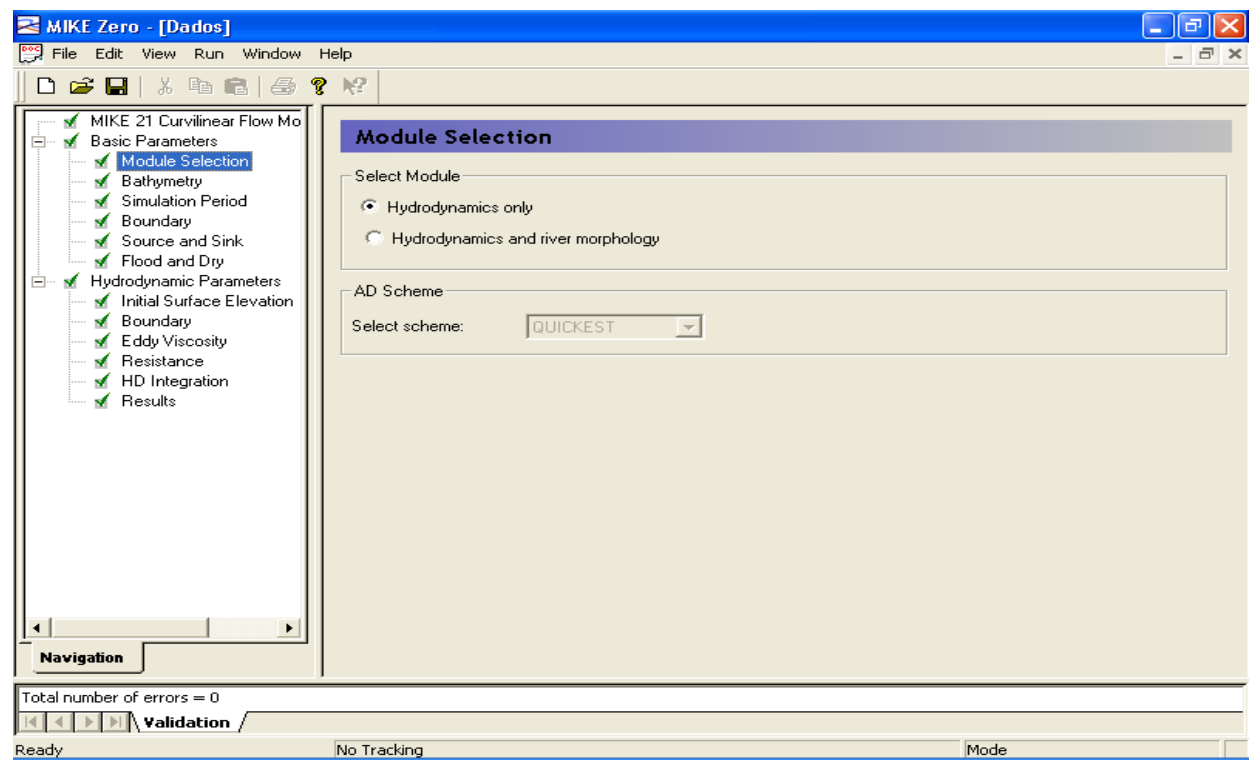

Figura 33. Seleção do tipo de simulação (somente hidrodinâmica, nesse momento). 
Os arquivos, já criados, contendo malha computacional e batimetria do domínio em estudo (FIGURA 32), são inseridos no modelo (FIGURA 34).

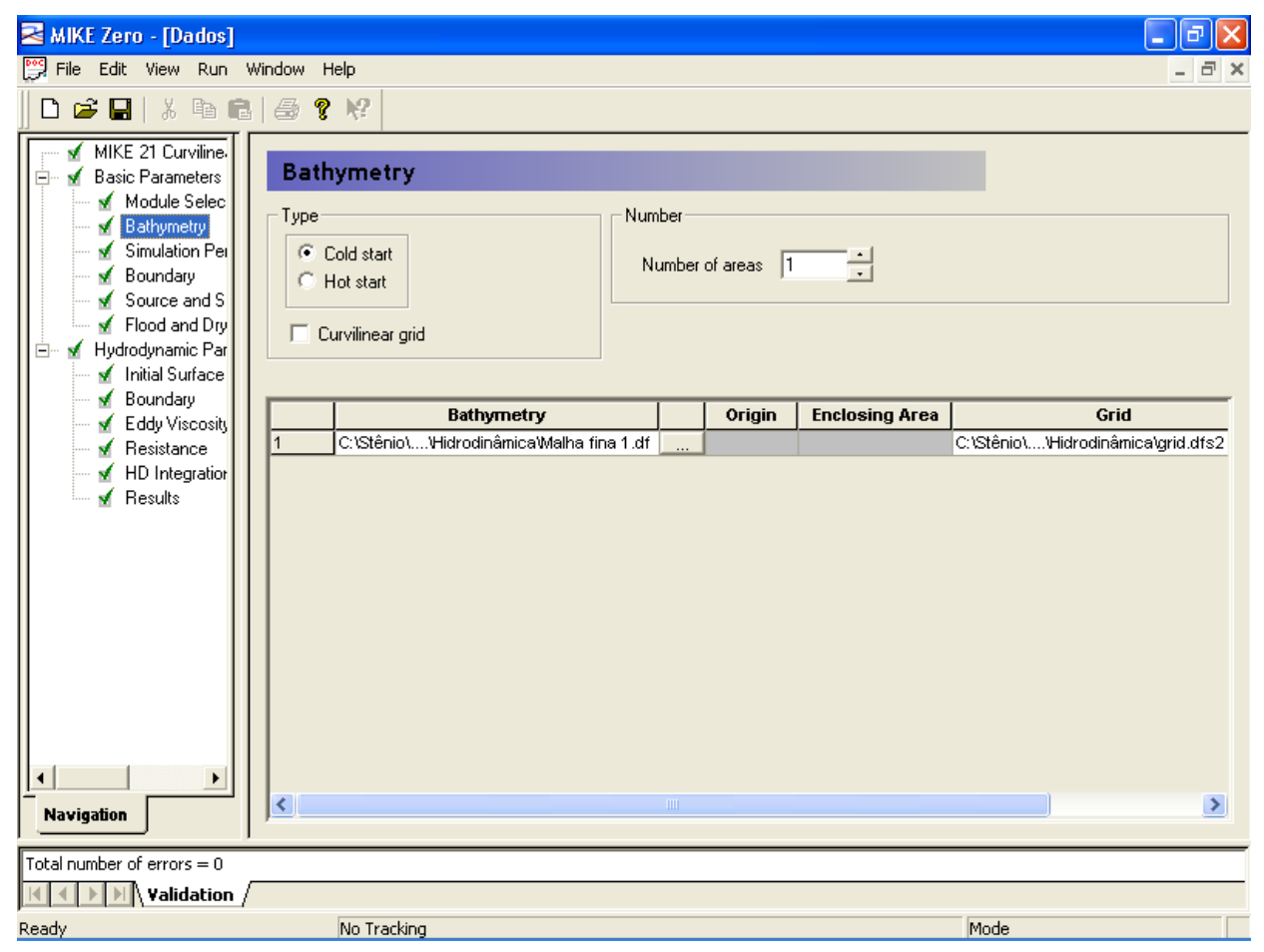

Figura 34. Carregamento dos arquivos malha computacional e batimetria.

O período de simulação é definido (FIGURA 35). Adotou-se um passo no tempo de 2 segundos, coerente com a malha computacional e a velocidade do fluido no reservatório. Isto foi verificado através do número de Courant, dentro da característica de variação de profundidade do reservatório. O manual do MIKE 21C especifica Courant máximo de 20, para casos de variações amenas de profundidades. No presente caso, os valores limites são 13,8 e 0,88, que correspondem à máxima e mínima profundidade na represa respectivamente. A simulação foi interrompida após 216.000 passos no tempo (5 dias de escoamento real), instante este maior que o tempo necessário para o estabelecimento do regime permanente (129.600 passos no tempo). O final dessa simulação representa exatamente o início da simulação do assoreamento (22 agosto de 1998) que foi realizada posteriormente. 


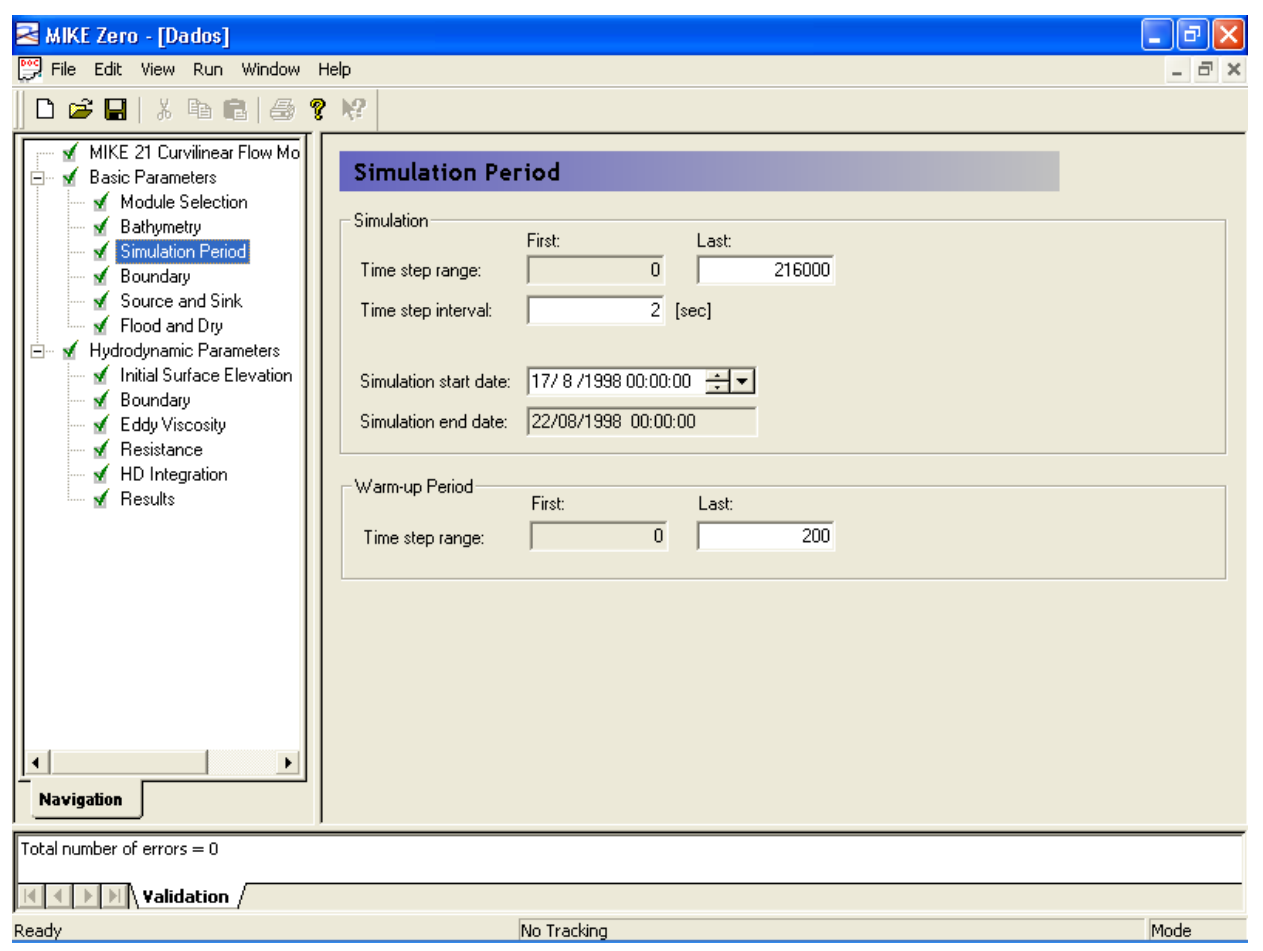

Figura 35. Período de simulação e passo de tempo.

Na opção Boundary (FIGURA 36), são inseridas as células de contorno do reservatório ou rio estudado. O MIKE 21C detecta automaticamente os contornos através da função Program detected quando estes fazem parte da fronteira da malha. Do contrário, como é o caso do presente estudo, a função User specified deve ser acionada. O número máximo de contornos contemplados pelo programa é de 14 (catorze). No estudo de grandes reservatórios (reservatório de Promissão, por exemplo), por haver um número de contornos superior ao valor supramencionado, necessitar-se-ia de uma divisão da malha acarretando em uma maior dificuldade para simulação. 


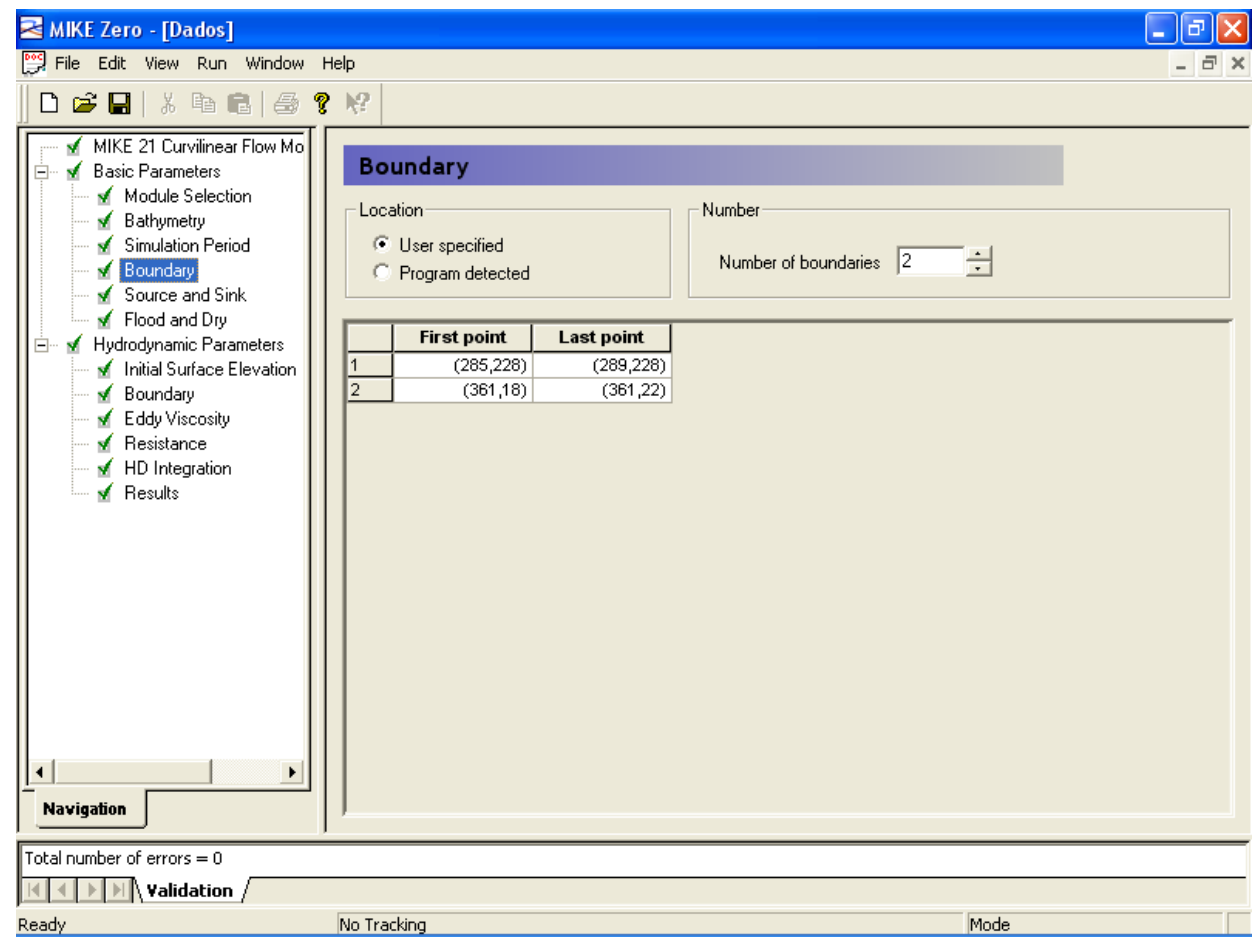

Figura 36. Especificação da quantidade de contornos e células correspondentes.

A função Source and Sink (FIGURA 37) permite abordar fontes ou sumidouros presentes no reservatório. No interior da Represa Velha existem minas que interferem no padrão do escoamento e principalmente na taxa de sedimentação. Como a localização e medição de vazão destas fontes são praticamente inviáveis, não foram consideradas na simulação. Descarregadores de fundo também foram executados na represa para a realização de flushing. Uma simulação desta operação poderia ser feita caso houvesse dados para calibração do modelo. Portanto, o número de fontes e sumidouros considerado pelas simulações deste trabalho foi nulo.

Na Figura 38 é mostrada a opção Flood and Dry, utilizadas para regiões inicialmente molhadas e que se tornam secas devido ao assoreamento e que podem tornar-se molhadas novamente mediante processo de erosão. Os valores adotados foram objetos de calibração, tendo como referência o manual do MIKE 21C e a experiência adquirida no trabalho de Souza (2006). Se os valores adotados para ambos são iguais, pode ocorrer instabilidade nos cálculos. 


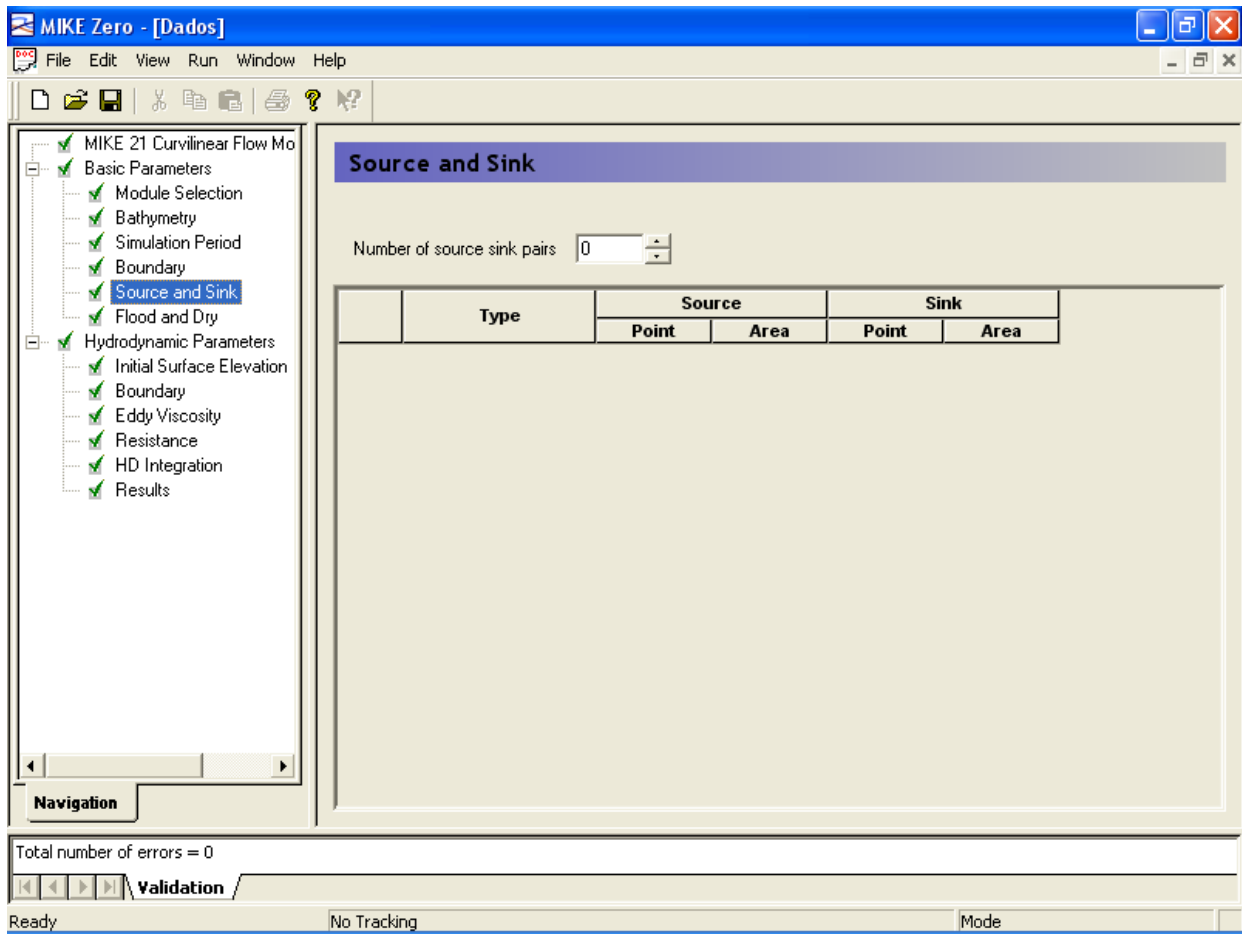

Figura 37. Pontos de fonte e sumidouro de massa (não foi considerado).

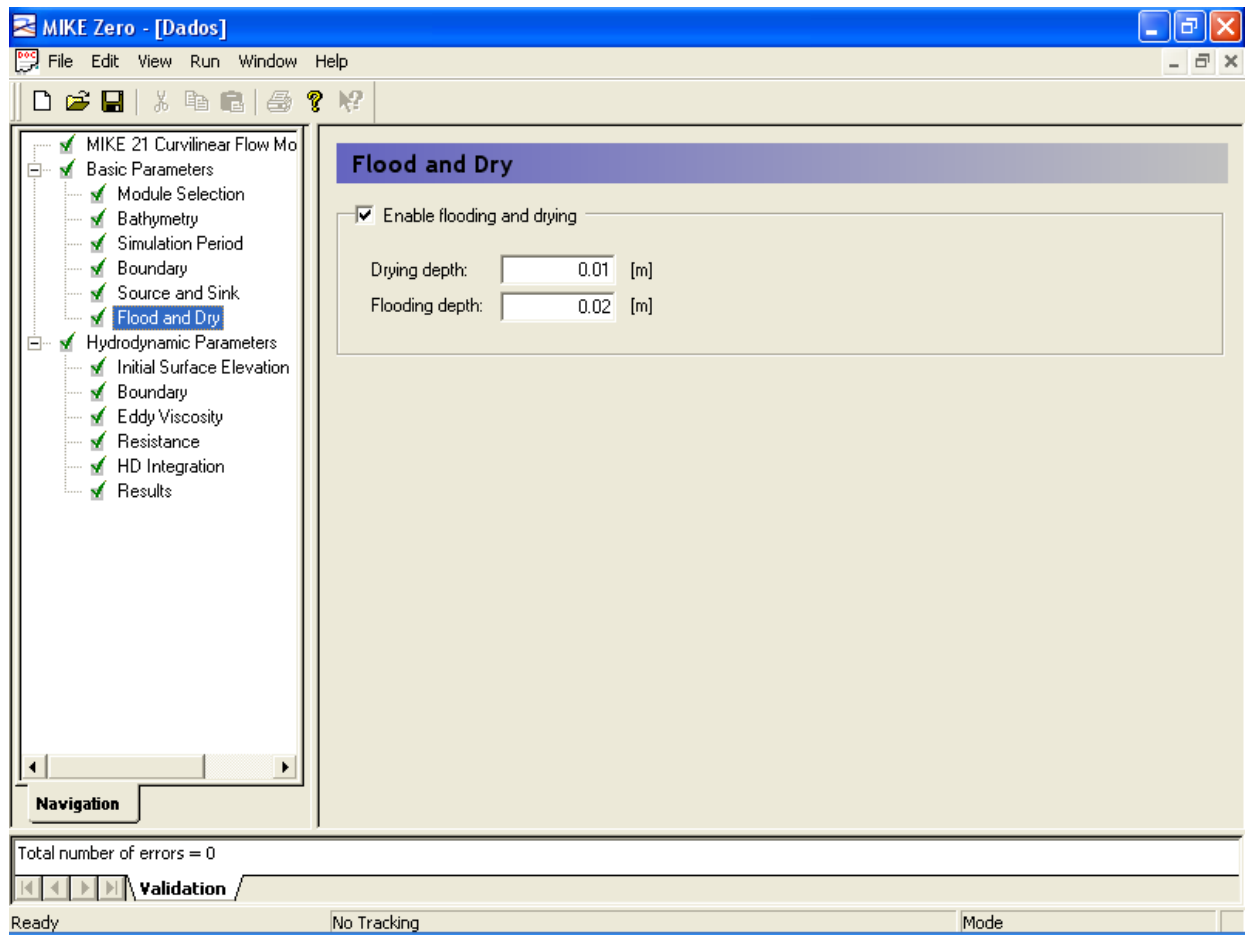

Figura 38. Profundidades consideradas no cálculo de regiões secas e molhadas. 
O nível de água no reservatório é considerado inicialmente constante (FIGURA 39). O valor de NA=10 m especificado nesta simulação refere-se à batimetria de agosto de 1998 . Vale ressaltar que este nível inicial considerado pelo programa envolve inclusive os canais de entrada e de saída. Uma simulação que se estendesse até um trecho de montante do córrego da Barrinha, cujo nível de água está acima do reservatório Represa Velha, ficaria prejudicada.

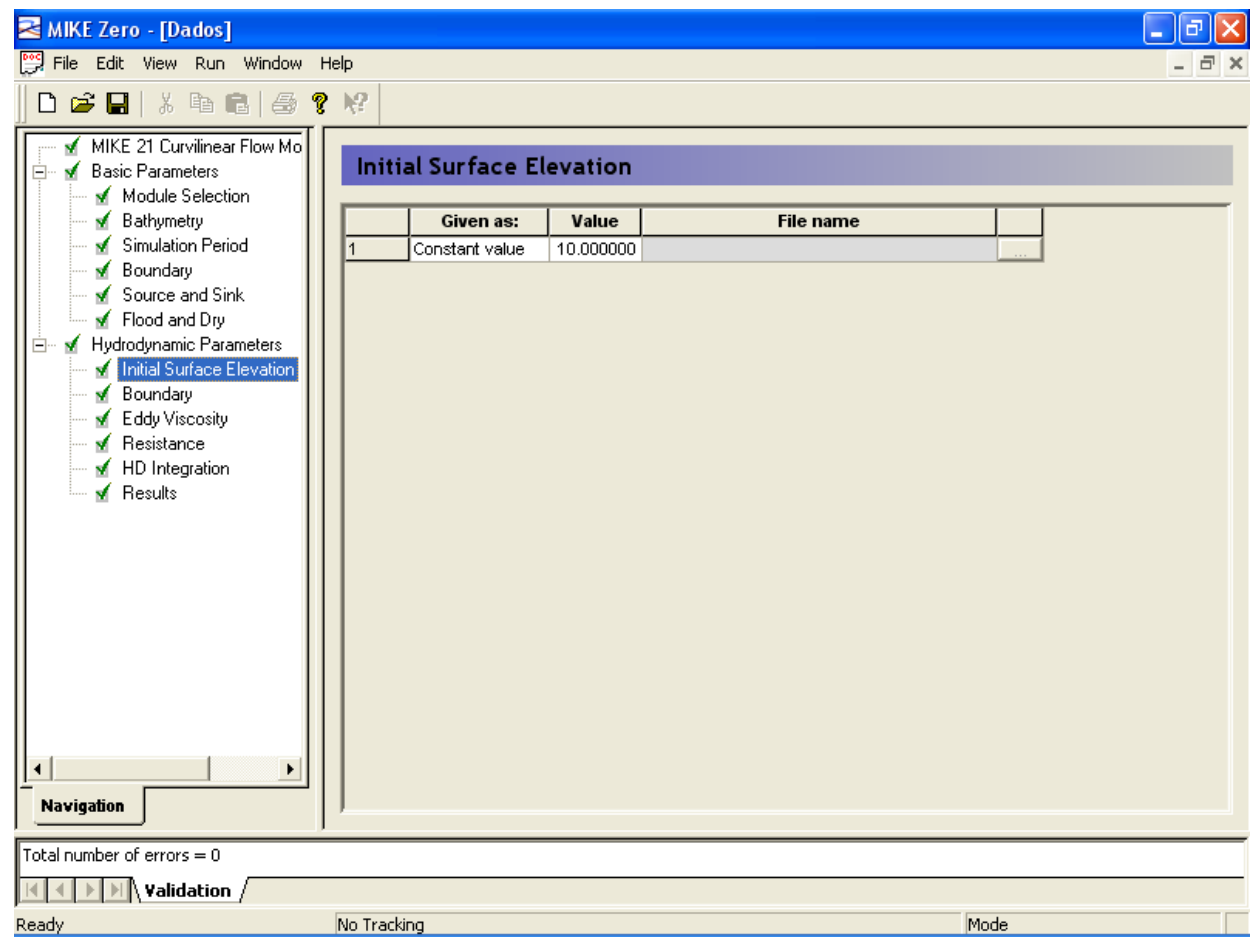

Figura 39. Nível de água inicial no reservatório.

As condições de contorno do problema foram definidas (FIGURA 40), como geralmente faz-se para escoamentos livres em regime fluvial, com a profundidade do escoamento a jusante e a vazão a montante. As vazões medidas na saída do reservatório foram adotadas como contorno de montante, uma vez que as minas de água existentes no reservatório não foram consideradas na simulação. Assim, as vazões de entrada e saída, em cada período da simulação são iguais. Com as características físicas do canal de saída (fraca declividade) foi obtida a altura de água via equação da energia $(\mathrm{y}=1,04 \mathrm{~m})$. Ambos parâmetros (vazão e altura de água na saída) são considerados constantes em cada período da 
simulação, que corresponde aos períodos de medição de campo. A vazão de $129 \mathrm{~L} / \mathrm{s}$ refere-se ao mês de agosto de 1998, onde foi realizada a primeira batimetria da represa.

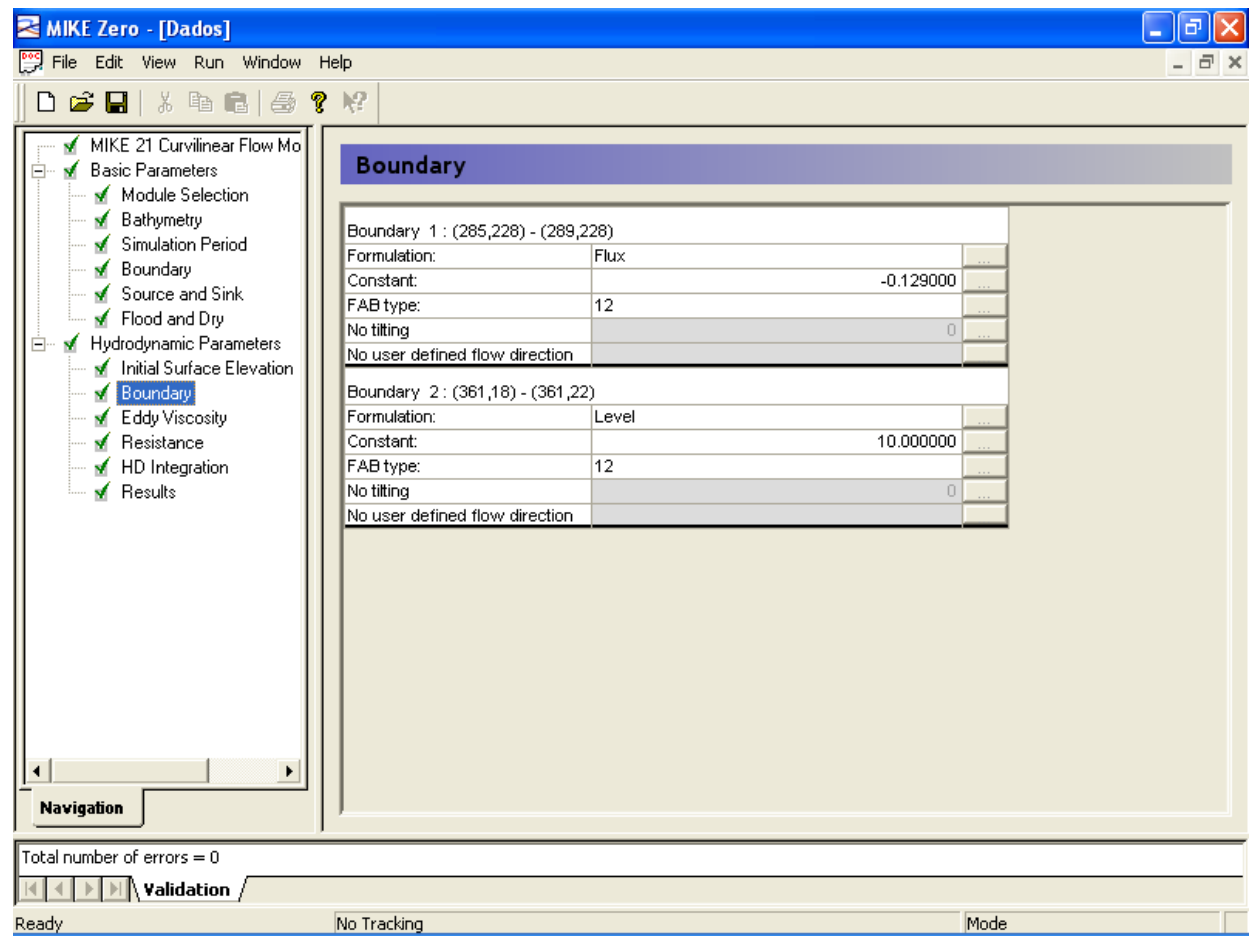

Figura 40. Condições de contorno do problema.

A viscosidade turbulenta (FIGURA 41) foi modelada a partir da formulação de Smagorinsky (1963). O parâmetro de calibração adotado foi $C_{S}=0,5$. Testes realizados por Souza (2006) não identificaram variações consideráveis no padrão de escoamento, mesmo quando utilizados os valores extremos de 0,25 e 1,0. Algumas simulações feitas nesta etapa variando estes coeficientes corroboram esta afirmação.

A formulação de Chezy é usada para se calcular a perda de carga do escoamento (equações de resistência). A calibração é feita a partir do parâmetro de entrada, que pode ser o próprio coeficiente de Chezy ou o coeficiente $M$ de Strickler $(=1 / \mathrm{n}$, com $\mathrm{n}$ sendo o coeficiente de Manning). Um arquivo com parâmetro constante para cada célula da malha também pode ser adotado. Neste trabalho, um valor constante foi adotado para o coeficiente de Strickler, contudo a resistência é atualizada através da equação seguinte: 


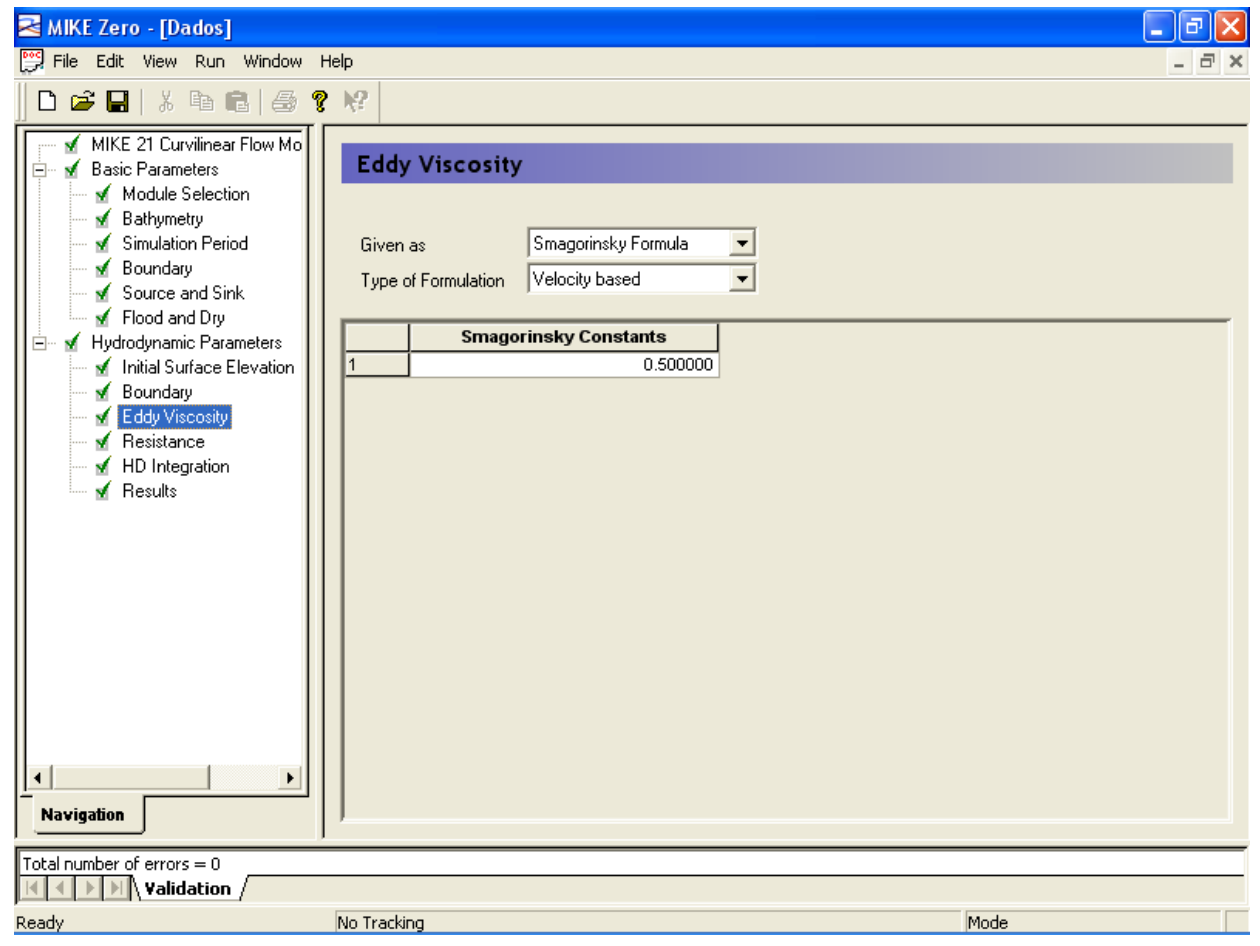

Figura 41. Escolha do modelo de turbulência.

$$
\mathrm{C}=\mathrm{M} \cdot \mathrm{h}^{1 / 6}
$$

onde:

M coeficiente de Strickler (no programa, M é considerado coeficiente de Manning);

h profundidade do escoamento;

C coeficiente de Chezy, usado no cálculo da resistência.

Adotou-se, para o reservatório estudado, $\mathrm{M}=20$, com $\mathrm{M}=1 / \mathrm{n}$ e $\mathrm{n}=0,05$ para rios com margens espraiadas e pouca vegetação (PORTO, 1999), como mostrado na Figura 42. Segundo DHI (2003, p.39), se a variação da profundidade de água do reservatório é considerável (caso típico da Represa Velha), valores entre 20 e $40 \mathrm{~m}^{1 / 3} / \mathrm{s}$ são normalmente utilizados, sendo sugerido o valor de $32 \mathrm{~m}^{1 / 3} / \mathrm{s}$ se nenhuma outra informação é disponível. No presente trabalho, este valor também foi testado e comparado do ponto de vista hidrodinâmico e de transporte de sedimentos. 


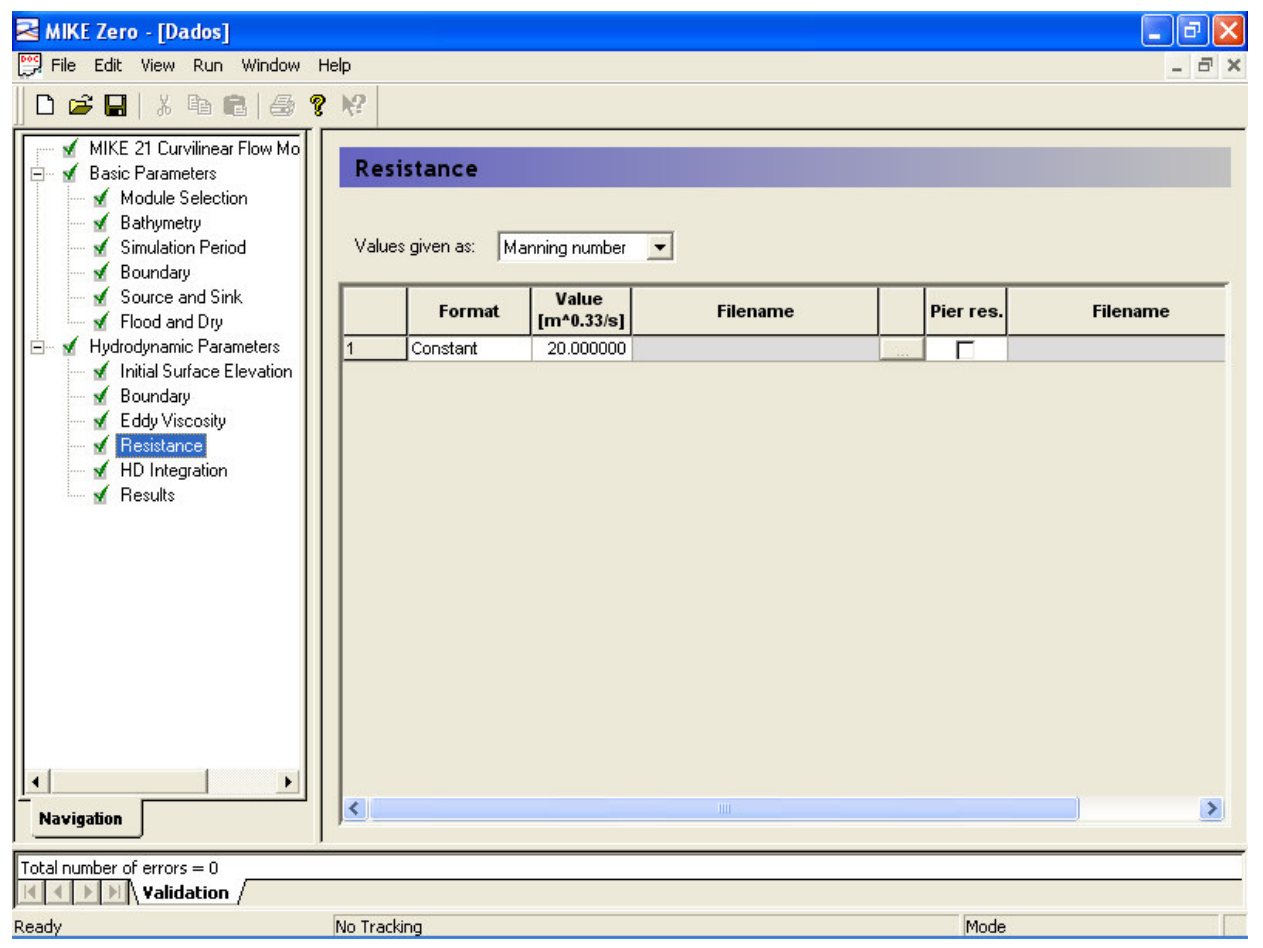

Figura 42. Parâmetro de resistência do escoamento.

As equações hidrodinâmicas, neste trabalho, são resolvidas a cada passo de tempo, através da opção Fuly dynamic como mostra a Figura 43.

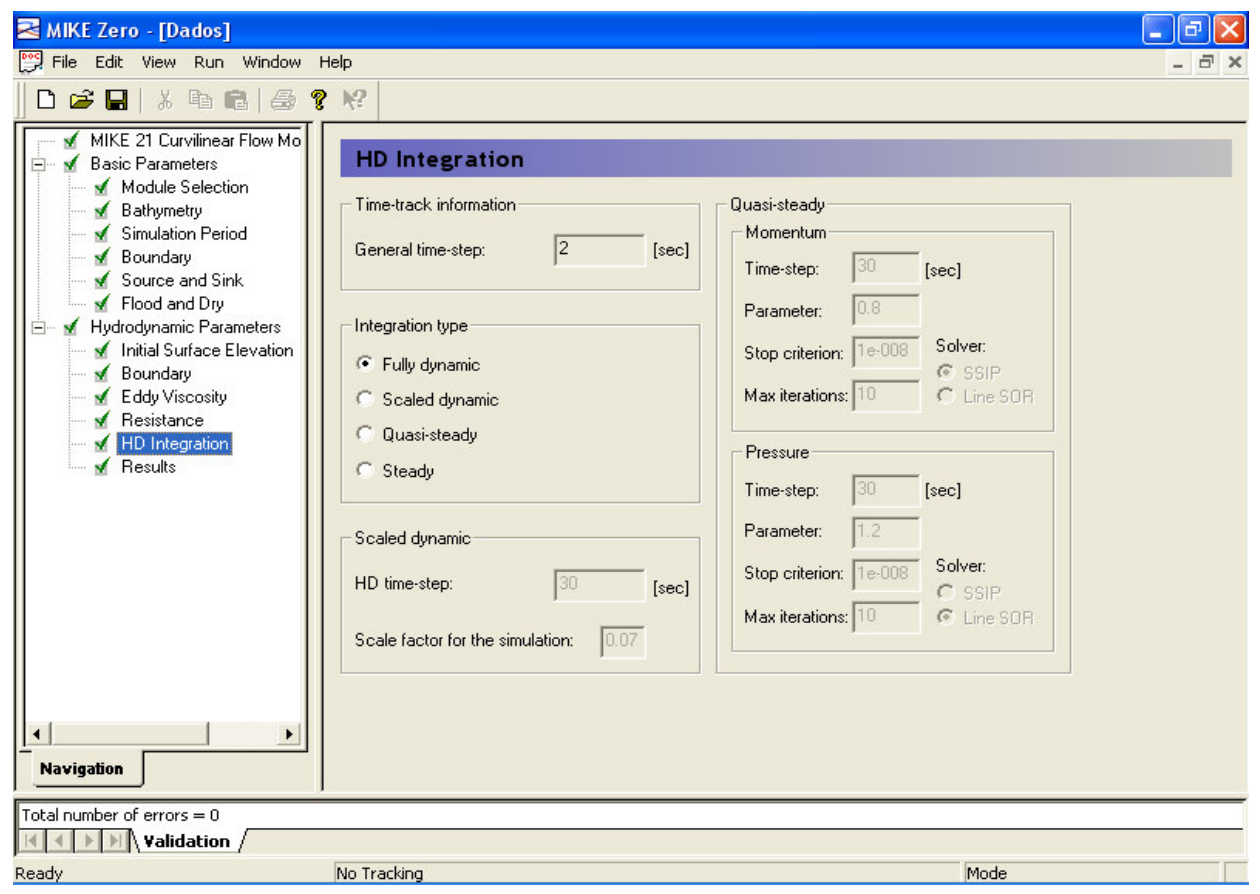

Figura 43. Tipo de integração das equações hidrodinâmicas (completamente dinâmica). 
O MIKE 21C ainda apresenta outras opções para a integração das equações em regime permanente e quase-permanente, que não foram utilizadas neste trabalho.

Os resultados da simulação são gravados a cada 900 passos (1800 s), para diminuição dos arquivos armazenados. A opção Generate hot start, armazena os dados finais de uma simulação para o início da simulação seguinte. Como a simulação foi fracionada entre os períodos da medição, vários arquivos do tipo HOT foram gerados. O arquivo HD armazena os dados para visualização de vazão, alturas de água e velocidades no reservatório. A tela de configuração do arquivo de resultados é apresentada na Figura 44 abaixo.

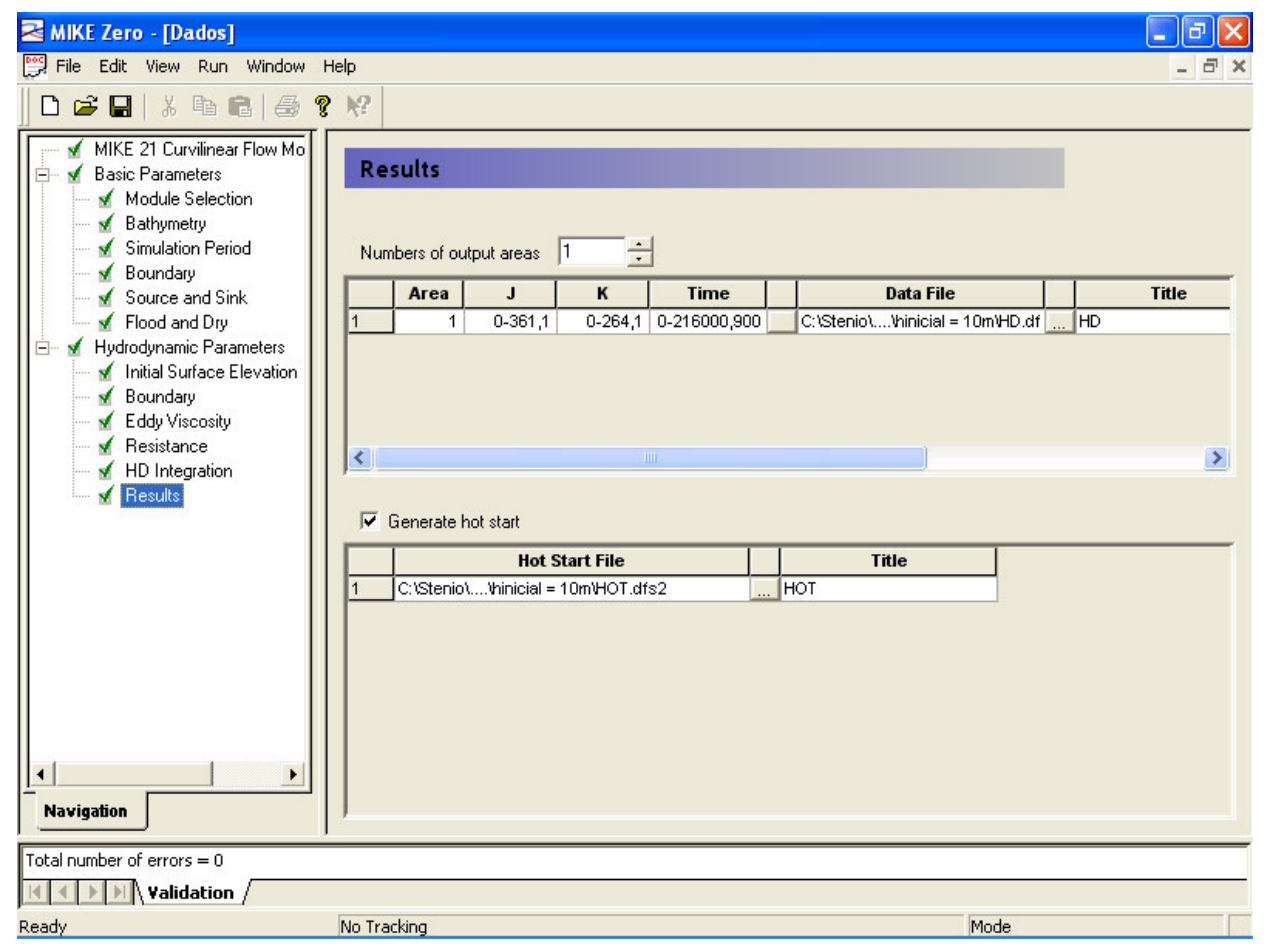

Figura 44. Tela de configuração do arquivo de resultados da simulação hidrodinâmica.

\subsubsection{Simulação do Assoreamento.}

Nesta etapa, a simulação hidrodinâmica realizada anteriormente foi usada para iniciar as simulações do assoreamento. Porém, uma ampliação do tamanho das células da malha se fez necessário, uma vez que o tempo computacional mostrou-se muito longo. Isto porque para 
cada atualização da geometria da represa, a hidrodinâmica do escoamento é recalculada na simulação do assoreamento. Para se ter uma idéia de tempo gasto, na menor simulação do período anual de medição (1 mês) dos quatro anos contemplados, o tempo computacional é de aproximadamente 56 horas. A malha inicial com $1 \mathrm{~m}$ de lado foi refeita, com interpolação linear da geometria e também da batimetria, com células de $2,5 \mathrm{~m}$ de lado. $\mathrm{O}$ padrão de escoamento entre as malhas foi comparado visualmente, pelos vetores velocidade, não mostrando alterações expressivas. Outros motivos para a utilização de uma malha mais grosseira foi o grande número de simulações preliminares para testar ferramentas do programa, fazer análise de sensibilidade e calibrar os parâmetros de entrada disponibilizados pelo MIKE 21C. Comparada as grades computacionais comumente utilizadas para simular escoamentos em rios e reservatórios reais do porte do sistema estudado, como em alguns trabalhos apresentados na revisão da literatura, ainda sim pode-se classificar a nova malha obtida como sendo relativamente fina.

Com a nova malha, de 7224 células (FIGURA 45), foi simulado o assoreamento no reservatório Represa Velha. As janelas do MIKE 21C para esta simulação, oportunamente apresentadas, referem-se a uma das combinações dos parâmetros utilizados (Configuração 1), uma vez que várias combinações foram testadas para se chegar a uma boa reprodução do assoreamento medido. A cada período da medição de campo uma nova simulação é implementada, considerando a vazão de entrada e a altura de água no canal de saída como sendo constantes entre os períodos. As principais janelas de dados de entrada do MIKE 21C, para a simulação do assoreamento, são apresentadas na sequência. 


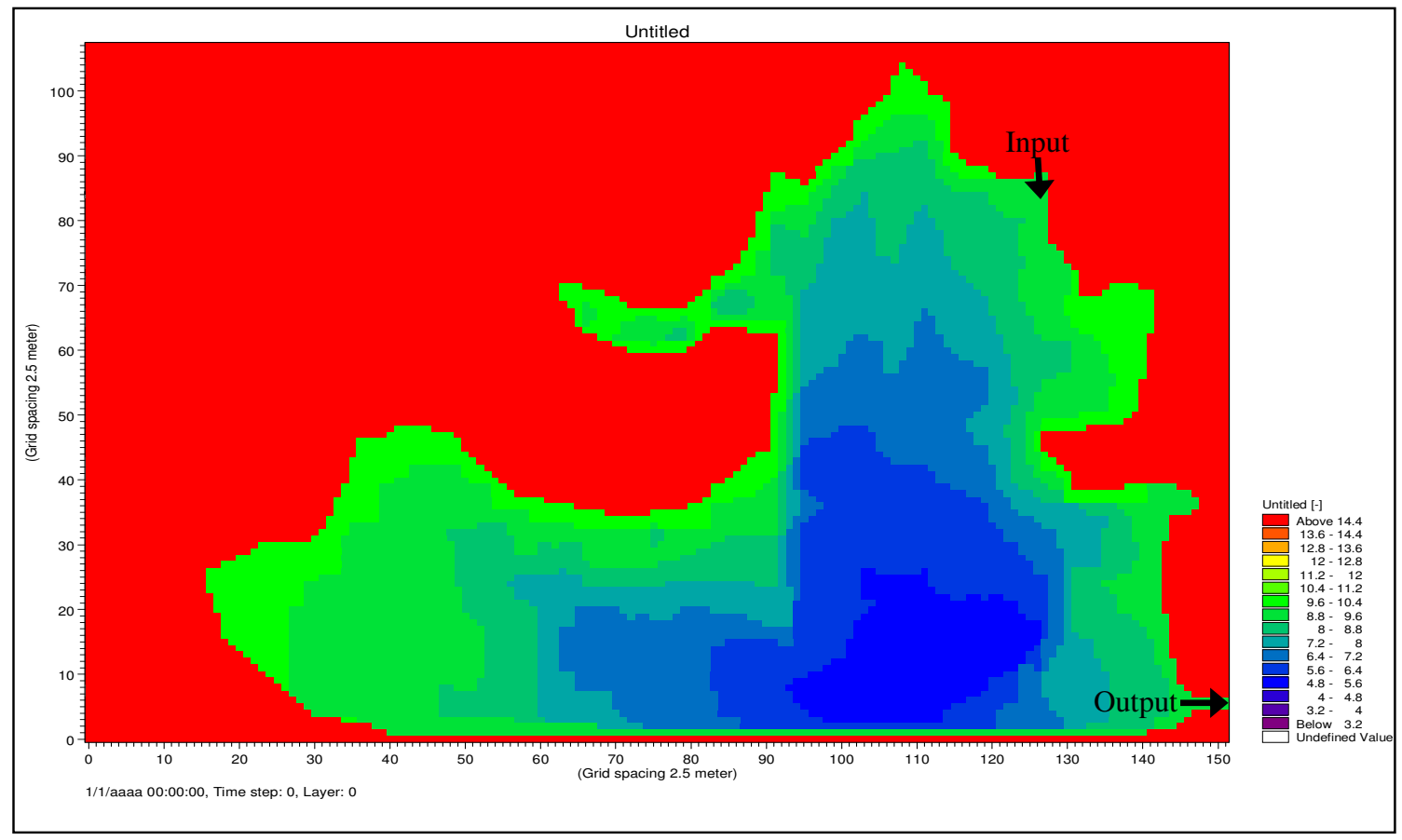

Figura 45. Nova malha computacional com 2,5m de lado.

Nesta etapa, é incluído o módulo morfológico para a simulação do assoreamento, contemplando o esquema para a resolução da equação de advecção-dispersão de sedimentos (FIGURA 46).

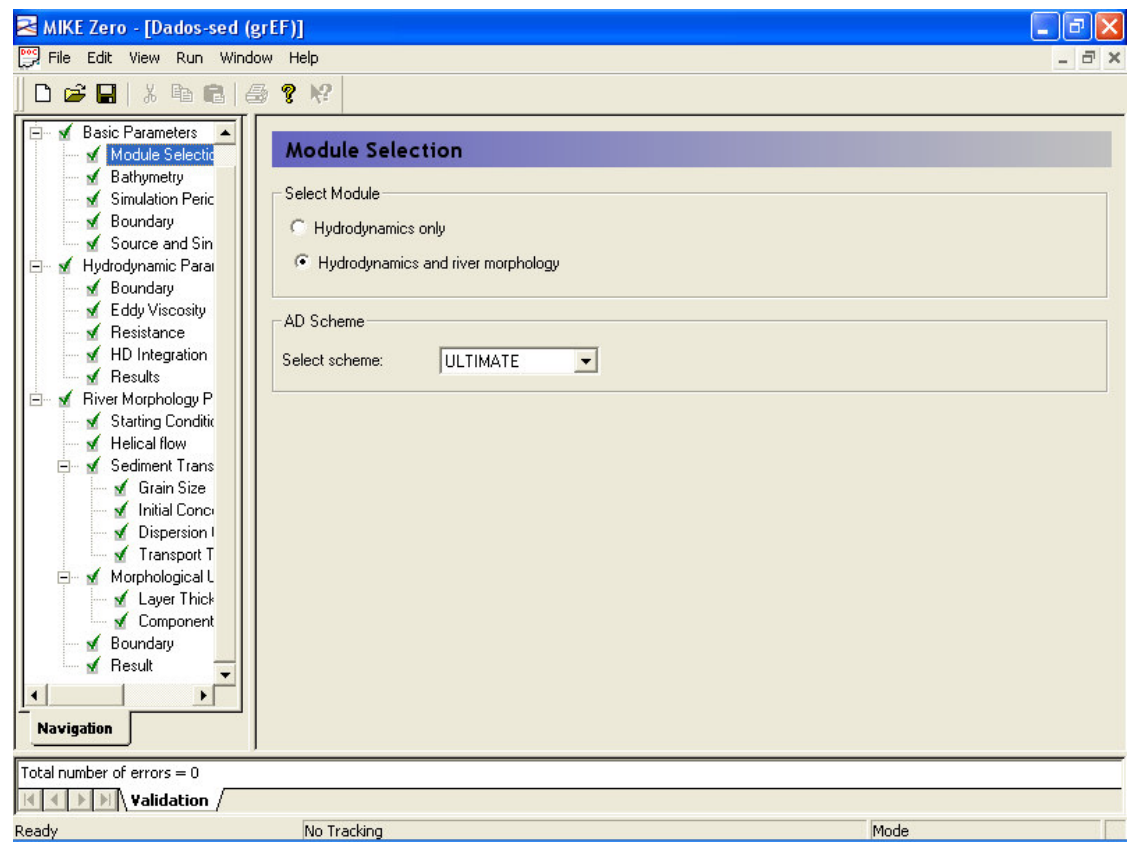

Figura 46. Inserção do módulo morfológico 
As janelas seguintes, até o primeiro tópico de resultados, correspondem às apresentadas na simulação hidrodinâmica. Modificações são feitas no Simulation Period (FIGURA 35) para cada período da medição, agora com passo de tempo de 5 segundos (mesmo Courant da malha original); nas condições de contorno Boundary (FIGURA 40) e no parâmetro Eddy Viscosity (FIGURA 41) onde foram testadas a formulação de Smagorinsky e a hipótese de viscosidade turbulenta constante.

O transporte de sedimento no MIKE 21C pode ser simulado através do diâmetro médio da amostra ou então considerando o diâmetro representativo das frações de solo obtidas no ensaio de caracterização. As simulações realizadas contemplaram ambas as configurações.

A primeira janela da simulação do assoreamento (FIGURA 47) consiste em estabelecer as condições iniciais de cálculo do assoreamento Starting Conditions, do ponto de vista de escala de tempo e tipos de simulação a serem abordadas. A escala de tempo para a resolução das equações de transporte de sedimentos adotada foi de 60 vezes a escala hidrodinâmica, ou seja, a cada 300 s. Este valor foi obtido após vários testes para verificação da estabilidade numérica, partindo de uma freqüência igual a 1. A freqüência determinada foi mantida em todas as configurações testadas. A vantagem principal da adoção de um passo de tempo maior na resolução do transporte de sedimentos se resume na geração de arquivos de resultados menores em tempos de simulação também reduzidos. As simulações calculadas envolveram escoamento helicoidal (Helical flow), transporte de sedimentos (Sediment transport) e modificação da morfologia (Morphological Update). A atualização da resistência ao escoamento (Alluvial resistence) em função da profundidade, também foi testada nas simulações. A equação de advecção dispersão é calculada explicitamente, cujos índices de iteração ( $A D$ time step e Maximum iterations) também são objetos de calibração. O MIKE 21C também apresenta uma opção que calcula AD de forma implícita. 


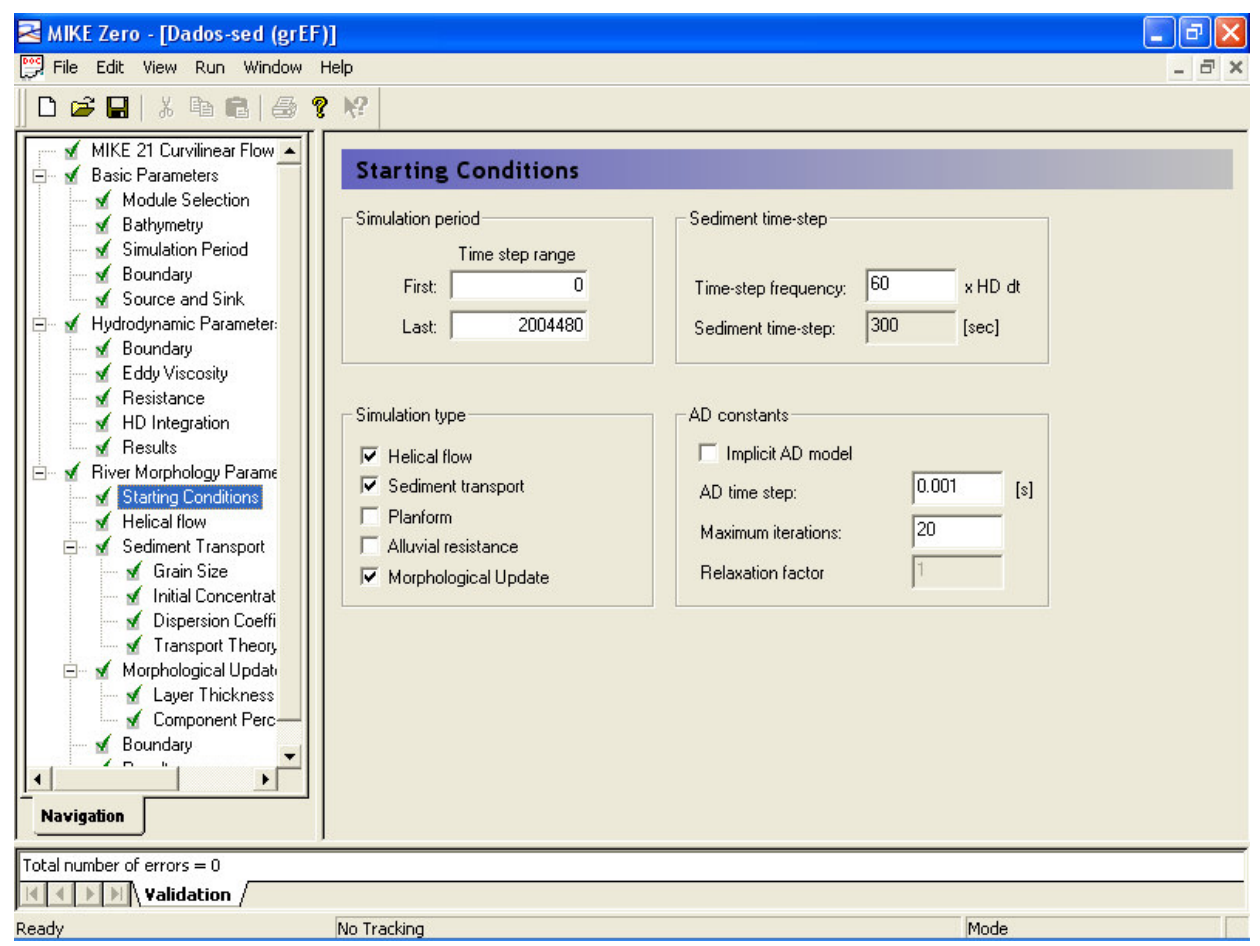

Figura 47. Estabelecimento das condições inicias da simulação do assoreamento.

Na janela apresentada na Figura 48 são observadas três frações de sedimentos obtidas no ensaio de caracterização, sendo uma não coesiva (areia) e duas coesivas (silte e argila). Simulações envolvendo o diâmetro médio da amostra (fração única) também foram realizadas. Dados de porosidade e densidade aparente do sedimento são inseridos, correspondentes às frações de areia, silte e argila, tendo como referência os trabalhos de Morris e Johnson (1967) além de Graf (1971), uma vez que os ensaios de laboratório realizados determinaram os parâmetros para a amostra total. O parâmetro crítico de Shields foi calculado na entrada do reservatório, envolvendo dados geométricos da seção, declividade, altura de água e vazão. Variações feitas neste parâmetro ocasionaram poucas mudança no padrão de transporte e deposição na represa. Um parâmetro que pode influenciar significativamente na acuracidade da simulação é a declividade de fundo. Os parâmetros de declividade são objetos de calibração, onde os valores utilizados nas simulações deste estudo seguiram a referência de Talmon et al. (1995) para rios naturais, o trabalho de Souza (2006), 
além da faixa especificada em DHI (2005). Já o valor de concentração máxima de sedimento em suspensão utilizado, que teve como base a medição de sedimentos suspensos, visa a manutenção da estabilidade da simulação. O fator 1 (Factor on fall velocity), relacionado à velocidade de queda do sedimento, pode ser modificado para alterar o espaço e o tempo de precipitação do mesmo.

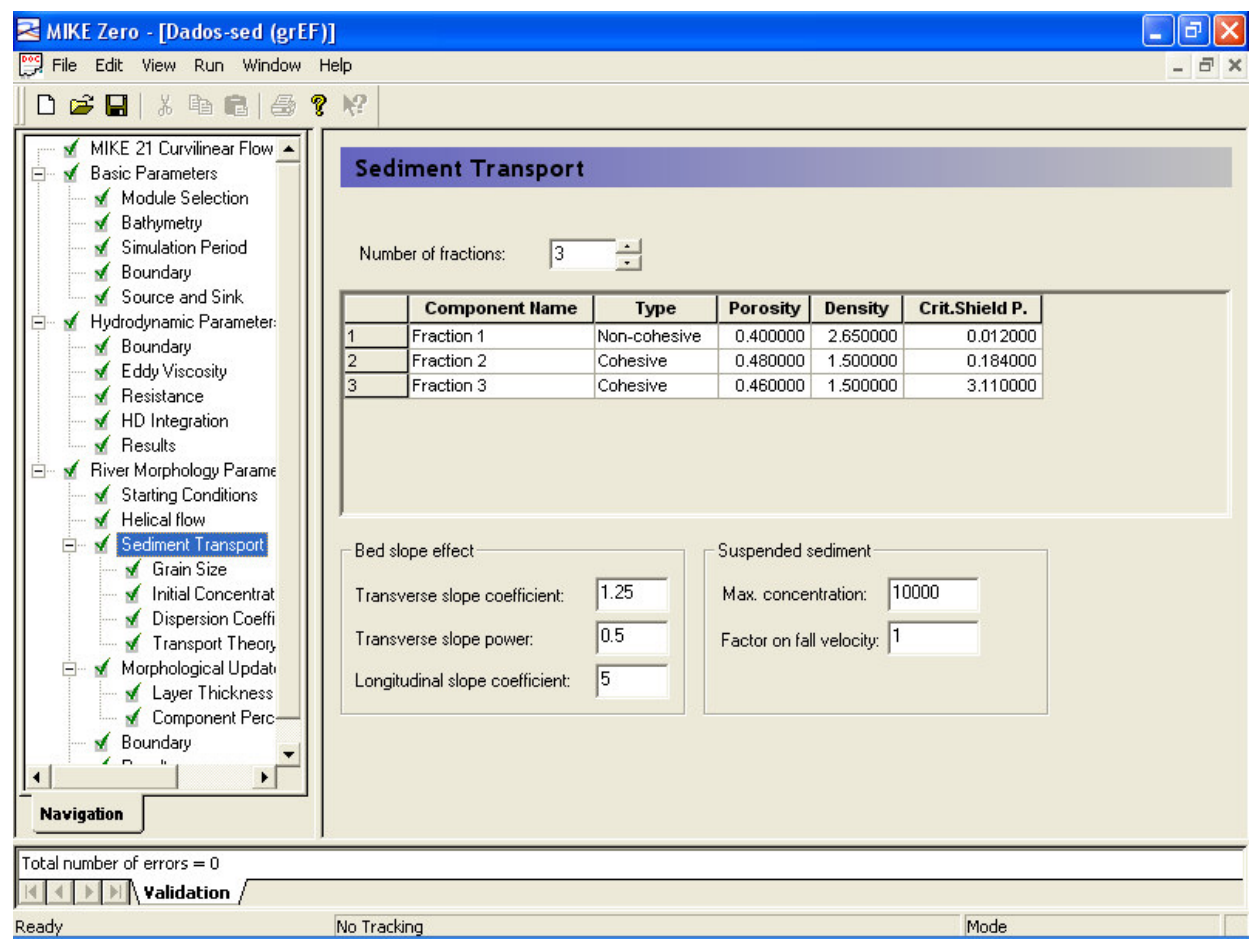

Figura 48. Tipo de sedimento, porosidade, densidade relativa, parâmetro crítico de Shields, efeito da declividade de fundo e sedimentos suspensos.

Os diâmetros $\mathrm{d}_{50}$ das frações de areia, silte e argila, obtidos a partir da curva granulométrica, são inseridos (FIGURA 49). Simulações envolvendo o d 50 geral da amostra $(0,049 \mathrm{~mm})$ também foram realizadas. Considerando esse diâmetro (silte grosso), foram realizadas simulações testando a hipótese de sedimento coesivo e, num segundo momento, como não coesivo. Trabalhos envolvendo o estudo das equações semi-empíricas clássicas, como o de Scapin (2005) e Coiado e Paiva (2008), demonstram limitações dos modelos na abordagem de sedimentos coesivos. 


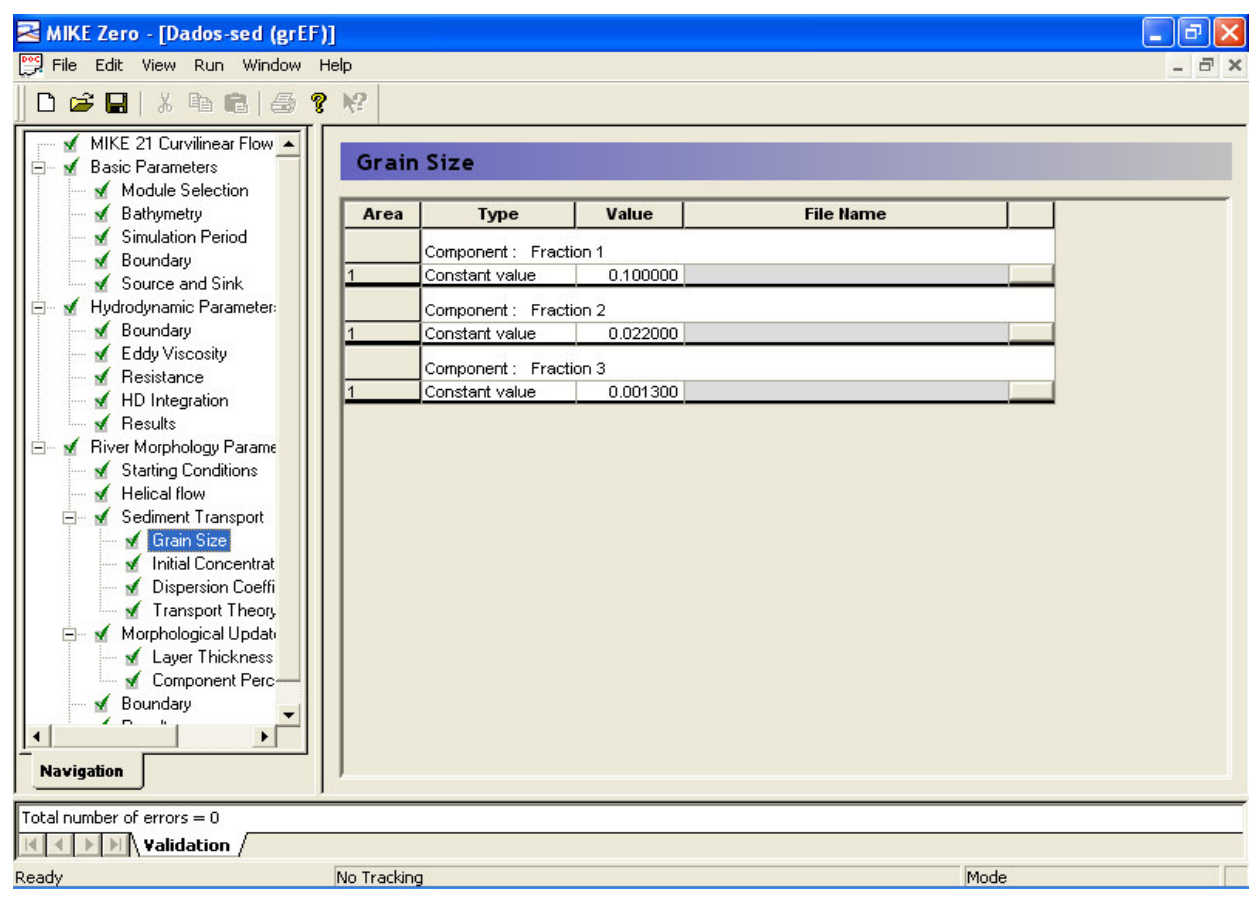

Figura 49. Diâmetro d $d_{50}$ dos grãos.

Em testes de laboratório, comumente a concentração de sedimentos inicial é igual a zero (água limpa). Em reservatórios reais, no início das campanhas de campo, uma concentração de sedimentos suspensos é existente e variável no espaço. O MIKE $21 \mathrm{C}$ contempla a concentração inicial como sendo constante ou variada. Para essa segunda possibilidade não se conseguiu uma resposta satisfatória em termos de sedimentos suspensos ao longo do tempo. No reservatório Represa Velha, onde as concentrações levantadas apresentam não uniformidade e, em alguns períodos, crescente de montante para jusante, uma calibração, partindo da média dos pontos P4, P5 e P6 (inorgânico), foi então proposta. As concentrações registradas nos pontos P1 e P3 são maiores que as registradas na entrada, em boa parte do tempo, sugerindo uma contribuição de sedimentos que não a do córrego da Barrinha. Segundo Bufon (2006), a contribuição via Bacia Hidrográfica nestes pontos é preponderante. Na Figura 50 são apresentados os valores da concentração inicial, correspondentes a cada fração de sedimento: areia (Fraction 1), silte (Fraction 2) e argila (Fraction 3). 


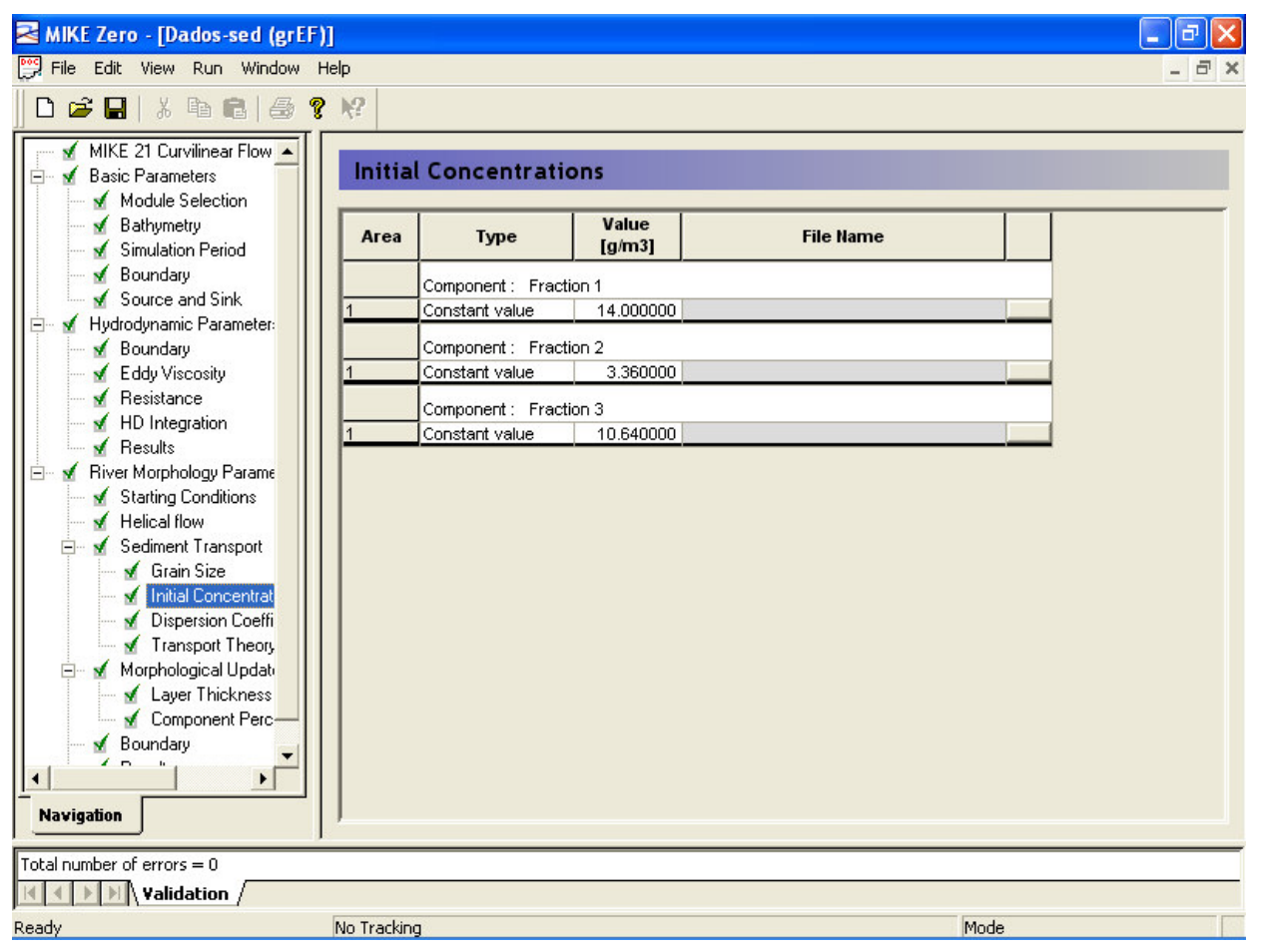

Figura 50. Concentração inicial de sedimentos no reservatório.

O modelo de transporte de sedimentos é escolhido para transporte de fundo (Bed load) e de suspensão (Suspended load). As simulações realizadas envolveram no cálculo as equações de Engelund-Hansen e Engelund-Fredsøe separadamente, ou combinadas na mesma simulação. No primeiro modelo, os percentuais de transporte de fundo e em suspensão podem ser obtidos através de duas maneiras: 1) simulações prévias, considerando $100 \%$ para ambas parcelas (DHI, 2005); 2) resultados obtidos pelo modelo de Engelund-Fredsøe. A Figura 51 apresenta a interface do programa para a escolha do modelo de transporte.

As condições de contorno especificadas (FIGURA 52) são a concentração constante na entrada e concentração nula no canal de saída, consideradas constantes em cada período da medição. A concentração inicial nula não impede a saída de sedimentos da represa através do canal. Testes utilizando a opção de fundo constante na saída também foram feitos, não se observando variações. 


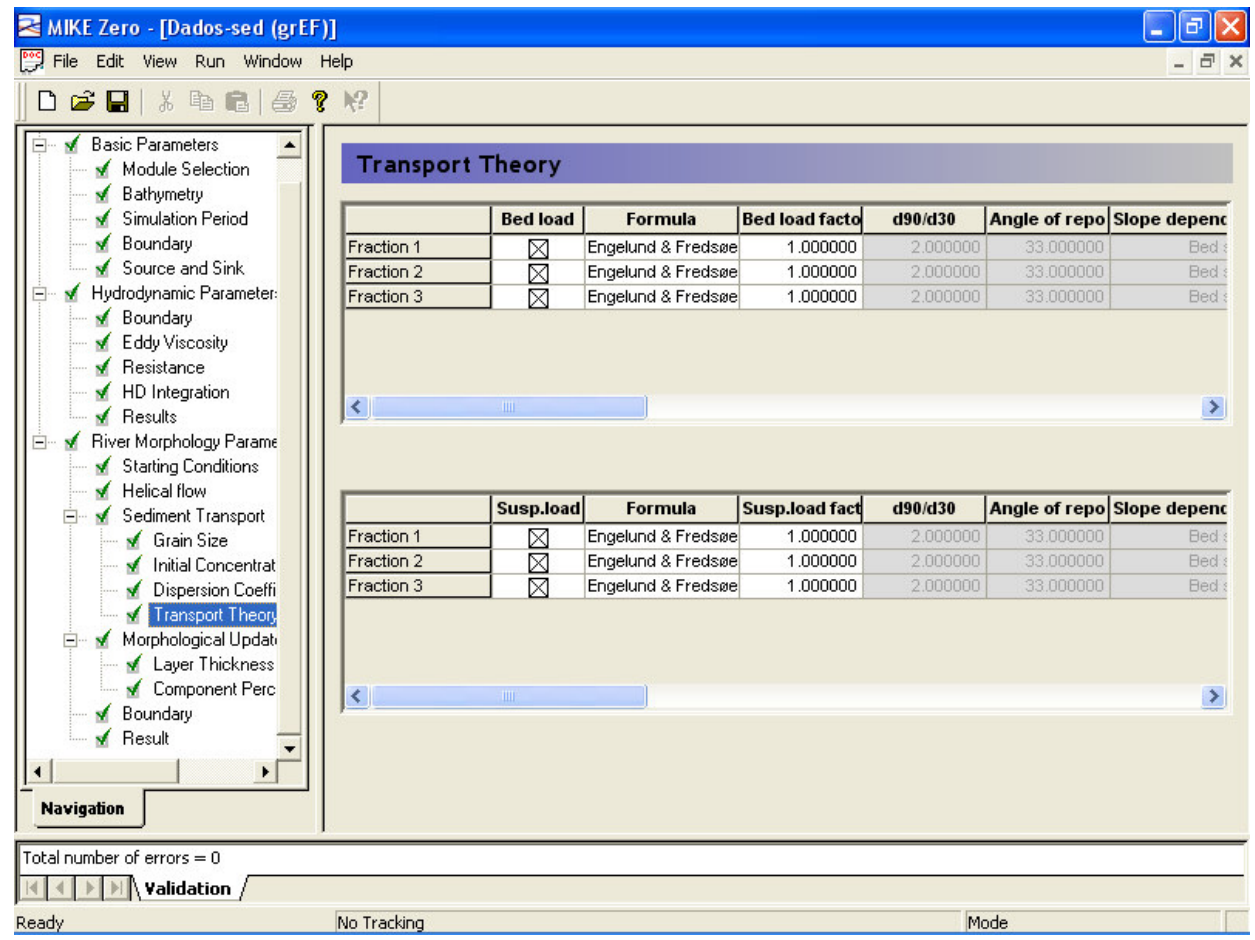

Figura 51. Escolha do modelo para o cálculo do transporte de sedimentos.

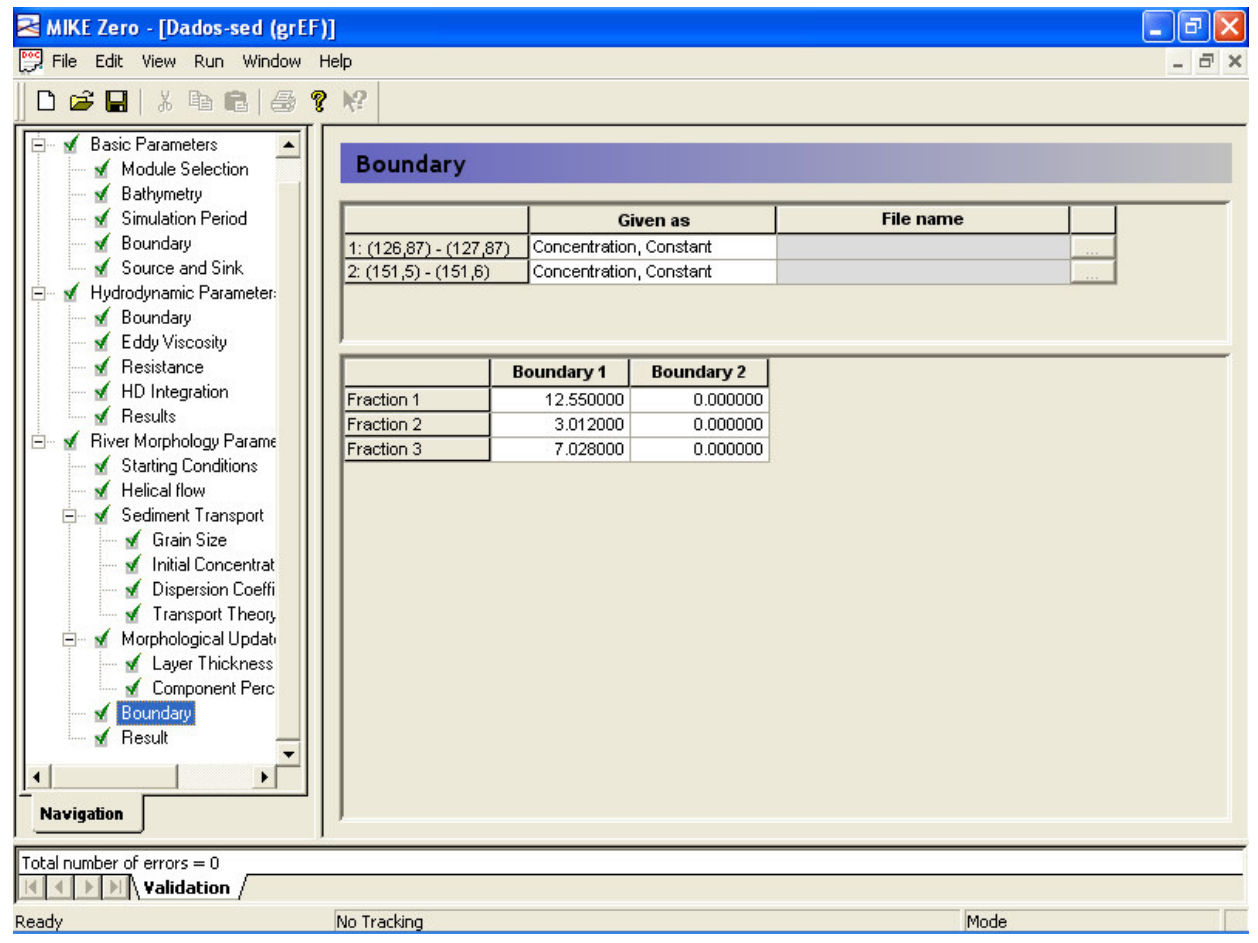

Figura 52. Condições de contorno para o transporte de sedimentos. 
Os resultados são gravados a cada 360 passos no tempo (30 minutos), mesma escala da simulação hidrodinâmica, envolvendo transporte de fundo, em suspensão, concentração, mudanças de fundo do reservatório e da superfície da água (FIGURA 53). Todos os passos, ora apresentados, para a simulação do assoreamento, são repetidos para cada período da medição de campo.

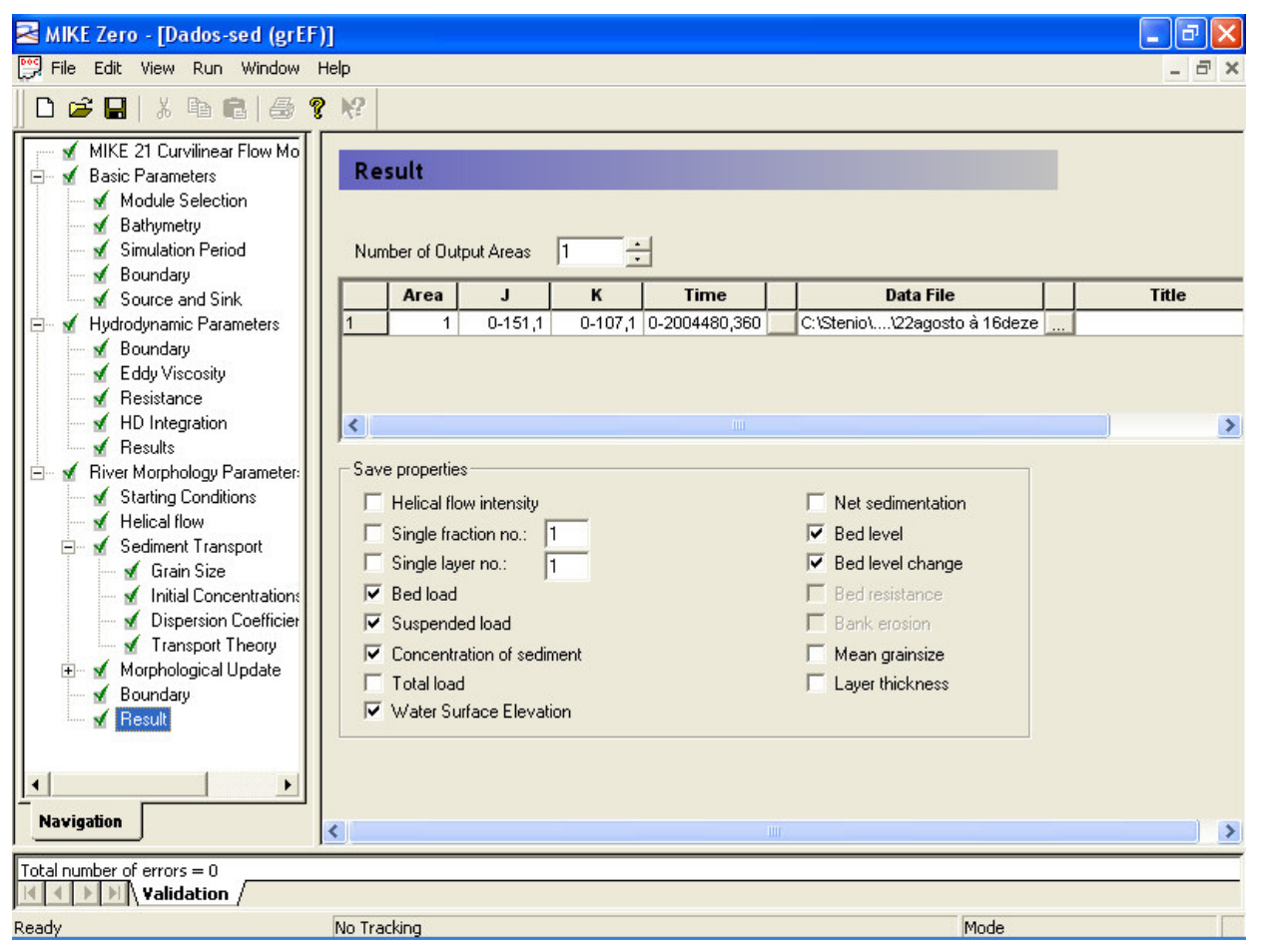

Figura 53. Tela de configuração dos arquivos de saída da simulação do assoreamento. 


\section{RESULTADOS}

Os resultados apresentados e discutidos neste capítulo abarcam a hidrodinâmica e o transporte de sedimento, simulados para o reservatório Represa Velha, bem como a comparação entre a batimetria levantada em campo e a obtida pelo MIKE 21C.

\subsection{Hidrodinâmica.}

Do ponto de vista hidrodinâmico, devido à disponibilidade de dados de vazão na entrada e saída do reservatório somente, não foi possível calibrar a simulação para o padrão espacial de escoamento na represa. Uma medição utilizando ADP (Acoustic Doppler Profile), em diferentes seções do reservatório, nos diferentes períodos, permitiria uma análise comparativa entre os padrões de velocidade medidos e simulados, por exemplo, proporcionando uma calibração mais realista. Os resultados apresentados, portanto, objetivam uma comparação do campo de velocidades para a malha inicial de $1 \mathrm{~m}$ de lado e a utilizada para simular o assoreamento (2,5 $\mathrm{m}$ de lado).

A seguir, na Figura 54, é apresentado o padrão de velocidades simulado na represa para ambas as malhas, para 5 dias de escoamento real (corresponde a 216000 e 86400 passos no tempo nas malhas fina e mediana respectivamente), onde o regime permanente já está estabelecido. Note que os vetores velocidade da entrada (E) até a saída (S) seguem um caminho preferencial, apresentando divergências deste a partir do centro da represa. 

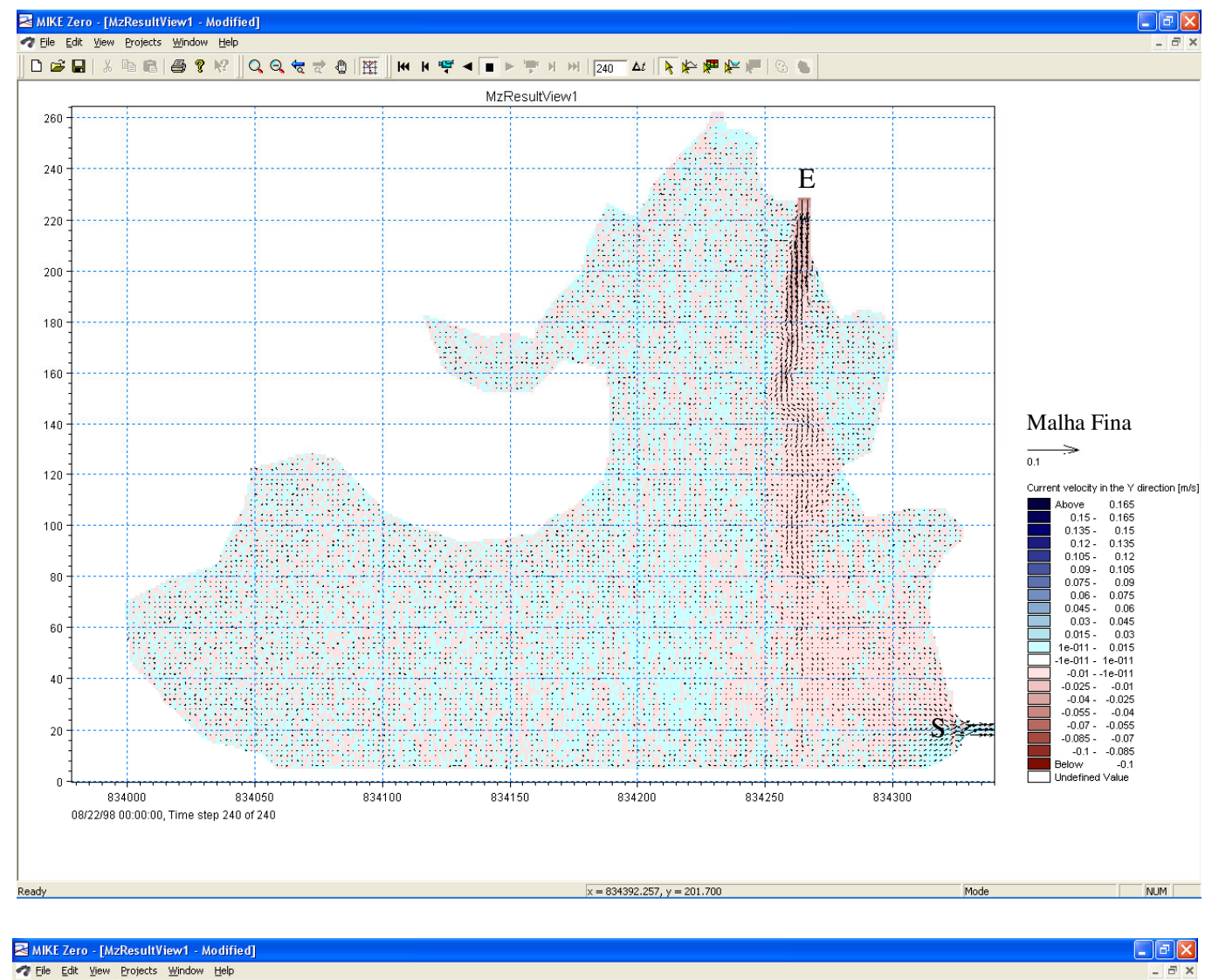

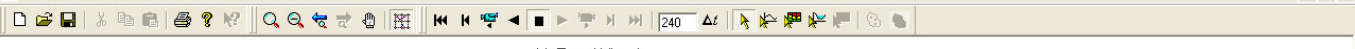

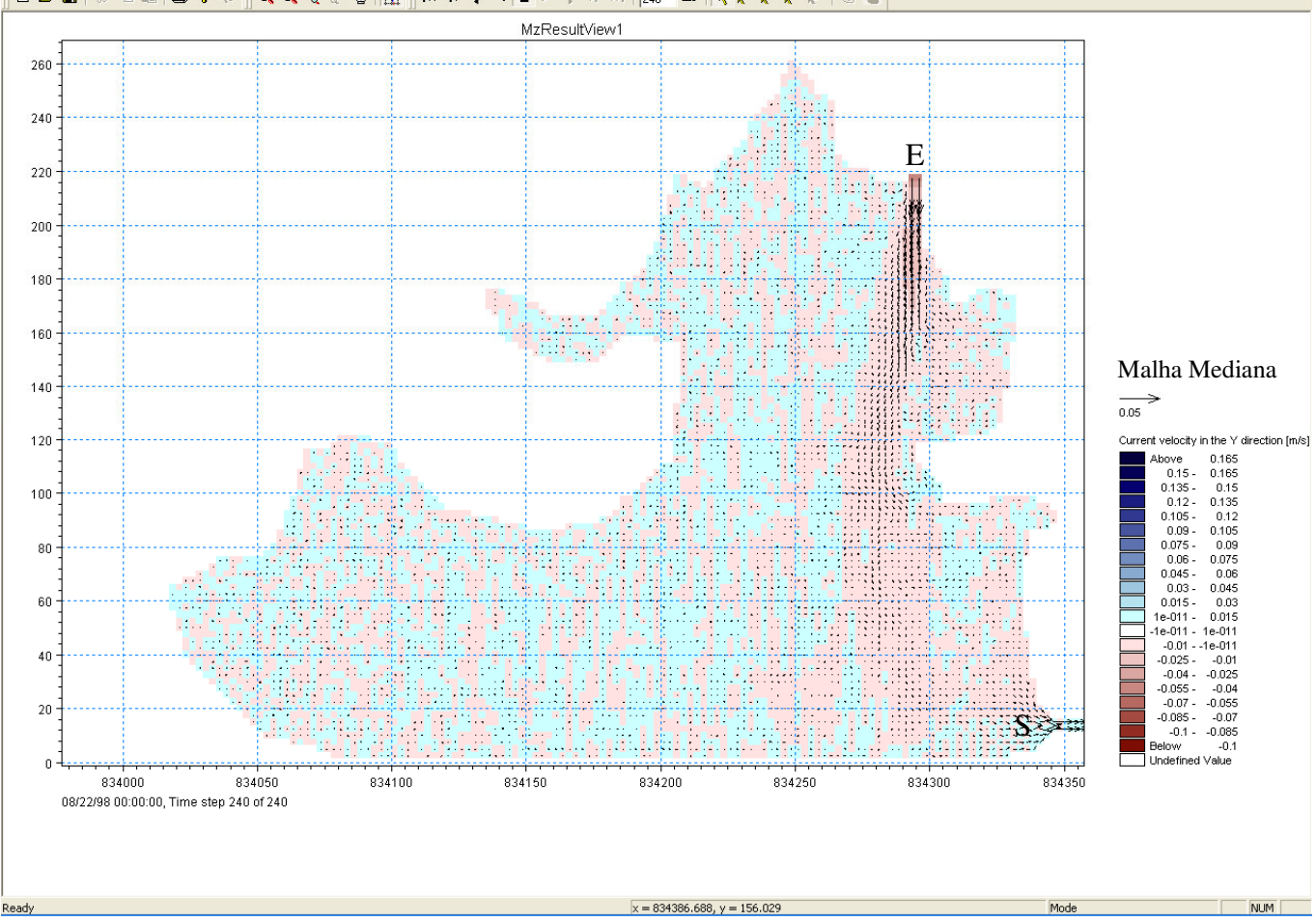

Figura 54. Vista geral do campo de velocidades (direção y - vertical) na represa para as malhas. 
Isto mostra uma prevalência de transporte advectivo até o centro do reservatório. Semelhança entre o padrão de velocidades instantâneas das malhas é também observado. Na escala de velocidades utilizada na simulação (escala de cores), os valores negativos correspondem aos vetores em sentido descendente e da direita para a esquerda (convenção do MIKE 21C). Nas Figuras de 56-58, podem ser visualizados os vetores velocidade nas regiões da entrada da represa, centro e saída, respectivamente, conforme demonstrado na Figura 55.

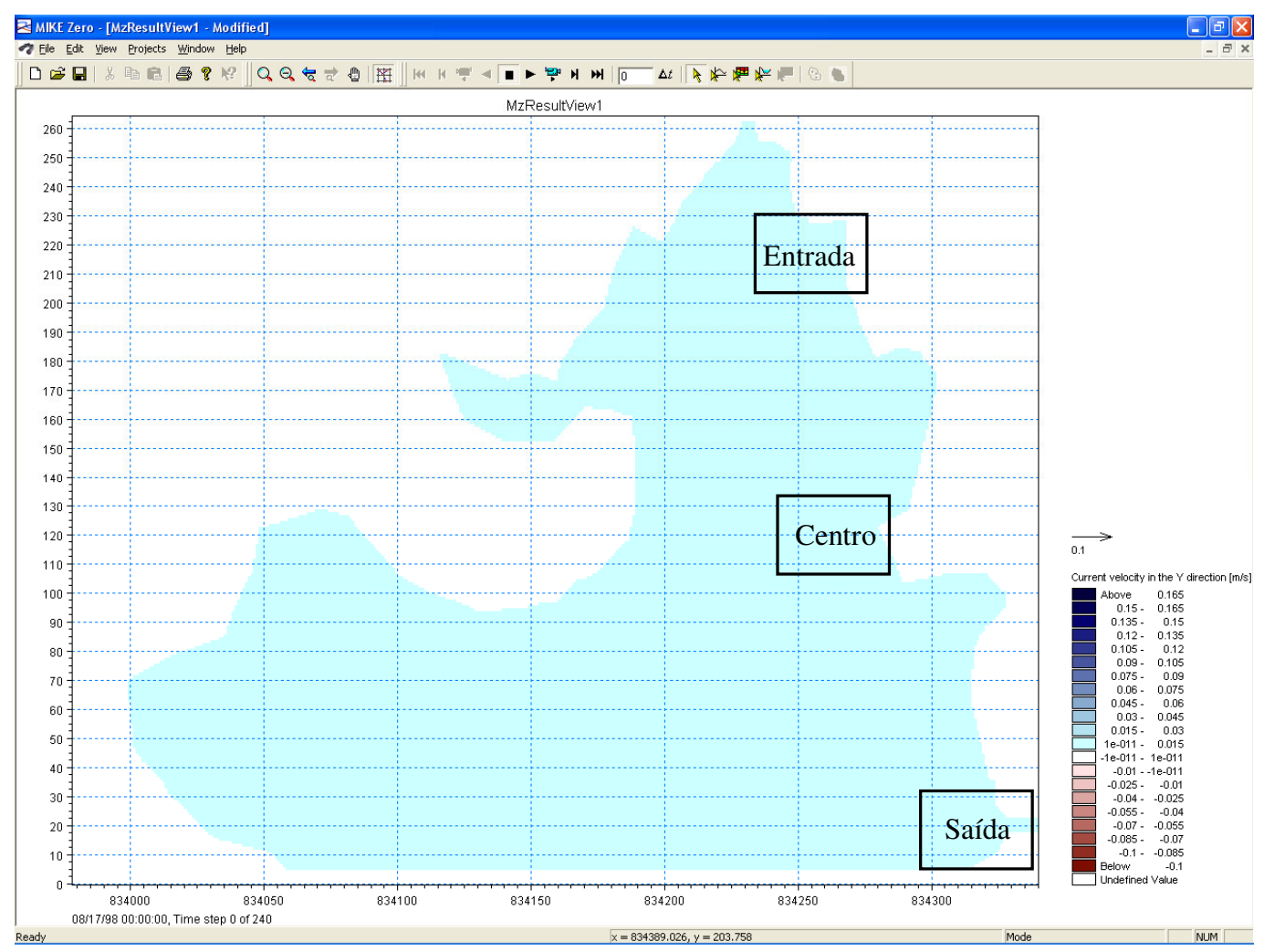

Figura 55. Regiões de entrada, centro e saída da represa, detalhadas nas Figuras 56-58

Nesta etapa da simulação hidrodinâmica várias foram às instabilidades numéricas identificadas, resultantes das variações de profundidade entre as células e expansões e contrações (por exemplo, entrada e saída da represa) da malha. Como solução, variações mais amenas da batimetria, nas regiões instáveis, e variações mais retilíneas da malha foram propostas. De acordo com DHI (2005), estes dois fatores correspondem às principais causas de instabilidade numérica. 

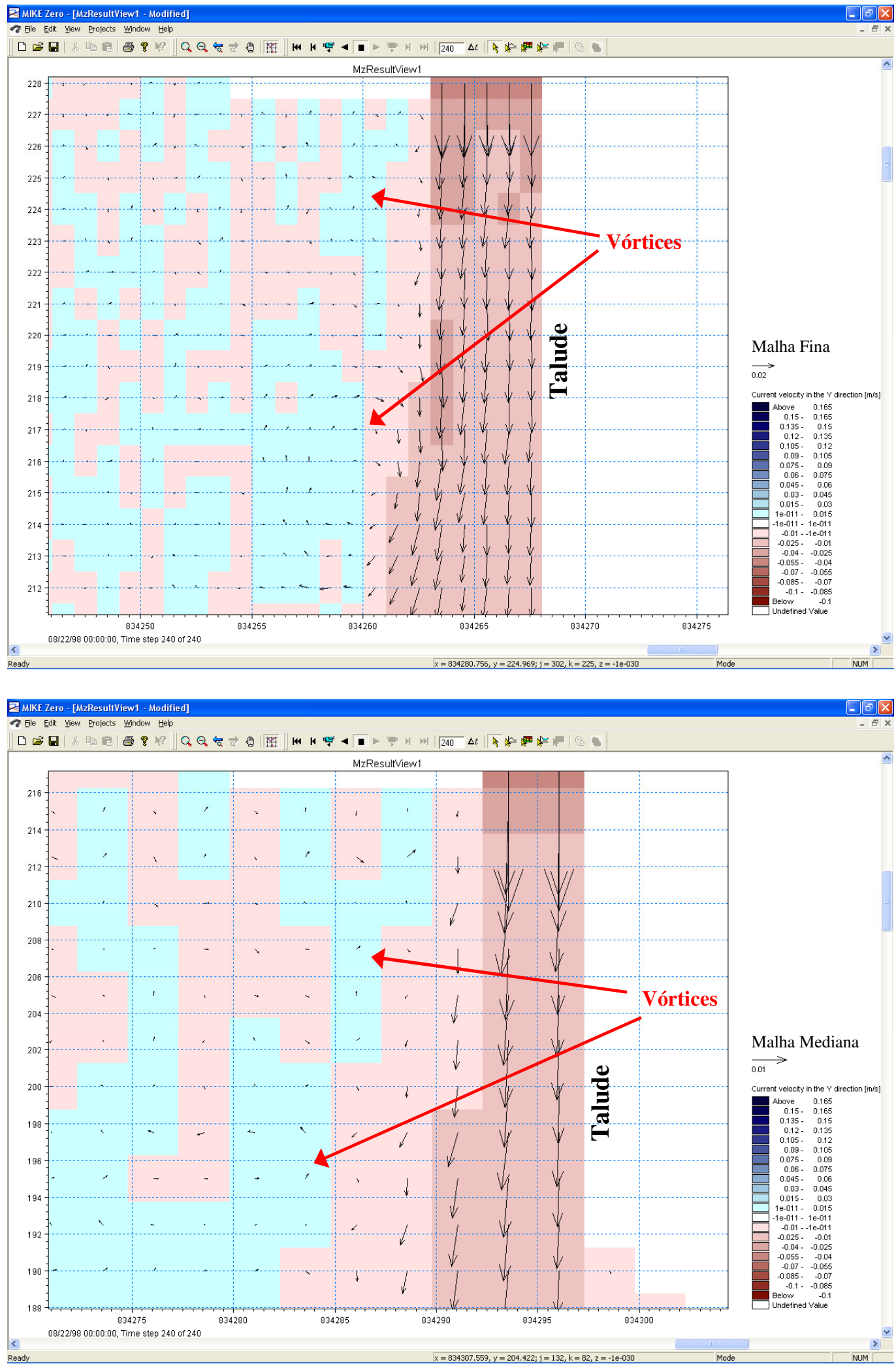

Figura 56. Campo de velocidades na entrada da represa 

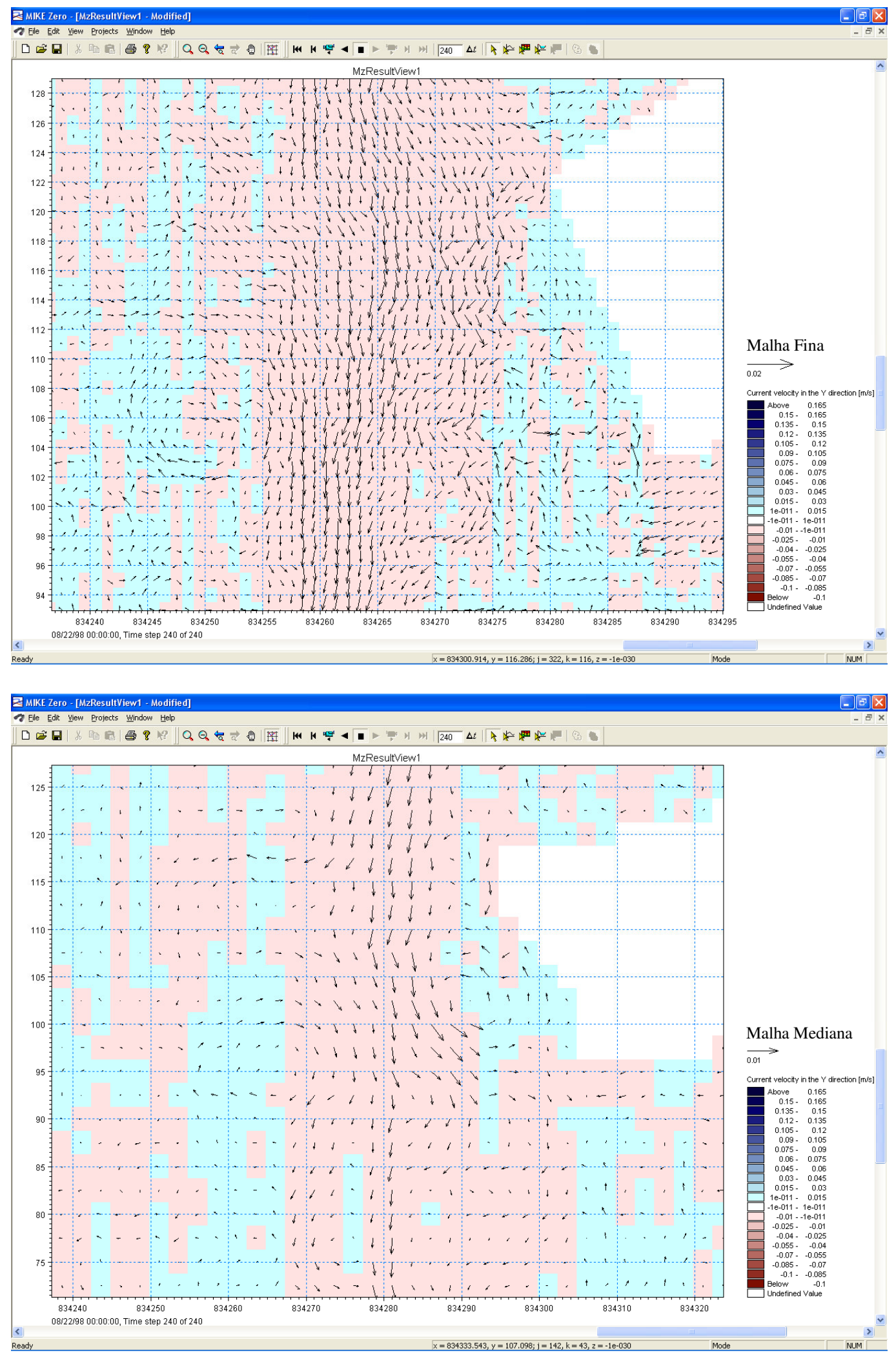

Figura 57. Campo de velocidades na região central da represa 

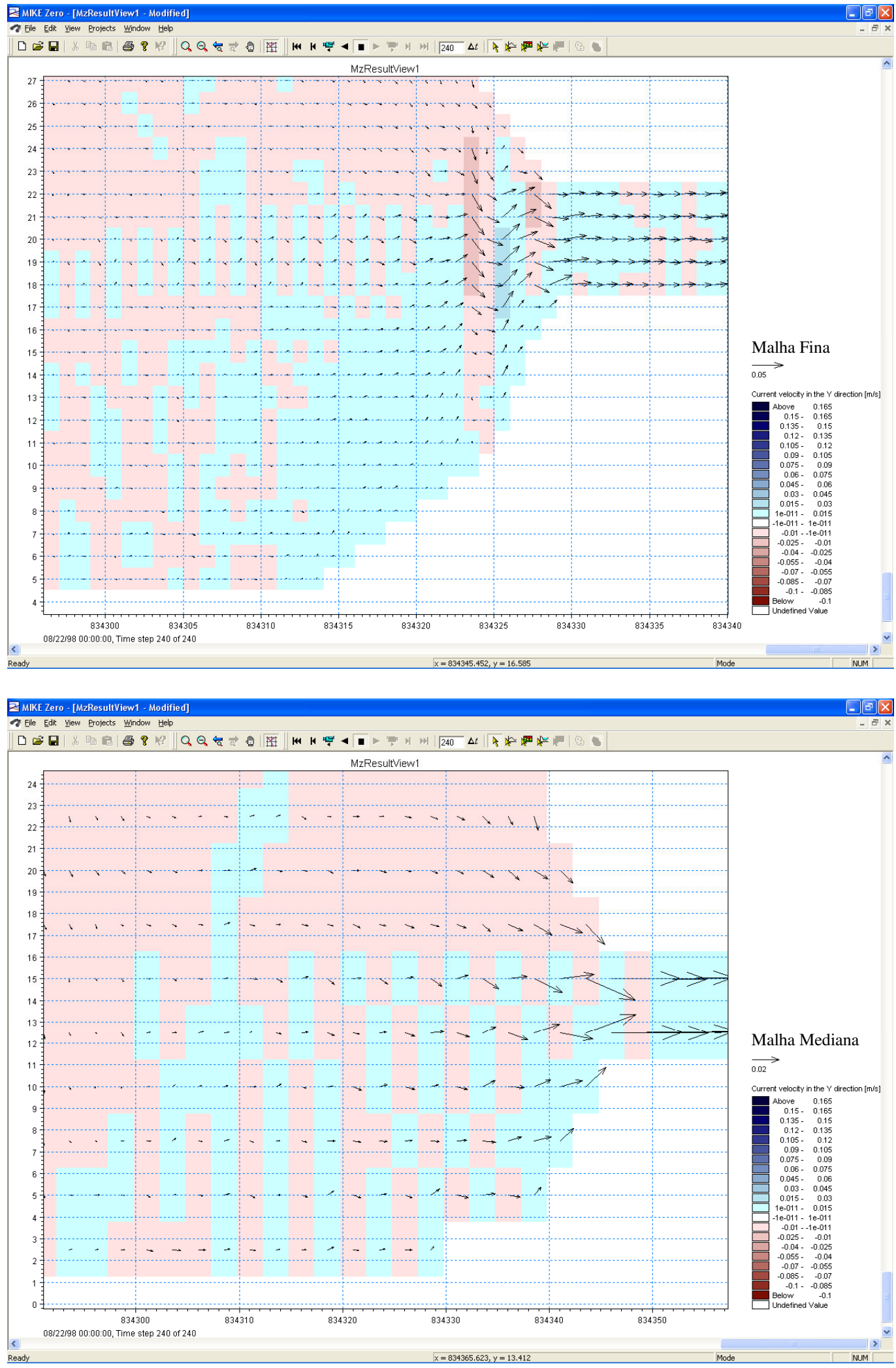

Figura 58. Campo de velocidades na região de saída da represa 
Se o padrão geral do campo de velocidades é semelhante, quando analisado em regiões específicas da represa, algumas divergências nos vetores, entre as malhas, são observadas. Isto se deve a discretização espacial proposta para ambas as "grades" bem como a interpolação linear feita entre os pontos da batimetria. Outra característica que pode ser observada na Figura 56 (malha fina) é a ocorrência de maior velocidade próxima do talude do que no centro do canal de entrada. Isto se deve pela não consideração, do MIKE $21 \mathrm{C}$, da condição de não deslizamento junto da parede.

Embora o comportamento do padrão hidrodinâmico apresentado nas Figuras 56-58 refere-se à vazão inicial $(\mathrm{Q}=129 \mathrm{~L} / \mathrm{s})$, uma comparação do padrão entre as malhas e verificação da ocorrência de instabilidades numéricas para a mais baixa vazão $(\mathrm{Q}=17 \mathrm{~L} / \mathrm{s})$ e a mais alta vazão $(Q=203 \mathrm{~L} / \mathrm{s})$ da série plurianual levantada foram implementados. As características gerais dos vetores de velocidade identificada para ambas as malhas foram semelhantes ao aqui apresentado.

Uma característica marcante identificada na simulação do reservatório estudado foi a de predominarem as baixas velocidades (FIGURA 59). Mesmo considerando a mais alta vazão da série plurianual medida na saída $(Q=203 \mathrm{~L} / \mathrm{s})$, se na região de entrada sempre foi registrado $\operatorname{Re}>500$, uma tendência ao regime laminar ocorreu da região central para jusante.

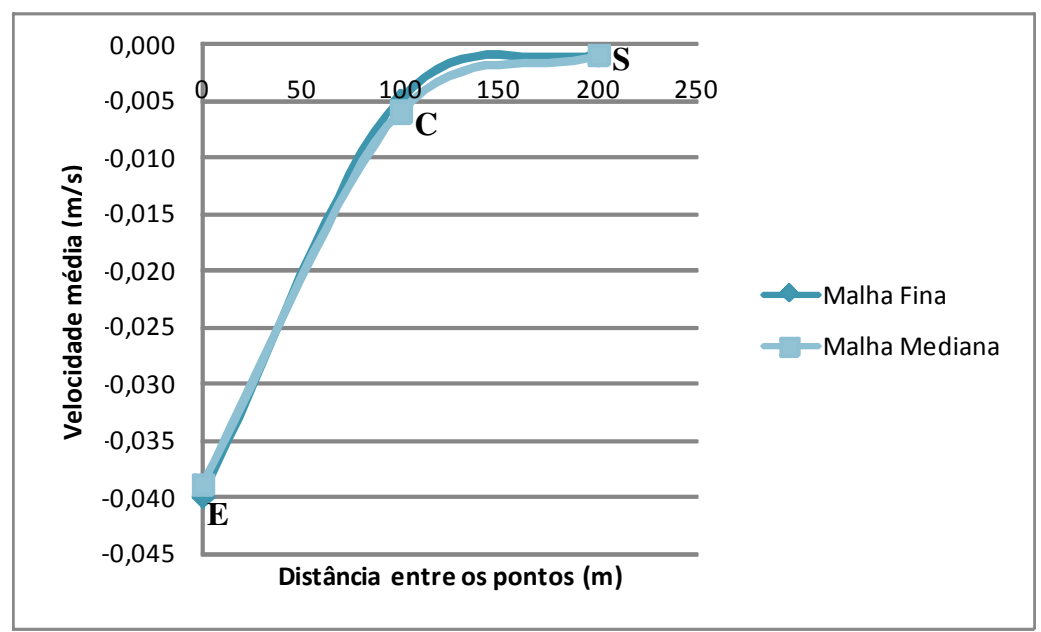

Figura 59. Velocidade média - V(m/s), obtida em 5 dias de escoamento real, simulado na entrada $(E)$, centro $(C)$ e próximo da saída $(S)$, para ambas as malhas, para $Q=203 \mathrm{~L} / \mathrm{s}$. 
Apesar das baixíssimas velocidades, principalmente após a entrada da represa, o padrão dos vetores ainda assim não apresentam uma característica própria de regime laminar. O código do MIKE $21 \mathrm{C}$ executa o balanço de massa em cada célula, considerando os fluxos de células vizinhas (esquema numérico), dentro de um processo iterativo. Se o erro estabelecido no código, como critério de parada do processo de iteração, estiver acima dos valores das baixas velocidades resultantes na represa, o processo iterativo é cessado como se as velocidades próximas do valor exato tivessem sido obtidas.

Além das minas de água presentes no reservatório, não medidas e, portanto não consideradas na simulação, o fato de se adotar as vazões levantadas na saída da represa como condição de contorno de entrada na simulação, também se deveu a esta característica de baixas velocidades. Simulações preliminares considerando as vazões obtidas na entrada como condição de contorno de entrada limitaram, em pouco tempo, a simulação do assoreamento. Nesses casos, uma barragem de sedimentos foi criada na entrada do reservatório, provocando divergência e interrupção dos cálculos.

Nas Figuras 60 e 61 é mostrada a influência da vazão de entrada (córrego da Barrinha) sobre o reservatório, referente à primeira vazão da série medida na saída $(\mathrm{Q}=129 \mathrm{~L} / \mathrm{s})$. Estas imagens, da tela de resultados, corroboram a característica de predomínio do transporte longitudinal na entrada da represa até as proximidades da região central, onde o escoamento difuso passa a ser observado. No caso de se ter uma evolução morfológica amena na entrada, dentro de um determinado período, de forma a não interferir no escoamento preferencial (longitudinal), o assoreamento na represa dar-se-ia nesta direção e sentido. Também pode ser observado, para ambas figuras, uma característica mais relacionada ao regime turbulento do que laminar. 


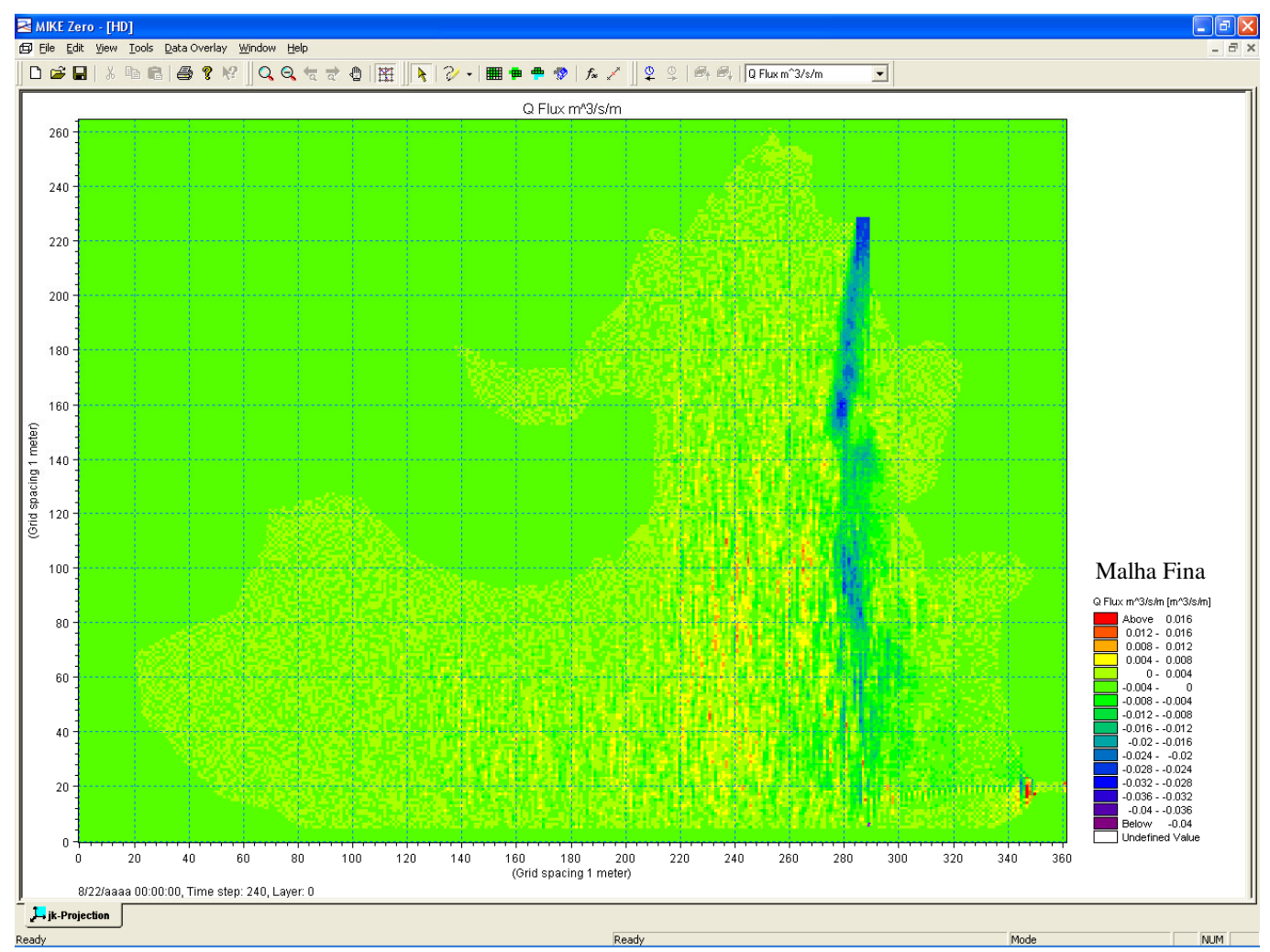

Figura 60. Vazão específica instantânea na represa $\left(Q-\mathrm{m}^{3} / \mathrm{s} / \mathrm{m}\right)$

A escala de cores mostra a modificação da intensidade da vazão específica na represa, para ambas as malhas (FIGURAS 60 e 61), correspondente ao instante final da simulação hidrodinâmica (regime permanente). A variação expressiva do fundo da represa é um fator que interfere na mudança da vazão específica. A vazão específica variou não somente no espaço, mas inclusive para cada instante de tempo do período. 


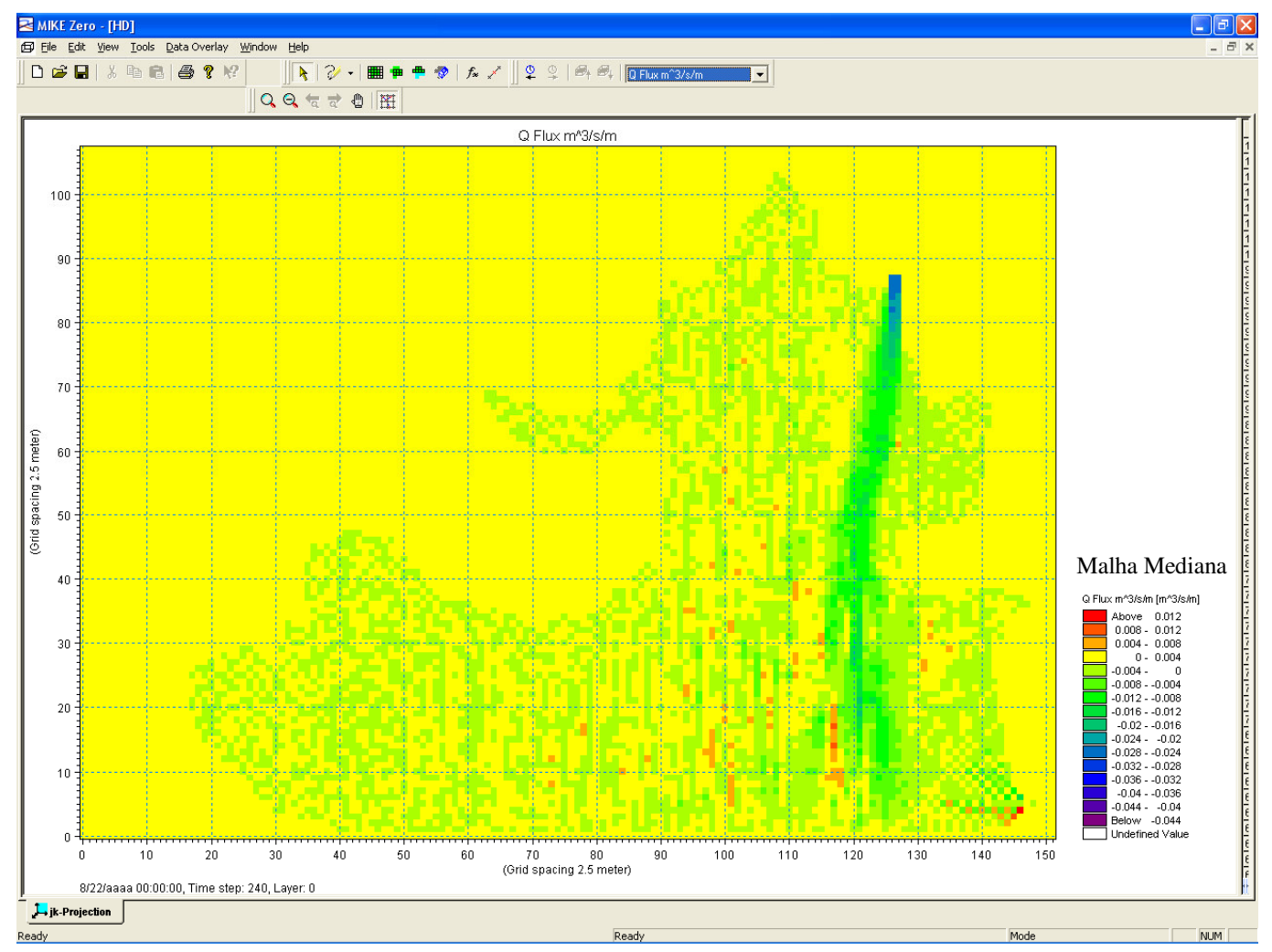

Figura 61. Vazão específica instantânea na represa $\left(Q-\mathbf{m}^{3} / \mathbf{s} / \mathbf{m}\right)$

Considerando um mesmo ponto no interior da represa, a velocidade não se mantém constante, mesmo após o escoamento ter atingido o regime permanente, o que justifica a variação temporal da vazão específica. No trabalho de Souza (2006) esta situação também foi identificada, sendo visualizada pela flutuação da velocidade instantânea em torno da média. Portanto, o regime permanente, atingido após 3 dias de escoamento real se refere ao escoamento médio na represa; e as flutuações são geradas pelo modelo de turbulência de Smagorinsky. Pontos de maior vazão específica (em vermelho) também são observados no reservatório, para as duas malhas, causados pelo efeito da aceleração no escoamento devido à transição entre represa e canal de saída. A flutuação da velocidade em torno da média, durante a simulação para 5 dias de escoamento real, num ponto da entrada, do centro e próximo da saída do reservatório, é mostrada na Figura 62 (malha fina) e Figura 63 (malha mediana). O 
padrão divergente na saída, deve-se a inexatidão na seleção do ponto no programa. Ambos, portanto, não são coincidentes, estando afastados de aproximadamente $13 \mathrm{~m}$.

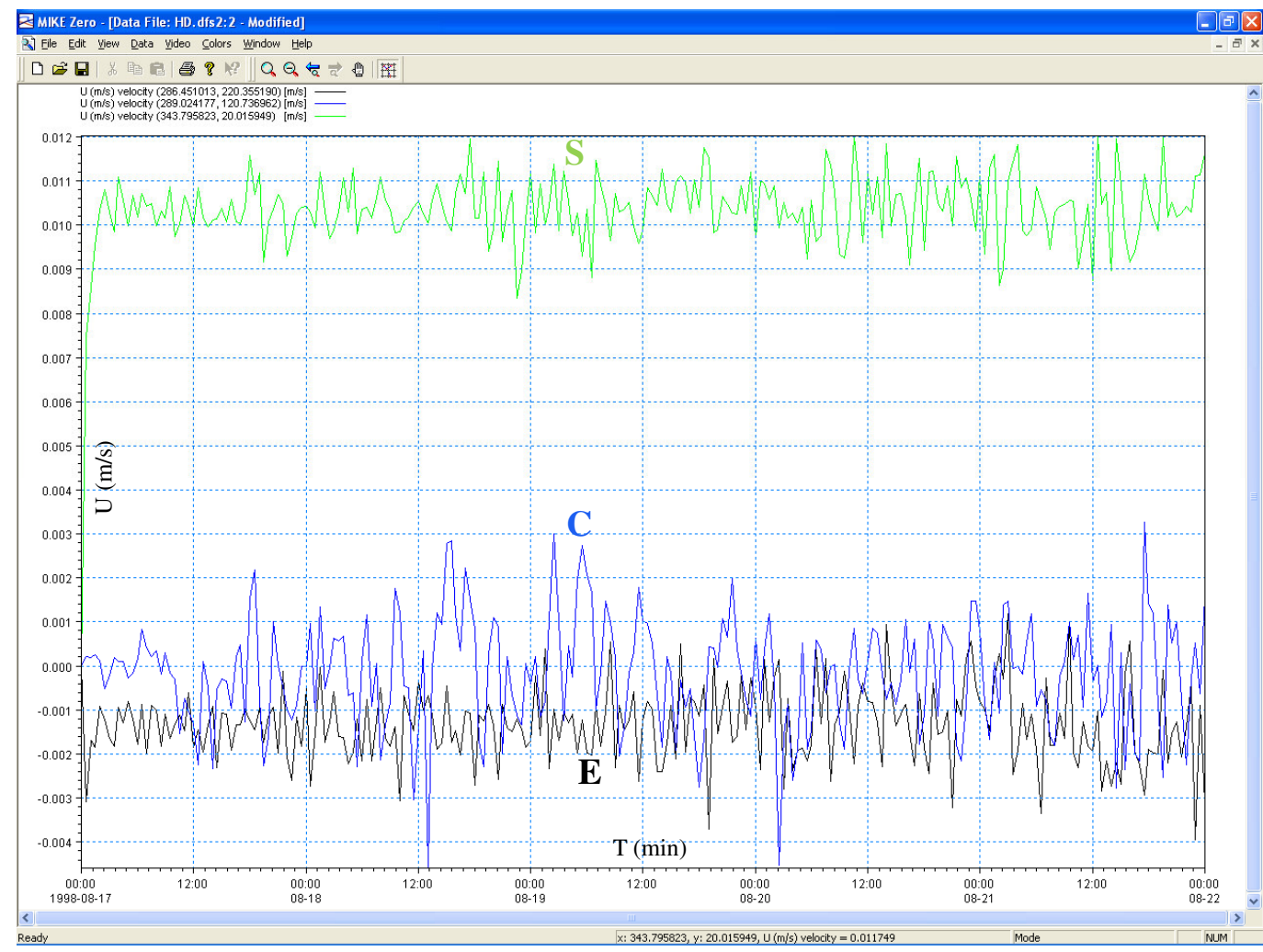

Figura 62. Variação temporal da componente da velocidade instantânea no sentido longitudinal da represa (direção y) nos pontos da entrada (E), centro (C) e próximo da saída (S), dentro do período de 5 dias de escoamento real para a malha fina.

Observada uma boa aproximação do padrão geral de escoamento entre ambas às malhas, passou-se a utilizar a malha mediana para o estudo de caso proposto, pelas razões já apresentadas e discutidas no item 4.3.3.3 do capítulo materiais e métodos.

Apesar de não se dispor de dados de campo referente ao perfil de velocidade em seções específicas, no interior do reservatório, uma análise de sensibilidade da hidrodinâmica (altura de água e velocidade) com os parâmetros de resistência e turbulência foi realizada. Foi verificado que o nível de água é praticamente insensível a alteração destes parâmetros (não se altera) e que o padrão de velocidade é alterado como teoricamente se prevê. Os testes foram feitos para o modelo de turbulência de Smagorinsky $\left(\mathrm{C}_{\mathrm{S}}=0,5\right)$ e viscosidade turbulenta 
constante $\left(v=0,01 \mathrm{~m}^{2} / \mathrm{s}\right)$; e parâmetro de resistência de Manning $\mathrm{M}=20$ e $\mathrm{M}=32$ (Apêndice p.

155-158). Estes parâmetros atuaram como calibradores das simulações de sedimentos.

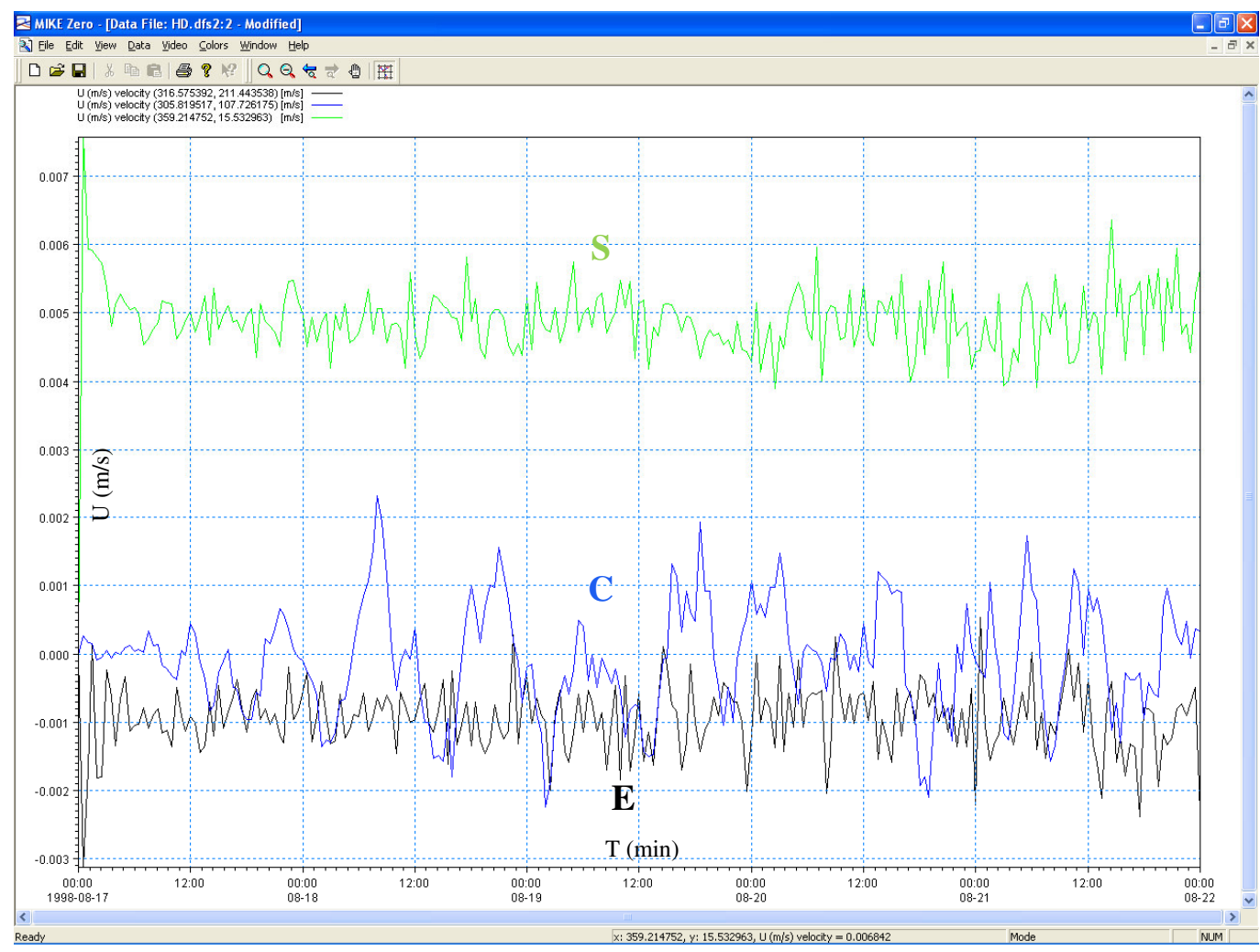

Figura 63. Variação temporal da componente da velocidade instantânea no sentido longitudinal da represa (direção y) nos pontos da entrada $(E)$, centro $(C)$ e próximo da saída (S), dentro do período de 5 dias de escoamento real para a malha mediana.

\subsection{Transporte de Sedimentos.}

O transporte de sedimento simulado foi comparado com dados de concentração de sólidos suspensos inorgânicos levantados em campo, de acordo com a distribuição espacial e temporal apresentados em 4.2.3 (Tabela 6), envolvendo períodos secos e de chuva. A cada período da medição uma nova simulação foi carregada com alteração das condições de contorno (vazão, altura de água e concentração de sedimentos). 
Na Figura 64 são mostrados os resultados da simulação referente ao transporte de sedimentos em suspensão na forma de concentração, considerando a Configuração 1, descrita no item 4.3.3.3, no período de 22 de agosto de 1998 a 27 de fevereiro de 1999. São comparados os pontos P5, P4 e P6 (centro, barragem e região de saída da represa), sendo que o ponto $\mathrm{P} 2$ representa a condição de contorno. Os pontos $\mathrm{P} 1$ e P3, por receberem contribuição de washload, não foram envolvidos. O MIKE 21C não permite uma entrada de sedimentos lateral, via Bacia Hidrográfica, na forma distribuída.

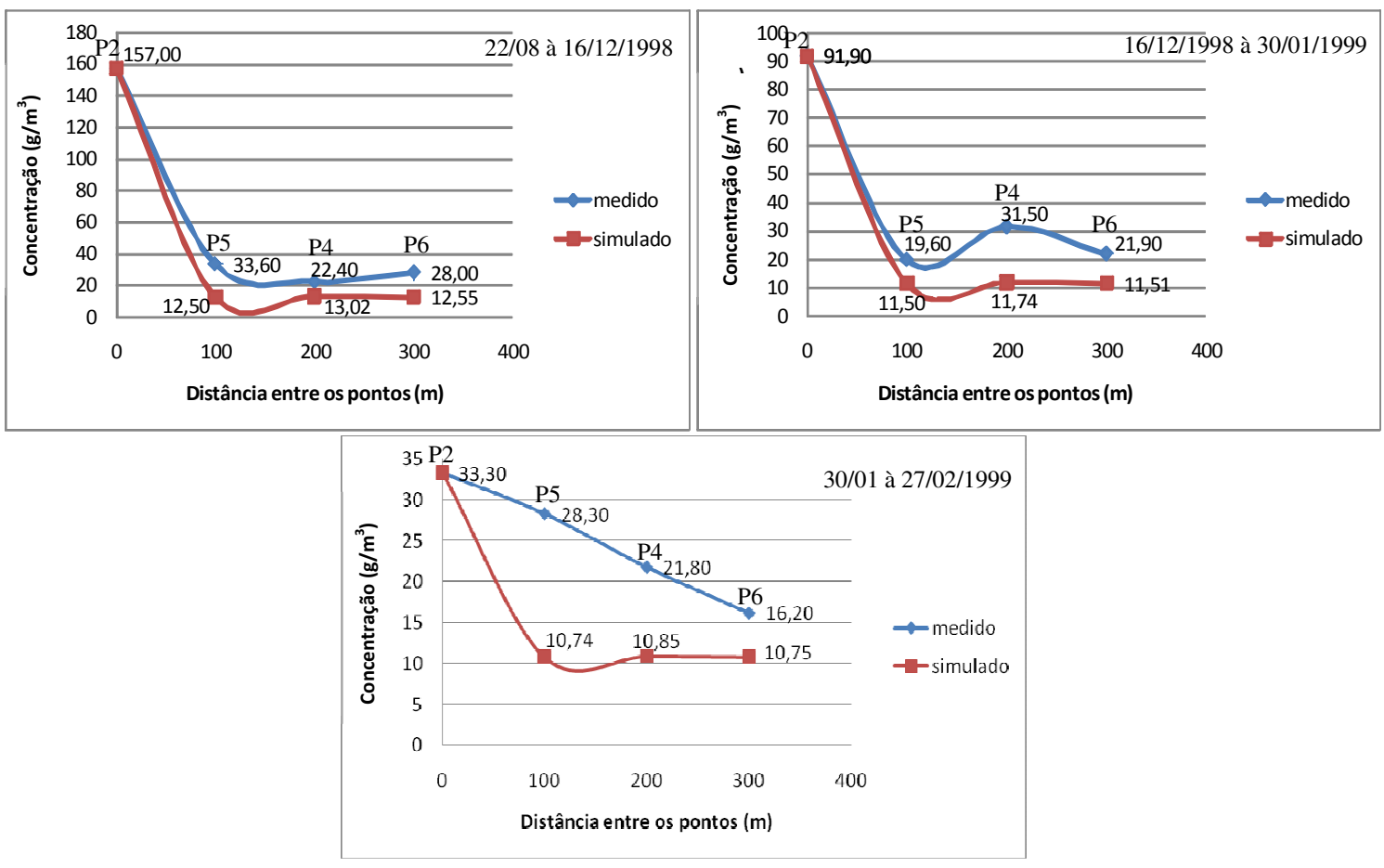

Figura 64. Variação espacial da concentração de sedimentos suspensos.

Uma boa aproximação entre a concentração medida e simulada é observada para o período inicial das campanhas (22/08 à 16/12/1998) e também para o período seguinte (16/12/1998 à 30/01/1999). Apesar disto, o menor erro relativo registrado entre os pontos comparados foi superior a 40\%. Testes realizados modificando os parâmetros de turbulência, rugosidade e a equação de transporte, na Configuração 1, não modificaram, praticamente, os resultados apresentados na Figura 64. Estes testes podem ser vistos parcialmente no Apêndice 
p. 159, para o período entre 31/01 à 27/02/2009. Atribuindo o valor total médio da concentração inicial $\left(\mathrm{Ci}=28 \mathrm{~g} / \mathrm{m}^{3}\right)$, que na Configuração 1 está distribuída entre as frações de areia (50\%), silte (12\%) e argila (38\%), para somente a fração de areia, tornou evidente que a parcela de sedimento não coesivo se deposita totalmente no início da simulação (na represa), fazendo com que a concentração de sedimentos suspensos no reservatório seja igual a zero (FIGURA 65).

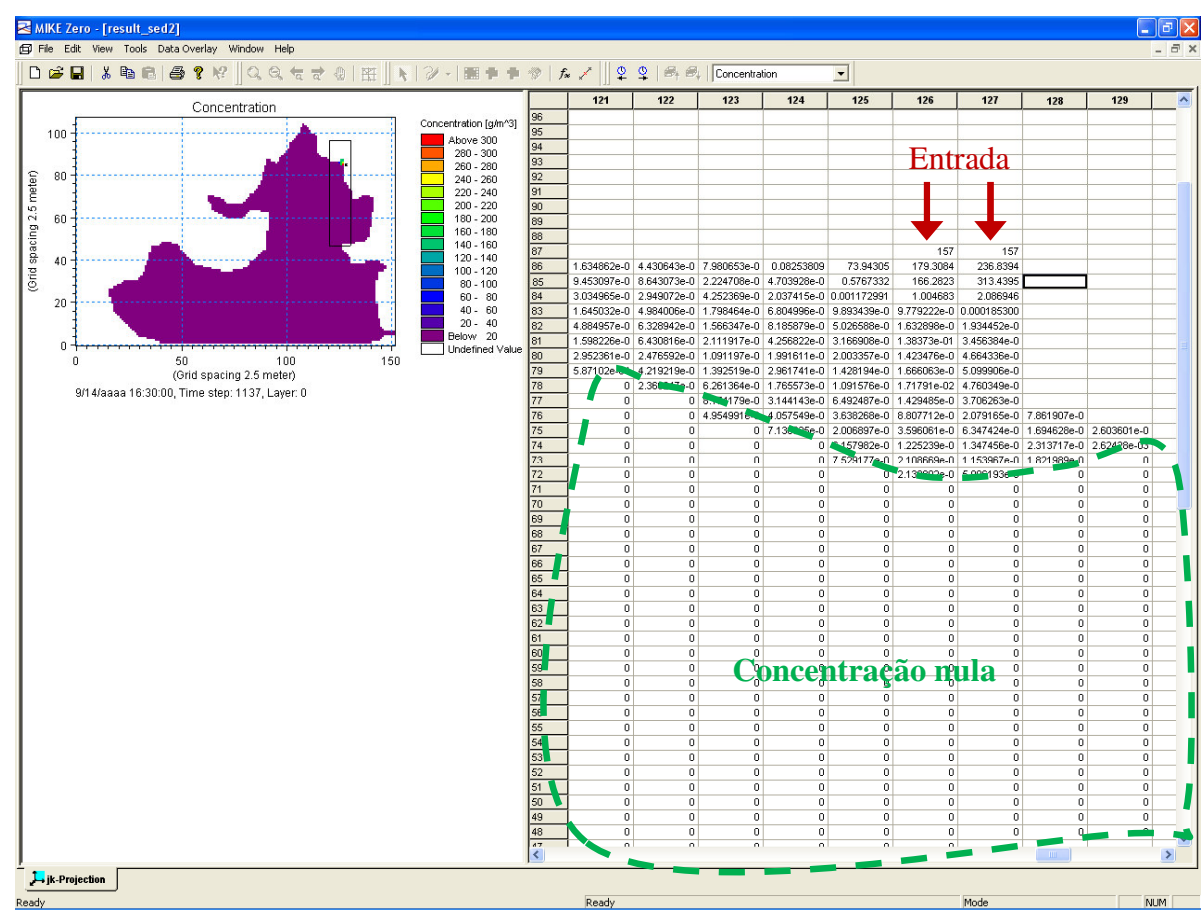

Figura 65. Tela de resultados da simulação de concentração $\left(\mathrm{g} / \mathrm{m}^{3}\right)$ - concentração inicial de sedimentos não coesivos (22/08 à 14/09/98).

Observa-se que mesmo havendo transporte em suspensão do córrego da Barrinha para o interior do reservatório, que no período mostrado é de $157 \mathrm{~g} / \mathrm{m}^{3}$ (na Entrada), a concentração ao longo da represa é nula (contorno em verde) como mostra a Figura 65. Isto aconteceu durante todos os períodos simulados. Este fato apresenta-se, teoricamente, como sendo um indicador de que em havendo transporte da parcela não coesiva para o interior do reservatório, este deve ocorrer preponderantemente na forma de transporte de fundo. É importante ressaltar que, apesar do cálculo da concentração média inicial não envolver os 
pontos P1 e P3, estes podem ser responsáveis pela variação das taxas medidas nos pontos P4, P5 e P6 no sistema real. Além disso, a concentração de sedimentos orgânicos, não considerada pelo modelo numérico, pode interferir no processo de deposição de sedimentos inorgânicos. Ainda, entre os períodos de medição de campo, a concentração de sedimentos suspensos naturalmente não é constante como considerado na simulação. Por fim, mesmo sabendo que uma boa calibração de sedimentos suspensos pode não garantir uma resposta adequada em termos de assoreamento simulado, esta etapa de ajuste é importante e necessária para que se tenha uma reprodução do problema real dentro das limitações do modelo numérico.

Desse modo, uma nova simulação foi proposta (Configuração 2), modificando o valor da concentração inicial das frações granulométricas, atribuindo o valor médio total entre os pontos P5, P4 e P6 à fração de argila, cuja calibração apresentou a melhor concordância. A Figura 66 mostra a tela de resultados da simulação de concentração, para esta nova configuração, correspondente ao mesmo período da Figura 65 (23 dias de escoamento real).

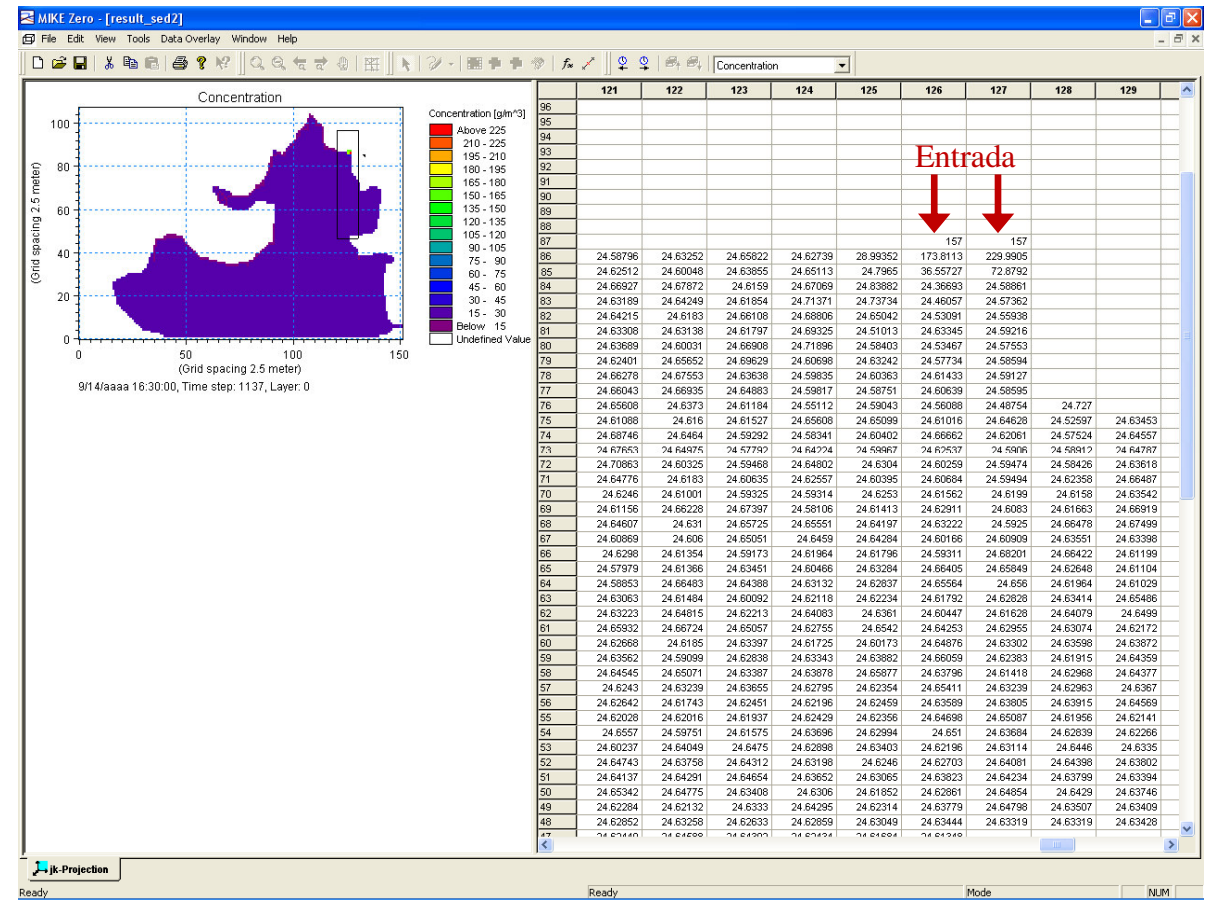

Figura 66. Tela de resultados da simulação de concentração $\left(\mathrm{g} / \mathrm{m}^{3}\right)$ - concentração inicial de sedimentos coesivos $(22 / 08$ à $14 / 09 / 98)$. 
Pode ser observada (FIGURA 66) a manutenção de uma concentração ao longo da represa, cujo valor é próximo da média entre P5, P4 e P6. Os gráficos dos resultados obtidos nesta simulação, para o período de 22 de agosto de 1998 a 21 de agosto de 1999, envolvendo todos os períodos da medição de campo, são mostrados na Figura 67.

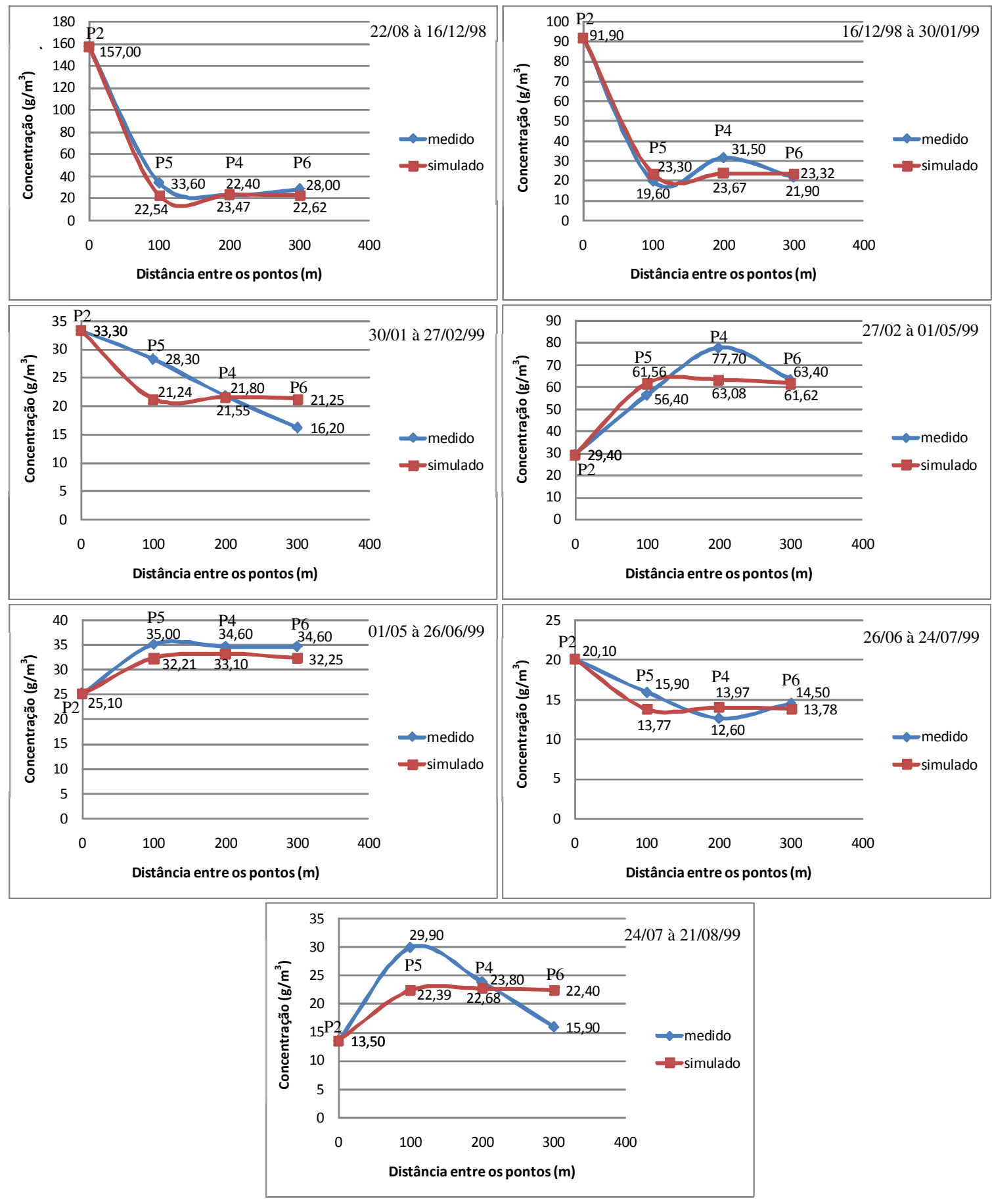

Figura 67. Concentração medida e simulada na represa (22/08/98 à 21/08/99) 
Note que o fato de considerar uma concentração média no reservatório, em cada período, conduz a um bom ajuste quando as concentrações medidas nos pontos P5, P4 e P6 são próximas. O maior erro relativo médio $(32,92 \%)$ foi registrado no período de 22 de agosto a 16 de dezembro de 1998 no ponto P5.

Uma calibração, nesta fase, envolvendo o diâmetro médio geral da amostra $\left(\mathrm{d}_{50}=0,049 \mathrm{~mm}\right)$, também foi implementada (Configuração 3). Do ponto de vista teórico, este diâmetro está na região limítrofe entre sedimento coesivo e não coesivo (para a ABNT, por exemplo, o diâmetro limite é de $0,050 \mathrm{~mm}$ ). Assim, a calibração se deu em duas simulações considerando estas duas características (coesivo e não coesivo). Após vários ajustes dos parâmetros de calibração, mesmo considerando uma situação mais favorável em termos de transporte de sedimentos (baixo parâmetro crítico de Shields e baixa densidade do sedimento), a concentração foi nula no reservatório, já no início da simulação, com exceção da entrada (FIGURA 68). Outra calibração envolvendo as faixas granulométricas, a partir da Configuração 2, na tentativa de obter uma melhor aproximação entre os perfis, também foi realizada (Configuração 4). As alterações foram $\theta_{\text {critShields }}=0,012$ (visando inclusive a ressuspensão de sedimentos), $\rho_{\mathrm{REL}}=1,1$ (sedimentos finos), $\rho_{\mathrm{REL}}=2,0$ (areia), redução pela metade do fator velocidade de queda $(€=0,5), \mathrm{M}=32$. $\mathrm{O}$ fator velocidade de queda é um parâmetro da "caixa preta" do modelo, cuja redução implica num maior tempo para a deposição em espaços também maiores. É interessante observar (além do aspecto da concentração inicial) que mesmo havendo predomínio, na entrada, do transporte de fluido no sentido longitudinal da represa, houve uma ocorrência de transporte de sedimentos suspensos por dispersão. Esta característica, na simulação, pode ser devida aos vórtices gerados pela diferença de velocidades (num primeiro momento), associando-se a um redirecionamento no fluxo (com o passar do tempo) devido à elevação do fundo na região próxima da entrada. A questão da modificação morfológica é discutida no tópico 5.3 a seguir. 


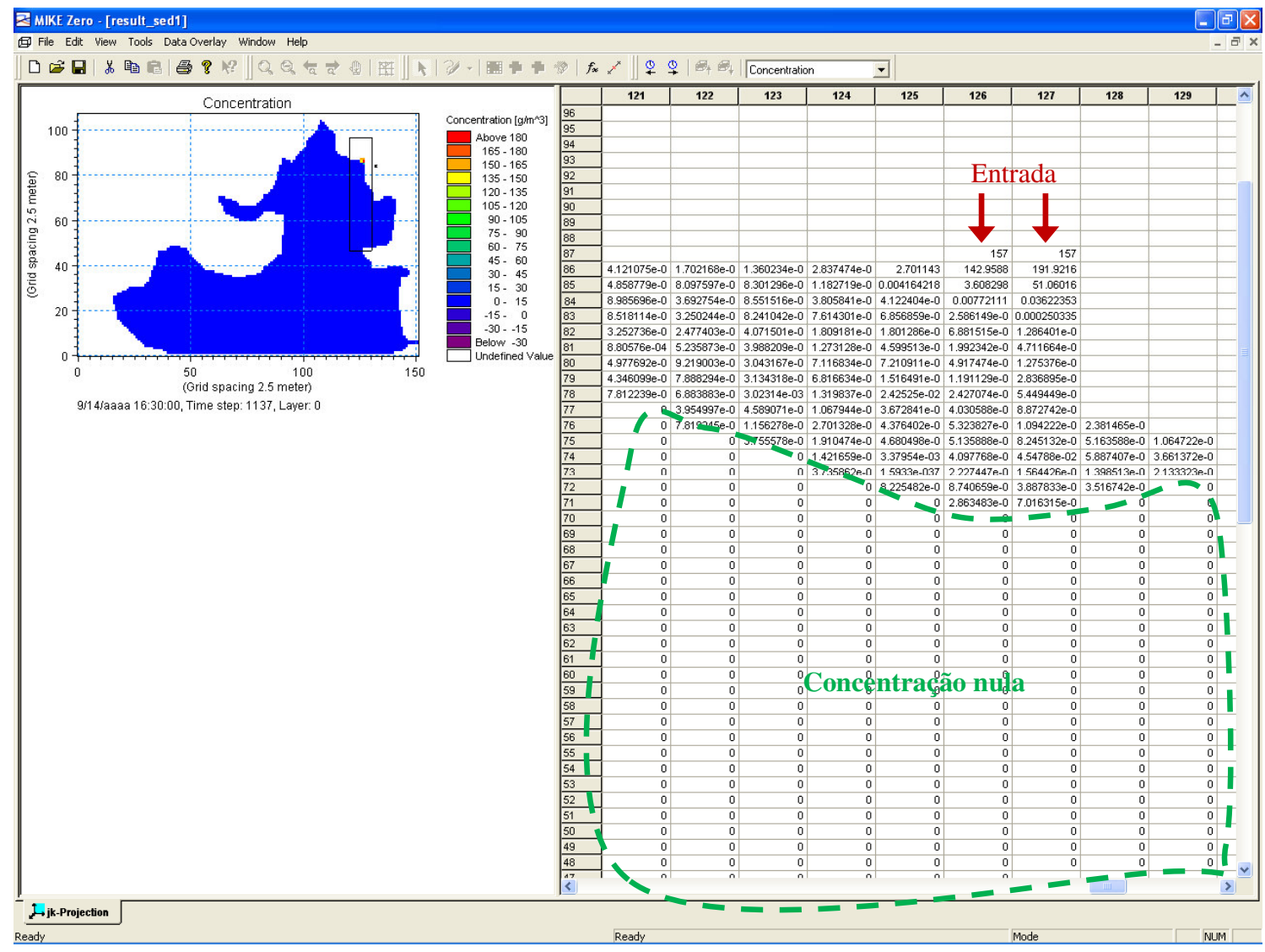

Figura 68. Tela de resultados da simulação de concentração $\left(\mathrm{g} / \mathrm{m}^{3}\right)$ - concentração inicial de sedimentos não coesivos - Configuração 3 (22/08 à 14/09/98).

\subsection{Modificação Morfológica.}

Apesar de o módulo de sedimentos do MIKE 21C permitir uma análise concomitante do transporte em suspensão, de fundo e consequentemente de mudança morfológica, esta última é destacada neste tópico, de forma a facilitar a discussão dos vários parâmetros de calibração.

As configurações 1 e 3 evidenciaram uma característica deposicional elevada na entrada, para a parcela de sedimento não coesivo (areia), fazendo com que ocorra uma formação de dunas, cujo topo se aproxima do nível de água. Uma das possíveis causas do fato se deve à baixa potência da corrente registrada ao longo do tempo. Em função deste aspecto, 
optou-se por modificar a abordagem da turbulência da Configuração 2, tendo como base os resultados obtidos em uma armadilha de sedimentos, no laboratório, por Souza (2006), utilizando o MIKE 21C como ferramenta. Segundo o autor, o Modelo de Turbulência de Grandes Escalas não captou a elevação da intensidade turbulenta. A razão disso é a aplicação do modelo de turbulência em caráter bidimensional com a equação integrada na vertical, e não em três dimensões. Por essa razão, a exemplo do trabalho anteriormente citado, optou-se pela utilização da viscosidade turbulenta constante. Na fase da simulação hidrodinâmica, o padrão do escoamento médio foi representado por uma viscosidade turbulenta constante. Com isso, a observação das flutuações de velocidade em torno de sua média não foi possível, mas poupouse esforço computacional na ausência de um equacionamento para a modelagem da turbulência.

Portanto, dos parâmetros calibrados para a concentração de sedimentos suspensos (Configuração 2), o parâmetro $\mathrm{C}_{\mathrm{S}}=0,5$ de Smagorinsky foi substituído pela viscosidade turbulenta constante $v=0,01 \mathrm{~m}^{2} / \mathrm{s}$, sem comprometimento da calibração da concentração. É valido ressaltar que o teste realizado com a formulação de Smagorinsky, neste trabalho, resultou numa alteração do formato do delta na entrada, mas não impactou expressivamente nas cotas do assoreamento final obtido para o período. Alguns estágios do assoreamento, antes do final do primeiro período de simulações (22/08/98 à 21/08/99) para a comparação batimétrica, são apresentados com o propósito de verificar o padrão de deposição e as alterações provocadas pelo mesmo na hidrodinâmica e no transporte de sedimentos durante este primeiro período de simulação. Na Figura 69, a Seção 1 (transversal) se localiza a 5 m da entrada numa extensão de 20 m e a Seção 2 (longitudinal) inicia-se na entrada, e também apresenta comprimento de $20 \mathrm{~m}$. As Figuras 70 e 71 mostram a hidrodinâmica e o perfil deposicional respectivamente, correspondentes ao instante de tempo de $86400 \mathrm{~s}$, já simuladas 24 horas de escoamento real. 


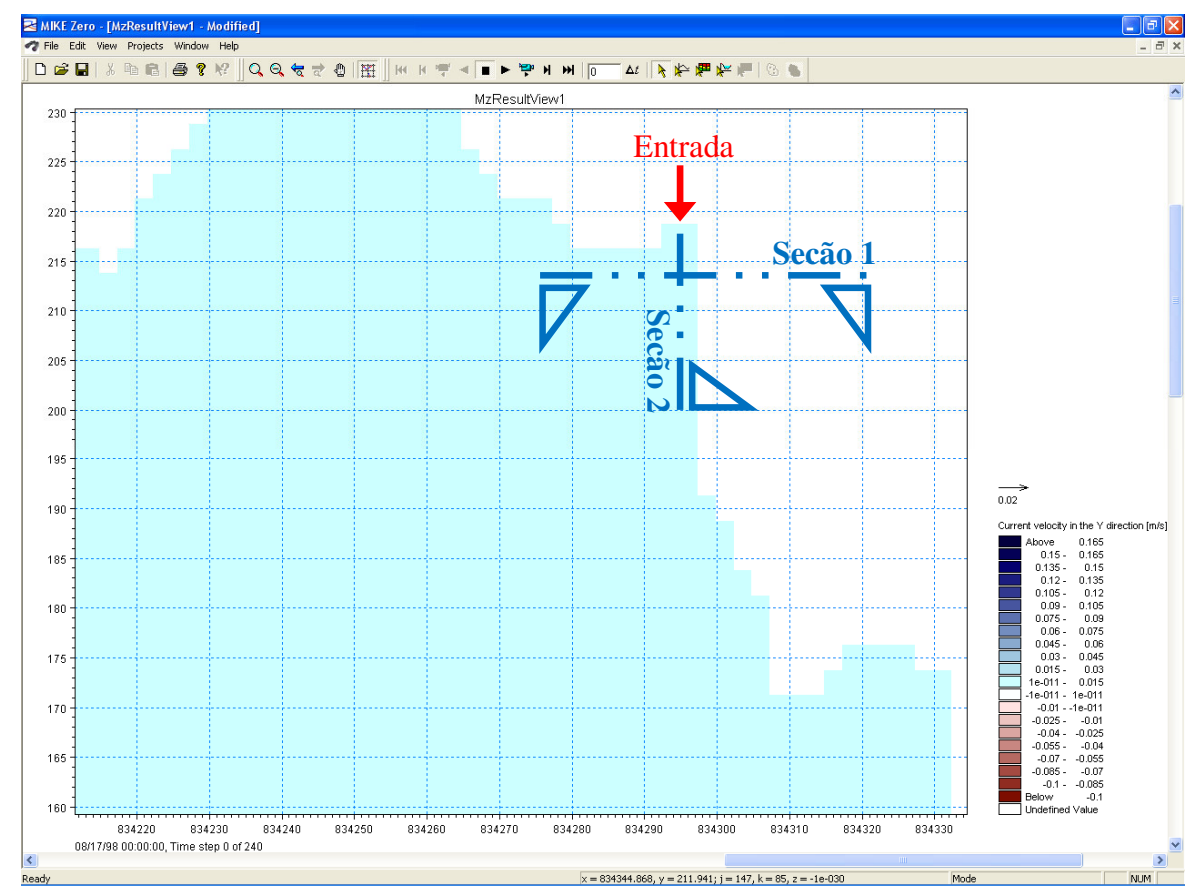

Figura 69. Região de análise da hidrodinâmica e assoreamento simulados.

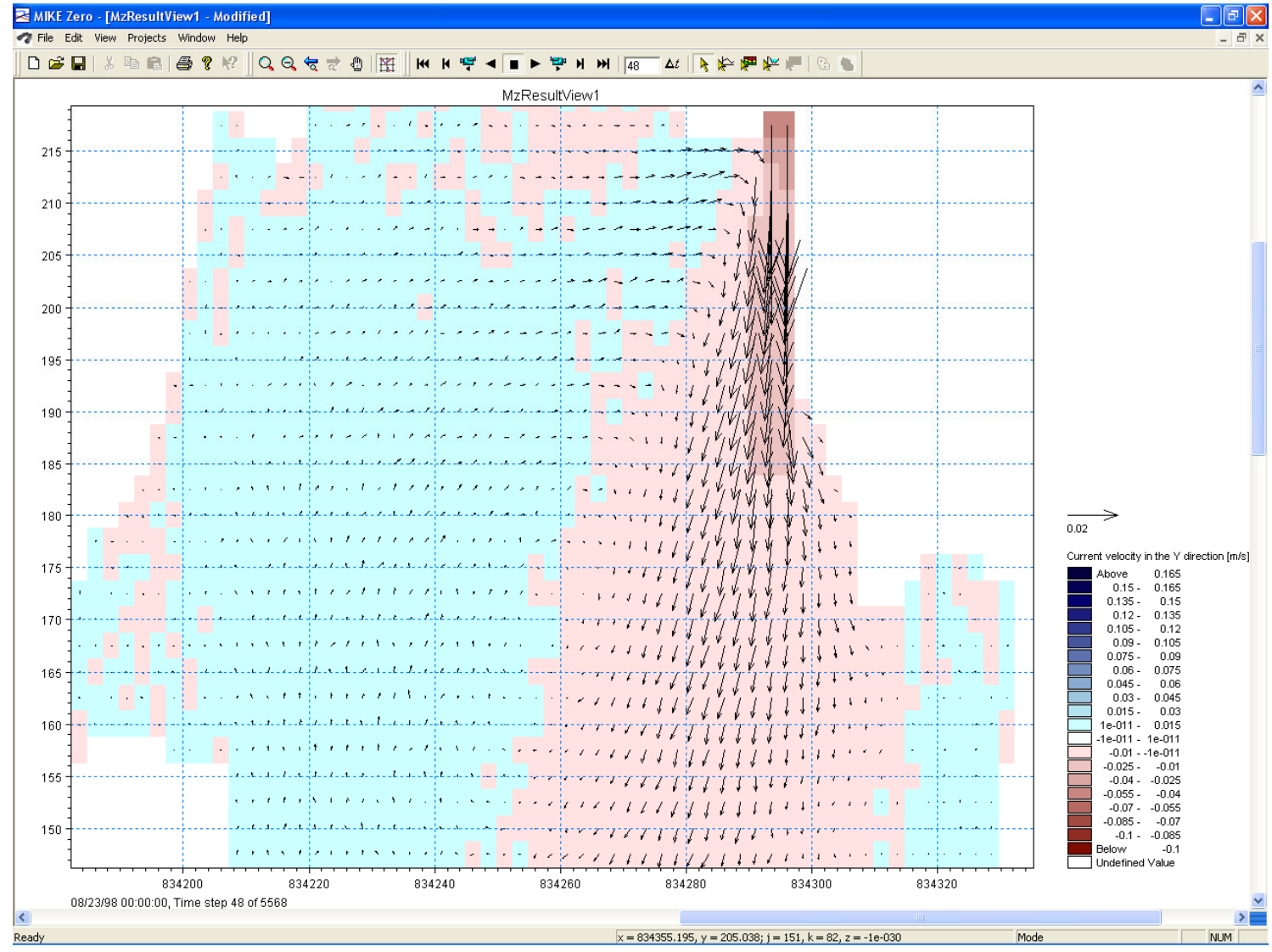

Figura 70. Hidrodinâmica na represa (instante $t=86400 s-23 / 08 / 1998$ às 00:00 $h$ ) período simulado: $22 / 08$ à $16 / 12 / 1998$. 
É notada, na Figura 70, a característica da hidrodinâmica com predomínio dos vetores velocidades no sentido longitudinal, e formação de uma macro-recirculação na represa.
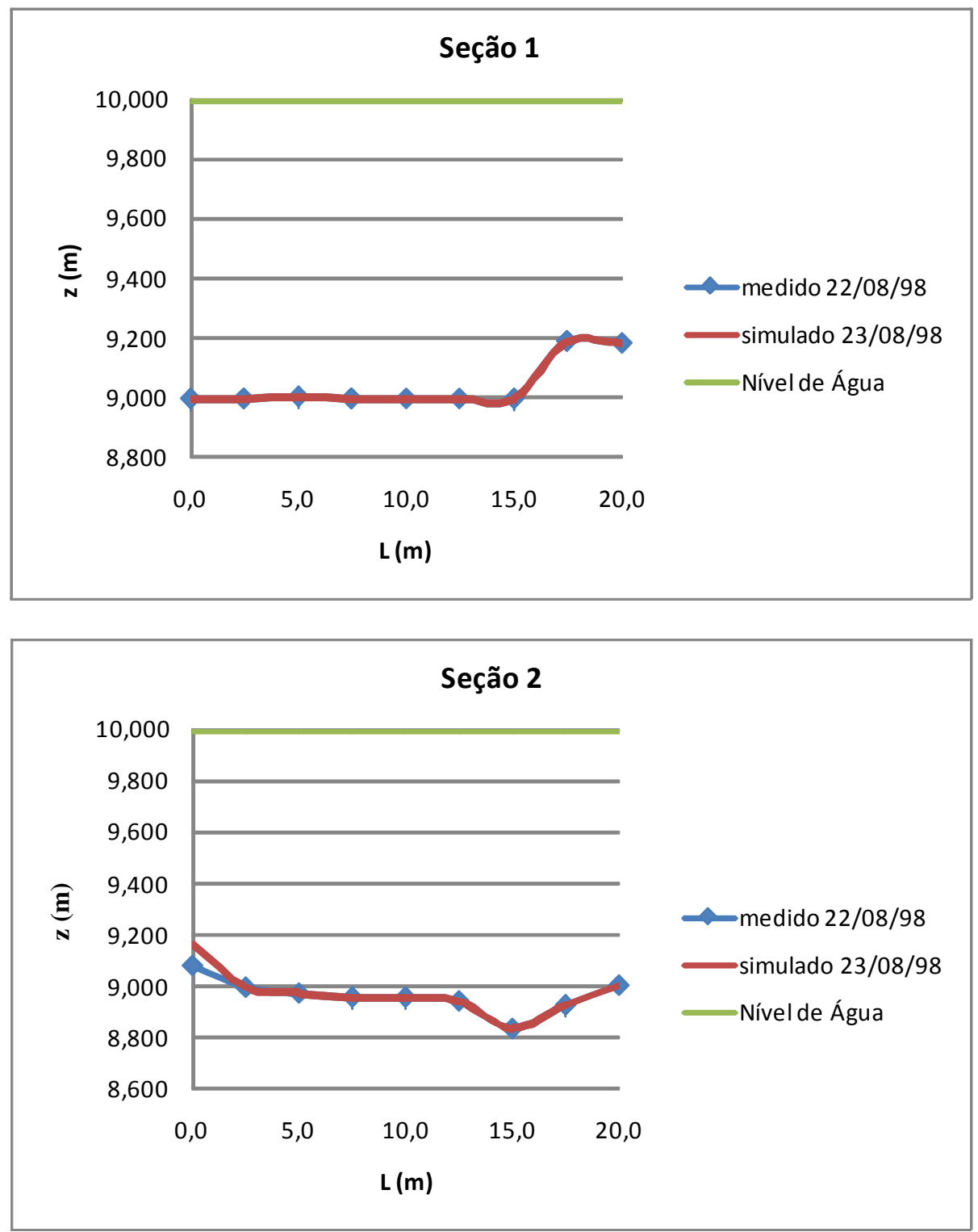

Figura 71. Perfil de assoreamento na entrada (instante $t=86400 s-23 / 08 / 1998$ às 00:00 $h$ ) período simulado: 22/08 à 16/12/1998.

Um pequeno assoreamento acontece na entrada do reservatório, nos primeiros 2,5 m (Seção 2), cuja magnitude não interfere no padrão hidrodinâmico. Uma frenagem na velocidade a jusante da entrada com redirecionamento do escoamento acontece a partir do instante $\mathrm{t}=3600000 \mathrm{~s}$, que corresponde ao dia 02/10/1998 às 16 horas (FIGURA 72). 


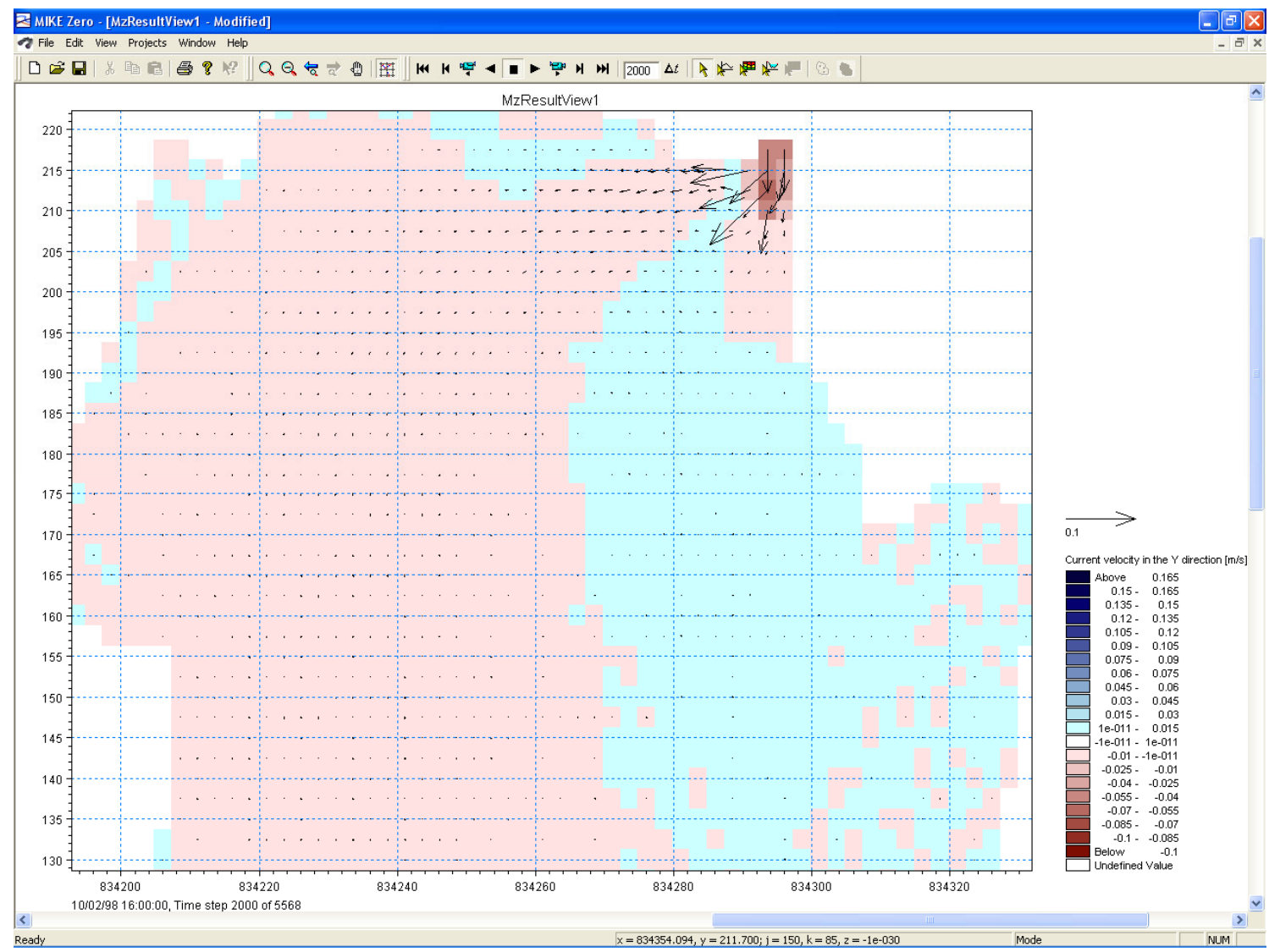

Figura 72. Hidrodinâmica na represa (instante $t=3600000 \mathrm{~s}-$ 02/10/1998 às 16:00 h) período simulado: 22/08 à 16/12/1998.

Pode ser observado também um aumento na velocidade próximo da entrada (escala de cores), justificada pela elevação do fundo, cujo pico acontece a $5 \mathrm{~m}$ da entrada, aproximandose do nível de água. Esta característica também é responsável pela mudança da direção do escoamento. Estas observações podem ser vistas na Figura 73, que contempla perfis de assoreamento, do instante mostrado, nas seções 1 e 2 . Nesta fase, testes propostos com valores do parâmetro de Shields mais baixos, redução do fator de velocidade de queda das partículas e baixa densidade do sedimento (Configuração 4) foram implementados. O objetivo foi analisar se a deposição intensa na entrada, registrada pela simulação, ocorria preponderantemente devido a estes fatores. O delta formado, apesar de algumas diferenças na morfologia, manteve a característica em termos de elevação (Apêndice p. 160). 

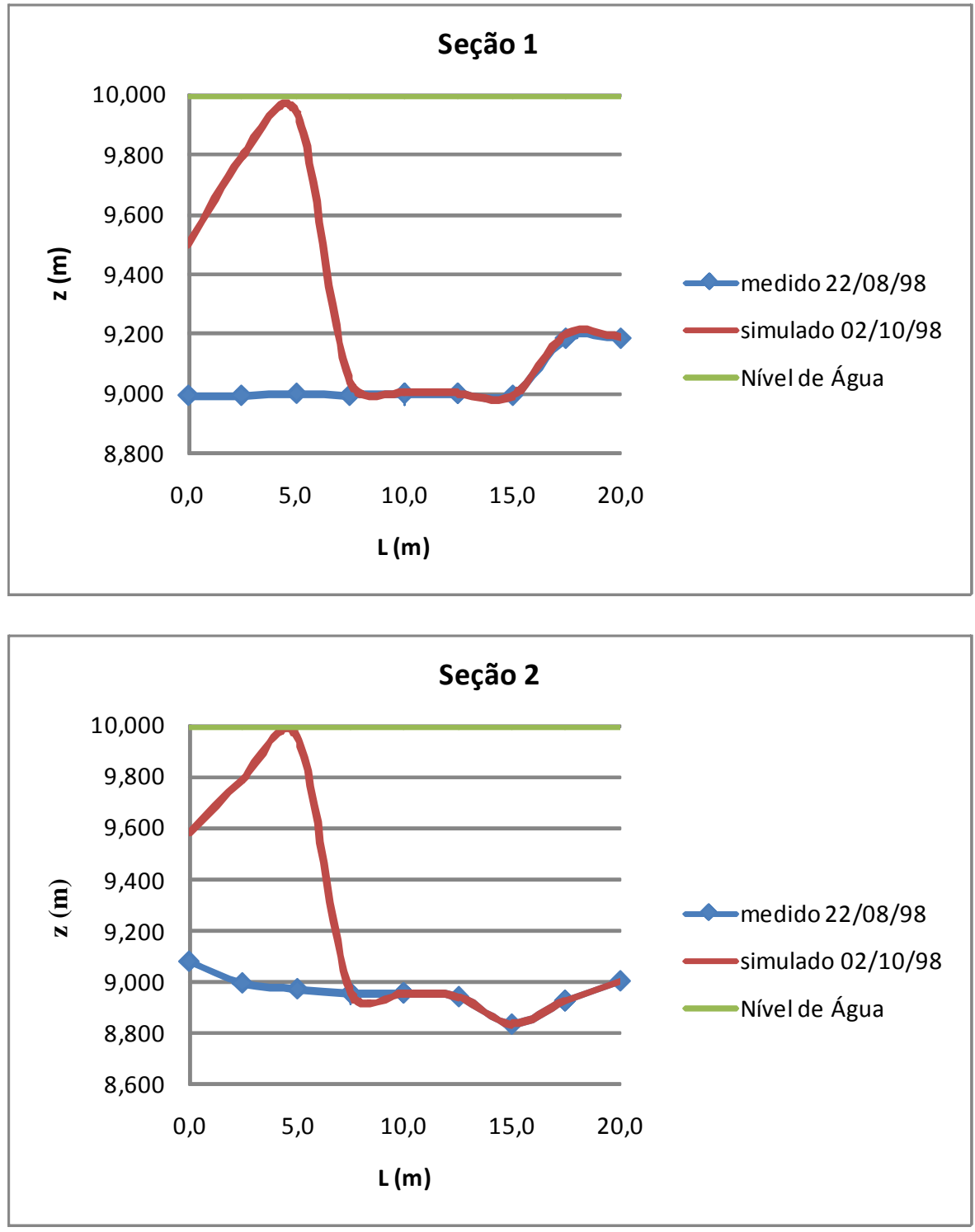

Figura 73. Perfil de assoreamento na entrada (instante $t=3600000 s-02 / 10 / 1998$ às 16:00 $h$ ) período simulado: 22/08 à 16/12/1998.

A Figura 74, a seguir, correspondente ao instante $t=5443200 \mathrm{~s}$ ou à $01 / 05 / 1999$ às 00:00 h (período simulado: 01/05 à 26/06/1999) mostra a intensificação da velocidade na entrada (escala de cores), em função da redução da seção transversal provocada pela elevação do fundo. Os vetores velocidade são distribuídos na entrada, com baixa intensidade ao longo do reservatório. 


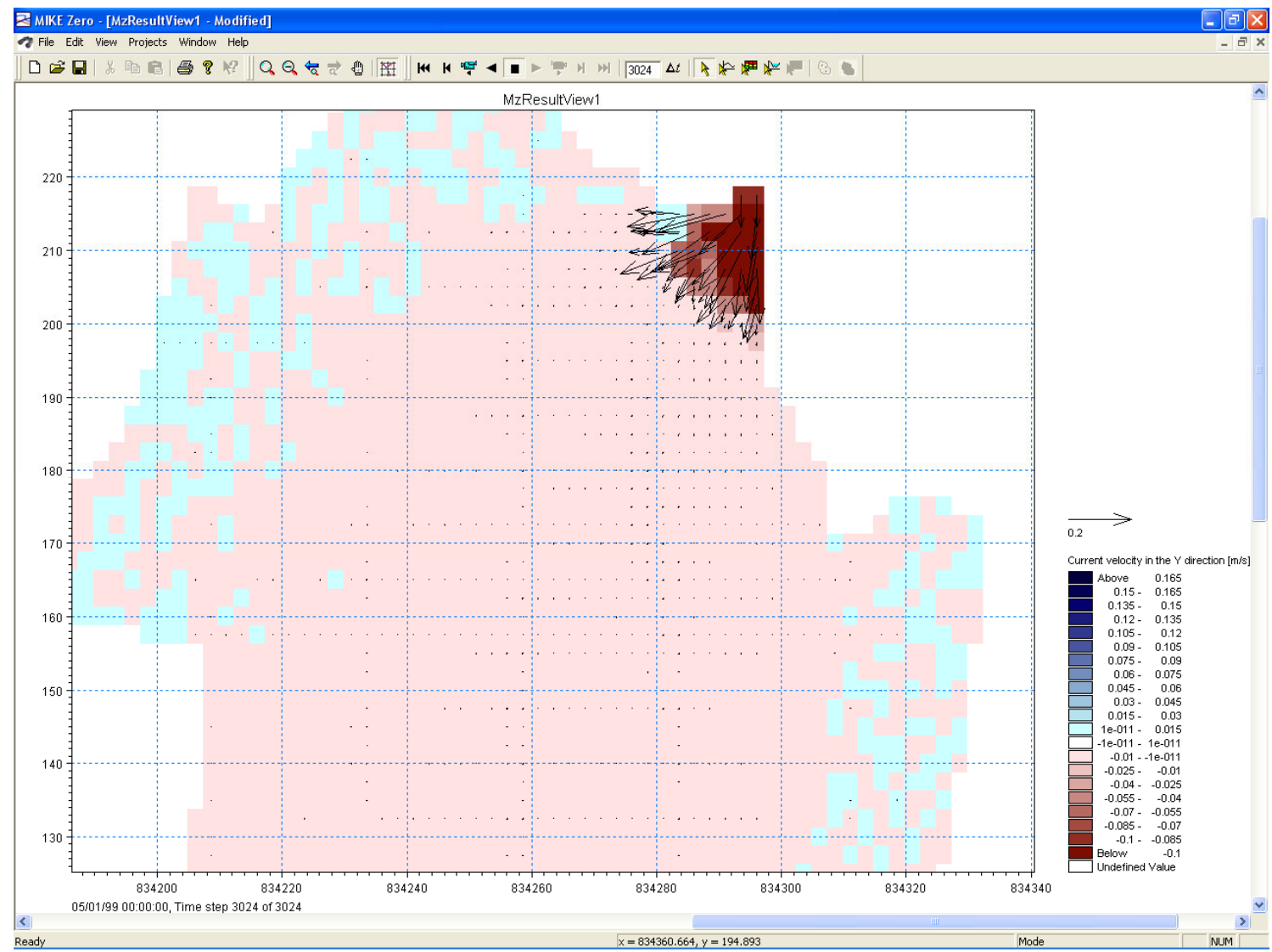

Figura 74. Hidrodinâmica na represa (instante $t=5443200 s-01 / 05 / 1999$ às 00:00 $h$ ) período simulado: 01/05 à 26/06/1999.

Mesmo com a elevação do fundo de forma intensa na entrada, não foram verificadas divergências numéricas no cálculo das velocidades. O perfil de fundo do referido instante, que permite observar a evolução morfologia no período, nas seções já descritas, é apresentado na Figura 75.

Apesar de não ter gerado resultados satisfatórios no trabalho de Souza (2006), uma calibração (Configuração 5) utilizando a equação de transporte total de sedimentos de Engelund-Hansen foi testada. Aplicações do método pela DHI, bem como em outros trabalhos como o de Kiat et al. (2008), com $\mathrm{d}_{50}$ maior que $0,15 \mathrm{~mm}$ e regime de altas vazões, têm mostrado resultados satisfatórios. A modificação do equacionamento ocorreu a partir da Configuração 2. Os resultados apresentaram instabilidade numérica a partir de 27/02/99, com 
um alto assoreamento na entrada constituindo em uma barragem de sedimentos (Apêndice p. 160).
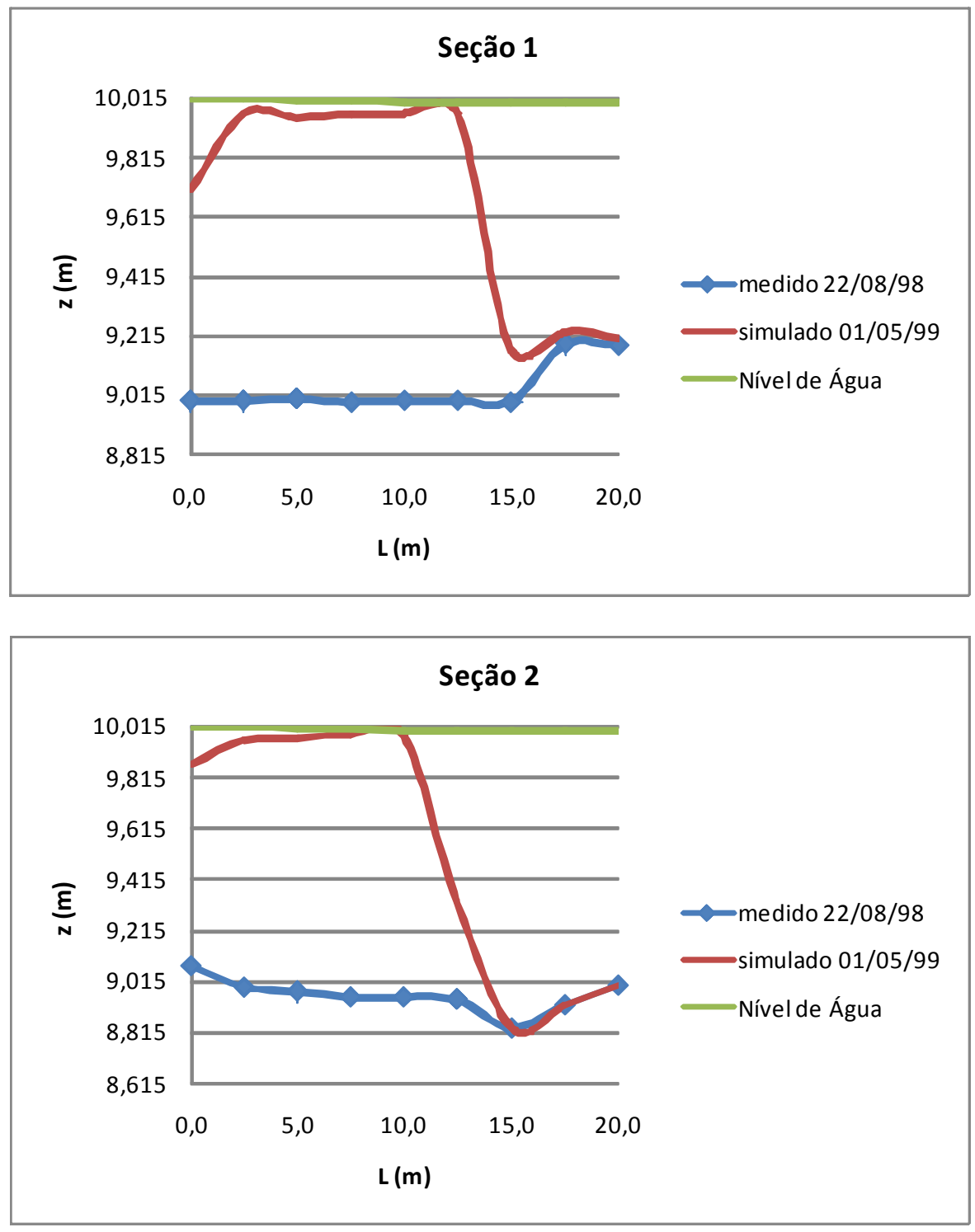

Figura 75. Perfil de assoreamento na entrada (instante $t=5443200 s-01 / 05 / 1999$ às 00:00 $h$ ) período simulado: 01/05 à 26/06/1999.

A partir deste momento, algumas células na entrada passaram a constituir ilhas, interrompendo o escoamento hídrico e de sedimentos através das mesmas. A Figura 76 mostra o padrão dos vetores velocidade, correspondente ao instante $t=2419200 \mathrm{~s}(21 / 08 / 1999)$, 
dentro do período de simulação 24/07 à 21/08/1999. As células em cor branca representam a ilha de sedimentos formada próxima da entrada da represa.

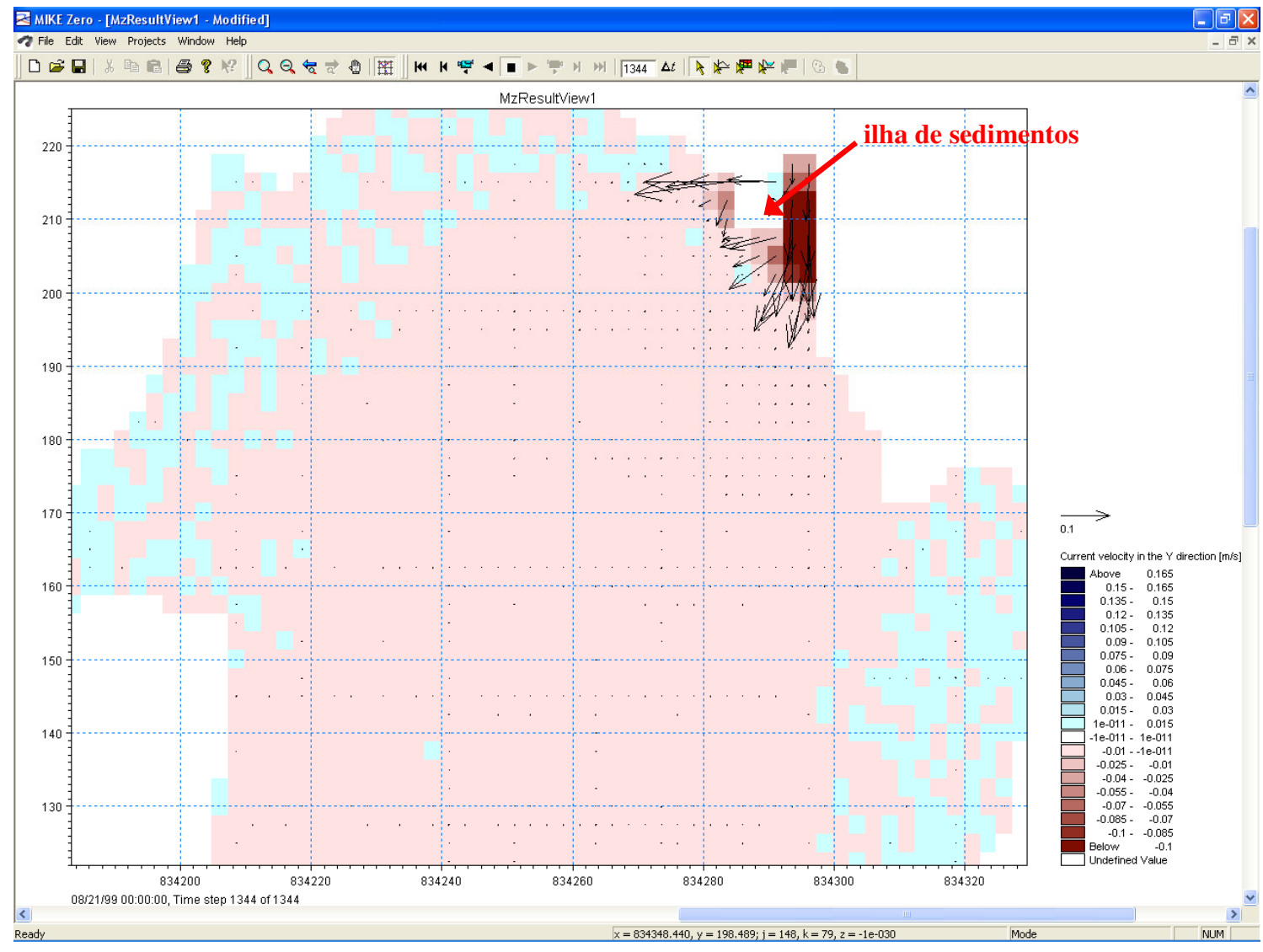

Figura 76. Hidrodinâmica na represa (instante $t=2419200 s-21 / 08 / 1999$ às 00:00 h) período simulado: 24/07 à 21/08/1999.

Mesmo com a criação da ilha de sedimentos, ainda assim não foi detectada divergência numérica na simulação. Note que, novamente, ocorre um redirecionamento do escoamento em função da barreira de sedimentos formada. O instante acima apresentado corresponde à data onde foi realizada a segunda campanha batimétrica. Com o prosseguimento da simulação, as primeiras divergências numéricas foram identificadas. A intensificação do assoreamento provocou o aumento da ilha de sedimentos até a constituição de um barramento total ao escoamento na entrada da represa. Este fato ocorreu no instante 513000 s (05/01/00 às 22:30 h), que corresponde ao período de simulação de 31/12/99 à 
28/01/00. A tela de resultados da hidrodinâmica para este instante, mostrando esta característica, é apresentada na Figura 77, e os perfis do assoreamento (Seções 1 e 2) na Figura 78.

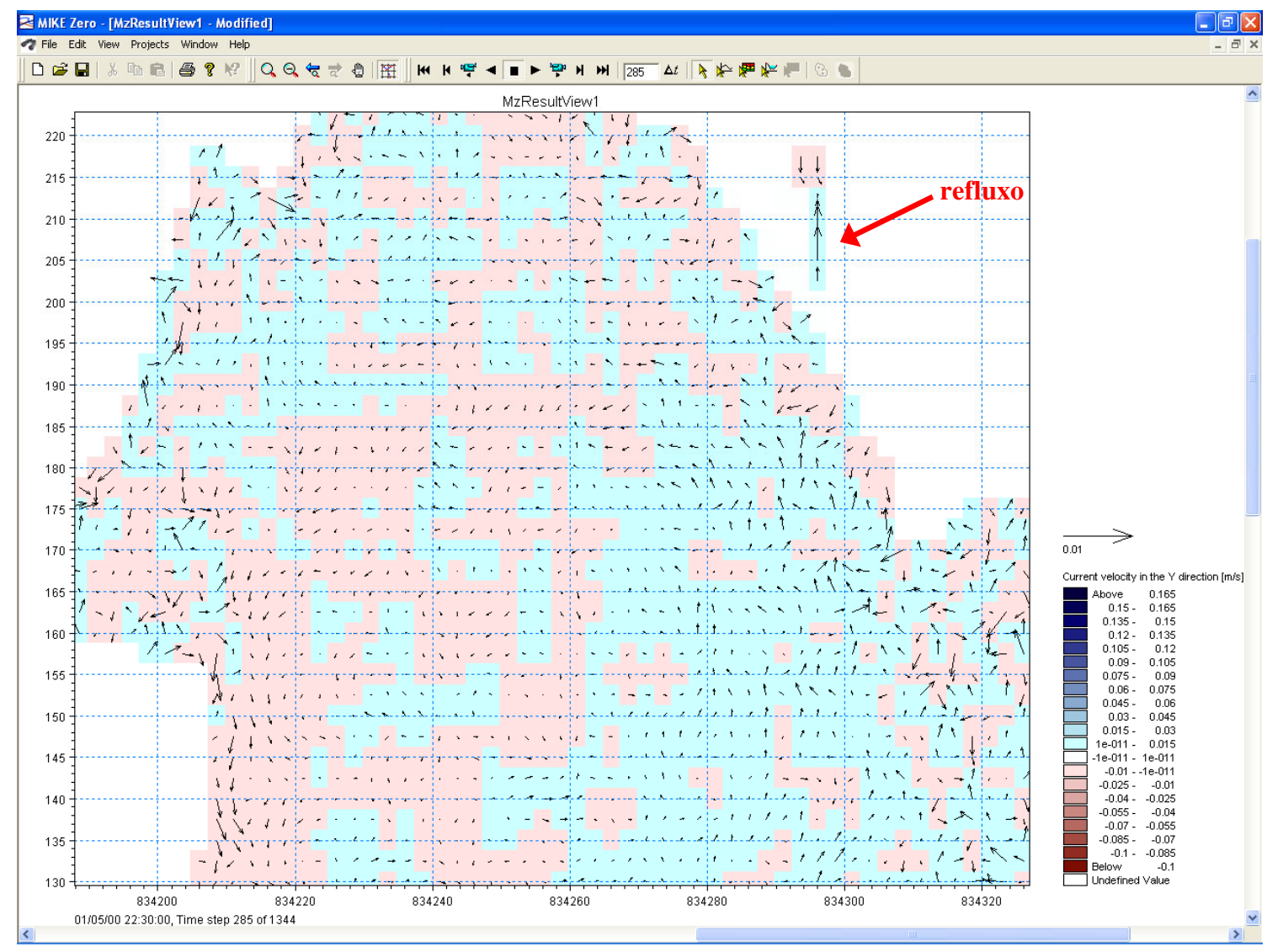

Figura 77. Hidrodinâmica na represa (instante $t=513000 s-05 / 01 / 2000$ às 22:30 h) período simulado: 31/12/1999 à 28/01/2000.

Note que em função da barreira de sedimentos criada na entrada, a simulação registra um retorno do escoamento de entrada (refluxo). A partir deste momento, todas as intervenções feitas no sentido de melhorar a simulação, visando ao objetivo de comparar a batimetria simulada àquelas observadas para os anos de 2000 e 2001, não resultaram em efeito positivo. Dessa forma, a discussão dos resultados do assoreamento ficou limitada aos dados obtidos, em campo e pela simulação, no ano de 1999. 

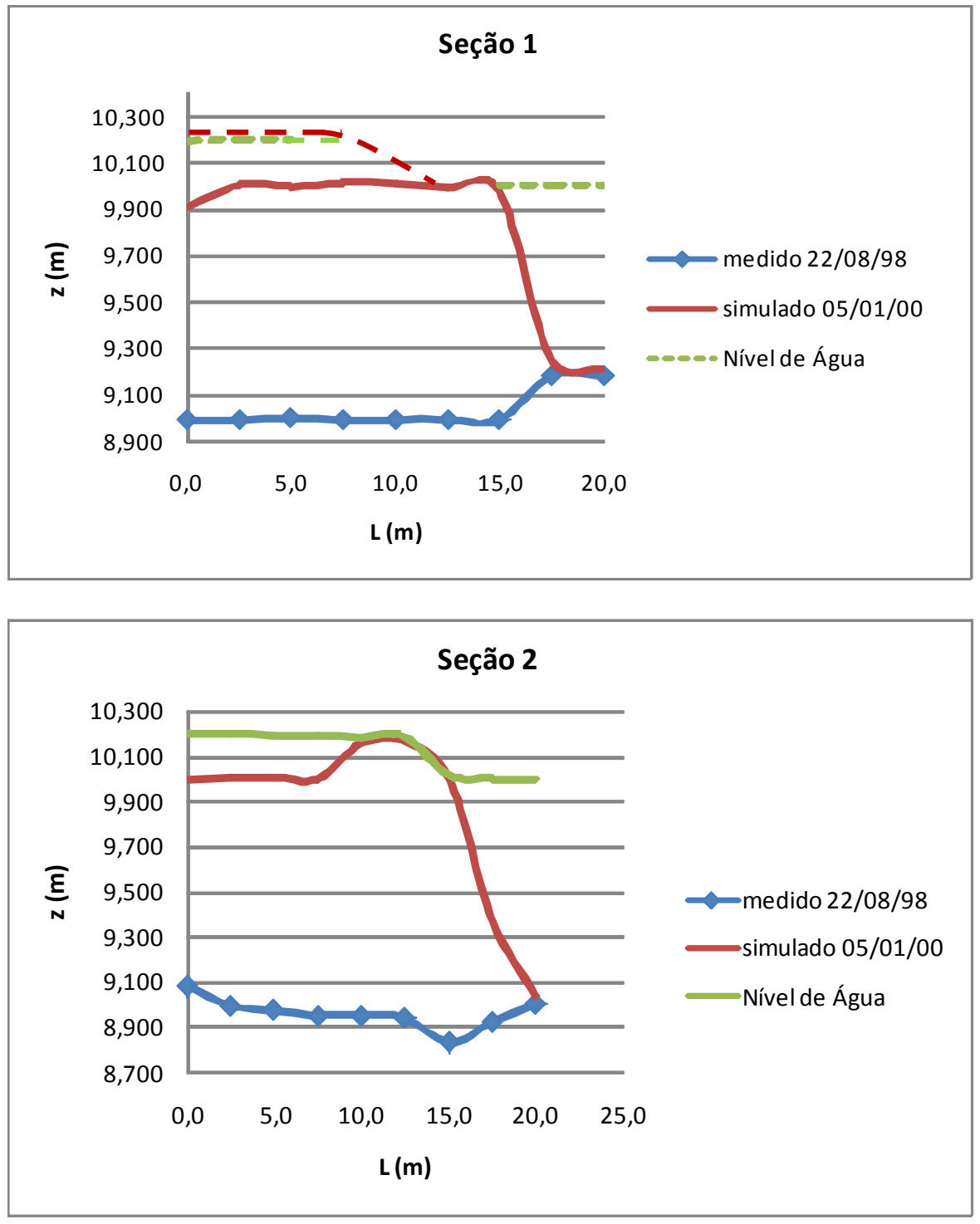

Figura 78. Perfil de assoreamento na entrada (instante $t=513000 \mathrm{~s}-05 / 01 / 2000$ às $22: 30 \mathrm{~h}$ ) período simulado: 31/12/1999 à 28/01/2000.

Portanto, os dados batimétricos observados (TABELA 3 - Materiais e Métodos) e simulados (FIGURA 76) do referido ano, são comparados através de seções transversais e longitudinais representativas. O esquema da represa, contendo as coordenadas de localização e o sentido de corte das seções, além dos pontos batimétricos contidos em cada uma delas, é apresentado na Figura 79. As seções foram escolhidas de forma a mostrar, de acordo com a intensidade do assoreamento observada, a diferença entre medido e simulado no reservatório. 


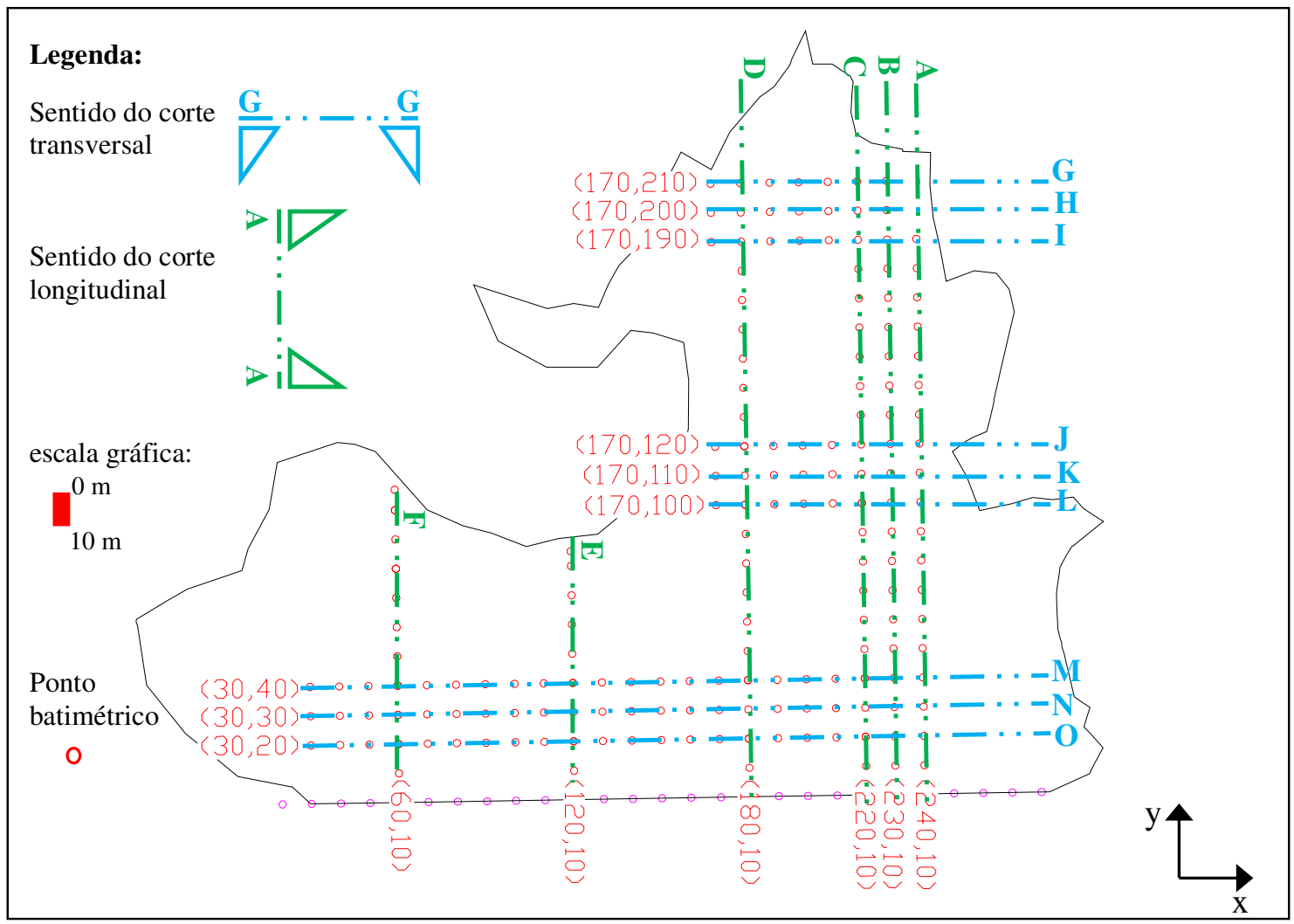

Figura 79. Esquemático do reservatório com a indicação dos cortes representativos para a comparação batimétrica entre medido e simulado (campanha de 21 de agosto de 1999).

As seções A, B e C, apresentadas nas Figuras 80, 81 e 82, respectivamente, mostram o perfil assoreado no sentido preferencial do escoamento. Pode ser observado, na região próxima da entrada, (início das seções A e B), um assoreamento simulado superior ao observado, com característica inversa após uma distância de aproximadamente $10 \mathrm{~m}$ para a jusante. Do ponto de vista da simulação, as baixas velocidades registradas são apontadas como a principal causa deste efeito. Na seção A, entre os marcos 20 m e 10 m inclusive, é identificada uma pequena erosão no assoreamento medido, não computada pela simulação. Este mesmo fato ocorreu na Seção B entre os marcos 100 m e 80 m, e 50 m e 30 m. Na seção C, que sofre influência predominantemente do escoamento por dispersão, foi registrada uma 
pequena taxa de deposição simulada no período, concordando com o perfil observado em campo, estando ambos próximos do perfil de fundo original.

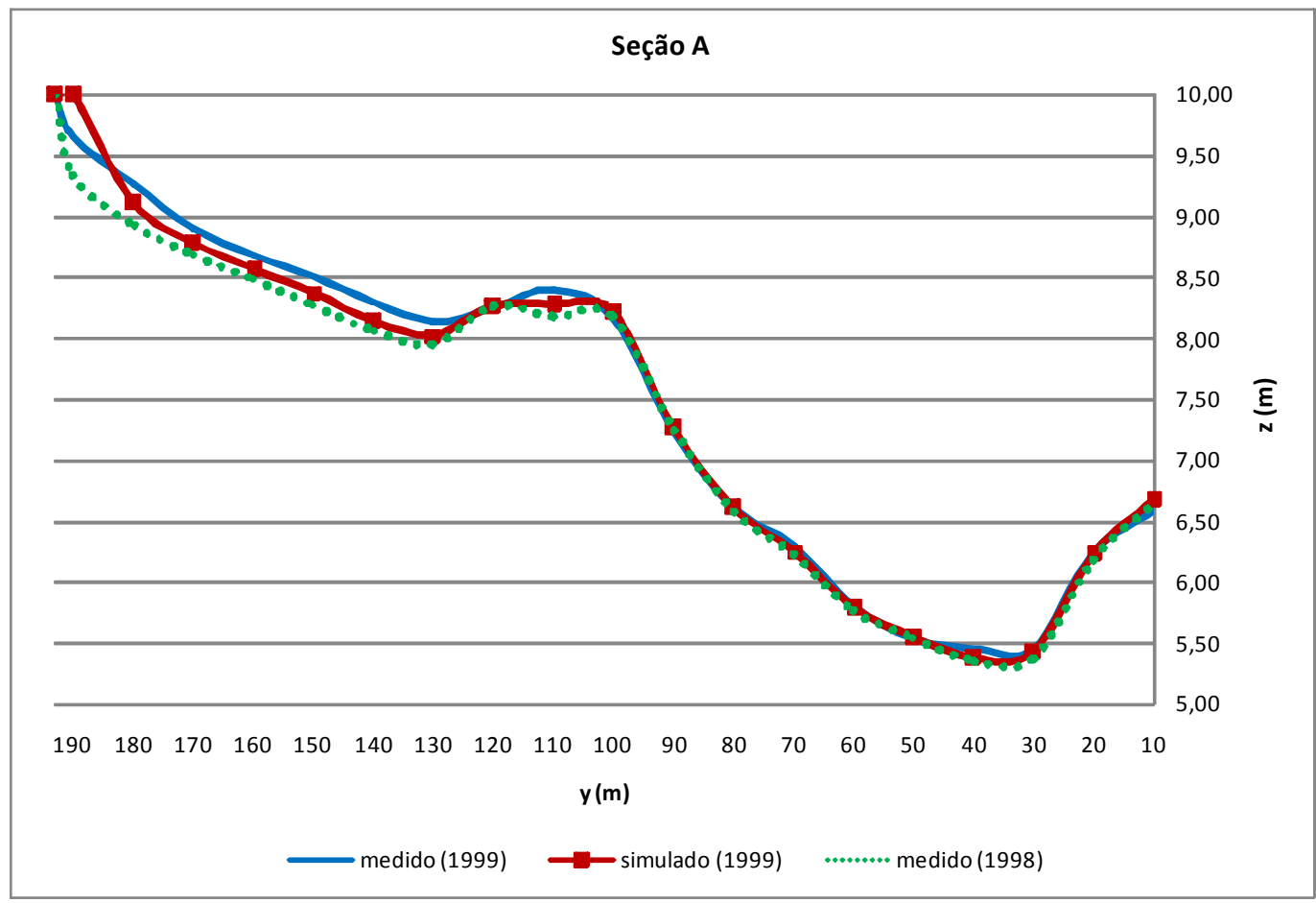

Figura 80. Comparação entre assoreamento medido e simulado na Seção A (21/08/1999)

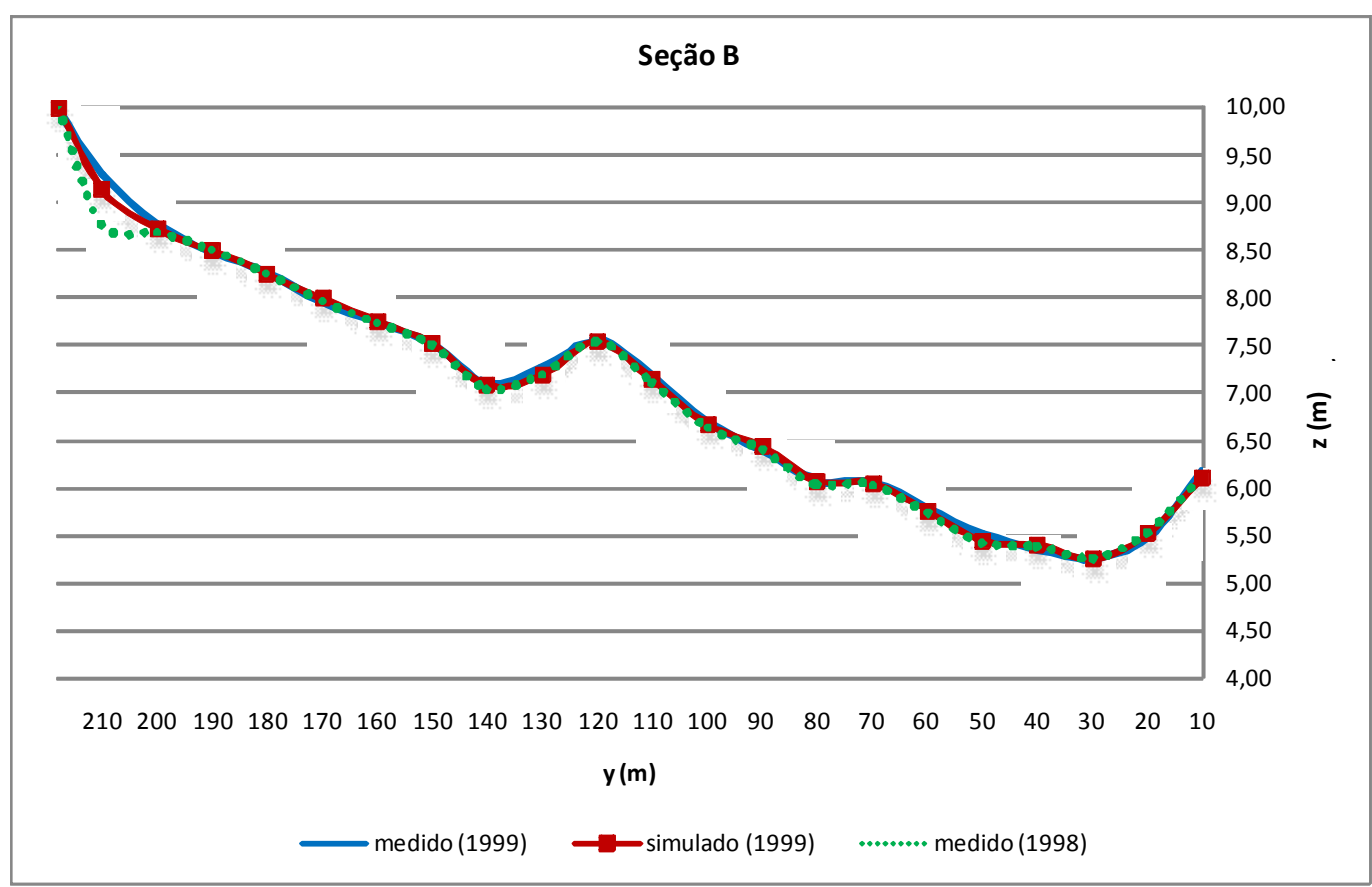

Figura 81. Comparação entre assoreamento medido e simulado na Seção B (21/08/1999) 


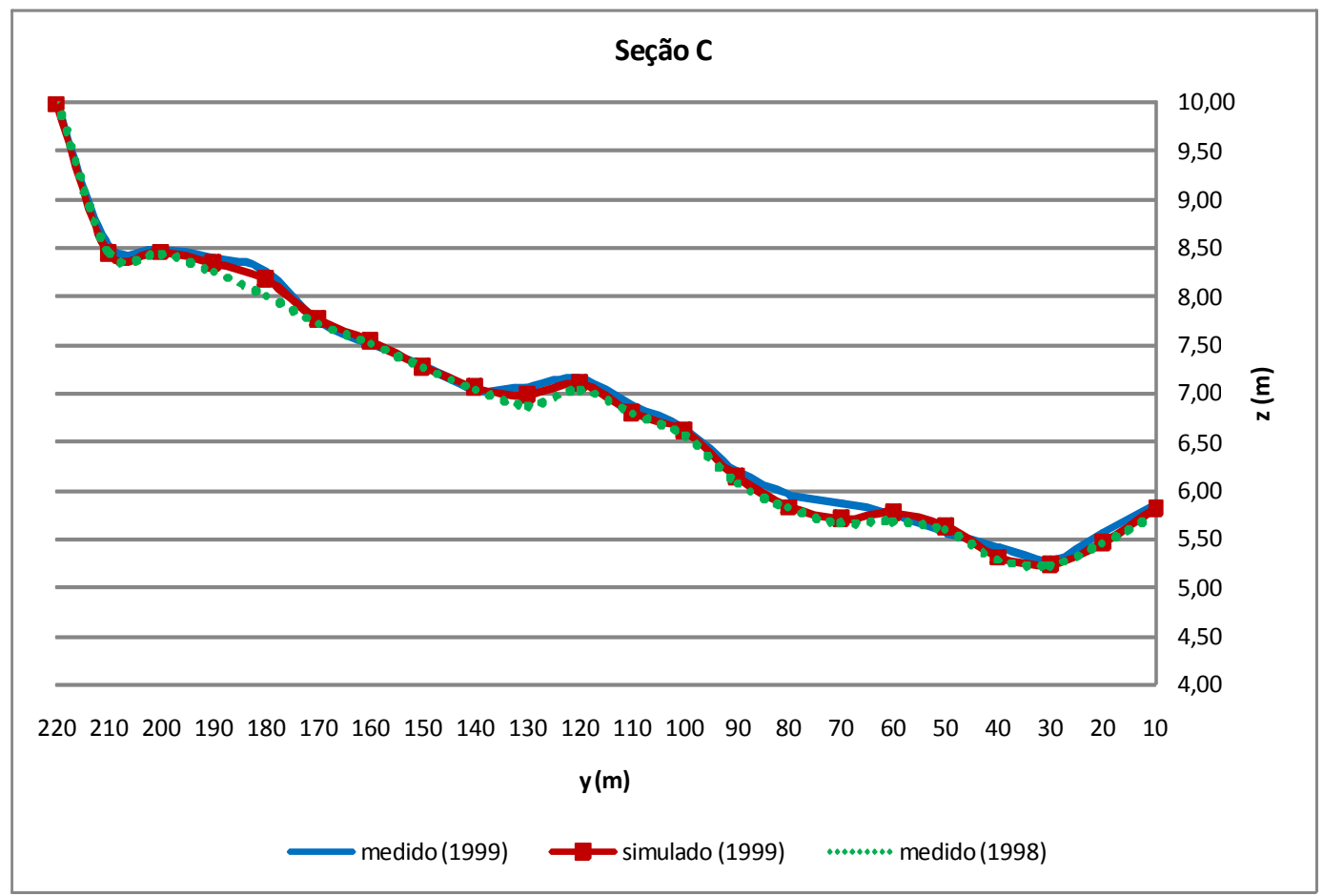

Figura 82. Comparação entre assoreamento medido e simulado na Seção C (21/08/1999)

A Seção D (FIGURA 83), situada a $60 \mathrm{~m}$ da entrada, apresentou um perfil de fundo simulado próximo ao observado, entre os marcos $220 \mathrm{~m}$ e $160 \mathrm{~m}$, onde o maior percentual obtido pelo modelo numérico, possivelmente se deve ao momento em que o escoamento é redirecionado a partir de $\mathrm{t}=3600000 \mathrm{~s}$ (FIGURA 72). Próximo ao marco $150 \mathrm{~m}$, da referida Seção, foi instalada uma das câmaras de sedimentação para amostragem (P1), onde foi registrada, em boa parte do tempo, concentrações de sedimentos superiores a entrada (TABELA 3 de Materiais e Métodos). Também no marco 90 m, uma elevação acentuada no perfil medido é observado. A região descrita, próxima da margem, é uma das quais onde a proteção da mata ciliar é rompida, contribuindo para a entrega de sedimentos à represa via washload. 


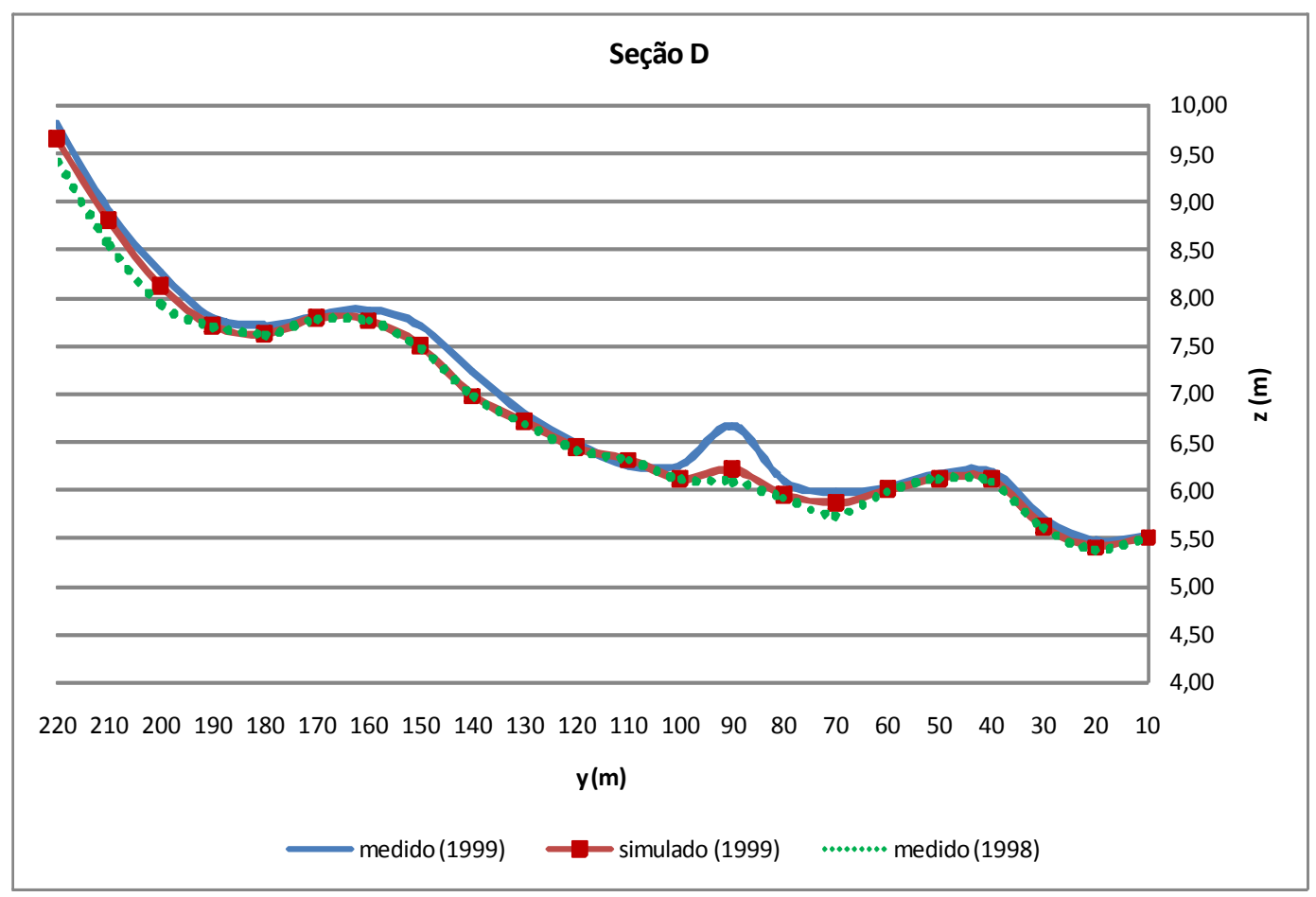

Figura 83. Comparação entre assoreamento medido e simulado na Seção D (21/08/1999)

As seções E e F (FIGURAS 84 e 85) são as que sofrem menos influência dos sedimentos transportados pelo córrego da Barrinha. No entanto, conforme relata Bufon (2006), o assoreamento nesta região, sobretudo próximo da seção F, é intenso. Isto se deve ao carreamento de sedimentos pela Bacia Hidrográfica. O assoreamento simulado, nestas duas seções concordou com o perfil original levantado em 1998, muito diferente dos registros de erosão-deposição na Seção E, e erosão na Seção F, observados em campo. As Seções G, H e I (FIGURAS 86, 87 e 88), transversalmente ao sentido principal do escoamento, na entrada da represa, evidenciam as características apresentadas para os trechos iniciais das Seções A, B, C e D. A Seção G apresenta uma aproximação satisfatória entre assoreamento simulado e observado, não sendo computada erosão entre os marcos 210 m e 190 m. Já para as seções H e I, a melhor concordância entre os perfis obtidos ocorre entre os marcos 240-195 m e 240 e $215 \mathrm{~m}$ respectivamente, região esta onde predomina o escoamento de montante. 


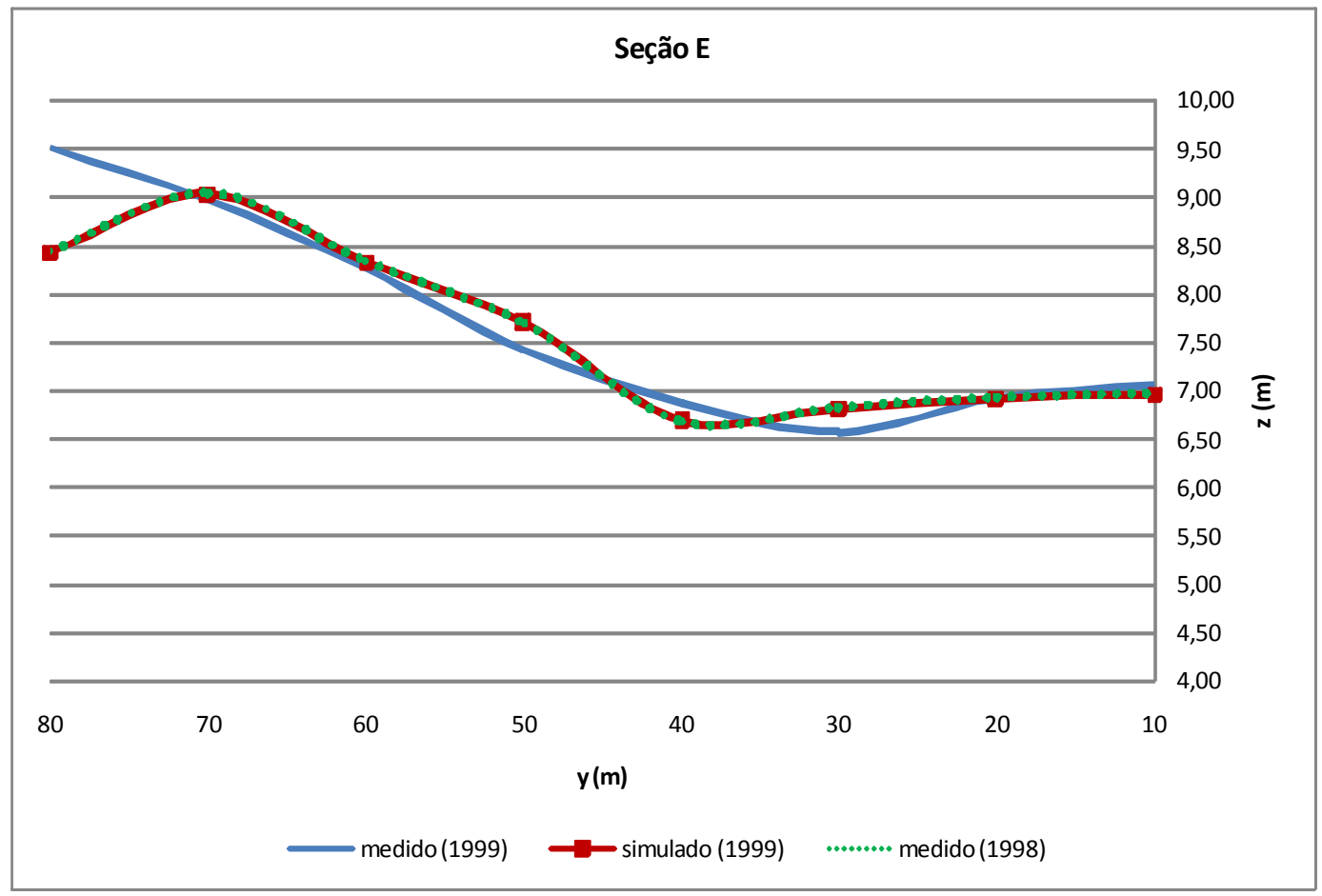

Figura 84. Comparação entre assoreamento medido e simulado na Seção E (21/08/1999)

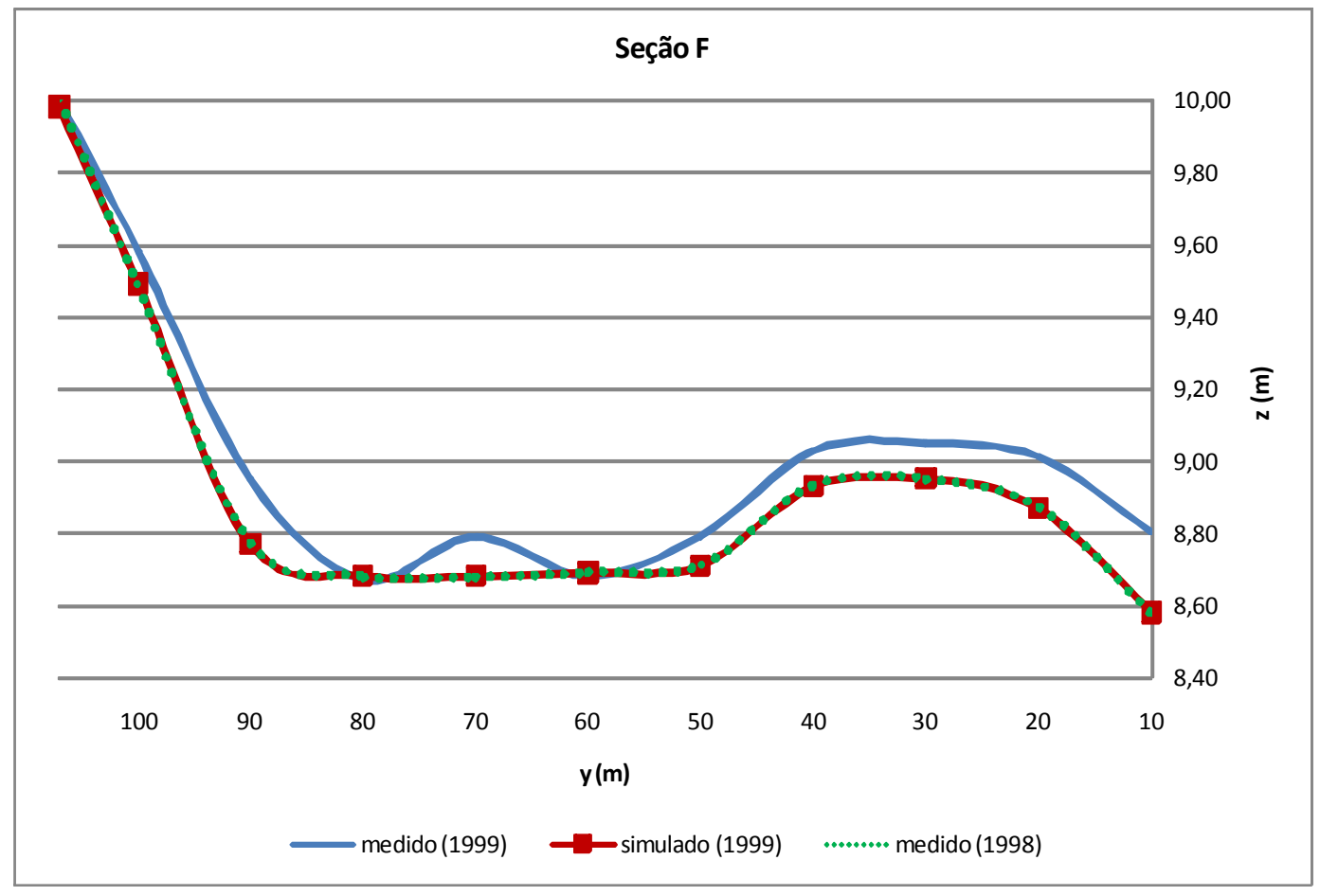

Figura 85. Comparação entre assoreamento medido e simulado na Seção F (21/08/1999) 


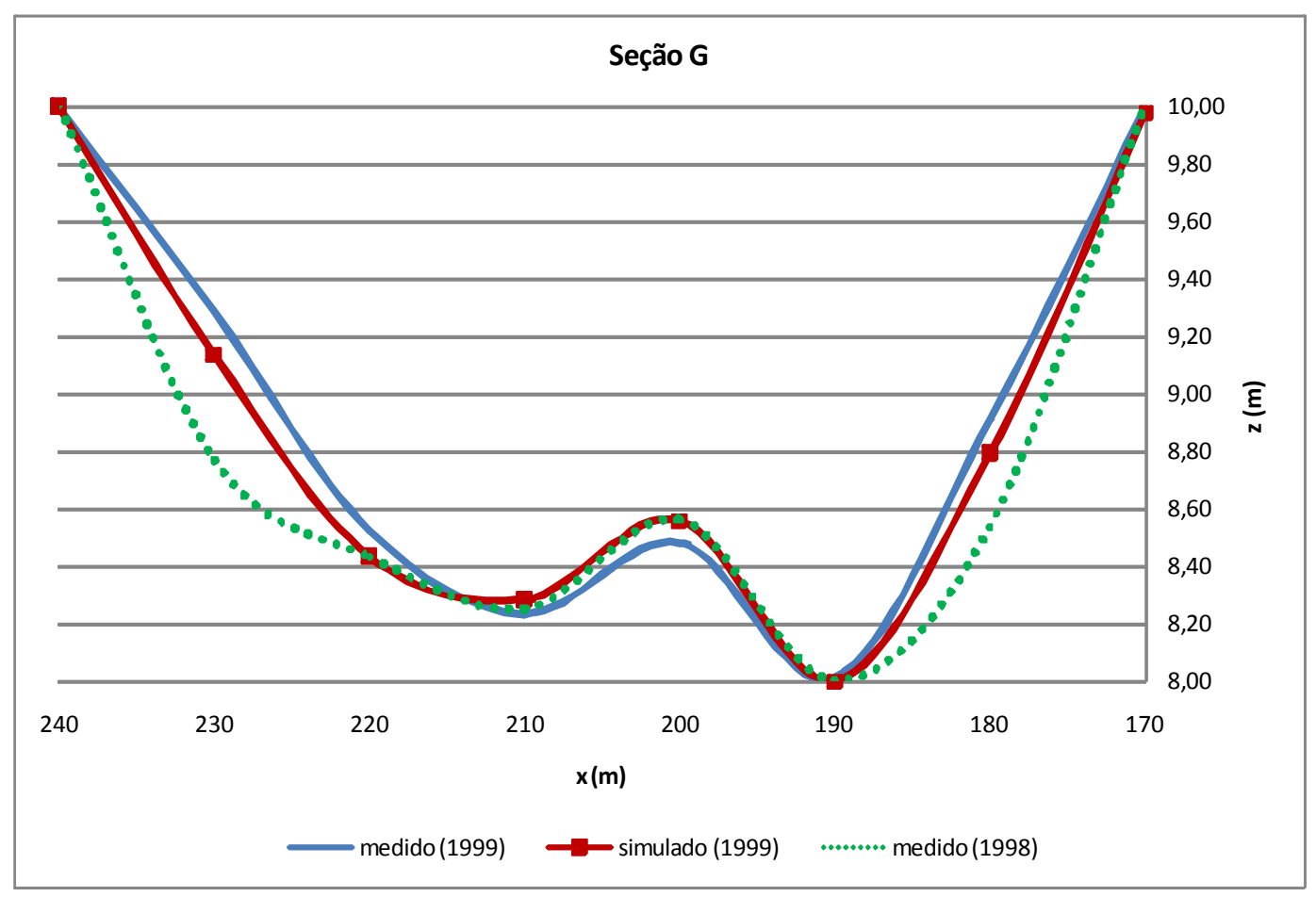

Figura 86. Comparação entre assoreamento medido e simulado na Seção G (21/08/1999)

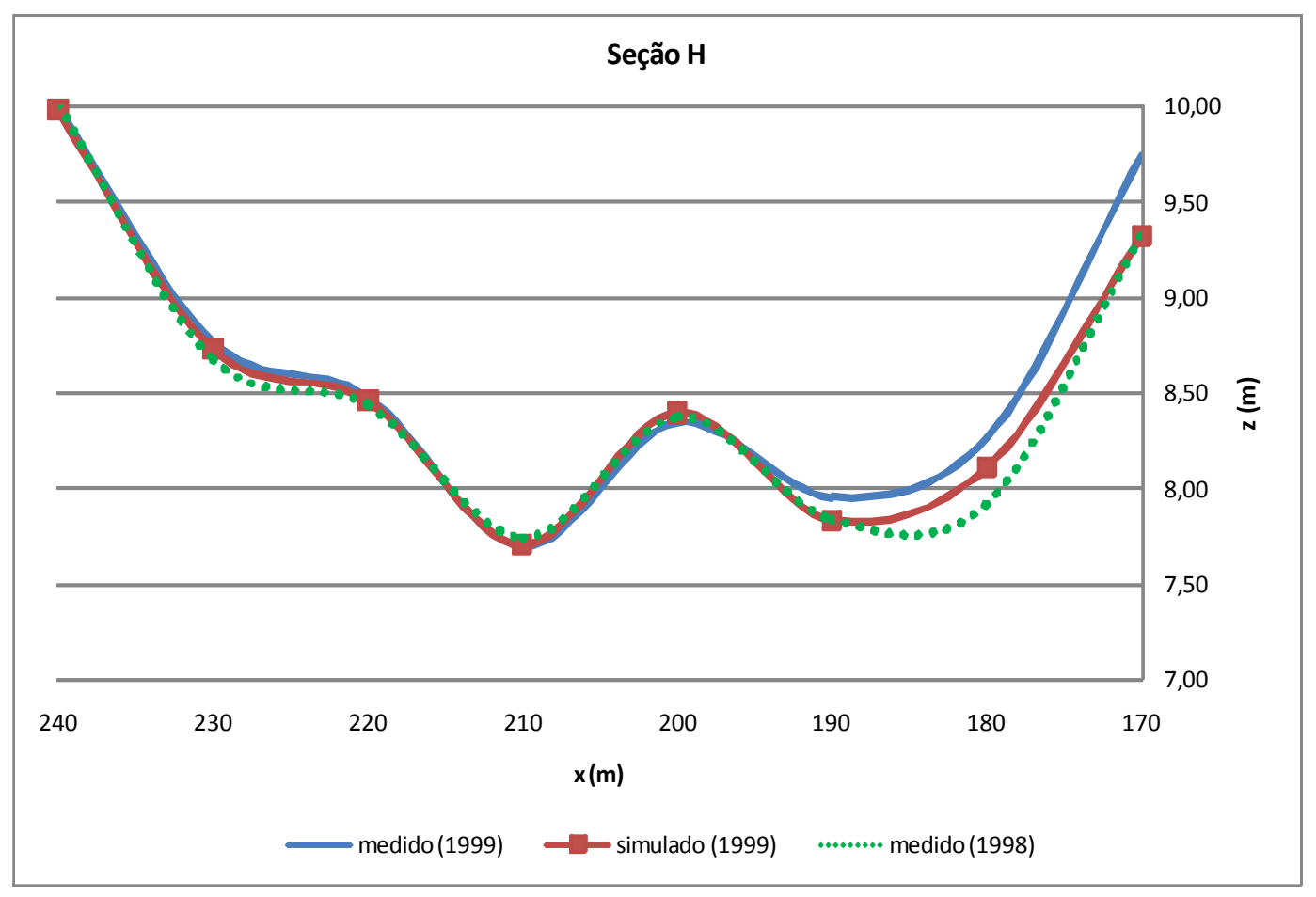

Figura 87. Comparação entre assoreamento medido e simulado na Seção H (21/08/1999) 


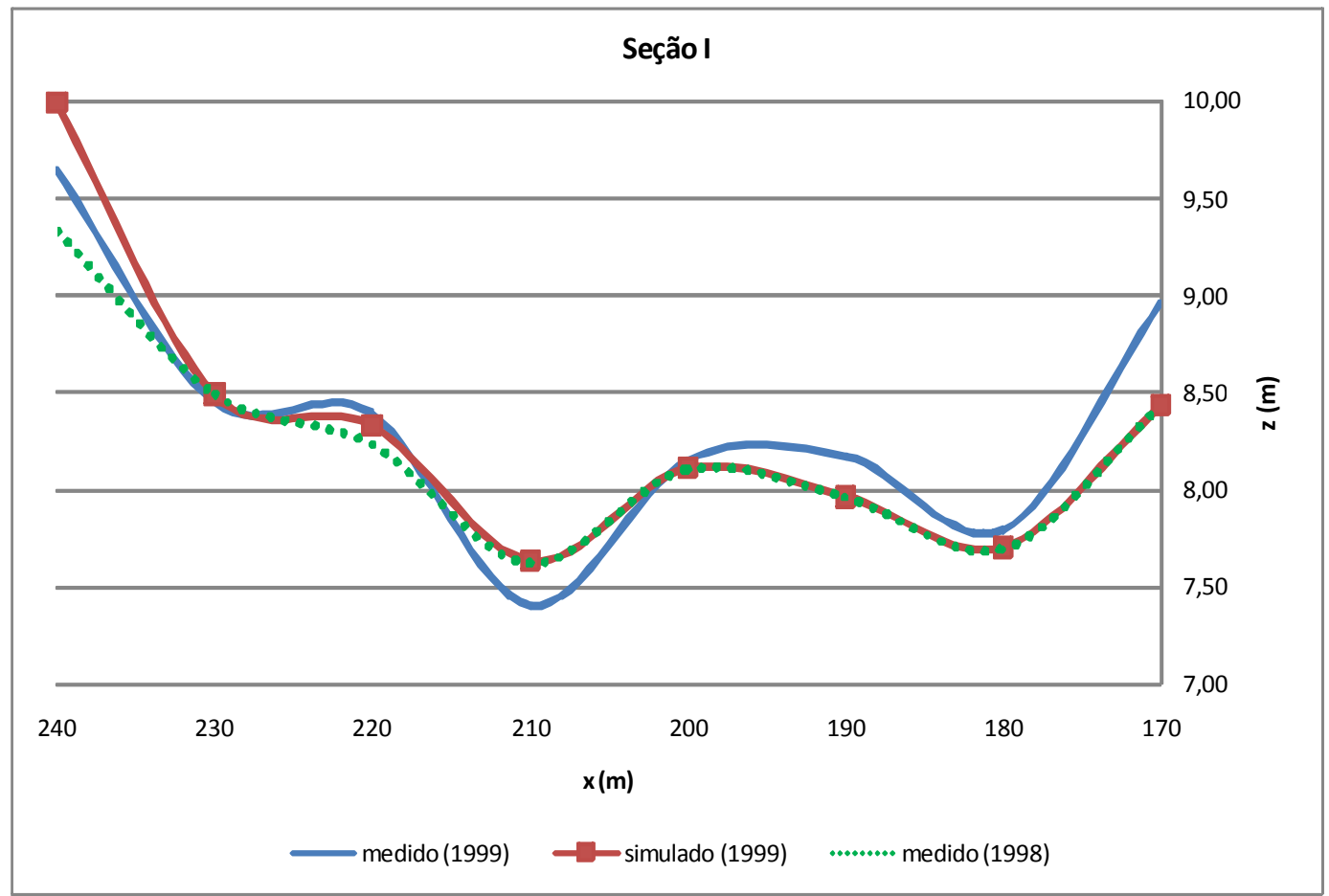

Figura 88. Comparação entre assoreamento medido e simulado na Seção I (21/08/1999)

Para as Seções transversais centrais (J, K e L), pode ser notada uma aproximação satisfatória entre os perfis de fundo simulado e medido, da margem esquerda (sentido do escoamento) até aproximadamente a região central (marco 200 m). A partir daí, até a margem direita, a influência da contribuição de sedimentos da Bacia Hidrográfica, que pode ser confirmada pelas medições de concentração de sólidos suspensos (P1), faz com que a aproximação entre os perfis não seja próxima em alguns trechos. A característica dos perfis de fundo transversais, simulado e medido, nas Seções J, K e L, pode ser vista nas Figuras 89, 90 e 91 respectivamente. Já para as Seções paralelas e próximas da barragem (M, N e O), o perfil de fundo simulado no período permaneceu praticamente invariável, com divergências de cotas consideráveis para trechos do perfil medido, se levado em conta o volume assoreado no período. As Seções M, N e O são retratadas pelas Figuras 92, 93 e 94 respectivamente. 


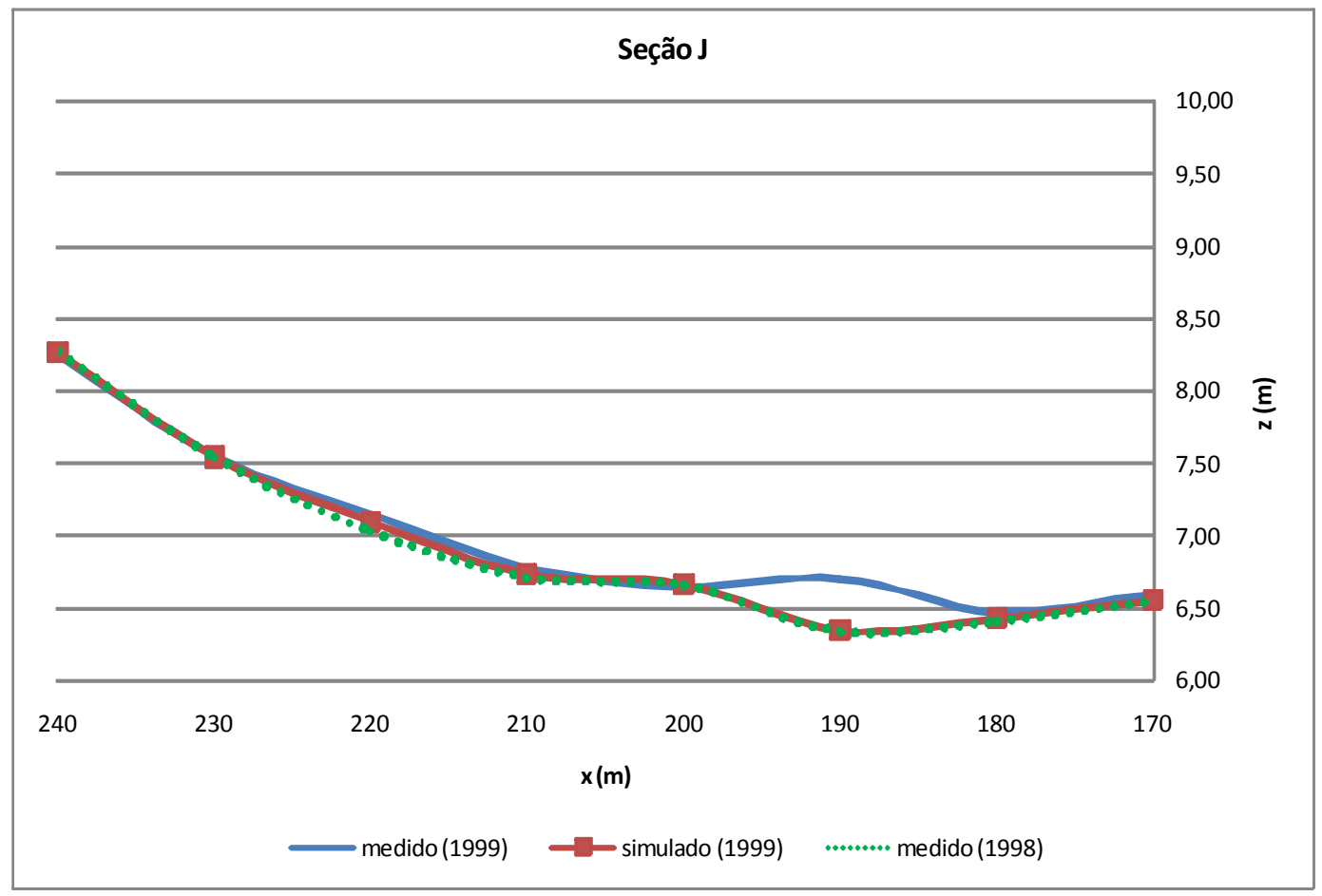

Figura 89. Comparação entre assoreamento medido e simulado na Seção J (21/08/1999)

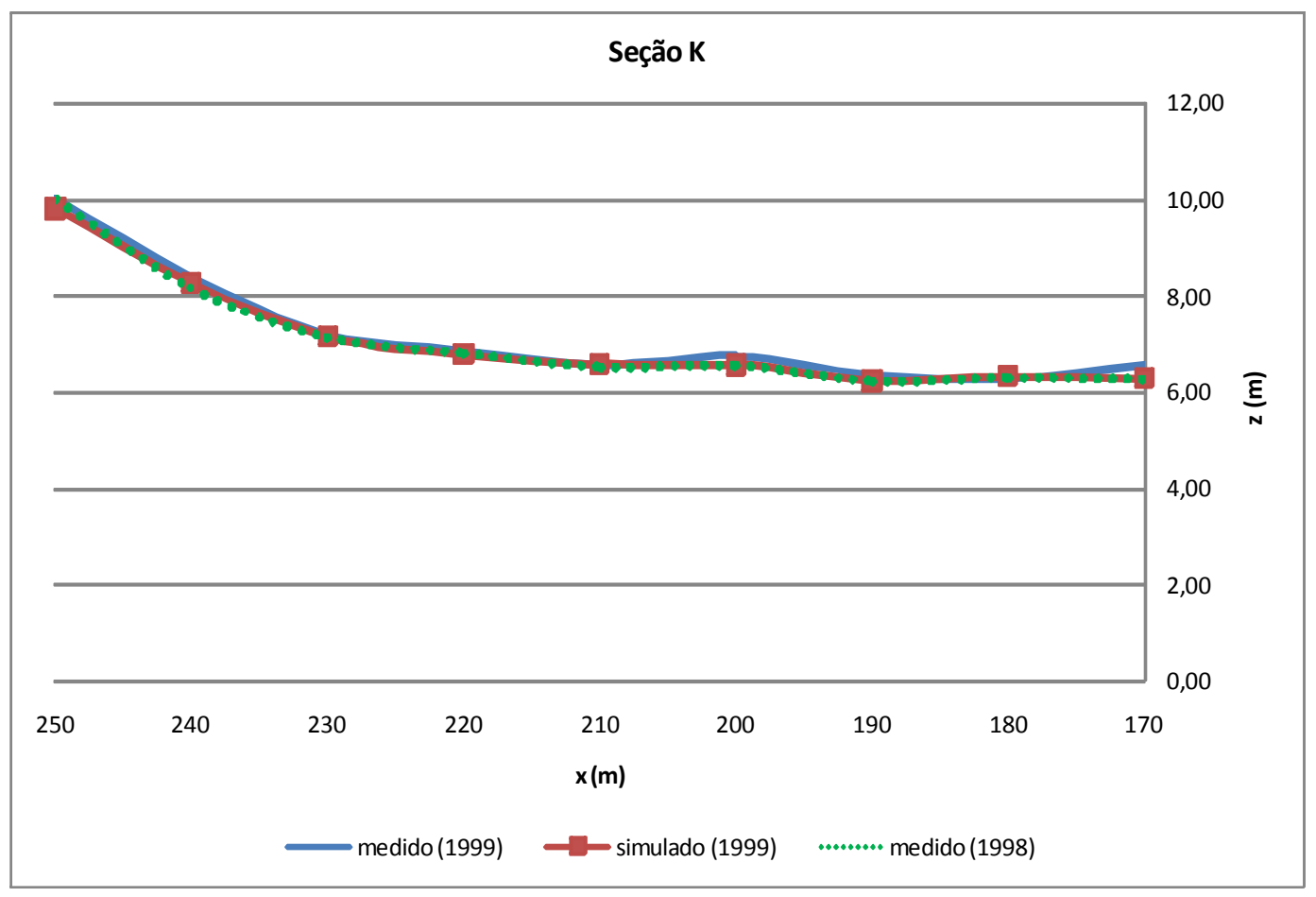

Figura 90. Comparação entre assoreamento medido e simulado na Seção K (21/08/1999) 


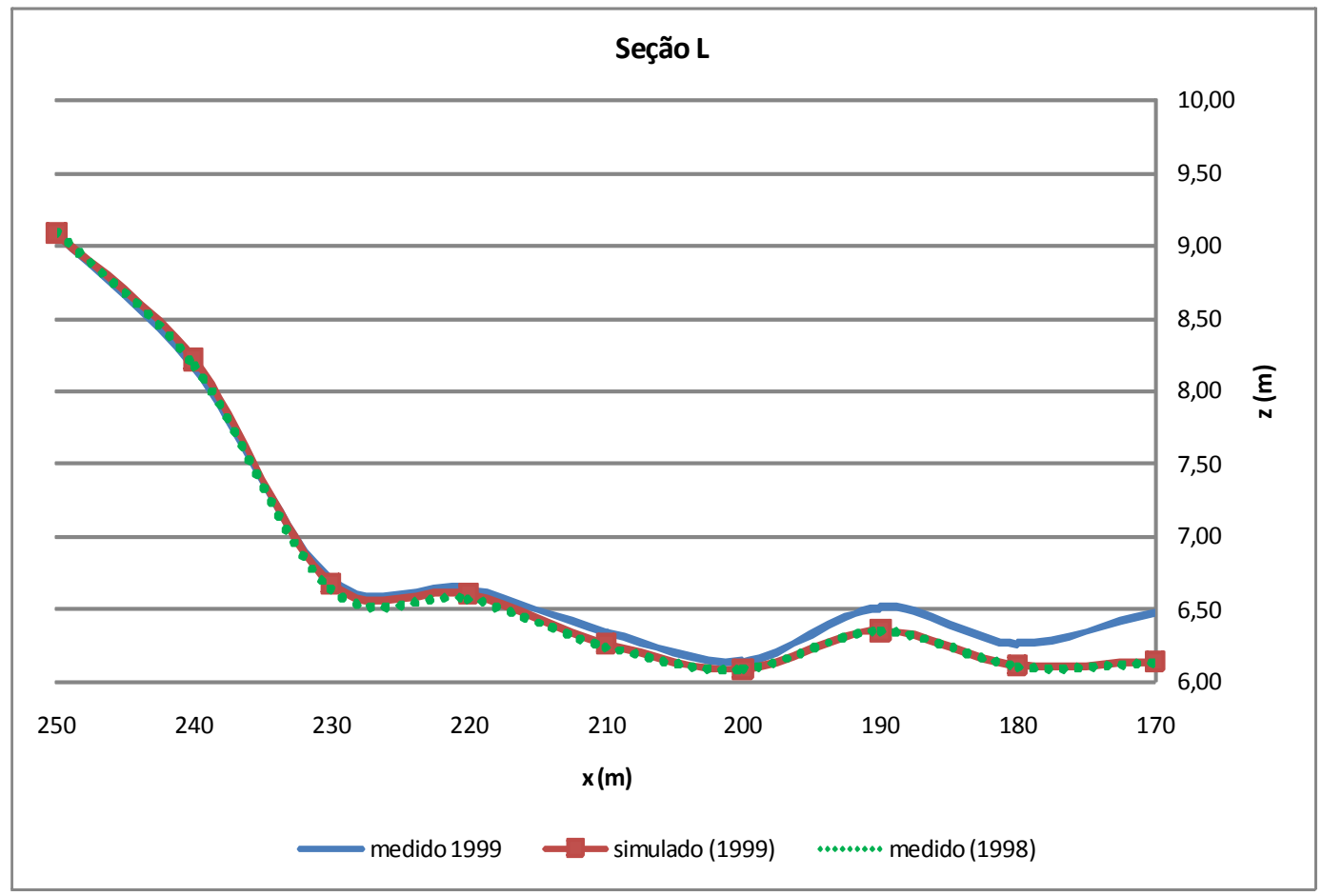

Figura 91. Comparação entre assoreamento medido e simulado na Seção L (21/08/1999)

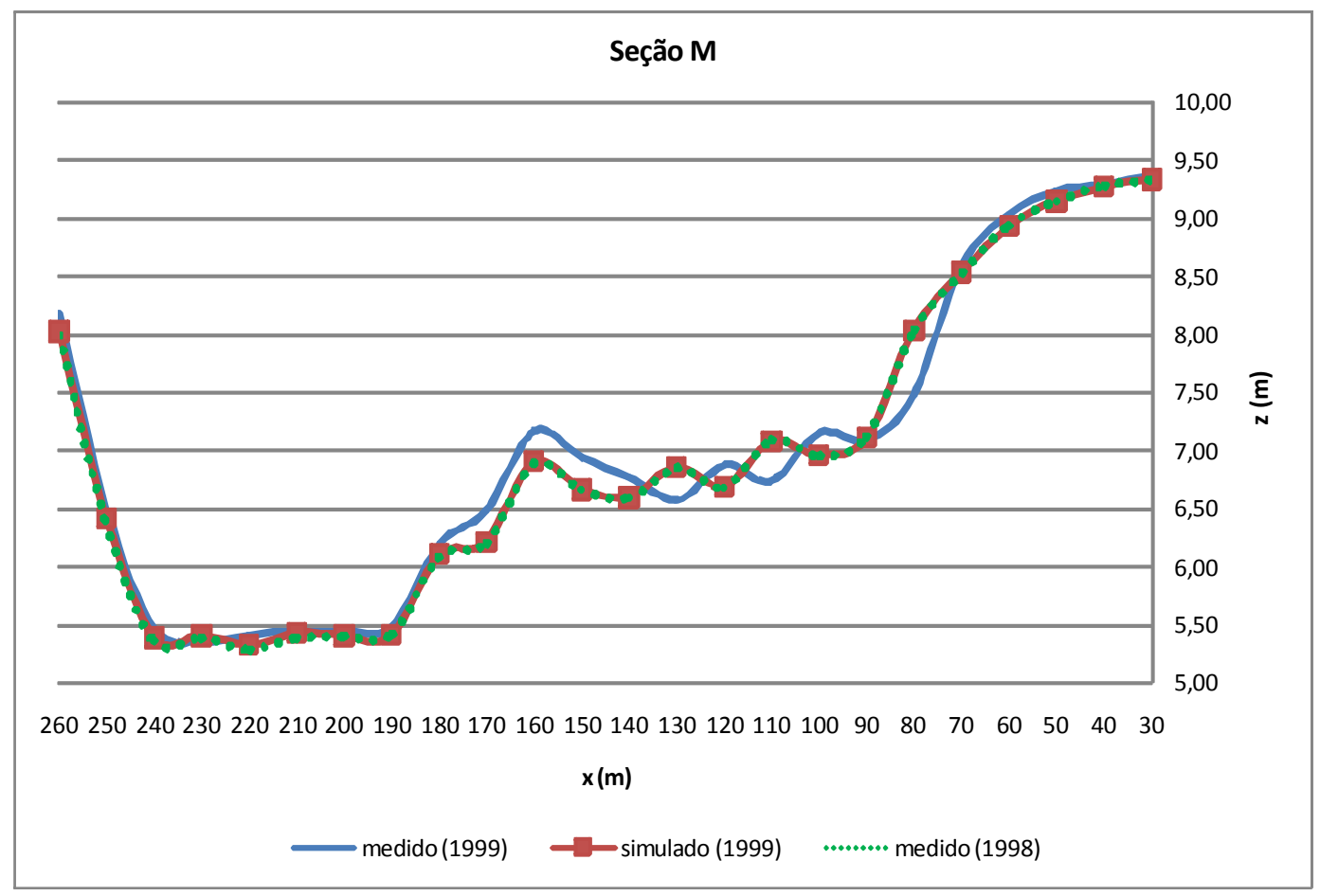

Figura 92. Comparação entre assoreamento medido e simulado na Seção M (21/08/1999) 


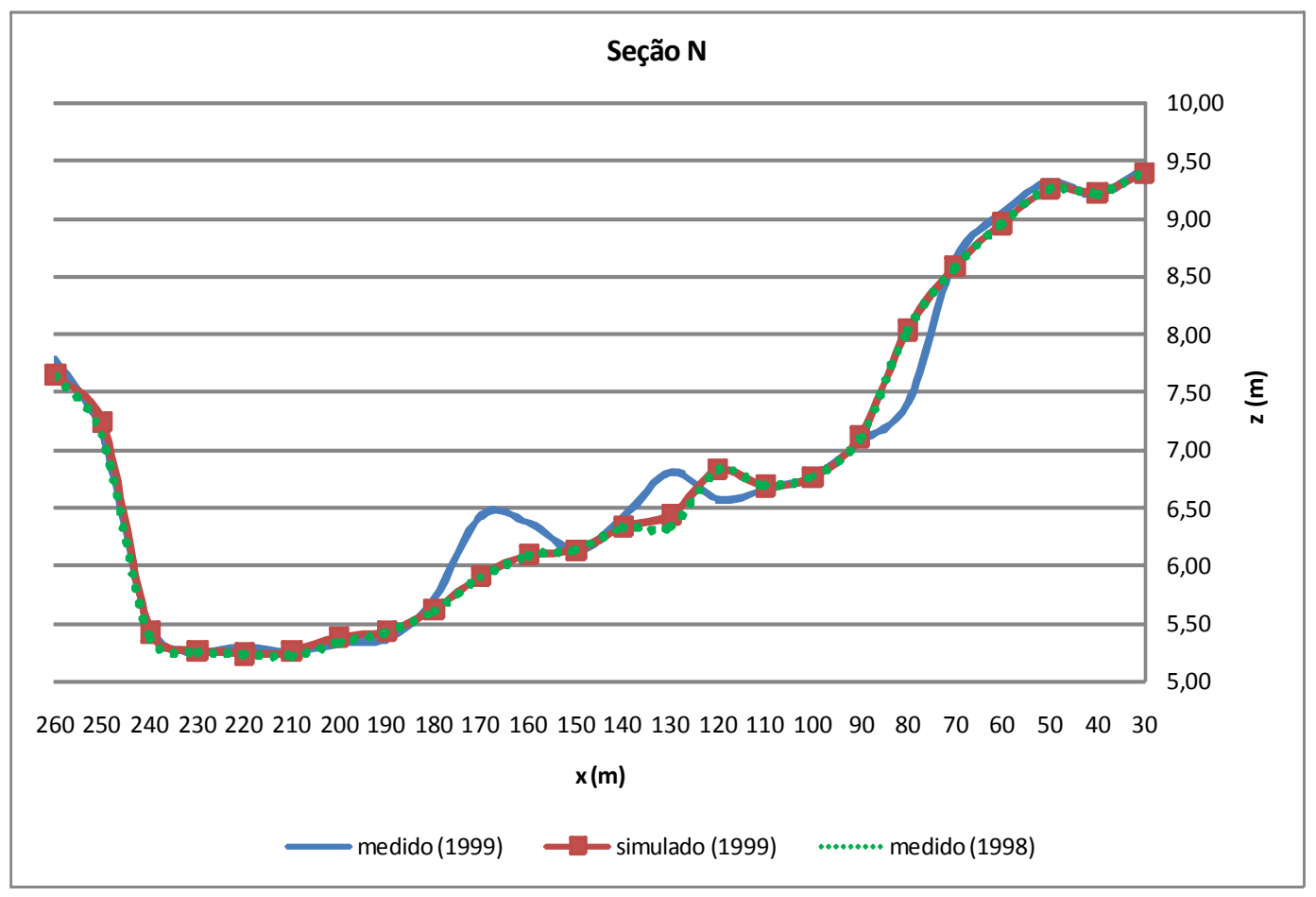

Figura 93. Comparação entre assoreamento medido e simulado na Seção N (21/08/1999)

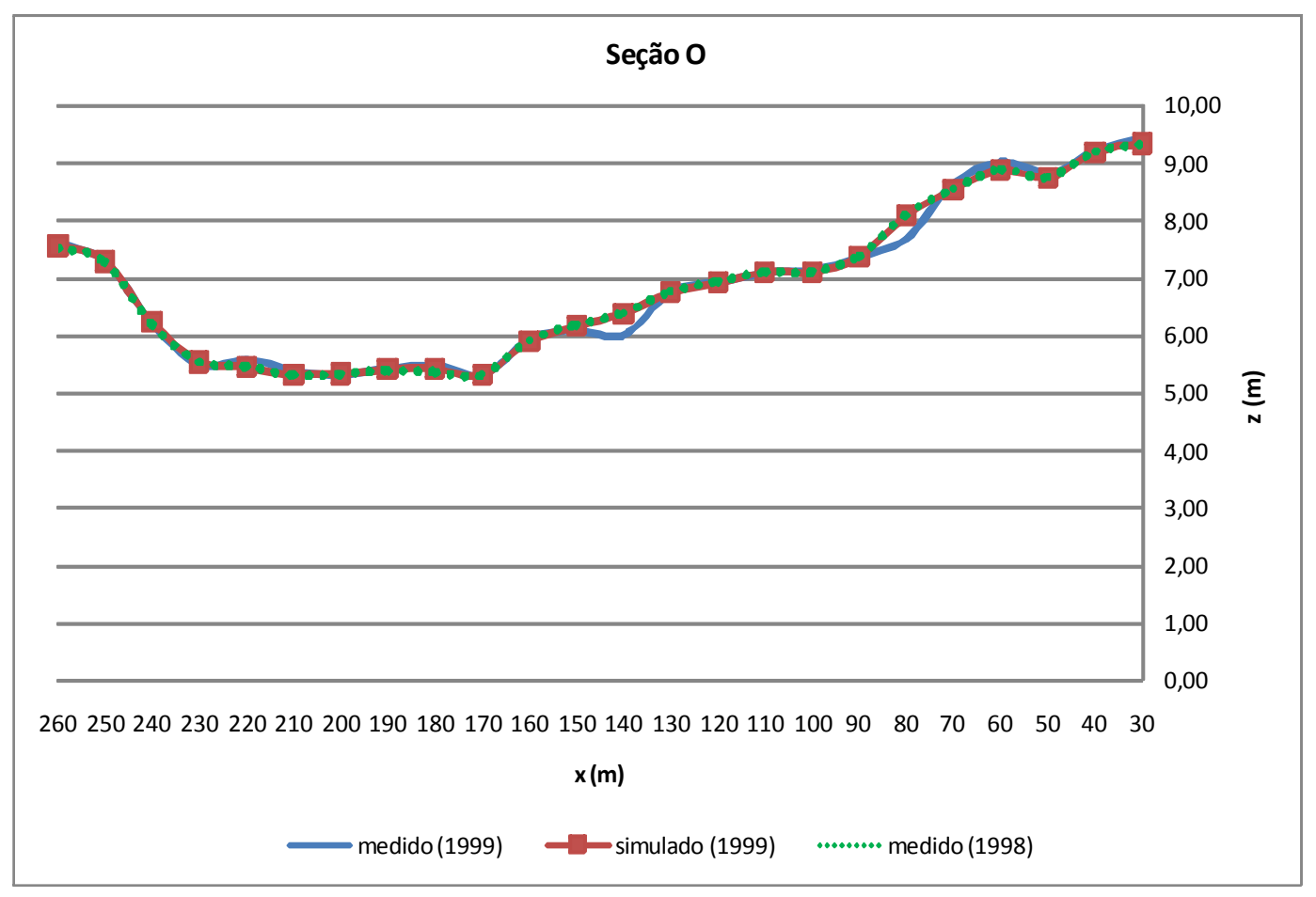

Figura 94. Comparação entre assoreamento medido e simulado na Seção O (21/08/1999) 
Com relação à visualização dos resultados, O MIKE 21C apresenta uma opção para o acompanhamento da evolução batimétrica, cuja utilização ficou prejudicada neste trabalho. A variação do fundo mostrada dentro de uma escala de cores do programa torna-se confusa e imperceptível, devido à variação de cotas do reservatório e ao pequeno assoreamento registrado no período. Mesmo com a apresentação na forma de seções transversais e longitudinais, em alguns pontos há dificuldade para comparar o assoreamento medido e simulado. Para tanto, os dados utilizados na elaboração das seções são disponibilizados na forma de Tabelas, constantes no Apêndice p.161-166. Pela mesma razão, a opção de geração de vídeos disponibilizada pelo programa, para o módulo de assoreamento, não foi aplicada, devido também a não disponibilidade de dados para permitir um acompanhamento do processo de deposição.

Outras simulações foram realizadas com o propósito de se conseguir um melhor ajuste entre assoreamento medido e simulado, sem tanto sucesso quanto ao obtido pela Configuração 2.

As deduções e comentários sobre os aspectos, positivos e negativos, que podem ter influenciado nos resultados finais apresentados do trabalho, são contemplados no item 6, conclusões. 


\section{CONCLUSÕES.}

Em linhas gerais, dentro da complexidade do caso abordado, pode-se dizer que o modelo numérico do MIKE 21C apresentou robustez, sendo capaz de gerar resultados de assoreamento semelhantes aos observados em campo. Em caráter específico, algumas conclusões devem ser aqui ressaltadas:

- As vazões reais medidas na entrada produziram valores de velocidade baixos. Nesta condição, o modelo numérico apresentou divergências devido à elevada deposição de sedimentos na entrada da malha do reservatório, o que não foi verificado para os dados de campo. Isto indicou uma limitação do MIKE 21C na abordagem deste tipo de situação. Mesmo após a consideração das vazões medidas na saída como condição de contorno de entrada, baixíssimas velocidades foram registradas em áreas do reservatório mais afastadas da entrada, predominantemente do centro para jusante. Mesmo na entrada, o assoreamento simulado continuou maior que o observado. A não alteração do fundo nas seções localizadas próximas da barragem, por exemplo, pode também estar relacionada ao padrão de velocidades na represa. Não havendo dados espaciais de velocidade levantados, deduz-se que o transporte de sedimento no reservatório, não ocorre preponderantemente pelo escoamento de entrada na represa. Além disso, o critério de parada do processo iterativo, utilizado no cálculo das velocidades, pode limitar a aplicação do modelo para baixas velocidades.

- $\quad$ As condições de contorno do problema, que são as vazões na entrada do reservatório (provenientes do córrego da Barrinha), em determinados períodos (na maioria períodos secos), ocorrem como jatos superficiais. Não se conseguiu reproduzir esta 
característica com o MIKE 21C que utiliza modelagem bidimensional em planta. Um modelo tridimensional poderia representar melhor o fenômeno real, neste aspecto.

- É disponibilizado pelo modelo uma opção que permite considerar escoamento básico (Source) bem como tomadas de água e descarregadores de fundo (Sink). No presente caso, onde há ocorrência de minas de água, esta opção foi desconsiderada devido à ausência de medições de campo. Isto, se por um lado pode não ser tão expressivo do ponto de vista de modelagem hidrodinâmica (baixas vazões), pode interferir diretamente na determinação da evolução morfológica. A variação de fundo ocorrida nas seções, ou em trechos delas, que não foram detectadas pela simulação, também pode estar associada a este fato.

- Quanto à modelagem da turbulência, não havendo disponíveis dados de campo para um acompanhamento contínuo da evolução morfológica mais detalhada, foi feita a opção de se utilizar viscosidade turbulenta constante com base nos resultados apresentados no trabalho de Souza (2006). Nesse trabalho é salientado o não acompanhamento, pelo Modelo de Turbulência de Grandes Escalas, do aumento da intensidade turbulenta com a elevação do fundo. No reservatório Represa Velha, onde ocorre uma elevação considerada do fundo na região da entrada, seria necessário uma abordagem do modelo em três dimensões e não um equacionamento bidimensional com integração vertical. Em trabalhos de modelagem realizados pela empresa detentora do programa (aplicando o modelo de Smagorinsky) o assoreamento no sistema real fica distante do nível de água, o que pode ser sugerido como um indicador para a aplicação deste modelo.

- A escolha do modelo clássico de transporte de sedimentos é feita com base nas recomendações teóricas do método e também nas experiências adquiridas com a sua aplicação. A equação aqui utilizada (Engelun-Fredsфe) foi testada no trabalho de 
Souza (2006), cujo diâmetro médio da areia $\left(\mathrm{d}_{50}=0,12 \mathrm{~mm}\right)$ é próximo da fração arenosa da represa $\left(\mathrm{d}_{50}=0,10 \mathrm{~mm}\right)$, além da proximidade dos módulos do campo de velocidades. A equação utiliza o critério de Shields para a determinação da tensão crítica de cisalhamento. Segundo estudos realizados por Coiado e Paiva (2008), com dados do Rio Atibaia SP, para as equações que utilizam o critério supramencionado, considerando os parâmetros diâmetro representativo e descarga líquida, observou-se uma variação muito grande entre a existência ou não de transporte, o que pode resultar em valores de descargas sólidas conservadoras. Além disso, as sete equações disponibilizadas pelo programa foram desenvolvidas para sedimentos não coesivos. No reservatório estudado, onde aproximadamente $50 \%$ dos sedimentos são coesivos, erros associados a este fato podem ter interferido no resultado da simulação.

- Outra questão importante foi a da escolha dos diâmetros representativos de sedimentos, baseados na curva granulométrica. Devido à heterogeneidade, o melhor resultado foi obtido para a simulação considerando as frações da classificação. Além de esboçar uma modelagem mais realista, no presente estudo, onde as baixas velocidades foram reinantes, o uso do $d_{50}$ da amostra homogênea conduziu a uma fração única de areia fina cuja deposição na entrada foi de forma acentuada, provocando divergência numérica.

- Em algumas regiões da represa, áreas de influência dos pontos P1 e P3 principalmente, a contribuição de sedimentos da bacia hidrográfica é expressiva. Certamente a maior taxa de assoreamento ocorrido nestas regiões se deve ao washload. O MIKE 21C considera entradas de sedimento no reservatório apenas via leito do rio, o que também pode impactar na diferença entre assoreamento medido e simulado registrada.

- Em se tratando de águas rasas, como é o caso da Represa Velha, o fator vento é importante no processo de transporte, podendo ter influenciado nos resultados do 
assoreamento final simulado. Apesar de o modelo numérico contemplar esta variável, a velocidade do vento foi desprezada neste trabalho por não se ter dados medidos.

- Outros fator físicos importantes, que pode ter interferido nos resultados, é a considerável presença de matéria orgânica. Uma abordagem mais criteriosa consideraria ainda a estratificação térmica e de sedimentos, valendo lembrar que os mesmos não interferem de maneira expressiva em sistemas de águas rasas.

- Como o assoreamento no período simulado foi pequeno, os erros resultantes, tanto no processo de medição, quanto os referentes ao modelo, assumem um caráter relevante no processo de análise de eficiência do modelo.

Desconsiderando todo o labor de calibração, ora dificultado pelas limitações do modelo, ora pela deficiência de alguns dados, conclui-se que a extrapolação para períodos futuros pode representar resultados satisfatórios dentro de um mesmo cenário. Considerando que as variáveis envolvidas no processo são dinâmicas, para longos períodos a extrapolação da simulação poderá remeter a uma resposta com erros consideráveis. Uma boa calibração do modelo deve ser subsidiada por um trabalho de levantamento de dados de campo, coerente com as necessidades do problema estudado. A ausência de uma medição com ADP (Adoup Sound Profile), espacial e temporal, neste trabalho, por exemplo, não permitiu uma análise comparativa do padrão hidrodinâmico na represa.

Por fim, uma grande dificuldade no processo de interpretação dos dados de saída gerados pelo modelo, para uma comprovação de sua real eficiência, foi encontrada. O esquema de aproximação numérica, simplificações e critérios utilizados, pertencem às chamadas “caixas pretas” dos programas comerciais, como o aqui utilizado. 
Neste âmbito de análises, conclusões e deduções, espera-se que o trabalho, a partir das dificuldades e experiências adquiridas, possa contribuir para os próximos passos envolvendo a modelagem numérica do transporte de sedimentos nos sistemas reais. 


\section{SUGESTÕES PARA TRABALHOS FUTUROS.}

Face às dificuldades encontradas neste trabalho para se obter resultados conclusivos sob determinados aspectos, sugere-se aos trabalhos seguintes algumas medidas para que se possa entender melhor a importância e o impacto das variáveis reais do fenômeno de assoreamento nos resultados da simulação numérica. Algumas sugestões:

- O desenvolvimento, no laboratório de hidráulica ambiental do CRHEA, de um protótipo, em escala maior do que a armadilha estudada no trabalho de Souza (2006) serviria para comprovar a eficiência do modelo, inclusive sob os aspectos de baixas velocidades e distância de transporte, além da abordagem de sedimentos coesivos e declividade de fundo. Uma das vantagens seria a ausência de matéria orgânica no processo. Velocidades poderiam ser observadas com a utilização de micromolinete. Os testes envolveriam valores de vazões variadas (constantes em cada período), inclusive para a hipótese de regime laminar.

- Outra opção seria o teste do modelo em um grande reservatório real, cuja taxa de assoreamento, num dado período, fosse representativa no corpo principal, a ponto de os erros envolvidos no processo de obtenção dos dados e simulação não serem significativos. O reservatório da Usina Hidrelétrica Mascarenhas, situado no Rio Doce, ES, de propriedade da ESCELSA, poderia ser uma boa escolha onde, além de atender a característica anteriormente citada, tem um regime de altas vazões e sedimentos predominantemente não coesivos. Para isto, dados de campo deveriam ser levantados com freqüência regular, de forma a possibilitar a calibragem do modelo num âmbito realista e viabilizando inclusive a questão do tempo computacional. 
- A utilização de um modelo tridimensional para estudar o reservatório Represa Velha, permitiria uma comparação e uma análise qualitativa dos resultados obtidos pelo MIKE 21C, apesar de serem modelos diferentes.

- Talvez o próximo passo seria o desenvolvimento, a longo prazo, pelos programas de pós graduação (SHS e SEA), de um modelo computacional próprio, onde se pudesse estudar a resposta de alguns parâmetros, do ponto de vista de equacionamento matemático e esquemas numéricos, pertencentes as caixas pretas dos programas comerciais. 


\section{REFERÊNCIAS BIBLIOGRÁFICAS}

ACKERS, P.; WHITE, W. R. Sediment transport: new approach and analysis. Journal of the Hydraulic Division, v. 99, n. HY11, p. 2041-2060, nov. 1973.

ALAMY FILHO, J. E. Modelação numérica de processos de sedimentação em escoamentos turbulentos e análise da ressuspensão em canais. Tese de Doutorado. Escola de Engenharia de São Carlos, Universidade de São Paulo, São Carlos, 2006. 232p.

ALAMY FILHO, J. E.; MAIA, A. G.; SOUZA, L. B. S.; VILLELA, S. M. Assoreamento do Reservatório de Salto Grande. V Encontro Nacional de Engenharia de Sedimentos, ENES, 2002. p.339-351.

ALVIM, A. M. Modelo matemático bidimensional de assoreamento em reservatórios. Dissertação (Mestrado) - Departamento de Hidráulica e Saneamento, Escola de Engenharia de São Carlos, Universidade de São Paulo, São Carlos, 1987. 154p..

AMERICAN SOCIETY OF CIVIL ENGINEERING - ASCE. River width Adjustment II: Modeling, by the ASCE Task Committee on Hydraulics, Bank Mechanics, and Modeling of River Width Adjustment. Journal of Hydraulic Engineering 124 (9), 1998. P.903-917.

ANNANDALE, G.W. Reservoir Sedimentation. Developments in Water Science, n. 29 New York: Elsevier Science Publishers, 1987. 221 p.

ASSELMAN, N.E.M. Fitting and interpretation of sediment rating curves. Journal of Hydrology (234), 2000. p. 228-248.

ATKINSON , E. The design of sluiced settling basins: a numerical modeling approach. Report OD 124. Oxon, UK: HR Wallingford. 1992.

AUPOIX, B. Eddy viscosity subgrid scale models for homogeneous turbulence. Macroscopic Modelling of Turbulent Flow, Lecture Notes in Physics, Proc. Sophie-Antipolis, França, 1984.

BAUME, J. P.; MALATERRE, P. O.; BELAUD, G.; LE GUENNEC, B. Sic: a $1 D$ hydrodinamic model for river and irrigation canal mdeling and regulation. In: Métodos numéricos em recursos hídricos nº 7 , ABRH, 2005. 81p. 
BELAUD, G. Modélisation dês processus de sédimentation em canal d'irrigation. Application à La gestion et La conception des réseaux. Thèse de doctoral Université Claude Bernard, Lyon, 2000. 200p.

BIOTA. Sub-bacias hidrográficas do Estado de São Paulo. 2004. Disponível em: <http://www.biota.org.br/info/saopaulo/bacias/>. Acesso em: 28 abr. 2006.

BORGES, F. S. P.; FILHO, O. C. R.; JUNIOR, G. W. Sensoriamento remoto e geoestatística aplicados à estimativa de batimetria em reservatórios do setor elétrico brasileiro. XII Simpósio Brasileiro de Sensoriamento Remoto, Goiânia, 2005. p. 2471-2478.

BRAMORSKI, J. Estudo da qualidade de sedimentos dos compartimentos de entrada do reservatório de Barra Bonita - SP. Dissertação de Mestrado. Escola de Engenharia de São Carlos, Universidade de São Paulo, São Carlos, 2004.

BUFON, A. G. M. Variação da taxa de sedimentação na represa Velha e sua influência sobre as características limnológicas do sistema. Um estudo de impacto ambiental. Monografia. Pirassununga, 1999. 80p.

BUFON, A. G. M. Variação temporal e espacial da taxa de sedimentação e das características limnológicas na microbacia do córrego da Barrinha, no município de Pirassununga. Dissertação de Mestrado. Centro de Estudos Ambientais, Universidade Estadual Paulista, Rio Claro, 2002. 180p.

BUFON, A.G.M. Estudo do assoreamento e sua relação com a vida útil do reservatório "Represa Velha". Tese de Doutorado - Instituto de Geociências e Ciências Exatas, Universidade Estadual Paulista, Rio Claro, 2006. 313p.

CARROL, R. W. H.; WARWICK, J. J.; JAMES, A. I.; MILLER, J. R. Modeling erosion and overbank deposition during extreme flood conditions on the Carson River, Nevada. Journal of Hydrology 297, 2004. 21p.

CARVALHO, N.O.; FILIZOLA JUNIOR, N.P.; SANTOS, P.M.C.; LIMA, J.E.F.W. Guia de avaliação de assoreamento de reservatórios. Agência Nacional de Energia Elétrica, ANEEL, 2000. Superintendência de Estudos e Avaliações Hidrológicas. 106p.

CARVALHO, N.O. Hidrossedimentologia prática. Rio de Janeiro: CPRM, 1994.

CHANG, C. K. Sediment transport in Kulim River, Kedah. M.Sc. Thesis. Penang: Universiti Sains Malaysia, 2006a. 
CHANG, H. H. Fluvial 12 - Mathematical model for erodible channels - User's manual. San Diego, 1993.

CHANG, H. H.; HARRISON, L. L.; LEE, W.; TU, S. Numerical modeling for sediment-passthrough reservoirs. Journal of Hydraulic Research, v.122, n.7, jul., 1996.

CHAO, X.; JIA, Y.; JR, F. D. S.; WANG, S. S. Y.; COOPER, C. M. Three-dimensional numerical modeling of cohesive sediment transport and wind wave impact in a shallow oxbow lake. Advances in Water Resources 31, 2008. p.1004-1014.

CHAVES, P.; MOREIRA, J. C.; XAVIER, M. C. R.; DOMINGUES, N. R. Modelagem hidrossedimentológica com o modelo Hec-Ras 4.0: Caso de estudo do rio Macaé. VIII Encontro Nacional de Engenharia de Sedimentos, ENES, 2008. 16p.

COELHO, M. A. Análise do processo de assoreamento do reservatório de Americana - SP. Dissertação de Mestrado - Instituto de Geociências e Ciências Exatas, Universidade Estadual Paulista. Rio Claro, 1993. 69p.

COGOLLO, P. R. J.; VILLELA, S. M. Mathematical model for reservoir silting. In: PORTO ALEGRE SYMPOSIUM OF SEDIMENT BUDGETS, proceedings..., dez 1988, Porto Alegre: IAHS Publication, n. 174.

COIADO, E.M. Assoreamento de Reservatórios. In: Paiva J.B.D.; Paiva E.M.C.D. (Orgs.). Hidrologia Aplicada à Gestão de Pequenas Bacias Hidrográficas. Porto Alegre: ABRH, 2001. p.395-426.

COIADO, E.M.; DE PAIVA, L.E.D. Análises sobre algumas fórmulas para o cálculo do transporte de sedimentos na camada do leito. IX Simpósio de Recursos Hídricos do Nordeste, ABRH, 2008. 20p.

COLLISCHONN, W.; MERTEN, G. H. Modelo matemático de transporte de sedimentos em rios aluviais 2:Análise do rio Taquari, MS. in: IV Encontro Nacional de Engenharia de Sedimentos - Caracterização quali-quantitativa da produção de sedimentos, 2000, Santa Maria. Anais, 11p.

DARGAHI, B. Three-dimensional flow modelling and sediment transport in the river Klarälven. Earth Surface Processes and Landforms 29, 2004. p. 821-852.

DENDY F. E. Sedimentation in the Nation's Reservoirs. Journal of Soil and Water Conservation. v.23, jul./aug. 1968. p. 135-137 
DE PAIVA, E.M.C.D. Métodos de estimativa da produção de sedimento sem pequenas bacias hidrográficas. in: Hidrologia aplicada à gestão de pequenas bacias hidrográficas, Org. por De PAIVA, J.B.D. De PAIVA, E.M.C.D. Porto Alegre: ABRH, 2001a. p.365-394.

DE PAIVA, J.B.D. Métodos de cálculo do transporte de sedimentos em rios. in: Hidrologia aplicada à gestão de pequenas bacias hidrográficas, Org. por De PAIVA, J.B.D. De PAIVA, E.M.C.D. Porto Alegre: ABRH, 2001b. p.365-394.

DHI, MIKE 21 Coastal Hydraulics and Oceanography. User Guide. Horsholm, Dinamarca, 2003.

DHI. MIKE 21C Scientific reference manual. Horsholm, Dinamarca, 2004.

DHI, MIKE 21C. River hydrodynamics and morphology. Technical and scientific documentation. Horsholm, Dinamarca, 2005. 95p.

DHI WATER AND ENVIRONMENT. Horsholm, Dinamarca, 2005. Apresenta de forma resumida validações e aplicações do programa MIKE 21C. Disponível em: $<$ www.dhisoftware.com $>$. Acesso em 02 de outubro.

DUNNE, T.; DIETRICH, W. Sediment sources in tropical drainage basins. in: Soil erosion and conservation in the tropics. Madison: American Society of Agronomy; Soil Science Society of America, 1982. p.41-55.

ENGELUND, F. AND HANSEN, E. A monographh on sediment transport in alluvial streams, Teknisk Forlag, Danish Technological University, Copenhague, Dinamarca, 1967.

ENGELUND, F.; FREDSØE, J. A sediment transport model for straight alluvial channels. Nordic Hydrology, 1976, v.7, n.5.

FEDERAL INTERAGENCY STREAM RESTORATION WORKING GROUP - FIRSRWG. Stream Corridor Restoration: Principles, Processes, and Practicies. (15 Federal agencies of the US Government), Portland, 2001.

FREAD, D. L. The NWS DAMBRK model: Theoretical background and user documentation. Hydrologic Research Laboratory. Office of Hydrology. National Weather Service, NOAA. Silver Spring, Maryland, 1991. 123p. 
FREAD, D. L. Flow routing. In: Maidment, Handbook of Hydrology. McGraw-Hill, New York, 1993.

GAILANI, J.; ZIEGLER, C. K.; LICK, W. Transport of suspended solids in the Lower Fox River. Journal of Great Lakes Reservoirs, v.17, n.4, 1991. p.479-494.

GALAPPATTI, R. A depth-integrated model for suspended transport. Report n.83-7, comm. on hydraulics, Department of Civil Engineering, Delft University of Technology, 1983.

GALIANO, V. A. Mapeamento geotécnico da quadrícula de Pirassununga - SP na escala 1:50000, como subsídio ao planejamento do meio físico. Dissertação de Mestrado. Centro de Ciências Exatas e de Tecnologia, Universidade Federal de São Carlos, São Carlos, 2001. 140 p.

GANJU, N. K.; SCHOELLHAMER, D. H. Calibration of an estuarine sediment transport model to sediment fluxes as an intermediate step for simulation of geomorphic evolution. Continental Shelf Research 29, 2009. p.148-158.

GESSLER, D.; HALL, B.; SPASOJEVIC, M.; HOLLY, F.; POURTAHERI, H.; RAPHELT, $\mathrm{N}$. Application of $3 D$ mobile bed, hydrodynamic model. Journal of Hydraulic Engineering, v.125, n.7, jul., 1999.

GHANI, Ab. A.; ZAKARIA, N. A.; ABDULLAH, R.; CHANG, C. K.; SINNAKAUDAN, S. K.; MOHD SIDEK, L.. River sediment data collection and analysis study, contract research no. JPS (PP)/SG/2/2000. Department of Irrigation and Drainage, Malaysia, Kuala Lumpur, 2003.

GIROLDO, J. Reservatórios de contenção de cheias existents na região metropolitana de São Paulo. Dissertação de Mestrado - Departamento de Engenharia Hidráulica e Sanitária da Universidade de São Paulo, São Paulo, 2003. 157 p.

GRAF, W. H. Hydraulics of sediment transport. McGraw-Hill Book Company. Copyright, 1971. 513p.

GUENNEC, B. L.; BELAUD, G.; BAUME, J. P. Modelagem unidimensional do transporte de sedimentos finos em suspensão nos rios Solimões, Madeira e Amazonas. VIII Encontro Nacional de Engenharia de Sedimentos, ENES, 2008. 11p.

HEINEMANN, H. G. Weight of reservoir sediment. Journal of the Hidraulic Division. v.88, n.HY5, 1962. p. 181-197. 
HORIUTI, K. Comparison of conservative and rotational forms in large-eddy simulation of turbulent channel flow. Journal of Computational Physics, 1987, n.71, p.34-370.

HU, K.; DING, P.; WANG, Z.; YANG, S. A 2D/3D hydrodynamic and sediment transport model for the Yangtze Estuary, China. Journal of Marine Systems, 2009. 23p.

IKEDA, S. Incipient motion of sand particles on slopes. Report of Foundation Engineering \& Construction Engineering, Saitama University, Japão, 1980.

JANSEN, P.H.; BENDEGOM, L. van; BERG, J. van den; VRIES, M. de; ZANEN, A. (1979). Principles of River Engineering. Pitman Publishing, 1979.

JIN, K. R.; JI, Z. G. Case study: Modeling of sediment transport and wind-wave impact in lake Okeechobee. Journal of Hydraulic Engineering, ASCE, nov., 2004. p.1055-1067.

KIAT, C. C.; GHANI, A. A.; ABDUlLAH, R.; ZAKARIA, N. A. Sediment transport modeling for Kulim River - A case study. Journal of Hydro-environment Research, 2008. p.47-59.

KIM, C. S.; LIM, H. S. Sediment dispersal and deposition due to sand mining in the coastal Waters of Korea. Continental Shelf Research 29, 2009. p.194-204.

KING, I. P. A finite element model for stratified flow - RMA10. Sydney, Resource Modelling Associates, 2003. 98p.

KLEEREKOPER, H. Introdução ao estudo da limnologia. Série Didática nº4, Ministério da Agricultura, Departamento Nacional da Produção Animal, Divisão de Caça e Pesca. Rio de Janeiro: Serviço de Informação Agrícola, 1944. 329p.

KOCH, F.G. Bed level computation for axis-symmetric curved channels. Report R5671X/W308 part1, Delft Hydraulic Laboratory. 1980.

KWON, J. I.; MAA, J. P. Y.; LEE, D. Y. A preliminary implication of the constant erosion rate model to simulate turbidity maximums in the York River, Virginia, USA. Estuarine and Coastal Fine Sediments Dynamics, 2007. p.331-354.

LANE, E.W. Progress report on studies on the design of stable channels by the Bureau of Reclamation. In: ASCE - IRR. AND DRAIN DIV., proceedings..., v.79. 1953. 
LEITE, M. A. Variação especial e temporal da taxa de sedimentação no reservatório de Salto Grande - SP e sua influência sobre as características limnológicas do sistema. Dissertação de Mestrado. Escola de Engenharia de São Carlos, Universidade de São Paulo, São Carlos, 1998. 170p.

LEONARD, A. Energy cascades in large-eddy simulations of turbulent fluid flows. Advances in Geophysics, 1974, n.18, p.237-247.

LICK, W.; LICK, J.; ZIEGLER, C. K. The resuspension and transport of fine-grained sediments in Lake Irie. Journal of Great Lakes Reservoirs, v.20, n.4, 1994. p.599-612.

LILLY, D. K. On the application of the eddy viscosity concept in the inertial subrange of turbulence. NCAR Manuscript No. 123, National Center for Atmospheric Research, Colorado, 1966.

LIMA, J.E.F.W.; FERREIRA, R.S.A; CRISTOFIDIS, D. O uso da irrigação no Brasil. In: Freitas, M.A.V., O estado das águas no Brasil. MME,MMA,OMM, 1999. p73-101.

LLORET RAMOS, C. L. Implicações ambientais de sedimentos efluentes de reservatórios Estudo de caso - Reservatório Billings. V Encontro Nacional de Engenharia de Sedimetos, ENES, 2002. p.103 - 110.

LOMBARDI NETO, F.; CAMARGO, O. A. Microbacia do córrego São Joaquim, município de Pirassununga. Campinas: IAC, 1992. 138p.

LOPES, S. J. L. Mathematical modeling of sediment deposition in reservoirs. Hydrology Papers, Colorado State University, Fort Collins, Colorado, jul., 1978.

MAIA, A. G. As conseqüências do assoreamento na operação de reservatórios formados por barragens. Tese de Doutorado - Escola de Engenharia de São Carlos, Universidade de São Paulo, São Carlos, 2006. 165p.

MAIA, A. G.; ALAMY FILHO, J. E.; SOUZA, L. B. S.; VILLELA, S. M.; SHULZ, H. E. Método simplificado para estimativa do volume assoreado de reservatórios. II Simpósio de Recursos Hídricos do Centro Oeste. ABRH. Campo Grande, MS, 2002.

MARICATO, F. E. Caracterização físico-química e sedimentação nas regiões de desembocadura dos rios Paranapanema e Taquari, e no reservatório Jurumirim - Alto Paranapanema. Dissertação de Mestrado. Escola de Engenharia de São Carlos, Universidade de São Paulo, São Carlos, 1994. 205p. 
MENESCAL, J. F. Modelo Matemático para Avaliação da Erosão a Jusante de Reservatórios: Estudo de Caso da Barragem do Castanhão-CE. Dissertação de Mestrado. Escola de Engenharia de São Carlos, Universidade de São Paulo, São Carlos, 2003.

MEYER-PETER, E. and MULLER, R. Formulas for bed load transport. In: CONGRESS IAHR, 2, 1948, Estocolmo, proceedings..., v.2, paper 2.

MOLINO, B.; GRECO, M.; ROWAN, J. S. A 2-D reservoir routing model: sedimentation history of Abbeystead Reservoir, U. K. Water Resources Management, v.15, 2001. p.109-122.

MORRIS, D. A.; JOHNSON, A. I. Summary of hydrologic and physical properties of rock and soil materials as analyzed by the hydrologic laboratory of the U.S. Geological Survey. U.S Geol. Surv. Water-Suppy Paper 1839-D, 1967. 42p.

MORRIS, G. L.; FAN, J. Reservoir sedimentation handbook. Mcgraw-Hill. New York, 1997. 365 p.

NATIONAL RESEARCH COUNCIL. An evaluation of flood-level prediction using alluvial river model. National Academy Press, Washington, D. C., 1983.

NICKLOW, J. W.; MAYS, L. W. Optimization of multiple reservoir networks for sedimentation control. Journal of Hydraulic Engineering, v.126, n.4, abrl, 2000.

OLESEN, K.W. Bed topography in shallow river bends. Faculty of Civil Engineering, Delft University of Technology, Report 87-1, 1987.

PAIVA, J. B. D. ; PAIVA, E. M. C. D. ; VILlELA, S. M. . Balanço Sedimentométrico do Canal e Vida Útil dos Reservatórios do Sistema Adutor Principal do Projeto de Transposição das Águas do Rio São Francisco. in: II Encontro Nacional de Engenharia de Sedimentos, ENES, 1996.

PAIVA, J. B. D. ; VILlELA, S. M. . Avaliação dos Métodos de Cálculo da Descarga Sólida em Rios. Revista Brasileira de Engenharia, v. 7, n. 2-1, 1989.

PHILIPS, J.M.; WEBB, B.W.; WALLING, D.E.; LEEKS, G.J.L. Estimating the suspended loads of river in Lois study area using infrequent samples. Hidrological Processes 13, 1999. p. 1035-1050. 
PONCE, R. J. C. Implantação de uma metodologia de cálculo de assoreamento de reservatórios com aplicação à bacia do rio Sinu - Colômbia. Dissertação de Mestrado. Escola de Engenharia de São Carlos, Universidade de São Paulo, São Carlos, 1986. 172p.

PORTO, R. M. Hidráulica Básica, EESC-USP São Carlos SP - Projeto Reenge, 1999.519p.

RIGHETTO, A. M. Hidrologia e Recursos Hídricos, EESC-USP São Carlos SP, Projeto Reenge, 1998. 819p.

RIJN, L. C. van. Part I: Bed load transport, v.110, out., 1984. Part II: Suspended load transport, v.110, nov., 1984. Journal of Hydraulic Engineering.

ROCHA, J. S.; FERREIRA, J. P. C. L. A Erosão Hídrica na Bacia do Rio Guadiana e o Assoreamento da Albufeira de Alqueva. Ministério da Habitação e Obras Públicas. Laboratório Nacional de Engenharia Civil. Memória 541. Lisboa. 1980.

ROZOWSKII, I.L. Flow of water in bends of open channels. 1957. English translation: Israel Progr.For Scientific Transl. Jerusalem, 1961.

SCAPIN, J. Caracterização do transporte de sedimentos em um pequeno rio urbano na cidade de Santa Maria - RS. Dissertação de Mestrado. Centro de Tecnologia da Universidade Federal de Santa Maria, Santa Maria RS, 2005. 115p.

SCHNITTER, N.J. A history of dams: the useful pyramids.Rotterdam: A.A.Balkema,1994.

SCHULZ, H. E. Alternativas em turbulência. Projeto Reenge. Escola de Engenharia de São Carlos, Universidade de São Paulo, São Carlos, 2001. 140p.

SHULZ, H. E. O essencial em fenômenos de transporte. Projeto Reenge. Escola de Engenharia de São Carlos, Universidade de São Paulo, São Carlos, 2003. 398p.

SILVA, V. et al. Relatório da microbacia do córrego da Barrinha. Pirassununga, CEPTA/IBAMA, 1994. 33p.

SILVA, A. M.; SCHULZ, H. E.; CAMARGO, P.B. Erosão e Hidrossedimentologia em Bacias Hidrográficas. São Carlos: Rima, 2003. 140 p. 
SIMÕES, S.J.C.; COIADO, E.M. Assoreamento de Reservatórios. In: Paiva J.B.D.; Paiva E.M.C.D. (Orgs.). Hidrologia Aplicada à Gestão de Pequenas Bacias Hidrográficas. Porto Alegre: ABRH, 2001. p.283-293.

SMAGORINSKY, J. General circulation experiment with the primitive equations. Monthly Weather Review, 1963, v.91, n.3, p.99-164.

SMART, G. M. and JAEGGI, M. N. R. Sediment Transport on Steep Slopes. Mitteilung nr. 64 of the Laboratory for Hydraulics, Hydrology and Glaciology at the Federal Techinical University, Zurich, 1983.

SMITH, N.A.F. A history of dams. London: Peter Davies, 1971.

SOUZA, C.F.; DORNELlES, A.M.; ACIOLI, L.A.; MERTEN, G. Comparação dentre estimativas de produção de sedimentos na Bacia do Rio Potiribu. VII Encontro Nacional de Engenharia de Sedimentos, ENES, 2006. 20 p.

SOUZA, L.B.S. Estudo experimental e modelagem numérica do escoamento e do assoreamento em uma armadilha de sedimentos. Tese de Doutorado - Escola de Engenharia de São Carlos, Universidade de São Paulo, São Carlos, 2006. 154 p.

STOSCHEK, O.; ZIMMERMANN, C. Water Exchange and sedimentation in na estuarine tidal harbor using three-dimensional simulation. Journal of Waterway, Port, Coastal, and Ocean Engineering, ASCE, 2006. p.410-414.

STRAND, R.I. Sedimentation. In: Design of Small Dams. U.S. Department of Interior. Washington: Bureau of Reclamation,1974. p.767-796.

TALMON, A. M. Bed topography of river bends with suspended sediment transport. Tese (Doutorado) - Delft University of Technology, Holanda, 1992.

TERABE, F. R.; FRIEDRICH, M. F.; OTA, J. J.; CAMARGO, A. S. G. Modelagem computacional da hidrodinâmica e do processo de transporte e deposição de sedimentos no reservatório de Fiú - modelo RMA10/11. VII Encontro Nacional de Engenharia de Sedimentos, ENES, 2006. 18p.

TUCCI, C.E.M; HESPANHOL, I; NETTO, O.M. Gestão da água no Brasil. Organização das Nações Unidas para a educação, ciência e cultura - UNESCO, 2001. 156p. 
UNIVERSIDADE DE SÃO PAULO. Diretrizes para apresentação de dissertações e teses da USP. SIBi-USP, 2004. 110p.

VANONI, V. A. Sedimentation Engineering. New York: Headquarters of the Society, 1975. p. 587-612.

VILLELA, S.M.; MATTOS, A. Hidrologia Aplicada. São Paulo: McGraw-Hill, 1975. 245p.

VILlELA, S. M. ; MATTOS, A. A Critical Analysis of Sediment Transport Measurement Method Used for a Brasilian River. in: US - Pakistan Binational Symposium on Mechanics of Alluvial Channels, Lahore Paquistão. Porceedings of the Symposium, 1985.

VILLELA, S. M. ; PONCE, R. J. C. Mathematical Model for Reservoir Silting. In: Sediment Budgets, Porto Alegre. Proceedings of the Porto Alegre Symposium of the International Association of Hydraulic Research, 1988. v. 174.

VILLELA, S. M. ; TEIXEIRA, E. C. . Some Factors Affecting Erosion of Bed Channels Protected with Riprap. In: Sediment Budgets, Porto Alegre. Proceedings of the Porto Alegre Symposium of the International Association of Hydraulic Research, 1988.

VRIEND, H. J. Steady flow in shallow channel bends. comm. on Hydraulics 81-3, Department of Civil Engineering, Delft University of Technology, Holanda, 1981.

WETZEL, R. G.; LIKENS, G. E. Limnological analysis. New York: Springer Verlag, 1991. $391 \mathrm{p}$.

WILLIAMS, J.R.; BERNDT, H.D. Sediment yield computed with universal equation. Journal of Hydraulic Engineering, 1972. v.98, n.12. p. 2087-2098.

YANG, C. T. Rate of energy dissipation and river sedimentation. $2^{\text {nd }}$ International Symposium on River Sedimentation, Nanjing, China, 1983. p.575-585.

YANG, C. T. Unit stream power equation for gravel. Journal of Hydraulic Division, ASCE, 110 (HY12), 1984. p.1783-1798.

ZIEGLER, C. K.; NISBET, B. S. Fine-grained sediment transport in Pawtuxet River, Rhode Island. Journal of Hydraulic Engineering, v.120, n.5, 1994. p.561-576.

ZIEGLER,C.K.; NISBET,B.S. Long-term simulation of fine-grained sediment transport in large reservoir. Journal of Hydraulic Engineering, ASCE. Vol.121, 1995. P. 773-781 


\section{APÊNDICES.}

Apêndice: "Texto ou documento elaborado pelo autor, de acordo com a NBR

14724/2002, a fim de complementar sua argumentação" (Universidade de São Paulo, 2004).

São apresentados a seguir:

- Resultados complementares da Simulação Hidrodinâmica.

- Resultados complementares da Simulação de Sedimentos. 


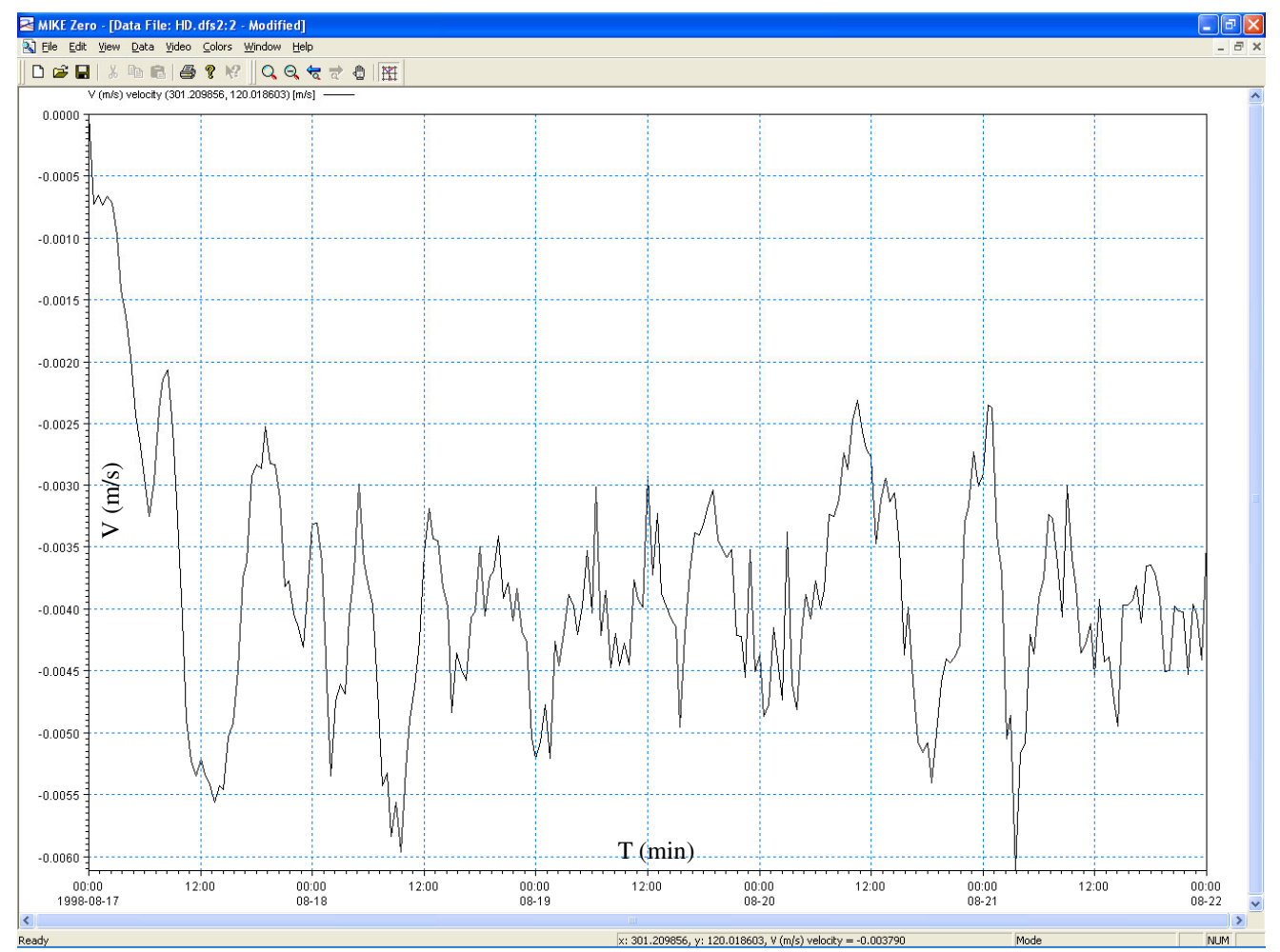

Perfil de velocidade num ponto central da represa durante 5 dias de escoamento real simulado $($ Smagorinsky $=0,5$ e $\mathrm{M}=20$ )

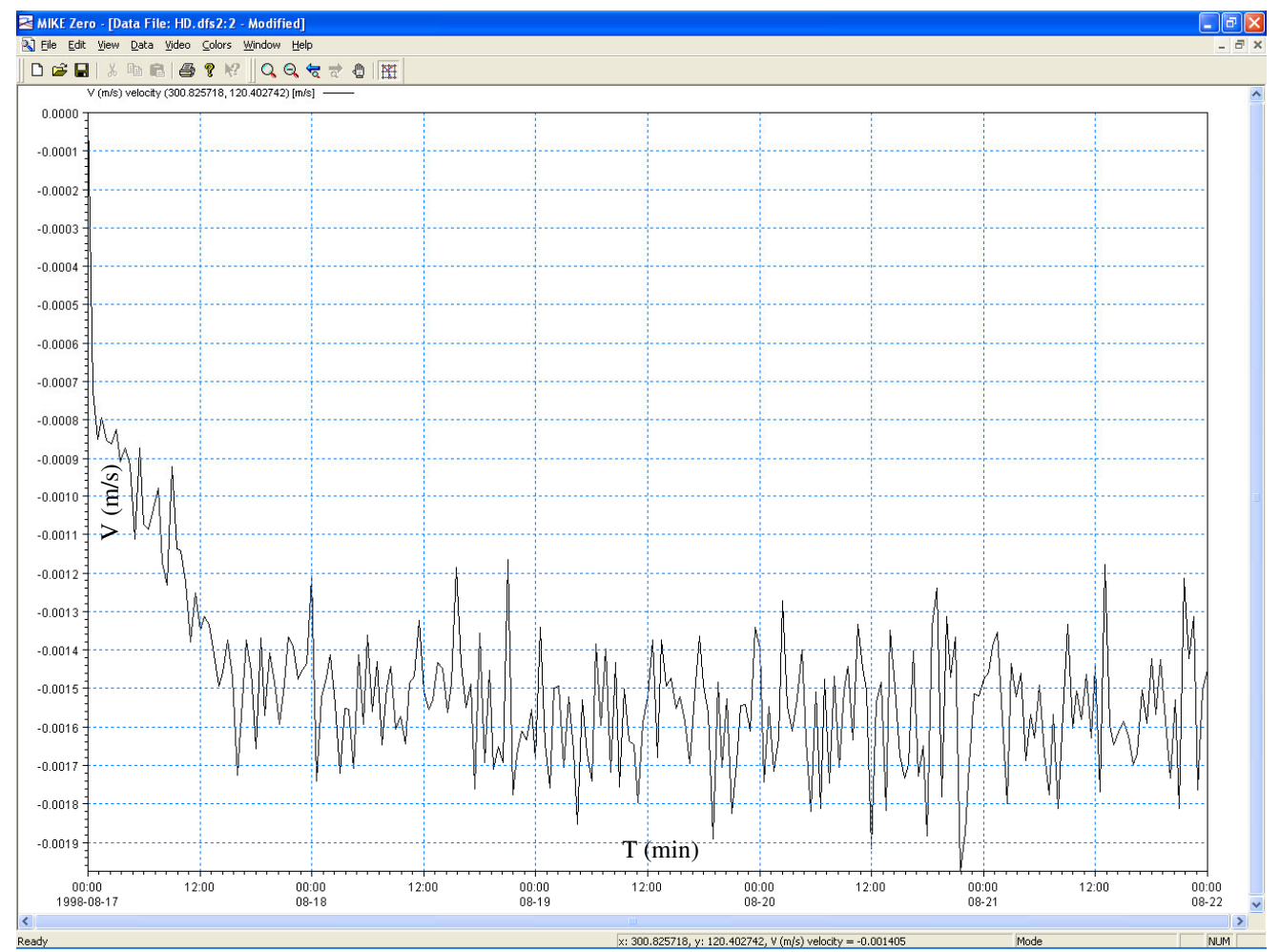

Perfil de velocidade num ponto central da represa durante 5 dias de escoamento real simulado $\left(v=0,01 \mathrm{~m}^{2} / \mathrm{s}\right.$ e $\left.\mathrm{M}=20\right)$ 


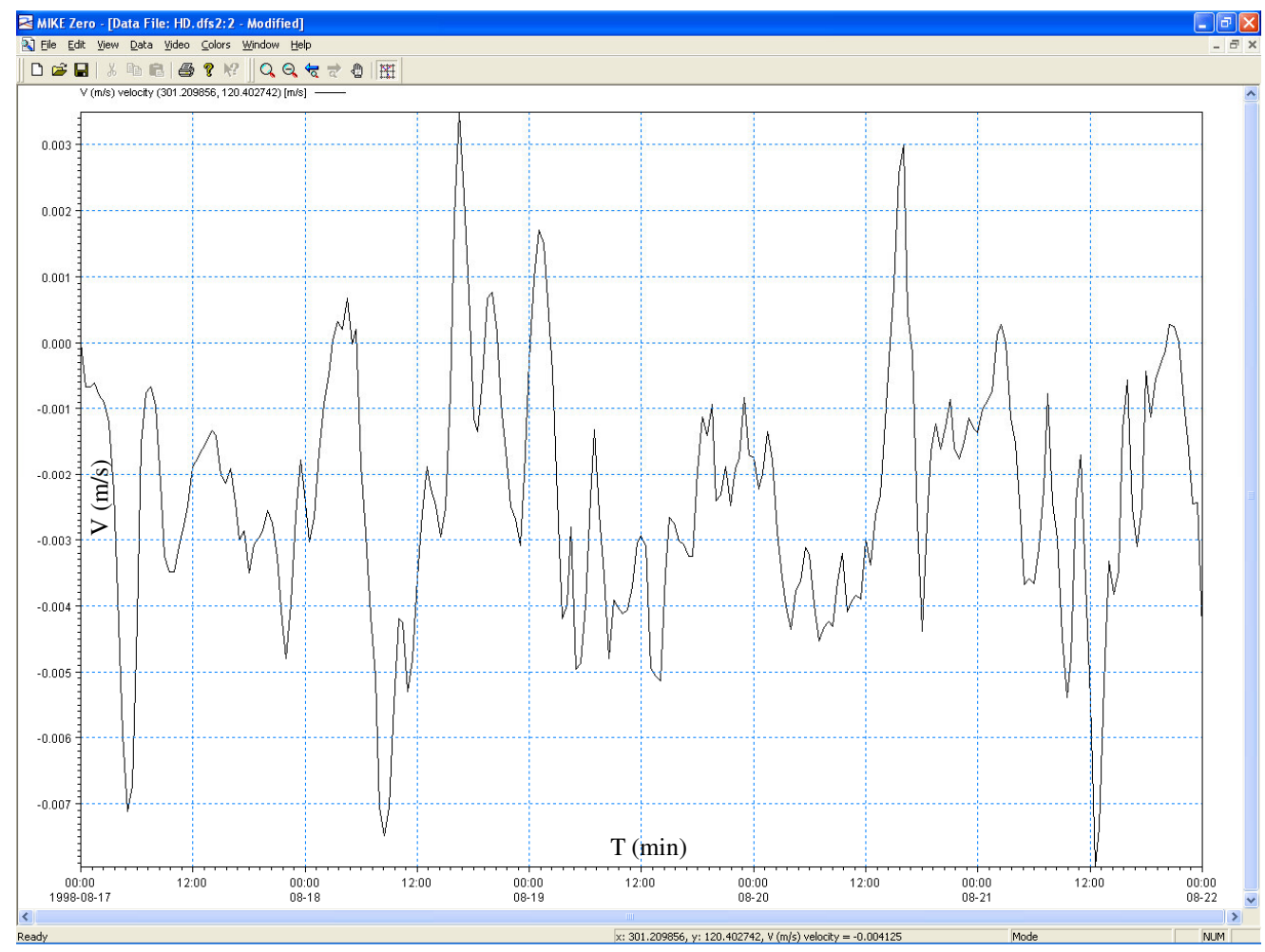

Perfil de velocidade num ponto central da represa durante 5 dias de escoamento real simulado (Smagorinsky = 0,5 e M=32)

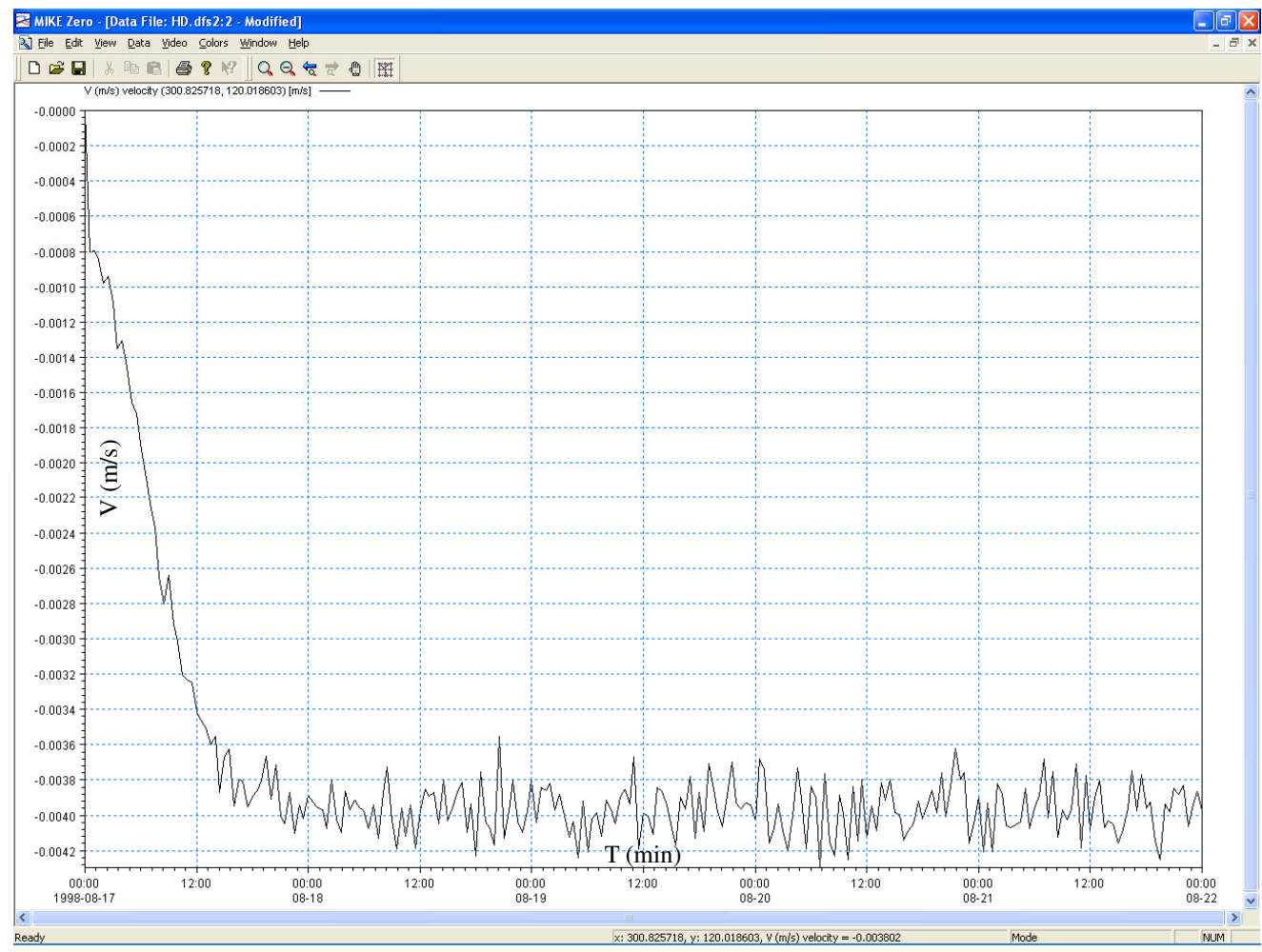

Perfil de velocidade num ponto central da represa durante 5 dias de escoamento real simulado $\left(v=0,01 \mathrm{~m}^{2} / \mathrm{s}\right.$ e $\left.\mathrm{M}=32\right)$ 


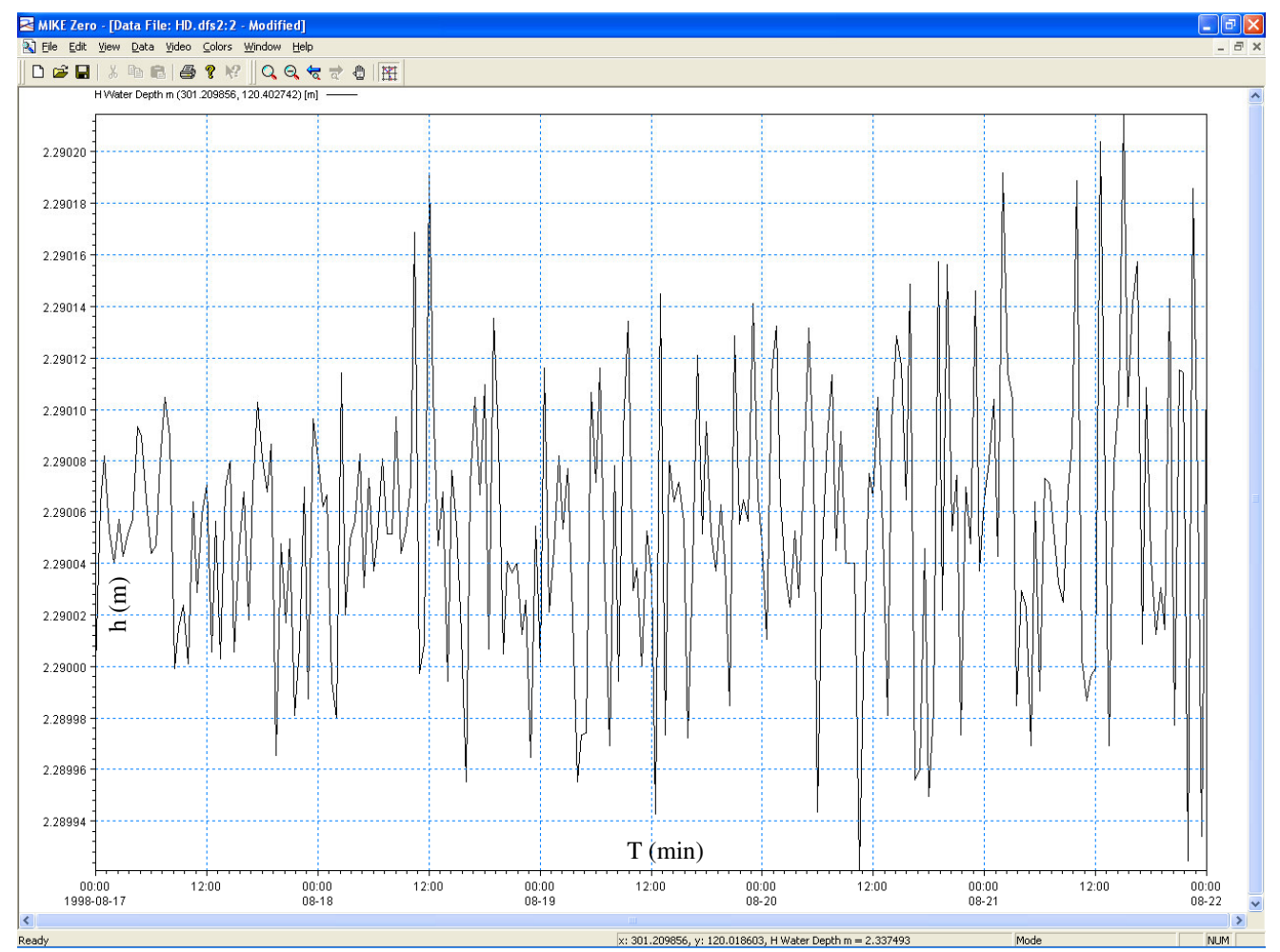

Variação da profundidade num ponto central da represa durante 5 dias de escoamento real simulado (Smagorinsky $=0,5$ e $M=20$ )

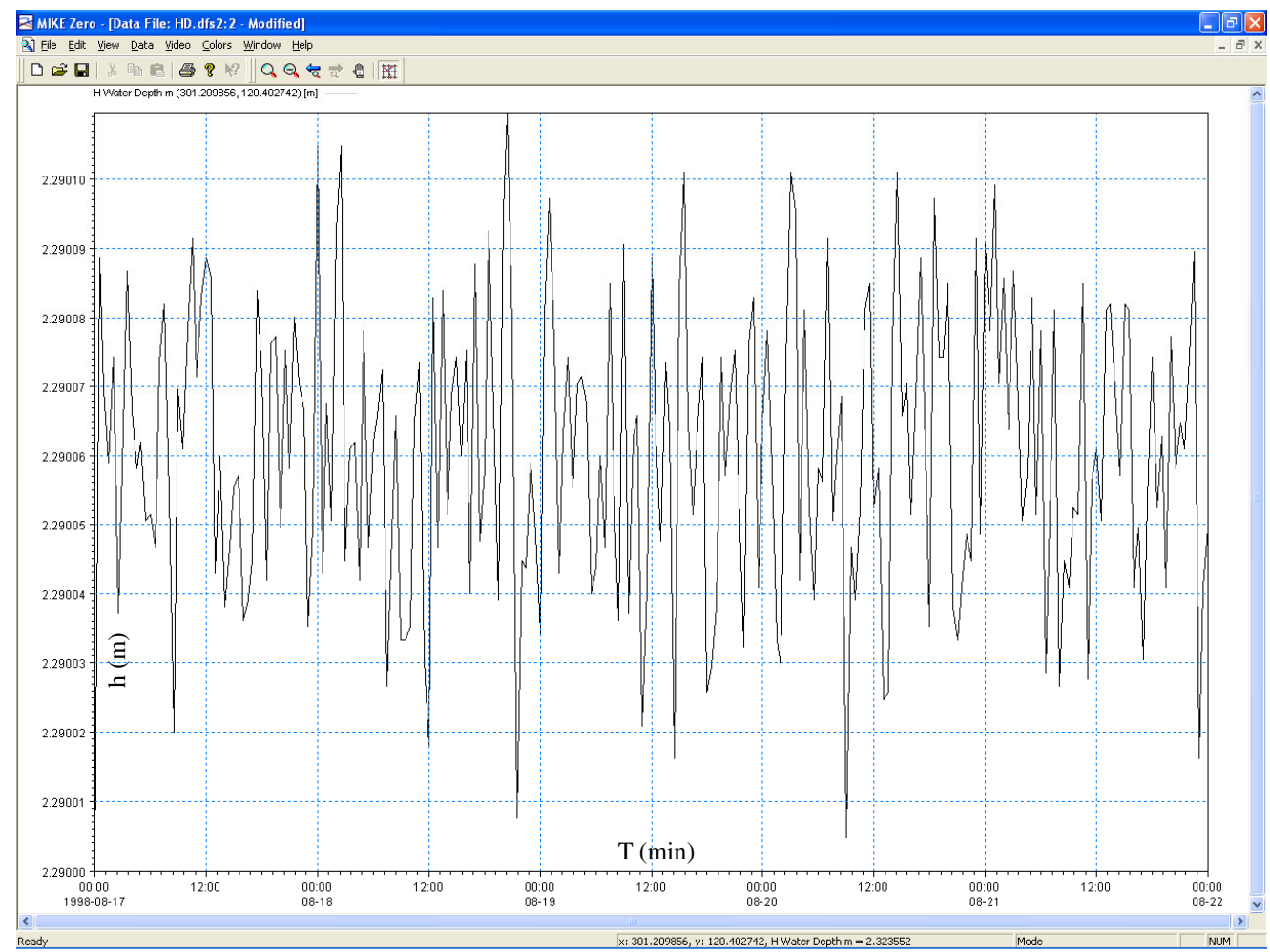

Variação da profundidade num ponto central da represa durante 5 dias de escoamento real simulado $\left(v=0,01 \mathrm{~m}^{2} / \mathrm{s}\right.$ e $\left.\mathrm{M}=20\right)$ 


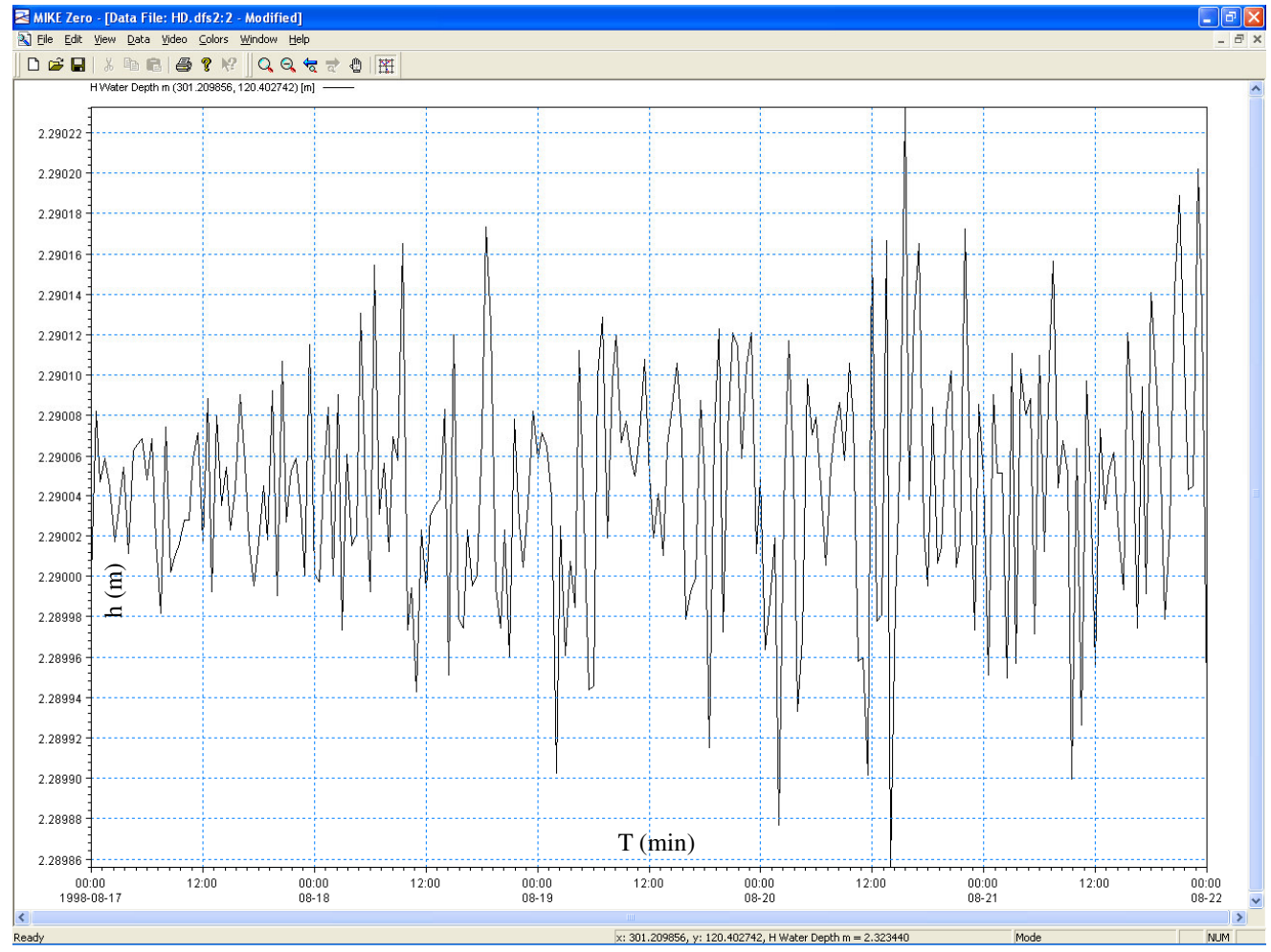

Variação da profundidade num ponto central da represa durante 5 dias de escoamento real simulado (Smagorinsky = 0,5 e $\mathrm{M}=32$ )

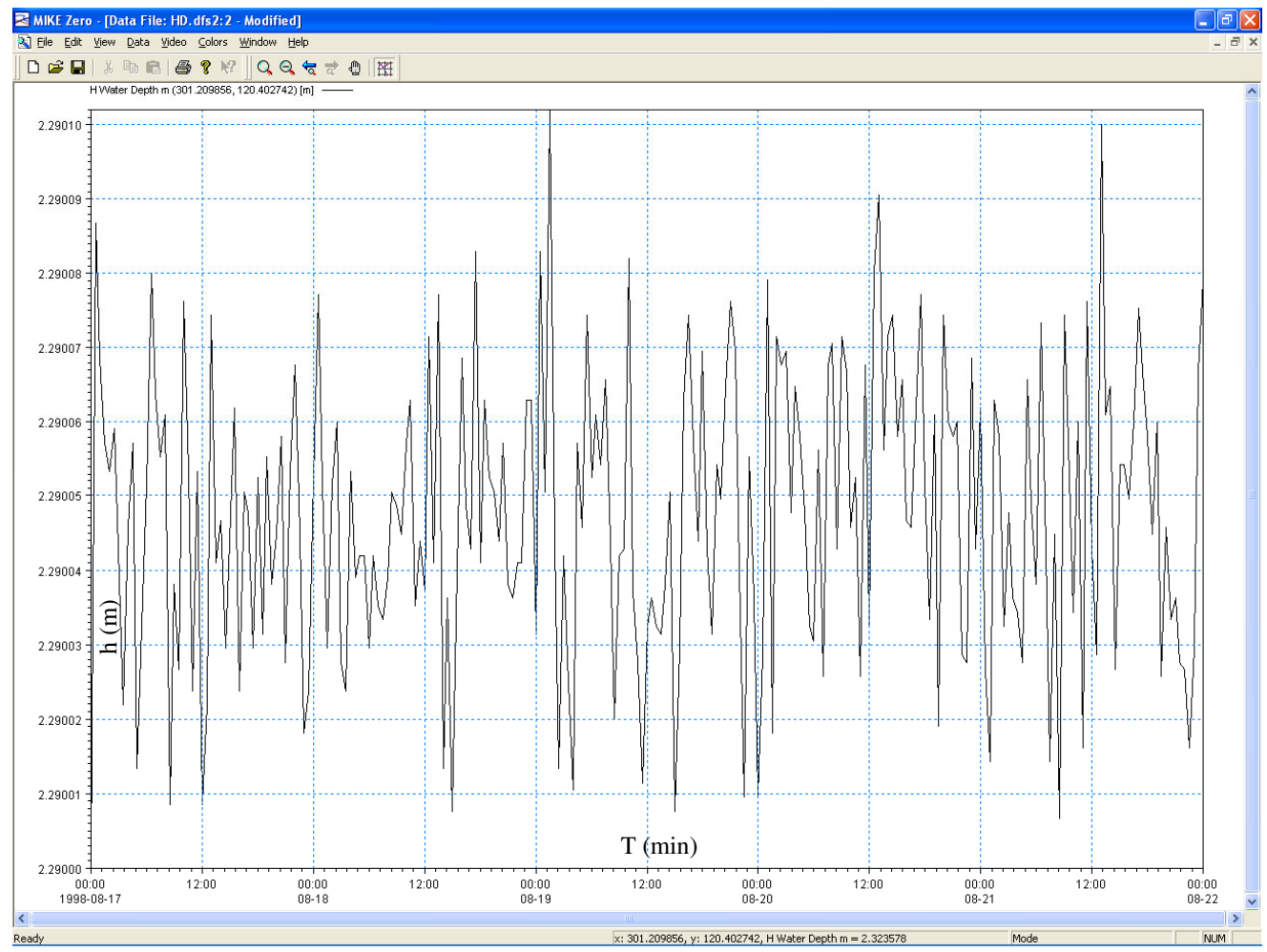

Variação da profundidade num ponto central da represa durante 5 dias de escoamento real simulado $\left(v=0,01 \mathrm{~m}^{2} / \mathrm{s}\right.$ e $\left.\mathrm{M}=32\right)$ 


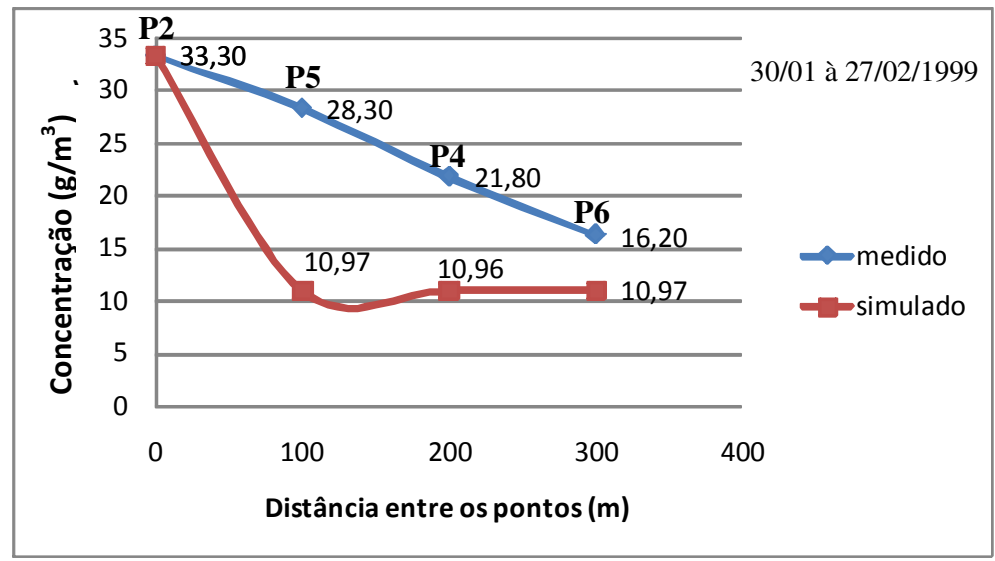

Variação espacial da concentração de sedimentos suspensos $\left(\mathrm{g} / \mathrm{m}^{3}\right)$ - Configuração 1 (equação de transporte - Engelund-Hansen)

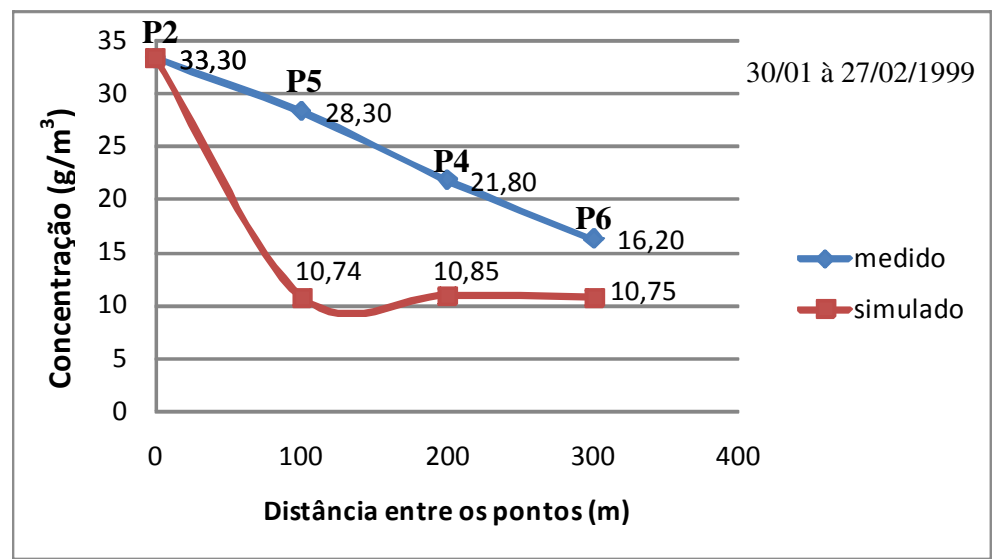

Variação espacial da concentração de sedimentos suspensos $\left(\mathrm{g} / \mathrm{m}^{3}\right)$ - Configuração 1 (viscosidade constante $-\mathrm{v}=0,01 \mathrm{~m}^{2} / \mathrm{s}$ )

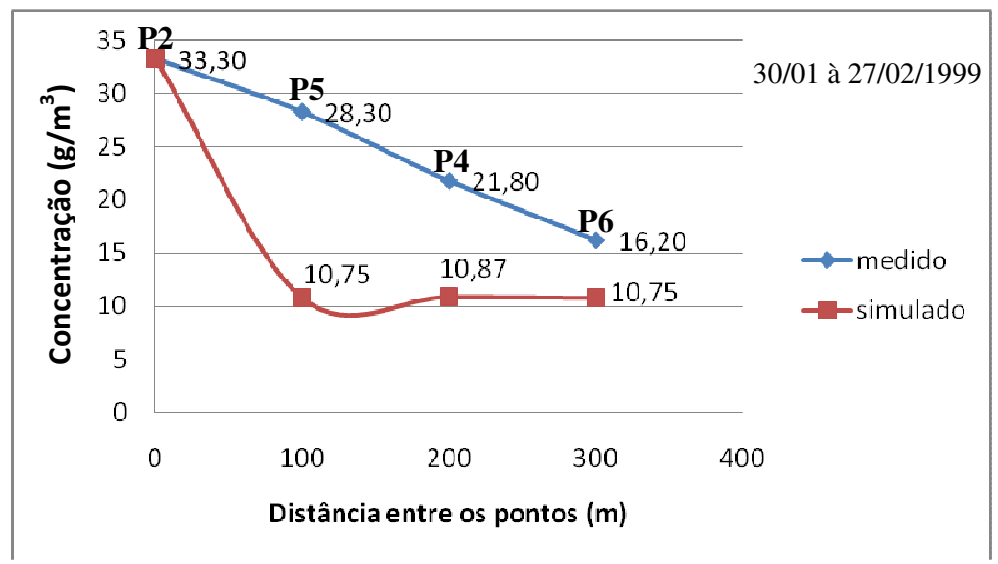

Variação espacial da concentração de sedimentos suspensos $\left(\mathrm{g} / \mathrm{m}^{3}\right)$ - Configuração 1

$$
(\mathrm{M}=32)
$$



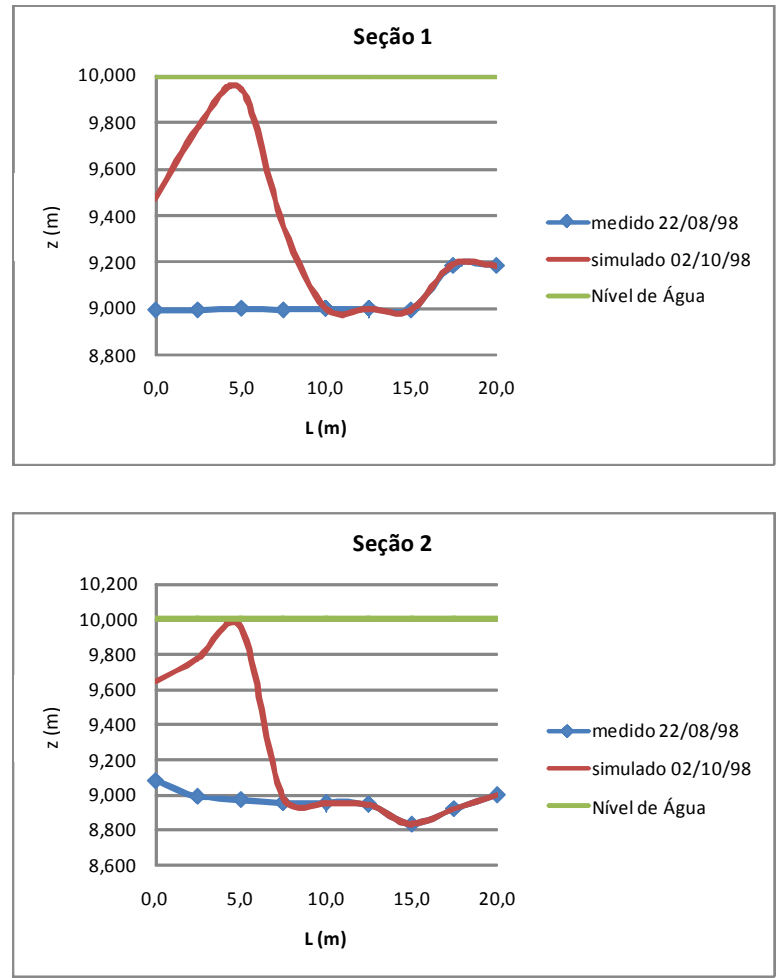

Configuração 4 - Perfil do assoreamento simulado na entrada em 02/10/1998.
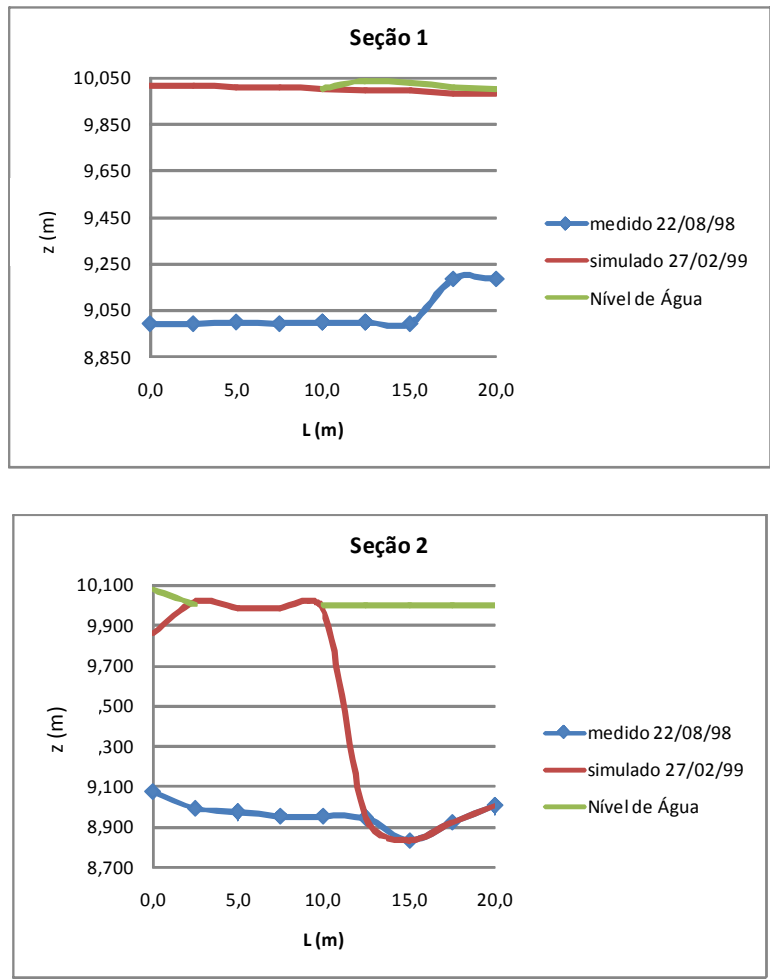

Configuração 5 - Perfil do assoreamento simulado na entrada em 27/02/1999. 


\begin{tabular}{cccc}
\hline \multicolumn{4}{c}{ Campanha de 21/08/1999 - Seção A } \\
$y(\mathrm{~m})$ & $\mathrm{z}(\mathrm{m})$ med. 1998 & $\mathrm{z}(\mathrm{m})$ med. 1999 & $\mathrm{z}(\mathrm{m})$ sim.1999 \\
\hline 193,0 & 10,00 & 10,00 & 10,00 \\
190,0 & 9,33 & 9,65 & 9,99 \\
180,0 & 8,93 & 9,27 & 9,11 \\
170,0 & 8,68 & 8,90 & 8,78 \\
160,0 & 8,48 & 8,67 & 8,56 \\
150,0 & 8,26 & 8,51 & 8,37 \\
140,0 & 8,06 & 8,29 & 8,13 \\
130,0 & 7,95 & 8,13 & 8,02 \\
120,0 & 8,26 & 8,25 & 8,26 \\
110,0 & 8,17 & 8,39 & 8,27 \\
100,0 & 8,17 & 8,16 & 8,21 \\
90,0 & 7,25 & 7,24 & 7,27 \\
80,0 & 6,58 & 6,62 & 6,61 \\
70,0 & 6,23 & 6,30 & 6,25 \\
60,0 & 5,77 & 5,81 & 5,79 \\
50,0 & 5,54 & 5,53 & 5,54 \\
40,0 & 5,35 & 5,46 & 5,38 \\
30,0 & 5,37 & 5,44 & 5,42 \\
20,0 & 6,18 & 6,24 & 6,23 \\
10,0 & 6,63 & 6,59 & 6,67 \\
\hline
\end{tabular}

Dados batimétricos medidos e simulados correspondentes a Seção A.

\begin{tabular}{cccc}
\hline \multicolumn{4}{c}{ Campanha de 21/08/1999 - Seção B } \\
$y(m)$ & $z(m)$ med. 1998 & $z(m)$ med. 1999 & $z(m)$ sim.1999 \\
\hline 218,0 & 10,00 & 10,00 & 9,98 \\
210,0 & 8,77 & 9,29 & 9,14 \\
200,0 & 8,67 & 8,77 & 8,73 \\
190,0 & 8,49 & 8,45 & 8,49 \\
180,0 & 8,25 & 8,26 & 8,25 \\
170,0 & 7,95 & 7,94 & 7,99 \\
160,0 & 7,72 & 7,73 & 7,75 \\
150,0 & 7,50 & 7,51 & 7,52 \\
140,0 & 7,03 & 7,10 & 7,08 \\
130,0 & 7,19 & 7,25 & 7,19 \\
120,0 & 7,53 & 7,54 & 7,54 \\
110,0 & 7,11 & 7,17 & 7,14 \\
100,0 & 6,63 & 6,69 & 6,67 \\
90,0 & 6,39 & 6,39 & 6,44 \\
80,0 & 6,03 & 6,07 & 6,07 \\
70,0 & 6,03 & 6,05 & 6,04 \\
60,0 & 5,73 & 5,79 & 5,75 \\
50,0 & 5,42 & 5,51 & 5,44 \\
40,0 & 5,38 & 5,34 & 5,40 \\
30,0 & 5,25 & 5,25 & 5,26 \\
20,0 & 5,53 & 5,48 & 5,53 \\
10,0 & 6,10 & 6,18 & 6,11 \\
\hline
\end{tabular}

Dados batimétricos medidos e simulados correspondentes a Seção B. 


\begin{tabular}{cccc}
\hline \multicolumn{4}{c}{ Campanha de 21/08/1999 - Seção C } \\
$y(m)$ & $z(m)$ med. 1998 & $z(m)$ med. 1999 & $z(m)$ sim.1999 \\
\hline 220,0 & 10,00 & 10,00 & 9,98 \\
210,0 & 8,43 & 8,52 & 8,43 \\
200,0 & 8,43 & 8,48 & 8,46 \\
190,0 & 8,23 & 8,39 & 8,33 \\
180,0 & 8,00 & 8,26 & 8,17 \\
170,0 & 7,70 & 7,74 & 7,76 \\
160,0 & 7,51 & 7,49 & 7,53 \\
150,0 & 7,26 & 7,28 & 7,26 \\
140,0 & 7,03 & 7,03 & 7,05 \\
130,0 & 6,86 & 7,06 & 6,97 \\
120,0 & 7,03 & 7,14 & 7,09 \\
110,0 & 6,78 & 6,87 & 6,79 \\
100,0 & 6,56 & 6,63 & 6,60 \\
90,0 & 6,07 & 6,20 & 6,13 \\
80,0 & 5,81 & 5,94 & 5,83 \\
70,0 & 5,66 & 5,86 & 5,70 \\
60,0 & 5,68 & 5,74 & 5,76 \\
50,0 & 5,58 & 5,55 & 5,61 \\
40,0 & 5,28 & 5,41 & 5,32 \\
30,0 & 5,22 & 5,28 & 5,23 \\
20,0 & 5,44 & 5,56 & 5,45 \\
10,0 & 5,73 & 5,85 & 5,80 \\
\hline
\end{tabular}

Dados batimétricos medidos e simulados correspondentes a Seção C.

\begin{tabular}{cccc}
\hline \multicolumn{4}{c}{ Campanha de 21/08/1999 - Seção D } \\
$y(m)$ & $z(m)$ med. 1998 & $z(m)$ med. 1999 & $z(m)$ sim.1999 \\
\hline 220,0 & 9,41 & 9,81 & 9,64 \\
210,0 & 8,53 & 8,91 & 8,79 \\
200,0 & 7,91 & 8,26 & 8,11 \\
190,0 & 7,69 & 7,79 & 7,70 \\
180,0 & 7,61 & 7,70 & 7,61 \\
170,0 & 7,77 & 7,81 & 7,78 \\
160,0 & 7,75 & 7,86 & 7,77 \\
150,0 & 7,46 & 7,71 & 7,49 \\
140,0 & 6,97 & 7,23 & 6,98 \\
130,0 & 6,68 & 6,78 & 6,70 \\
120,0 & 6,41 & 6,47 & 6,43 \\
110,0 & 6,30 & 6,26 & 6,32 \\
100,0 & 6,10 & 6,26 & 6,11 \\
90,0 & 6,08 & 6,66 & 6,21 \\
80,0 & 5,91 & 6,08 & 5,94 \\
70,0 & 5,73 & 5,97 & 5,86 \\
60,0 & 5,98 & 6,03 & 6,00 \\
50,0 & 6,11 & 6,17 & 6,11 \\
40,0 & 6,08 & 6,18 & 6,10 \\
30,0 & 5,60 & 5,70 & 5,61 \\
20,0 & 5,37 & 5,47 & 5,41 \\
10,0 & 5,49 & 5,53 & 5,51 \\
\hline & & &
\end{tabular}

Dados batimétricos medidos e simulados correspondentes a Seção D. 


\begin{tabular}{cccc}
\hline \multicolumn{4}{c}{ Campanha de 21/08/1999 - Seção E } \\
$y(\mathrm{~m})$ & $\mathrm{z}(\mathrm{m})$ med. 1998 & $\mathrm{z}(\mathrm{m})$ med. 1999 & $\mathrm{z}(\mathrm{m})$ sim.1999 \\
\hline 80,0 & 8,43 & 9,51 & 8,43 \\
70,0 & 9,03 & 8,96 & 9,03 \\
60,0 & 8,33 & 8,25 & 8,33 \\
50,0 & 7,69 & 7,42 & 7,69 \\
40,0 & 6,68 & 6,87 & 6,68 \\
30,0 & 6,82 & 6,56 & 6,82 \\
20,0 & 6,92 & 6,91 & 6,92 \\
10,0 & 6,96 & 7,06 & 6,96 \\
\hline
\end{tabular}

Dados batimétricos medidos e simulados correspondentes a Seção E.

\begin{tabular}{cccc}
\hline \multicolumn{4}{c}{ Campanha de 21/08/1999 - Seção F } \\
$y(\mathrm{~m})$ & $z(\mathrm{~m})$ med. 1998 & $\mathrm{z}(\mathrm{m})$ med. 1999 & $\mathrm{z}(\mathrm{m})$ sim.1999 \\
\hline 107,0 & 10,00 & 10,00 & 9,98 \\
100,0 & 9,49 & 9,58 & 9,49 \\
90,0 & 8,77 & 8,95 & 8,77 \\
80,0 & 8,68 & 8,67 & 8,68 \\
70,0 & 8,68 & 8,79 & 8,68 \\
60,0 & 8,69 & 8,68 & 8,69 \\
50,0 & 8,71 & 8,79 & 8,71 \\
40,0 & 8,93 & 9,03 & 8,93 \\
30,0 & 8,95 & 9,05 & 8,95 \\
20,0 & 8,87 & 9,01 & 8,87 \\
10,0 & 8,58 & 8,80 & 8,58 \\
\hline
\end{tabular}

Dados batimétricos medidos e simulados correspondentes a Seção F.

\begin{tabular}{cccc}
\hline \multicolumn{4}{c}{ Campanha de 21/08/1999 - Seção G } \\
$x(\mathrm{~m})$ & $z(\mathrm{~m})$ med. 1998 & $z(\mathrm{~m})$ med. 1999 & $z(\mathrm{~m})$ sim.1999 \\
\hline 240,0 & 10,00 & 10,00 & 10,00 \\
230,0 & 8,77 & 9,29 & 9,14 \\
220,0 & 8,43 & 8,52 & 8,43 \\
210,0 & 8,25 & 8,23 & 8,28 \\
200,0 & 8,56 & 8,48 & 8,56 \\
190,0 & 8,00 & 8,01 & 8,00 \\
180,0 & 8,53 & 8,91 & 8,79 \\
170,0 & 10,00 & 10,00 & 9,98 \\
\hline
\end{tabular}

Dados batimétricos medidos e simulados correspondentes a Seção G.

\begin{tabular}{cccc}
\hline \multicolumn{4}{c}{ Campanha de 21/08/1999 - Seção H } \\
$x(\mathrm{~m})$ & $z(\mathrm{~m})$ med. 1998 & $z(\mathrm{~m})$ med. 1999 & $z(\mathrm{~m})$ sim.1999 \\
\hline 240,0 & 10,00 & 10,00 & 9,98 \\
230,0 & 8,67 & 8,77 & 8,73 \\
220,0 & 8,43 & 8,48 & 8,46 \\
210,0 & 7,74 & 7,69 & 7,70 \\
200,0 & 8,37 & 8,34 & 8,39 \\
190,0 & 7,83 & 7,95 & 7,83 \\
180,0 & 7,91 & 8,26 & 8,11 \\
170,0 & 9,32 & 9,74 & 9,32 \\
\hline
\end{tabular}

Dados batimétricos medidos e simulados correspondentes a Seção H. 


\begin{tabular}{cccc}
\hline \multicolumn{4}{c}{ Campanha de 21/08/1999 - Seção I } \\
$x(\mathrm{~m})$ & $z(\mathrm{~m})$ med. 1998 & $z(\mathrm{~m})$ med. 1999 & $z(\mathrm{~m})$ sim.1999 \\
\hline 240,0 & 9,33 & 9,65 & 9,99 \\
230,0 & 8,49 & 8,45 & 8,49 \\
220,0 & 8,23 & 8,39 & 8,33 \\
210,0 & 7,62 & 7,40 & 7,63 \\
200,0 & 8,10 & 8,15 & 8,11 \\
190,0 & 7,96 & 8,17 & 7,96 \\
180,0 & 7,69 & 7,79 & 7,70 \\
170,0 & 8,43 & 8,96 & 8,43 \\
\hline
\end{tabular}

Dados batimétricos medidos e simulados correspondentes a Seção I.

\begin{tabular}{cccc}
\hline \multicolumn{4}{c}{ Campanha de 21/08/1999 - Seção J } \\
$x(\mathrm{~m})$ & $z(\mathrm{~m})$ med. 1998 & $\mathrm{z}(\mathrm{m})$ med. 1999 & $\mathrm{z}(\mathrm{m})$ sim.1999 \\
\hline 240,0 & 8,26 & 8,25 & 8,26 \\
230,0 & 7,53 & 7,54 & 7,54 \\
220,0 & 7,03 & 7,14 & 7,09 \\
210,0 & 6,71 & 6,77 & 6,73 \\
200,0 & 6,65 & 6,64 & 6,66 \\
190,0 & 6,33 & 6,70 & 6,34 \\
180,0 & 6,41 & 6,47 & 6,43 \\
170,0 & 6,54 & 6,59 & 6,55 \\
\hline
\end{tabular}

Dados batimétricos medidos e simulados correspondentes a Seção J.

\begin{tabular}{cccc}
\hline \multicolumn{4}{c}{ Campanha de 21/08/1999 - Seção K } \\
$x(\mathrm{~m})$ & $z(\mathrm{~m})$ med. 1998 & $z(\mathrm{~m})$ med. 1999 & $\mathrm{z}(\mathrm{m})$ sim.1999 \\
\hline 250,0 & 10,00 & 10,00 & 9,80 \\
240,0 & 8,17 & 8,39 & 8,27 \\
230,0 & 7,11 & 7,17 & 7,14 \\
220,0 & 6,78 & 6,87 & 6,79 \\
210,0 & 6,51 & 6,56 & 6,58 \\
200,0 & 6,54 & 6,74 & 6,55 \\
190,0 & 6,20 & 6,36 & 6,23 \\
180,0 & 6,30 & 6,26 & 6,32 \\
170,0 & 6,28 & 6,56 & 6,30 \\
\hline
\end{tabular}

Dados batimétricos medidos e simulados correspondentes a Seção K.

\begin{tabular}{cccc}
\hline \multicolumn{4}{c}{ Campanha de 21/08/1999 - Seção L } \\
$x(\mathrm{~m})$ & $z(\mathrm{~m})$ med. 1998 & $z(\mathrm{~m})$ med. 1999 & $\mathrm{z}(\mathrm{m})$ sim.1999 \\
\hline 250,0 & 9,08 & 9,08 & 9,08 \\
240,0 & 8,17 & 8,16 & 8,21 \\
230,0 & 6,63 & 6,69 & 6,67 \\
220,0 & 6,56 & 6,63 & 6,60 \\
210,0 & 6,24 & 6,34 & 6,26 \\
200,0 & 6,08 & 6,14 & 6,08 \\
190,0 & 6,35 & 6,51 & 6,35 \\
180,0 & 6,10 & 6,26 & 6,11 \\
170,0 & 6,13 & 6,48 & 6,14 \\
\hline
\end{tabular}

Dados batimétricos medidos e simulados correspondentes a Seção L. 


\begin{tabular}{cccc}
\hline \multicolumn{4}{c}{ Campanha de 21/08/1999 - Seção M } \\
$x(\mathrm{~m})$ & $z(\mathrm{~m})$ med. 1998 & $z(\mathrm{~m})$ med. 1999 & $\mathrm{z}(\mathrm{m})$ sim.1999 \\
\hline 260,0 & 7,99 & 8,18 & 8,02 \\
250,0 & 6,39 & 6,49 & 6,41 \\
240,0 & 5,35 & 5,46 & 5,38 \\
230,0 & 5,38 & 5,34 & 5,40 \\
220,0 & 5,28 & 5,41 & 5,32 \\
210,0 & 5,38 & 5,44 & 5,42 \\
200,0 & 5,39 & 5,44 & 5,40 \\
190,0 & 5,41 & 5,47 & 5,41 \\
180,0 & 6,08 & 6,18 & 6,10 \\
170,0 & 6,20 & 6,47 & 6,21 \\
160,0 & 6,89 & 7,16 & 6,90 \\
150,0 & 6,65 & 6,94 & 6,66 \\
140,0 & 6,59 & 6,77 & 6,59 \\
130,0 & 6,85 & 6,57 & 6,85 \\
120,0 & 6,68 & 6,87 & 6,68 \\
110,0 & 7,08 & 6,73 & 7,08 \\
100,0 & 6,95 & 7,14 & 6,95 \\
90,0 & 7,11 & 7,09 & 7,11 \\
80,0 & 8,03 & 7,47 & 8,03 \\
70,0 & 8,53 & 8,59 & 8,53 \\
60,0 & 8,93 & 9,03 & 8,93 \\
50,0 & 9,14 & 9,23 & 9,14 \\
40,0 & 9,27 & 9,28 & 9,27 \\
30,0 & 9,33 & 9,36 & 9,33 \\
\hline
\end{tabular}

Dados batimétricos medidos e simulados correspondentes a Seção M.

\begin{tabular}{cccc}
\hline \multicolumn{4}{c}{ Campanha de 21/08/1999 - Seção N } \\
$x(\mathrm{~m})$ & $z(\mathrm{~m})$ med. 1998 & $\mathrm{z}(\mathrm{m})$ med. 1999 & $\mathrm{z}(\mathrm{m})$ sim.1999 \\
\hline 260,0 & 7,64 & 7,78 & 7,65 \\
250,0 & 7,13 & 7,13 & 7,24 \\
240,0 & 5,37 & 5,44 & 5,42 \\
230,0 & 5,25 & 5,25 & 5,26 \\
220,0 & 5,22 & 5,28 & 5,23 \\
210,0 & 5,21 & 5,25 & 5,25 \\
200,0 & 5,33 & 5,32 & 5,37 \\
190,0 & 5,41 & 5,36 & 5,43 \\
180,0 & 5,60 & 5,70 & 5,61 \\
170,0 & 5,89 & 6,43 & 5,90 \\
160,0 & 6,08 & 6,36 & 6,09 \\
150,0 & 6,13 & 6,13 & 6,13 \\
140,0 & 6,32 & 6,41 & 6,33 \\
130,0 & 6,33 & 6,80 & 6,43 \\
120,0 & 6,82 & 6,56 & 6,82 \\
110,0 & 6,68 & 6,66 & 6,68 \\
100,0 & 6,76 & 6,76 & 6,76 \\
90,0 & 7,11 & 7,06 & 7,11 \\
80,0 & 8,03 & 7,41 & 8,03 \\
70,0 & 8,58 & 8,63 & 8,58 \\
60,0 & 8,95 & 9,05 & 8,95 \\
50,0 & 9,25 & 9,31 & 9,25 \\
40,0 & 9,21 & 9,19 & 9,21 \\
30,0 & 9,39 & 9,43 & 9,39 \\
\hline
\end{tabular}

Dados batimétricos medidos e simulados correspondentes a Seção N. 


\begin{tabular}{cccc}
\hline \multicolumn{4}{c}{ Campanha de 21/08/1999 - Seção O } \\
$x(\mathrm{~m})$ & $z(\mathrm{~m})$ med. 1998 & $z(\mathrm{~m})$ med. 1999 & $\mathrm{z}(\mathrm{m})$ sim.1999 \\
\hline 260,0 & 7,50 & 7,61 & 7,55 \\
250,0 & 7,28 & 7,30 & 7,28 \\
240,0 & 6,18 & 6,24 & 6,23 \\
230,0 & 5,53 & 5,48 & 5,53 \\
220,0 & 5,44 & 5,56 & 5,45 \\
210,0 & 5,30 & 5,38 & 5,31 \\
200,0 & 5,31 & 5,29 & 5,32 \\
190,0 & 5,39 & 5,39 & 5,40 \\
180,0 & 5,37 & 5,47 & 5,41 \\
170,0 & 5,31 & 5,31 & 5,31 \\
160,0 & 5,89 & 5,91 & 5,89 \\
150,0 & 6,16 & 6,08 & 6,17 \\
140,0 & 6,37 & 5,98 & 6,37 \\
130,0 & 6,75 & 6,75 & 6,75 \\
120,0 & 6,92 & 6,91 & 6,92 \\
110,0 & 7,09 & 7,08 & 7,09 \\
100,0 & 7,09 & 7,11 & 7,09 \\
90,0 & 7,37 & 7,36 & 7,37 \\
80,0 & 8,09 & 7,67 & 8,09 \\
70,0 & 8,53 & 8,61 & 8,53 \\
60,0 & 8,87 & 9,01 & 8,87 \\
50,0 & 8,73 & 8,81 & 8,73 \\
40,0 & 9,18 & 9,19 & 9,18 \\
30,0 & 9,33 & 9,44 & 9,33 \\
\hline
\end{tabular}

Dados batimétricos medidos e simulados correspondentes a Seção O. 


\section{ANEXO A}

Anexo: "Texto ou documento não elaborado pelo autor, de acordo com a NBR14724/2002, que serve de fundamentação, comprovação e ilustração" (Universidade de São Paulo, 2004).

Síntese dos métodos de Engelund-Hansen (1967) e Engelund-Fredфe (1976) de acordo com DHI (2005). 


\section{Engelund and Hansen model}

The model by Engelund and Hansen (1967) is a total load model that divides the sediment transport into bed load and suspended load by the relations:

$$
\begin{aligned}
& S_{M}=k_{b} \cdot S_{t} \\
& S_{d L}=k_{t} \cdot S_{t}
\end{aligned}
$$

Where the total sediment transport is obtained by:

$$
S_{t}=0.05 \frac{C^{2}}{g} \theta^{\frac{5}{2}} \sqrt{(s-1) g d_{S 0}^{3}}
$$

The time scale $t_{s}$ for adaptation to the equilibrium concentration profile is determined by:

$$
t_{s}=\frac{h}{2 w_{s}}
$$

The equilibrium concentration is simply specified as the suspended load divided by the water flux and converted from volumetric concentration to mass concentration:

$c_{e}=\frac{S_{s l}}{u \cdot h} \cdot s \cdot 10^{6}$

\section{Engelund and Fredsøe model}

The probability of a moving sediment grain can, according to Engelund and Fredsøe (1976), be determined by the expression:

$$
p=\left[1+\left(\frac{\frac{\pi}{6} \mu_{d}}{\theta^{\prime}-\theta_{c}}\right)^{4}, \theta^{-\frac{1}{4}}>\theta_{\mathrm{c}}\right.
$$

The dynamic friction coefficient $\mu_{d}$ is assumed to be equal to: $\mu_{d}=0.51=\tan 27^{\circ}$. The nondimensional skin shear stress is defined by:

$$
\theta^{\prime}=\frac{u_{f}^{\prime}{ }^{2}}{(s-1) g d_{s 0}}
$$


Where the friction velocity related to skin friction is calculated from the assumption of a logarithmic velocity profile:

$u_{f}=\frac{\bar{u}}{6+2.5 \ln \left(\frac{h}{2.5 d_{s 0}}\right)}$

The bed load transport rate is estimated from:

$S_{b f}=5 p \cdot\left(\sqrt{\theta^{\prime}}-0.7 \sqrt{\theta_{c}}\right) \sqrt{(s-1) g d_{s 0}^{3}}$

The reference concentration near the bed is calculated from an empirical relation obtained by Zyserman and Fredsøe (1994):

$c_{b}=\frac{0.331\left(\theta-\theta_{c}\right)^{1.75}}{1+\frac{0.331}{0.46}\left(\theta-\theta_{c}\right)^{1.75}}$

The empirical relation was established from analysis of the experimental data sets of Guy et al. (1966) and covers a range from pure bed load to dominant suspended transport. The influence of lateral bed slope is included in the relation through a reduced critical Shields stress for onset of motion.

Numerical integration is performed along a logarithmic vertical scale, because a greater density of computational points is required close to the bottom, where the largest velocity gradients occur. The non-dimensional vertical coordinate is obtained from the relation:

$\eta_{j}=\eta_{j \cdot 1}+\Delta \cdot 1.08^{j-1}$

Where the step height $\Delta$ is determined by:

$$
\Delta=\frac{I}{\left(\frac{1-1.08^{99}}{1-1.08}\right)-I}
$$

Due to the specific value of the exponent in Eq (2.104), it is seen that the depth is divided into 99 segments. The velocity profile is assumed to be:

$u(\eta)=\frac{\sqrt{g}}{0.4 C} \ln \left(\frac{\eta}{\eta_{0}}\right)$ 


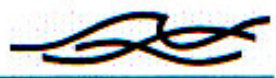

Where the no slip level $\eta_{0}$, is obtained from:

$\eta_{o}=\exp \left(\eta_{o}-I-\frac{0.4 C}{\sqrt{g}}\right)$

Eq (2.106) is solved by iteration.

The normalised vertical concentration profile is specified in the following way:

$c(\eta)=\left(\frac{1-\eta}{\eta} \cdot \frac{a}{1-a}\right)^{Z}$

Where the reference level $a$ is defined by:

$a=\frac{2 \cdot d_{50}}{h}$

The Rouse suspension parameter is defined as:

$Z=\frac{w_{s}}{\kappa_{u_{f}}}$

The suspended load transport rate is obtained from:

$S_{s l}=c_{b} u h \cdot \int_{N_{0}} u(\eta) \cdot c(\eta) d \zeta$

The equilibrium mass concentration $c_{e}$, is determined from:

$c_{e}=\frac{S_{s l}}{u h} s \cdot 10^{6} \quad\left[\mathrm{~g} / \mathrm{m}^{3}\right]$

The time scale $t_{s}$, is defined as:

$t_{s}=\frac{h_{s}}{w_{s}}$

In Eq (2.112) the height of the centroid $h$. of the concentration profile above the bed is determined, as suggested by van Rijn. 


\section{ANEXO B}

Anexo: "Texto ou documento não elaborado pelo autor, de acordo com a NBR14724/2002, que serve de fundamentação, comprovação e ilustração" (Universidade de São Paulo, 2004).

Reprodução do trabalho de Engelund and Fredsøe (1976). 
Nordic Hydrology, 7, 1976, 293-306

No part may be reproduced by any process without written permission from the author(s)

\title{
A Sediment Transport Model for
}

\section{Straight Alluvial Channels}

\author{
Frank Engelund and Jørgen Fredsøe \\ Technical University of Denmark, Copenhagen
}

\begin{abstract}
The paper presents a simple mathematical model for sediment transport in straight alluvial channels. The model, which is based on physical ideas related to those introduced by Bagnold (1954), was originally developed in two steps, the first describing the bed load transport (Engelund 1975) and the second accounting for the suspended load (Fredsøe and Engelund 1976). The model is assumed to have two advantages as compared with empirical models, first it is based on a description of physical processes, secondly it gives some information about the quantity and size of the sand particles in suspension and the bed particles.
\end{abstract}

\section{Introduction}

One of the basic difficulties in sediment transport theory is the definition of bed load versus suspended load, and some authors have even tried to overcome the problem by disregarding any such distinction. However, there are several good reasons for maintaining it, mostly, of course, related to the nature of the physical processes. The authors would like to draw the attention to the fact that the instability of erodible beds which leads to the formation of sand dunes (or antidunes) can only be explained satisfactorily by a theory which clearly distinguishes between bed load and suspended load. It is found that transition between dunes and plane bed is very sensitive to a correct estimation of these transport rates (Engelund and Fredsøe 1974, Fredsøe and Engelund 1975, and Fredsøe 1976a). The stability analysis even gives an indication of one relevant way of defining the difference between the transport of bed load and 


\section{F. Engelund and J. Fredsøe}

suspension, respectively: The bed load is that part of the total load which accomodates to spatial changes in the tractive stress, so that spatial lag may be neglected, assuming inertia of the bed particles to be negligible. On the other hand, the suspended load responds with a certain lag, because the particles have to settle a certain distance before they become deposited. This lag depends on flow conditions and sediment properties and can be estimated from an equation of continuity.

Also in other problems in the field of river morphology and sedimentation a clear distinction between bed load and suspended load is important. For example it was found (Engelund 1976) that the transverse bed slope in river bends increases in linear proportion to the ratio $q_{S} / q_{B}$. Concerning the sedimentation of river navigation channels is, it was demonstrated (Fredsøe 1976b) that the rate of sedimentation for longitudinal currents is a function of the bed load, rather than of the total load. Further it might be mentioned that observations seem to indicate that the occurrence of meandering or braiding depends on the ratio $q_{S} / q_{B}$, so that the greater the relative amount of suspension is, the more pronounced is the tendency towards braiding. This tendency is until now not fully understood.

An obvious possibility is to define the bed load as the particles in the lowest layer of moving grains. Typically the particles move by rolling, sliding, or in short jumps. This definition is in accordance with the original definition by H. A. Einstein (1950): Bed load is the bed particles moving in the so-called "bed layer", defined as "a flow layer, 2 grain diameters thick, immediately above the bed."

In this treatise Einstein presented one of the first theoretical approaches to the problem of predicting theoretically the rate of bed load transport, applying theory of probability to account for the statistical variation of the forces acting on bed particles. If the magnitude of the instantaneous agitating forces on a certain bed particle exceeds the stabilizing forces, the particle is supposed to be eroded and to start moving along the bed, until it becomes deposited downstream at a location, where the magnitude of the instantaneous forces makes deposition possible. From such consideration Einstein found that the rate of bed load transport could be described by a relation between two non-dimensional quantities

$$
\Phi=\frac{q_{B}}{\sqrt{(s-1) g d^{3}}} \text { and } e=\frac{\tau_{0}}{(s-1) \rho g d}=\frac{U_{f}^{2}}{(s-1) g d}
$$

in which

$$
\begin{aligned}
q_{B}= & \text { rate of bed load transport in volume of material per unit time and unit } \\
& \text { width of the channel } \\
s \quad= & \text { relative density of sediment } \\
g= & \text { acceleration of gravity } \\
d= & \text { fall diameter of sediment particle } \\
\rho= & \text { fluid density } \\
\tau_{0}= & \text { bed shear stress (=tractive stress) }
\end{aligned}
$$




\section{A Sediment Transport Model for Straight Alluvial Channels}

$U_{f}=$ friction velocity $=\sqrt{\tau_{0} / \rho}=\sqrt{g D I}$

$D=$ mean depth

$I$ = energy gradient (slope)

(D) is a non-dimensional form of the transport rate, while

$\theta$ is the non-dimensional tractive stress (Shield's parameter).

When calculating the transport rate of the suspended load Einstein applied the concentration distribution

$$
\frac{c}{c_{a}}=\left(\frac{D-y}{y} \frac{a}{D-a}\right)^{z}
$$

in which

$$
\begin{aligned}
& c=\text { concentration of suspended sediment (at } y \text { above the bed) } \\
& c_{a}=\text { concentration at reference level }(y=a) \\
& D=\text { depth of water } \\
& y=\text { distance from bed level } \\
& z=w / 0.4 U_{f} \text { (the Rouse number) where } w \text { is the settling velocity. }
\end{aligned}
$$

Eq. (2) was derived by Ippen and Rouse (1937) and experimentally verified by Vanoni (1946). It suffers from the drawback that $c_{a}$ usually cannot be predicted. The present paper suggests a method for calculation of $c_{a}$, based on a single dynamical principle. When $c_{a}$ is known the transport rate $q_{s}$ is found from

$$
q_{s}=\int_{a}^{D} c U d y
$$

$U$ being the mean flow velocity at the distance $y$ from the bed. Einstein's paper contains some excellent graphs which facilitate this calculation quite considerably.

In case the bed is covered by dunes the shear velocity $U_{f}$ should be replaced by

$$
U_{f}^{\prime}=\sqrt{g D^{\prime} I}
$$

in which the reduced depth $D^{\prime}$ is found from the equation (Einstein 1950)

$$
\frac{V}{U_{f}^{\prime}}=\frac{V}{\sqrt{g D^{\prime} I}}=6+2.5 \ln \frac{D^{\prime}}{k}
$$

where $k$ is the surface roughness, which is usually a little larger than the sediment size and may be taken as $2.5 \mathrm{~d}$ (Engelund and Hansen 1972). $V$ is the mean velocity of the flow.

R. A. Bagnold (1954) pointed out a short-coming of the previous theories by formulating the following paradox: Consider the ideal case of fluid flow over a bed of uniform, perfectly piled spheres in a plane bed, so that all particles are equally exposed, statistical variations due to turbulence being neglected.

When a gradually increasing tractive stress exceeds a critical value, all particles in the upper layer are peeled off simultaneously and are dispersed in the fluid. Hence the next layer of particles is exposed to the flow and should consequently also be peeled off. The result is that all subsequent underlying layers are also eroded, so that 


\section{F. Engelund and J. Fredsøe}

a stable bed could not exist at all, when the shear stress exceeds the critical value.

Bagnold explained the paradox by assuming that in a water-sediment mixture the total shear stress $\tau$ would be separated in two parts

$$
\tau=\tau_{F}+\tau_{G},
$$

where ${ }^{\tau} F$ is the shear stress transmitted by the intergranular fluid, while ${ }^{\tau} G$ is the shear stress transmitted because of the interchange of momentum caused by the encounters of solid particles, i.e. tangential dispersive stress.

Hence, Bagnold's description of the physical process is, that when a layer of spheres is peeled off, some of the spheres may go into suspension while others will be transported as bed load. Thus a dispersive pressure on the next layer of spheres will develop and act as a stabilizing agency. Hence, a certain part of the total bed shear stress $\tau$ is transmitted as a grain shear stress $\tau_{G}$ and a correspondingly minor part as a fluid stress $\left(\tau_{F}=\tau-\tau_{G}\right)$. Continuing this argumentation, it is understood that exactly so many layers of spheres will be eroded that the residual fluid stress $\tau F$ on the first immovable layer is equal to the critical tractive stress $\tau_{c}$. Hence, the mechanism in transmission of a tractive shear stress $\tau$ greater than $\tau_{c} c$ is the following: $\tau_{C}$ is transferred directly by fluid shear stress to the immobile bed while the residual stress $\tau-\tau_{C}$ is transferred to the moving particles and further from these to the fixed bed as a dispersive stress.

By theoretical and experimental research Bagnold developed the following expression for the dispersive shear stress due to the grain collisions

$$
F_{S}=0.013 \rho s \lambda^{2} d^{2}\left(\frac{d U}{d y}\right)^{2}
$$

where $\lambda$ is the so-called linear concentration, which is related to the volume concentration by the equation

$$
c=\frac{0.65}{(1+1 / \lambda)^{3}}
$$

and $y$ is the distance from the bed.

We shall later revert to an application of these expressions.

In recent publications (R. Fernandez Luque 1974, R. Fernandez Luque and R. van Beek 1976) certain modifications of Bagnold's ideas were suggested together with a consistent theory for the transport of bed load on a plane bed, considering the motion of individual particles. The theory is supported by a series of interesting experimental observations.

One of the basic issues is that close to incipient particle motion (i.e. small transport rates) only the topmost grains will be eroded, and the bed load will not effectively reduce the fluid part of the turbulent bed shear stress. This can also hardly be expected as, under these conditions, the bed load particles cover only a small portion of the bed surface, because only few particles will be in motion. According to the model of Fernandez Luque et al. the bed load particles reduce the maximum fluid shear stress at the bed surface to the critical value $\tau_{c}$ by exerting an average reaction 
force on the surrounding fluid. Hence the bed load forms a "protection shield " at higher bed load concentrations, which controls the erosion rate. We shall revert to this idea later on.

The experiments presented by these authors are of special interest, because they avoid the complication of dune influence, as the observations were carried out for very small transport rates mostly before bed waves became appreciable.

\section{The Rate of Bed Load Transportation $\mathrm{q}_{\mathrm{B}}$}

In the following it is attempted to approach the bed load transportation problem by considering the motion of the individual particles. Information about the transport velocity of single particles has been obtained by experiments published by Meland and Normann (1966). These experiments were carried out with single spherical glass beads moving over a bed of rhombohedrally packed spherical beads. In some of the runs the moving single particle was of the same size as those of the bed, while in other cases the bed particles were either larger or smaller. Following these authors notation $d$ denotes the diameter of the migrating particle, while $k$ is the diameter of the bed particles.

On the basis of these measurements it is attempted to develop a semi-empirical law for the mean transport velocity $U_{B}$ of a particle moving as bed load. To this end we consider the most important forces determining the motion of an immersed particle:

1) The agitating forces, drag $F_{D}$ and lift $F_{L}$, and

2) the stabilizing forces, reduced gravity (immersed weight) and the frictional forces resulting from the occasional contacts between particle and bed.

An exact description of forces and particle motion is impossible due to the complex character of the phenomenon. What we can do is to establish a "model equation" containing the time-averaged quantities, and from this equation we can hope to obtain sufficient information to be able to identify the parameters necessary for a relevant description of the process.

The agitating forces may be represented in form of a drag

$$
\text { c } \frac{1}{2} \rho\left[\alpha U_{f}-U_{B}\right]^{2} \frac{\pi}{4} d^{2}
$$

in which $U_{f}$ and $U_{B}$ are the friction velocity and the migration velocity of the particle, respectively. $\alpha U_{f}$ is the flow velocity at a distance of about one or two grain diameter $d$ from the fixed bed. Assuming the validity of the ordinary velocity distribution in rough channels, $\alpha$ must be of the order of 6 to 10. The factor $c$ stands for the drag (and lift) coefficient, but as the time variation of the agitating forces differs considerably from that of the stabilizing forces, we can hardly expect the value of $c$ to be exactly equal to the static value. 


\section{F. Engelund and J. Fredsøe}

The frictional force acting on the particle is written as

$$
\rho g(s-1) \frac{\pi}{6} d^{3} \beta
$$

where $s$ is the relative density of the particles, and $\beta$ is the dynamic friction coefficient. Actually the gravity of the particle should be corrected for a small dynamic lift $F_{L}$. However, this may be done by changing the value of $c$.

The model equation then expresses the average equilibrium of agitating and stabilizing forces

$$
c \frac{1}{2} \rho\left(\alpha U_{f}-U_{B}\right)^{2} \frac{\pi}{4} d^{2}=\rho g(s-1) \frac{\pi}{6} d^{3} B \text {, }
$$

from which

$$
\frac{U_{B}}{U_{f}}=\alpha\left[1-\sqrt{\theta_{0} / \theta}\right]
$$

where $\theta$ is given by Eq. (1), and

$$
\theta_{0}=\frac{4 \beta}{3 \alpha^{2} c}
$$

$\theta_{0}$ is seen- to be the limiting value of $\theta$ for which a particle located on the bed is just immobile. It is natural to relate this to the critical value $\theta_{c}$ corresponding to Shield's criterion. As a particle lying on the bed is easier to move than a particle located in the bed, it must be expected that $\theta_{0}<\theta_{c}$. A crude estimate can be obtained from Eq. (10) by insertion of the following values, partly obtained by the subsequent analysis:

$$
B=\tan 27^{\circ}, \quad \alpha=9, \quad c=0.6,
$$

which gives $\theta_{0}=0.014$, which is between one half and one fourth of the generally accepted values of $\theta_{c}$.

It is probably better to evaluate $\theta_{0}$ by considering the experiments of Fernandez. Luque et al., which indicated $\theta_{0}$ to be about half $\theta_{c}$, so that Eq. (9) may be written

$$
\frac{U_{B}}{U_{f}}=\alpha\left[1-0.7 \sqrt{\theta_{c} / \theta}\right]
$$

Comparison of this expression with Meland and Normann's result indicated that for suitable choice of $\theta_{C}$ and $\alpha=10$, a very good agreement is obtained, as demonstrated in Fig. 1. Fernandez Luqué's results, also indicated in this figure, are more satisfactory in the sense that $\theta_{\mathcal{C}}$ was measured directly and $U_{B}$ was determined as the mean transport velocity in a natural bed.

Eq. (11) was first suggested by Fernandez Luque and was checked by experiments with different slopes of the bed surface. It was found to hold irrespective of the inclination angle $\delta$, provided the proper value of $\theta_{c}$ was inserted. The experiments indicate that we must take

$$
\theta_{c}=\theta_{c, 0}[1+\tan \delta]
$$


A Sediment Transport Model for Straight Alluvial Channels

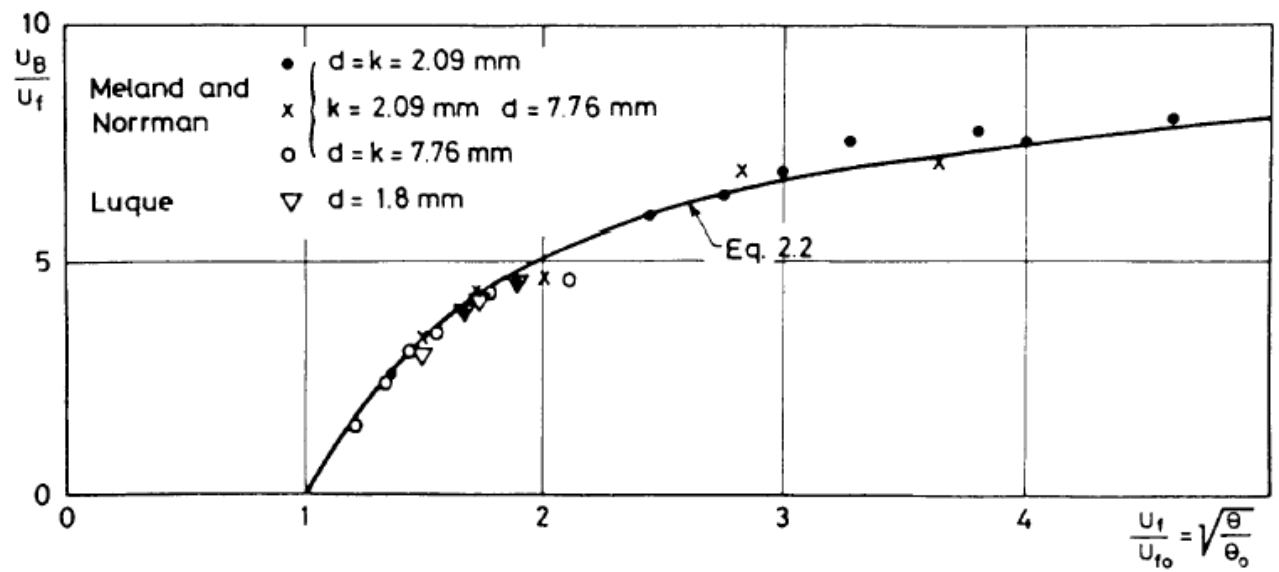

Fig. 1. Experiments of the transport velocity $U_{B}$ of bed load particles.

where $\theta_{\mathcal{c},{ }_{0}}$ is the value of $\theta_{\mathcal{c}}$ for horizontal bed. $\delta$ is positive when the particles move uphill.

For sand the value of $\alpha$ was found to be 9.3.

From the knowledge of mean particle velocity we can now derive an expression for the rate of bed load transport $q_{B}$ under the assumption that the bed load is the transport of a certain fraction $p$ (= probability) of the particles in a single layer. As the total number of surface particles per unit area is $1 / d^{2}$, we get

$$
q_{B}=\frac{\pi}{6} d^{3} \frac{p}{d^{2}} U_{B}
$$

or, after insertion of Eq. (11)

$$
q_{B}=9.3 \frac{\pi}{6} d p U_{f}\left[1-0.7 \sqrt{\theta} c^{/ \theta}\right]
$$

This is made non-dimensional by the divisor $\sqrt{(s-1) g d^{3}}$ (of Eq. (1)):

$$
\Phi_{B}=5 p(\sqrt{\theta}-0.7 \sqrt{\theta})
$$

From the experiments of Fernandez Luque et al. we can get some empirical information about $p$, because the measurements comprise $\phi_{B}, \theta$, and $\theta_{C}$. The result is given in Fig. 2, where the values of $p$ calculated from Eq. (13) are plotted against $\theta$. The experiments are particularly interesting because the transport rates were so small that all particles moved as bed load and without the disturbing effect of dunes and ripples. In case of larger transport rates this technique is no longer applicable, so that we must find other ways to obtain the necessary information.

Another useful series of data is that presented by Guy et al. (1966). For the present purpose, the evaluation of $p$, the experiments with sand size $d=0,93 \mathrm{~mm}$ are particularly suited as explained below. Because of the dune formations it is neccessary to divide the total shear stress in two components 


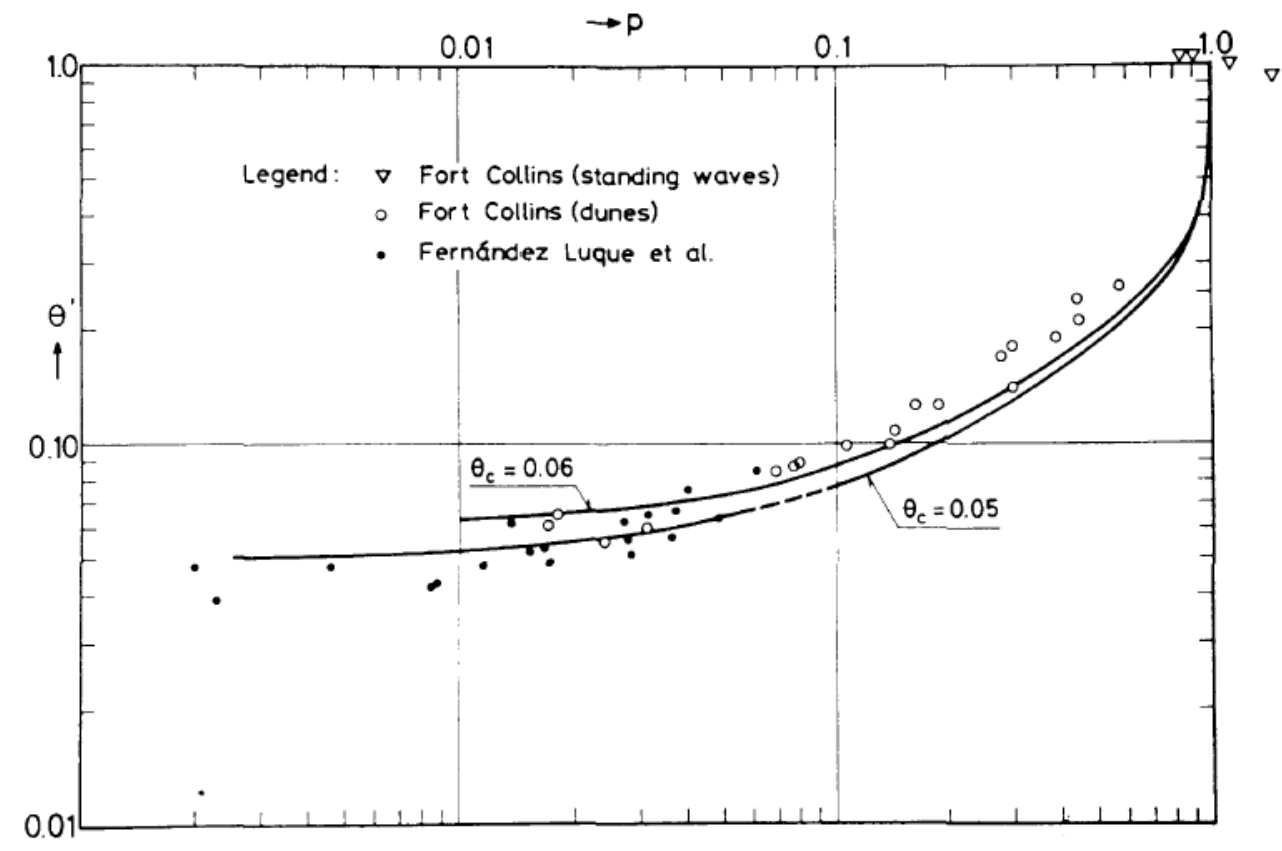

Fig. 2. The probability function $p$ versus $\theta$.

$$
\tau=\tau^{\prime}+\tau^{\prime \prime} \quad, \quad \frac{\tau^{\prime}}{\rho}=U_{f}^{\prime 2}
$$

where only the first term, which corresponds to the skin friction, is directly active in the bed load process. $\tau$ ' (or $U_{f}$ ) is calculated from Einstein's procedure of Eqs. (4) and (5). Similarily, we have the non-dimensional version of Eq. (13).

$\theta=\theta^{\prime}+\epsilon$

In all the expre.sions derived above, $\theta$ should consequently be substituted by $\theta^{\prime}$ in order to correct for the effect of dunes.

Another difficulty in applying ordinary flume data is that the total sediment load usually has a component of suspension, which has to be subtracted from the total load in order to obtain the bed load proper. The selected series of experiments has the particular advantage that the amount of suspended load was always a minor part of the total.

There are two different methods of evaluation of the bed load transport. The first one is to take the total load and subtract the measured suspended load. The second one is to consider the measured dune height $h$ and the migration velocity $a$ and then apply the equation

$$
q_{B} \simeq \frac{1}{2}(1-m) a h
$$




\section{A Sediment Transport Model for Straight Alluvial Channels}

where $m$ is the porosity of the sand bed.

Of course there is a considerable amount of uncertainty associated with both methods, which makes it so important to select experiments where the suspension is small. In the runs considered, the two methods were found to agree fairly well. Hence, after making an estimate of $\theta_{c}$ (e.g. by Shield's diagram), we can now calculate the value of $p$ from Eq. (13), substituting the calculated value of $\theta$ ' for $\theta$. The result of such an analysis is also shown in Fig. 2, where the Fort Collins points and Fernandez Luque's data are seen to form a fairly consistent picture.

Now we are able to make a first check on the above-mentioned assumption that only the part $\tau \dot{c}$ of the total shear stress $\tau$ is transferred directly to the immobile bed as skin friction, while the residual part $\tau-\tau_{\mathcal{C}}$ is carried as drag on the moving bed particles and indirectly transferred to the bed by occasional encounters. This idea leads to the equation

$$
\tau \neq \tau_{c}+n F_{D} \text {, }
$$

where $F_{D}$ is the average drag on a single moving bed particle, while $n$ is the number of moving particles per unit area. If this expression is divided by $\rho g(s-1) d$, and $F_{D}$ is estimated as

$$
F_{D} \approx \rho g(s-1) \frac{\pi}{6} d^{3} \beta
$$

the resulting equation becomes

$$
\theta=\theta_{c}+\frac{\pi}{6} \beta\left(n d^{2}\right)=\theta_{c}+\frac{\pi}{6} \beta p
$$

From this $p$ can be determined, if $\theta_{c}$ and $\beta$ are known. From investigations of flow in meanders (Engelund 1975, Gottlieb 1976) the value of the dynamic friction angle $\varphi$ is known to be slightly smaller than the static (i.e. angle of repose), the value $\psi=27^{\circ}$ being reasonable for ordinary sand. Taking $\theta_{c}=0.05$ we get

$$
\theta=0.05+0.2668 p \text {, }
$$

which is given in Fig. 2 for comparison with Fernandez Luque's experiments. The agreement is acceptable for small values of $\theta$, but for the larger values the curves fall below the Fort Collins data. The explanation for this seems to be that Eq. (15) is only valid as long as there is no suspension, a point we shall revert to later in greater detail.

The next problem is what happens at very large transport rates. In this extreme the argument leading to Eq. (15) does obviously not hold. If we stick to the model that the bed load is a single layer of particles, the maximum value of $p$ must be unity corresponding to a simultaneous motion of all particles in the layer.

In the Fort Collins series four runs (corresponding to wstanding waves") are marked by triangles in Fig. 2. In these runs the transport rate was large but still largely occurring as bed load. The fact that they all gave values of $p$ close to unity is an experimental support for the idea that $p$ approaches unity for increasing values of $\theta$. 


\section{F. Engelund and J. Fredsøe}

If a limiting value of $p=1$ is accepted, the expression for $\mathrm{p}$ has to be modified as for instance

$$
p=\left[1+\left(\frac{\frac{\pi}{6} \beta}{\theta-\theta_{c}}\right)^{4}\right]^{-1 / 4}
$$

which is about equal to Eq. (15) for $\theta$ close to $\theta_{c}$ and approaches unity for large values of $\theta$. Eq. (16) is given in Fig. 2 for $\theta_{C}=0.05$ and 0.06 .

\section{The Suspended Load}

For large values of $\theta^{\prime}$ the transfer of shear stress to the bed surface is no longer well described by Eq. (15), because it neglects the dispersive stress from the suspended load. In order to take account of this we have to introduce Bagnold's expression and write

$$
\tau^{\prime}=\tau_{e}+n F_{D}+F_{S},
$$

in which $F_{S}$ is the dispersive stress as given by Eq. (6), where a specific value of the velocity gradient will have to be inserted. Assuming the classical logarithmic velocity distribution to be at least approximately valid, we get

$$
\frac{d U}{d y}=\frac{2.5 U_{f}^{\prime}}{y}
$$

The dispersive stress acting on the bed must depend on this velocity gradient calculated for a value of $y$ about equal to one particle diameter $d$. The following calculations indicated that the value $y=1.73 d$ yielded the best agreement with observation of the actual a mount of suspension. so that Eq. (17) becomes

$$
\tau^{\prime}=\tau_{c}+n F_{D}+0.027 \text { ps }\left(\lambda_{b} U_{f}^{\prime}\right)^{2},
$$

where $\lambda_{b} b$ is the linear concentration at bed level. In nondimensional form this equation becomes

$$
\theta^{\prime}=\theta_{c}+\frac{\pi}{6} B p+0.027 s \theta^{\prime} \lambda_{b}^{2}
$$

By Eq. (7) we can now calculate the corresponding volumetric bed concentration $c_{b}$ as

$$
c_{b}=\frac{0.65}{\left(1+1 / \lambda_{b}\right)^{3}}
$$

Hence this model provides a method for calculation of $c_{b}$ from the requirements of momentum transfer to the immobile sand surface if $p$ is known.

When $\theta$ becomes very large, corresponding to large suspended transport rates, we assume $p$ to be unity and find that 


$$
\lambda_{b}=\frac{\sqrt{\theta^{1}-0.3}}{0.027 s \theta^{1}}+3.74
$$

for ordinary sand with $s=2.65$. This corresponds to the volumetric bed concentration $c_{b}=0.32$, which is estimated to be a reasonable maximum value for suspended sediment in motion. Theoretically $c_{b}$ can be as large as 0.65 , but this corresponds to firm packing and does not allow free motion of the particles.

In the general case $c_{b}$ must be determined from Eqs. (19) and (20), assuming $p$ to be given by Eq. (16) (an illustrative example is given below). For fixed values of $\theta_{\mathcal{C}}, \beta$, and $s$, the bed concentration depends on $\theta^{\prime}$ only. This relationship is presented in Fig. 3 for $\theta_{c}=0.05, s=2.65$, and $\beta=\tan 27^{\circ}=0.51$. Note that $c_{b}$ becomes extremely small for $\theta^{\prime}<0.1$ and that it approaches 0.32 for large values of $\theta^{\prime}$.

To proceed further it is necessary to obtain an estimate of the size of the particles moving in suspension. This is achieved by means of the criterion

$$
w<0.80_{f}^{\prime},
$$

which states that only particles with a fall velocity $w$ smaller than this threshold value will move in suspension. When the distribution curve for $w$ is known it is possible to estimate the "effective fall velocity" for the suspended fraction (Raudkivi 1976). Criteria of the type (21) seem to be generally accepted (Middleton 1976).

When $w$ has been determined the transport rate of suspended load can be calculated from Eqs. (2) and (3), as described by Einstein (1950). The bed load transport is obtained from Eqs. (13) and (16).

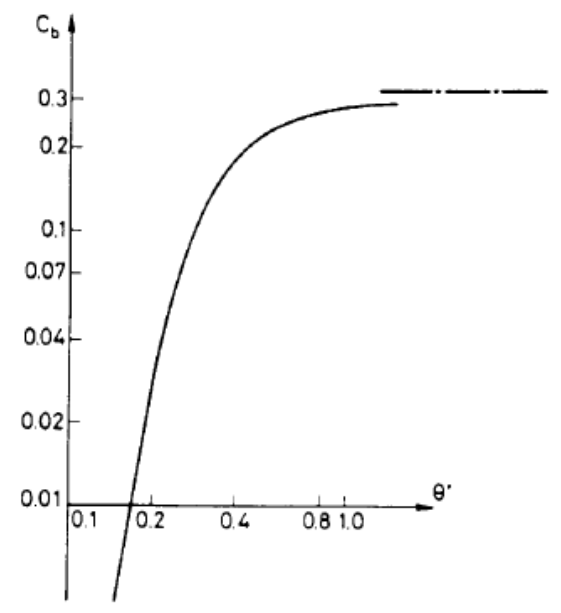

Fig. 3. Bed concentration $c_{b}$ versus $\theta^{\prime}$, assuming $\theta_{\mathrm{c}}=0.05$, $s=2.65$, and $\mathrm{B}=0.51$. 


\section{F. Engelund and J. Fredsøe}

The problem is now how the theory can be controlled by comparison with experiments. It is well-known, that measurements of the transport rates of bed load and suspended load separately is difficult and always associated with considerable uncertainty. Likewise, the mean particle size of the suspended load is rather uncertain.

In adapting the Fort Collins data (Guy et al. 1966) we have tried to compare the calculated bed load transport rates with the measurements applying Eq. (14) (which is rather doubtful for large transport rates). Although the scatter is rather large, the general trend in the comparison is satisfactory. A similar remark applies to the suspended particle size.

The total rate of sediment transport, however, can be measured with good accuracy. Hence, the most significant test is to compare the total load with the theory, which is done in Fig. 4.

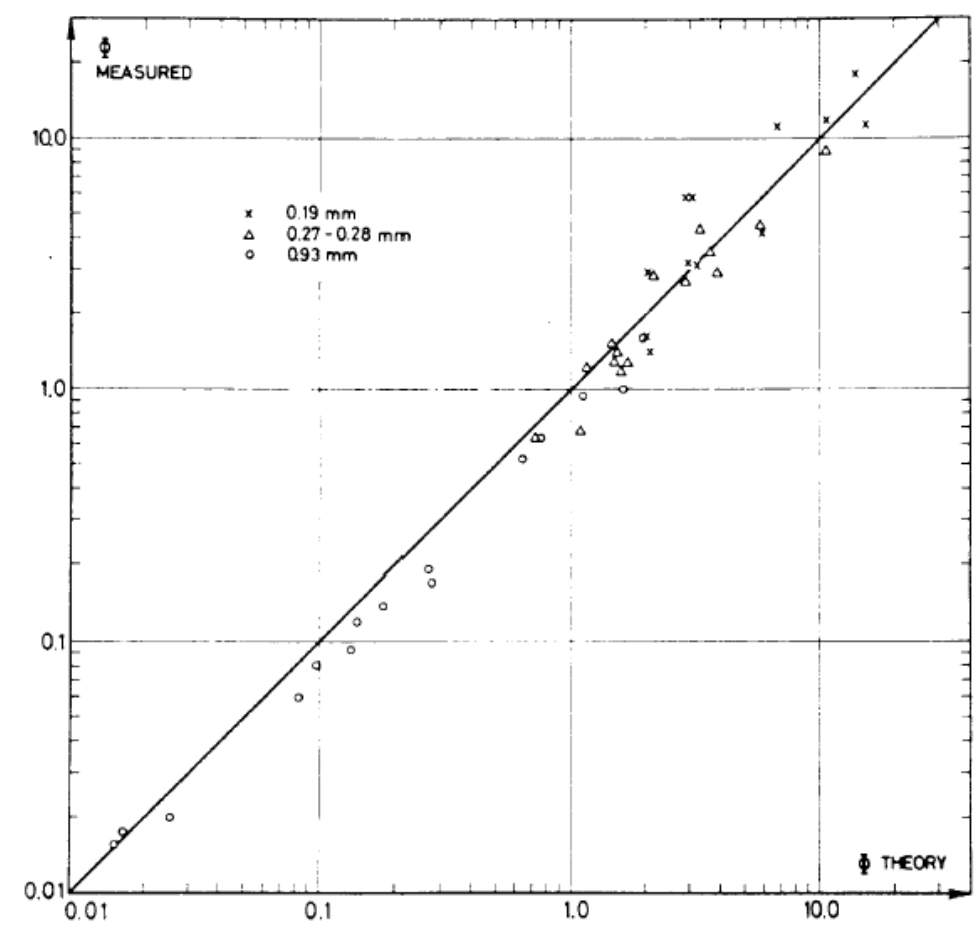

Fig. 4. Comparison between measured and calculated rates at total sediment transport. 


\section{Example}

As an illustrative example we consider run 21 from the Fort Collins report (Guy et al. 1966) from the series using sand with the mean fall diameter $d=0.28 \mathrm{~mm}$. The data for this run are:

$\begin{array}{ll}\text { Slope } I & =0.00131 \\ \text { Depth } D & =0.326 \mathrm{~m} \\ \text { Mean velocity } V & =0.725 \mathrm{~m} / \mathrm{s} \\ \text { Temperature } T & =16 .{ }^{\circ} 5 \mathrm{C}\end{array}$

The hydraulic roughness of the surface is estimated to $k=2.5 d$. Hence, from Eq. (5) we get $D^{\prime}=0.116 \mathrm{~m}$ and $U_{f}^{\prime}=0.0386 \mathrm{~m} / \mathrm{s}$. From this we find that

$$
\theta^{\prime}=\frac{D^{\prime} I}{(s-1) d}=0.329
$$

With $\theta_{c}=0.05$ and $B=0.51$ Eq. (16) gives $p=0.859$ and the non-dimensional rate of bed load transport is calculated from Eq. (13):

$$
\Phi_{B}=1.79
$$

If the same quantity is estinated from Eq. (14) we get $\varphi_{B}=1.22$. The critical fall velocity $w_{c}$ is (Eq. (21)) $0.8 U_{f}^{\prime}=0.031 \mathrm{~m} / \mathrm{s}$. From the distribution of particle fall velocity it is found that the mean fall velocity of the suspended part is about $w=$ $0.023 \mathrm{~m} / \mathrm{s}$, corresponding to a fall diameter of $0.20 \mathrm{~mm}$. The measured mean diameter of the suspended particles was in this case considerably smaller, about $0.16 \mathrm{~mm}$. (For the runs in general the agreement between measured and calculated particle sizes for the suspended material was better and no trend in the deviations was found).

The value of $z$ becomes

$$
z=\frac{\omega}{0.4 U_{f}^{1}}=1.49
$$

The lower limit a for the integral in Eq. (3) is taken as $a=2 d$.

According to Einstein (1950) Eq. (13) can be written as

$$
\Phi_{s}=11 . \overline{6}, \theta^{\prime} c_{b}\left(\frac{a}{d}\right)\left[I_{1} \ln \frac{30 D}{k}+I_{2}\right] \text {, }
$$

where $I_{1}$ and $I_{2}$ are obtained from his diagrams as 0.40 and -2 , respectively. From Eqs. (19) and (20) or from Fig. $3 c_{b}$ is found to be 0.14 , so that the non-dimensional transport rate of suspended material becomes

$$
\Phi_{S}=1.94
$$

The total sediment transport rate thus becomes

$$
\Phi_{t}=\Phi_{b}+\Phi_{s}=3.73
$$

to be compared with the measured value 3.46 . 


\section{F. Engelund and J. Fredsøe}

\section{References}

Bagnold, R. A. (1954) Experiments on a gravity-free dispersion of large solid spheres in a Newtonian fluid under shear. Proc. Roy. Soc. London (A) 225, 49.

Einstein, H. A. (1950) The bed-load function for sediment transport in open channel flows. U.S. Dept. of Agriculture, Techn. Bulletin No. 1026.

Engelund, F. and Hansen, E. (1972) A monograph on sediment transport in alluvial streams. Technical Press, Copenhagen.

Engelund, F. and Fredsøe, J. (1974) Transition from dunes to plane bed in alluvial channels. Series Paper 4, Inst. Hydrodynamics and Hydraulic Eng., Tech. Univ. Denmark.

Engelund, F. (1974) Flow and bed topography in channel bends. J. Hyd. Div., ASCE, vol. 100. No. HY 11 .

Engelund, F. (1975) Steady transport of moderately graded sediment (part 2). Progress Report No. 35, Inst. Hydrodynamics and Hydraulic Eng., Tech. Univ. Denmark.

Engelund, F. (1976) Experiments in curved alluvial channel (part 2). Progress Report No. 38, Inst. Hydrodynamics and Hydraulic Eng., Tech. Univ. Denmark.

Fernandez Luque, R. (1974) Erosion and transport of bed sediment (Diss.), Krips Repro B. V. - Meppel.

Fernandez Luque, R., and van Beek, R. (1976) Erosion and transport of bed-load sediment. $J$. Hyd. Research, vol. 14 No. 2.

Fredsøe, J., and Engelund, F. (1975) Bed configurations in open and closed alluvial channels. Series Paper 8, Inst. Hydrodynamics and Hydraulic Eng., Tech. Univ. Denmark.

Fredsøe, J. (1976 a) Sediment inertia as cause of river antidunes. Discussion, J. Hyd. Div., ASCE, vol. 102 HY 1.

Fredsøe, J. (1976 b) Levelling of side slopes in river navigation channels. Progress Report No. 38, Inst. Hydrodynamics and Hydraulic Eng., Tech. Univ. Denmark.

Fredsøe, J., and Engelund, F. (1976): Bed concentration of suspended material. Progress Report No. 39, Inst. Hydrodynamics and Hydraulic Eng., Tech. Univ. Denmark.

Gottlieb, L. (1976) Three-dimensional flow pattern and bed topography in meandering channels. Series Paper 11, Inst. Hydrodynamics and Hydraulic Eng., Tech. Univ. Denmark.

Guy, H. P., Simons, D. B., and Richardson, E. V. (1966) Summary of alluvial channel data from flume experiments, 1956-61. U.S. Geological Survey professional paper 462 - I.

Meland, N., and Normann, J. O. (1966) Transport velocities of single particles in bed-load motion. Geografiska Annaler, Vol. 48, A.

Middleton, G. V. (1976) Hydraulic interpretation of sand size distributions. Journal of Geology, Vol. 84, pp. 405-426.

Raudkivi, A. J. (1976) Loose boundary hydraulics. 2. edition. Pergamon Press.

Rouse, H. (1937) Modern conceptions of the mechanics of turbulence. Trans. ASCE 102, pp. 463-543.

Vanoni, V. A. (1946) Transportation of suspended sediment by water. Trans. Am. Soc. Civ. Engrs., Vol. I11, pp. 67-133.

Received: 25 October, 1976

\section{Address:}

Institute of hydrodynamics and hydraulic engineering ISVA, Technical University of Denmark,

Bldg. 115,

2800-Lyngby, Denmark 